(Abbreviated Title)

EFFECTS OF ULTRASONIC VIBRATIONS ON HEAT TRANSFER TO LIQUIDS 
(Abbreviated Title)

EFFECTS OF ULTRASONIC VIBRATIONS ON HEAT TRANSFER TO LIQUIDS 
EFFECTS OF ULTRASONIC VIBRATIONS ON HEAT TRANSFER TO LIQUIDS BY NATURAL CONVECTION AND BY BOILING 


\title{
EFFECTS OF ULTRASONIC VIBRATIONS ON HEAT TRANSFER TO LIQUIDS BY NATURAI CONVECTION AND BY BOILING
}

by

SAU WAI WONG, B.Eng., M.Eng. (Chem,)

\author{
A thesis submitted to the Faculty of Graduate Studies \\ and Research in partial fulfilment of the \\ requirements for the degree of \\ Doctor of Philosophy
}

Chemical Engineering Department, McGill University, Montreal. lst October, 1966

(C) Sau Wai Wong 1967 


\title{
EFFECTS OF ULTRASONIC VIBRATIONS ON HEAT TRANSFER
}

TO LIQUIDS BY NATURAL CONVECTION AND BY BOILING

\author{
SAU WAI WONG
}

\begin{abstract}
The effects of ultrasonic vibrations on heat transfer to water and methanol by natural convection and by bolling were measured at three acoustic energy levels.with frequency ranging from 20.6 to 306 kcps, using electrically heated platinum wires of diameters 0.007 and $0.010 \mathrm{in.}$. Up to an eight-fold increase in heat transfer coefficient was obtained in natural convection, but the effects diminished with increased temperature difference and became negligible in the well-developed nucleate boiling region. High-speed photographs showed that the Increase was due to the motion of cavitation bubbles on the wire surface. The heat transfer results were correlated as a function of local cavitation activity values measured by a technique developed for this work.

Ultrasonic vibrations at a frequency of $20.6 \mathrm{kcps}$ had a negligible effect on the burnout heat flux and the critical temperature difference in methanol at $i 13^{\circ} \mathrm{F}$ using platinum wire of $0.007 \mathrm{in}$. diameter.
\end{abstract}




\section{ACKNOWLEDGEMENTS}

The author wishes to express his sincere apprectation to $\mathrm{Dr}$. W.Y. Chon for his continued interest in directing this research. He is also indebted to:

Dr. M.E. Weber for his interest and many suggestions during the course of this investigation.

The National Research Council of Canada for financial assistance in the form of two Studentships.

Mr. L.R. Heffell for his assistance in the high speed photographic study.

Miss S. Paulin for reviewing the manuscript.

His wife for her untiring perseverence throughout these past years. 
TABLE OF CONTENTS

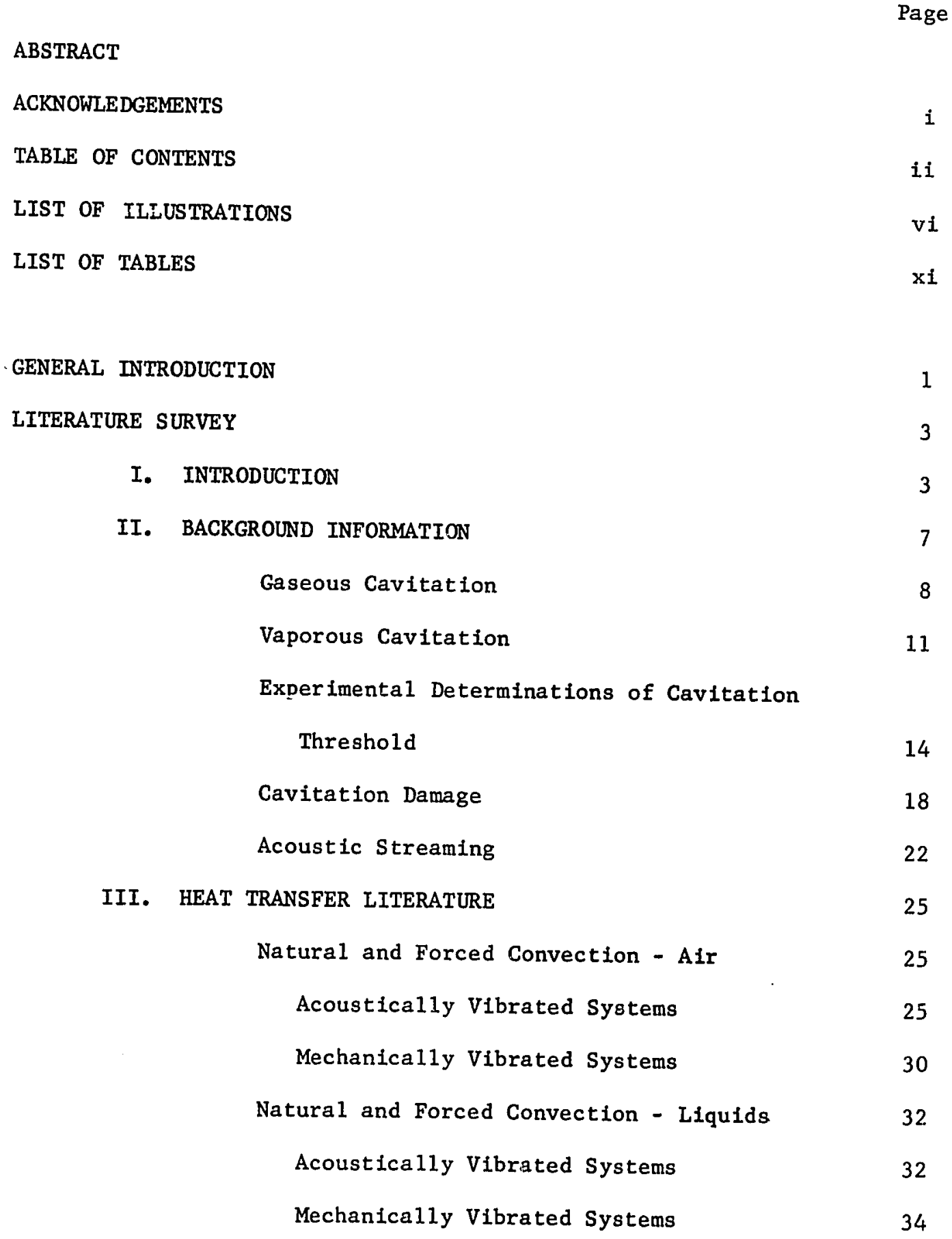


Boiling Heat Transfer

IV. GENERAL COMMENTS

\section{NOMENCLATURE}

REFERENCES

PRESENT INVESTIGATION

INTRODUCTION

PART I. MEASUREMENT OF SOUND FIELD IN LIQUIDS

INTRODUCTION

58

EXPER IMENTAL

Equipment

60

Materials

65

Preparation of Specimen

Procedure

69

RESULTS

DISCUSSION OF RESULTS

CONCLUS IONS

NOMENCLATURE

REFERENCES

PART II. EFFECTS OF ULTRASONIC VIBRATIONS ON HEAT TRANSFER TO LIQUIDS BY NATURAL CONVECTION AND BY BOILING

INTRODUCTION

EXPERIMENTAL 
Materials 92

Procedure and Observations 92

Heat Transfer Experiments without Vibration 93

Determination of the Critical Sound Pressure 93

Heat Transfer Experiments with Ultrasonic Vibrations $\quad 95$

RESULTS

Critical Sound Pressure 97

Heat Transfer Data 103

High Speed Photography Study $\quad 117$

DISCUSSION OF EXPERIMENTAL RESULTS 133

High Speed Photography Study 133

$\begin{array}{ll}\text { Critical Sound Pressure } & 140\end{array}$

Heat Transfer Results $\quad 144$

CORRELATION OF EXPERTMENTAL DATA 146

DISCUSSION OF CALCULATED RESULTS $\quad 165$

$\begin{array}{lr}\text { CONCLUSIONS } & 170\end{array}$

$\begin{array}{lr}\text { NOMENCLATURE } & 174\end{array}$

REFERENCES $\quad 176$

PART III. EFFECTS OF ULTRASONIC VIBRATIONS ON BURNOUT HEAT FLUX AND CRITICAL TEMPERATURE DIFFERENCE

INTRODUCTION

$\begin{array}{lr}\text { RESULTS AND DISCUSSION } & 180\end{array}$

$\begin{array}{ll}\text { CONCLUSIONS } & 184\end{array}$ 
REFERENCES

Page

185

SUMMARY AND CONTRIBUTION TO KNOWLEDGE 186

$\begin{array}{ll}\text { SUGGESTIONS FOR FUTURE WORK } & 190\end{array}$

APPENDIX A - INFORMATION ON TRANSDUCERS USED IN THIS WORK A-1

APPENDIX B - SOUND PRESSURE DATA

APPENDIX C - CAVITATION DAMAGE DATA C-1

APPENDIX D - HEAT TRANSFER DATA

APPENDIX E - CRITICAL SOUND PRESSURE DATA E-1

APPENDIX F - SAMPLE CALCULATIONS $\quad$ F-1

APPENDIX G- PHOTOGRAPHIC STUDY OF THE SURFACE CONDITIONS OF PIATINUM WIRE

G-1 


\section{LIST OF ILLUSTRATIONS}

Page

LITERATURE SURVEY

FIGURE 1 Boiling of Water at $212^{\circ} \mathrm{F}$ on an Electrically Heated Platinum Wire, Showing Different Regions

PRESENT INVESTIGATION

Part I

FIGURE 1 Schematic Diagram of Apparatus

FIGURE 2 Photograph of the Experimental Apparatus

FIGURE 3 Supporting Frame for Cavitation Damage Specimen and Platinum Wire

FIGURE 4 Cavitation Damage Specimen with Polyethylene Bag

FIGURE 5 Some Typical Sound Pressure Profiles on the Cavitation Damage Specimen

FIGURE 6 Determination of the Time of Exposure of a Specimen in a Cavitating Liquid

FIGURE 7 Percent Soll Removal as a Function of Apparent Electrical Power Input to Transducers at $20.6 \mathrm{kcps}$ with an Exposure Time of 1 Minute. Dist11led Water at $113^{\circ} \mathrm{F}, 149^{\circ} \mathrm{F}$ and $180^{\circ} \mathrm{F}$

FIGURF 8 Percent Soll Removal as a Function of Apparent Electrical Power Input to Transducers at $20.6 \mathrm{kcps}$ with an Exposure Time of 1 Minute. Methanol at $95^{\circ} \mathrm{F}$ and $113^{\circ} \mathrm{F}$ 
FIGURE 9 Percent Soil Removal as a Function of Apparent Electrical Power Input to the Transducers for Distilled Water at $149^{\circ} \mathrm{F}$ and Methanol at $113^{\circ} \mathrm{F}$ with $f=44.1 \mathrm{kcps}$, Exposure Time $=1$ Minute

FIGURE 10 Percent Soil Removal as a Function of Apparent Electrical Power Input to the Transducers for Distilled Water at $149^{\circ} \mathrm{F}$ and Methanol at $113^{\circ} \mathrm{F}$ with $f=108 \mathrm{kcps}$, Exposure Time $=1$ minute

FIGURE 11 Percent Soil Removal as a Function of Apparent Electrical Power Input to the Transducers for Distilled Water at $149^{\circ} \mathrm{F}$ and Methanol at $113^{\circ} \mathrm{F}$ with $f=306 \mathrm{kcps}$, Exposure Time $=1$ Minute

\section{Part II}

FIGURE I Some Typical Temperature History Curves During the Determination of Critical Sound Pressure

FIGURE 2 Variation of Critical Sound Pressure as a Function of the Wire Temperature at $20.6 \mathrm{kcps}$ in Distilled Water at $113^{\circ} \mathrm{F}$ and $149^{\circ} \mathrm{F}$

FIGURE 3 Variation of Critical Sound Pressure as a Function of the Wire Temperature at $20.6 \mathrm{kcps}$ in Methanol at $95^{\circ} \mathrm{F}$ and $113^{\circ} \mathrm{F}$

FIGURE 4 Variation of Critical Sound Pressure as a Function of the Wire Temperature at Different Frequencies in Distilled Water at $149^{\circ} \mathrm{F}$ 
FIGURE 5 Variation of Critical Sound Pressure as a Function of the Wire Temperature at Different Frequencies in Methanol at $113^{\circ} \mathrm{F}$

FIGURE 6 Effect of $20.6 \mathrm{kcps}$ Ultrasonic Vibrations on Heat Transfer Rates in Distilled Water at $149^{\circ} \mathrm{F} \quad 104$ FIGURE 7 Effect of $20.6 \mathrm{kcps}$ Ultrasonic Vibrations on Heat Transfer Rates in Distilled Water at $113^{\circ} \mathrm{F}$

FIGURE 8 Effect of $20.6 \mathrm{kcps}$ U1trasonic Vibrations on Heat Transfer Rates in Methanol at $113^{\circ}$ F

FIGURE 9 Effect of $20.6 \mathrm{kcps}$ U1trasonic Vibrations on Heat Transfer Rates in Methanol at $95^{\circ} \mathrm{F}$

FIGURE 10 Effect of U1trasonic Vibrations on Heat Transfer Rates in Distilled Water at $149^{\circ} \mathrm{F}$ with $f=44.1$ kcps

FIGURE 11 Effect of Ultrasonic Vibrations on Heat Transfer Rates in Distilled Water at $149^{\circ} \mathrm{F}$ with $\mathbf{f}=108 \mathrm{kcps} 109$ FIGURE 12 Effect of Ultrasonic Vibrations on Heat Transfer Rates in Methanol at $113^{\circ} \mathrm{F}$ with $\mathrm{f}=44.1 \mathrm{kcps}$

FIGURE 13 Effect of Ultrasonic Vibrations on Heat Transfer Rates in Methanol at $113^{\circ} \mathrm{F}$ with $\mathrm{f}=108 \mathrm{kcps}$

FIGURE 14 Effect of Ultrasonic Vibrations on Heat Transfer Rates in Methanol at $113^{\circ} \mathrm{F}$ with $\mathrm{f}=306 \mathrm{kcps}$

FIGURE 15 Natural Convection Heat Transfer from Horizontal Platinum Wires to Liquids

FIGURE 16 Cavitation Bubble Motion on a Heated Wire, Methanol at $113^{\circ} \mathrm{F}$, with $\Delta t=22^{\circ} \mathrm{F}$ and $\mathrm{q} / \mathrm{A}=18,700 \mathrm{BTU} / \mathrm{hr} \mathrm{ft}^{2} 119$ 
FIGURE 17 Cavitation Bubble Motion on a Heated Wire, Methanol at $113^{\circ} \mathrm{F}$ with $\Delta t=42^{\circ} \mathrm{F}$ and $\mathrm{q} / \mathrm{A}=37,700 \mathrm{BTU} / \mathrm{hr} \mathrm{ft}^{2}$

FIGURE 18 Cavitation Bubble Motion on a Heated Wire, Methanol at $113^{\circ} \mathrm{F}$ with $\Delta t=81^{\circ} \mathrm{F}$ and $\mathrm{q} / \mathrm{A}=167,000 \mathrm{BTU} / \mathrm{hr} \mathrm{ft}^{2}$

FIGURE 19 Cavitation Bubble Motion on a Heated Wire, Distilled Water at $149^{\circ} \mathrm{F}$ with $\Delta t=50^{\circ} \mathrm{F}$ and $\mathrm{q} / \mathrm{A}=20,900 \mathrm{BTU} / \mathrm{hr} \mathrm{ft}{ }^{2}$

FIGURE 20 Correlation of Heat Transfer Data in the Low Heat Flux Region at $f=20.6 \mathrm{kcps}$

FIGURE 21 Correlation of Heat Transfer Data in the Low Heat Flux Region at $f=44.1 \mathrm{kcps}$

FIGURE 22 Correlation of Heat Transfer Data in the Low Heat Flux Region at $f=108 \mathrm{kcps}$

FIGURE 23 Correlation of Heat Transfer Data in the Low

Heat Flux Region at $f=306$ kcps

FIGURE 24 Correlation of Heat Transfer Data in the Low Heat Flux Region in Terms of a Normalized Nusselt Number at $\mathrm{f}=20.6 \mathrm{kcps}$

FIGURE 25 Correlation of Heat Transfer Data in the Low Heat Flux Region in Terms of a Normalized Nusselt Number at $\mathrm{f}=44.1 \mathrm{kcps}$

FIGURE 26 Correlation of Heat Transfer Data in the Low Heat Flux Region in Terms of a Normalized Nusselt

Number at $f=108 \mathrm{kcps}$ 
Page

FIGURE 27 Correlation of Heat Transfer Data in the Low

Heat Flux Region in Terms of a Normalized

Nusselt Number at $£=306 \mathrm{kcps}$

FIGURE 28 Correlation of Heat Transfer Data in the High Heat Flux Region at $f=20.6 \mathrm{kcps}$

FIGURE 29 Correlation of Heat Transfer Data in the High Heat Flux Region at $f=44.1 \mathrm{kcps}$

FIGURE 30 Correlation of Heat Transfer Data in the High Heat Flux Region at $f=108 \mathrm{kcps}$

\section{Part III}

FIGURE 1 Effect of 20.6 kcps U1trasonic Vibrations on Burnout Heat Flux and Critical Temperature Difference in Methanol at $113^{\circ} \mathrm{F}$ 


\section{LIST OF TABLES}

Page

LITERATURE SURVEY

TABLE 1 Correlations for Acoustic Cavitation Threshold

PRESENT INVESTIGATION

$\underline{\text { Part I }}$

TABLE 1 Effective Value of Sound Pressure on the Specimen at $f=20.6 \mathrm{kcps}$

TABLE 2 Effective Value of Sound Pressure on the Specimen at $\mathrm{f}=44.1 \mathrm{kcps}$

TABLE 3 Effective Value of Sound Pressure on the Specimen at $f=108 \mathrm{kcps}$

TABLE 4 Effective Value of Sound Pressure on the Specimen at $f=306 \mathrm{kcps}$

\section{Part II}

TABLE 1 Values of Percentage Soll Removed at Which Heat Transfer Data Were Measured

TABLE 2 Experimental Conditions Selected for High Speed Photography Study

TABLE 3 Summary of Slope and Intercept of Correlations

TABLE 4 Summary of slope and Intercept for Correlations at Different Frequencies

\section{Part III}

TABLE 1 Effects of Ulirasonic Vibrations on Burnout Heat Flux and Critical Temperature Difference 


\section{GENERAL INTRODUCTION}

In recent years, there has been increased interest in the effects of vibrations on heat transfer. These studies are conducted because most industrial applications involve systems with some degree of relative vibration or pulsation of the fluld and the surface. Other investigators, however, have studied the problem with the object of increasing the heat transfer rate.

The limited number of papers published on the Influence of vibrations on boiling heat transfer is mainly concerned with the Increase of the value of burnout heat flux or that of the critical temperature difference. Such information is useful for design calculations in such high power density systems as rocket engines and nuclear reactors. The results of these studies have varied from no effect to almost a $100 \%$ increase in the value of the burnout heat flux. The effects of vibrations on nucleate bolling, however, have hardly been touched upon.

In convective heat transfer, most of the work done 18 for gages. In the case of a liquid where the existence of two phases is possible, less Information is avallable and the results from these studies show a wide discrepancy.

It was the purpose of this study to establish the Important variables in heat transfer to liquids by natural convection as well as by bolling in sound flelds of 20 to $300 \mathrm{kcps}$ and for sound pressures well above the cavitation threshold of the 1iquid. Attempts were made to determine the controlling mechanism in these processes. One of 
the limitations in this type of study is that specific results will be strongly dependent on the geometry of the system. In the present work, local values of the amplitude of vibration in the heat transfer surface were measured directly. 


\section{IITERATURE SURVEY}

\section{INTRODUCTION}

Boiling heat transfer data are generally presented graphically with $\log (q / A)$ as the ordinate and $\log (\Delta t)$ as the abscissa, where $(q / A)$ is the heat flux density and $(\Delta t)$ is the temperature difference between the heating surface and the fluid saturation temperature. The data plotted this way yield the characteristic bolling curve which has a similar shape for all fluid-surface combinations. The data shown in Figure 1 were obtained by Nukiyama ${ }^{(1)}$ in 1934 for water bolling at atmospheric pressure on a submerged, electrically heated, platinum wire. In the region $A B$, the 1 iquid water is being superheated by natural convection. As the temperature difference increases, nucleate boiling (BC) takes place where vapor bubbles form at specific points on the heating surface. In this range the heat flux increases rapidly with a moderate increase in wire temperature as new active points appear. At point $C$, the heat flux goes through a maximum, the peak heat flux, at a temperature difference called the "critical $\Delta t$ ". Beyond the critical $\Delta t$ value, a large fraction of the heating surface is covered by vapor, which, because of its poor thermal conductivity, tends to insulate the surface. The insulating effect of the vapor becomes so large at the "critical $\Delta t$ " that the heat flux diminishes as the temperature difference is further increased. This corresponds to the transition-film bolling region $C D$. In the film boiling region $D E F$, a stable film of vapor covers the heating surface and heat is transferred through the 
FIGURE 1

BOILING OF WATER AT $212^{\circ} \mathrm{F}$ ON AN ELECTRICALLY HEATED PLATINUM WIRE, SHOWING DIFFERENT REGIONS 


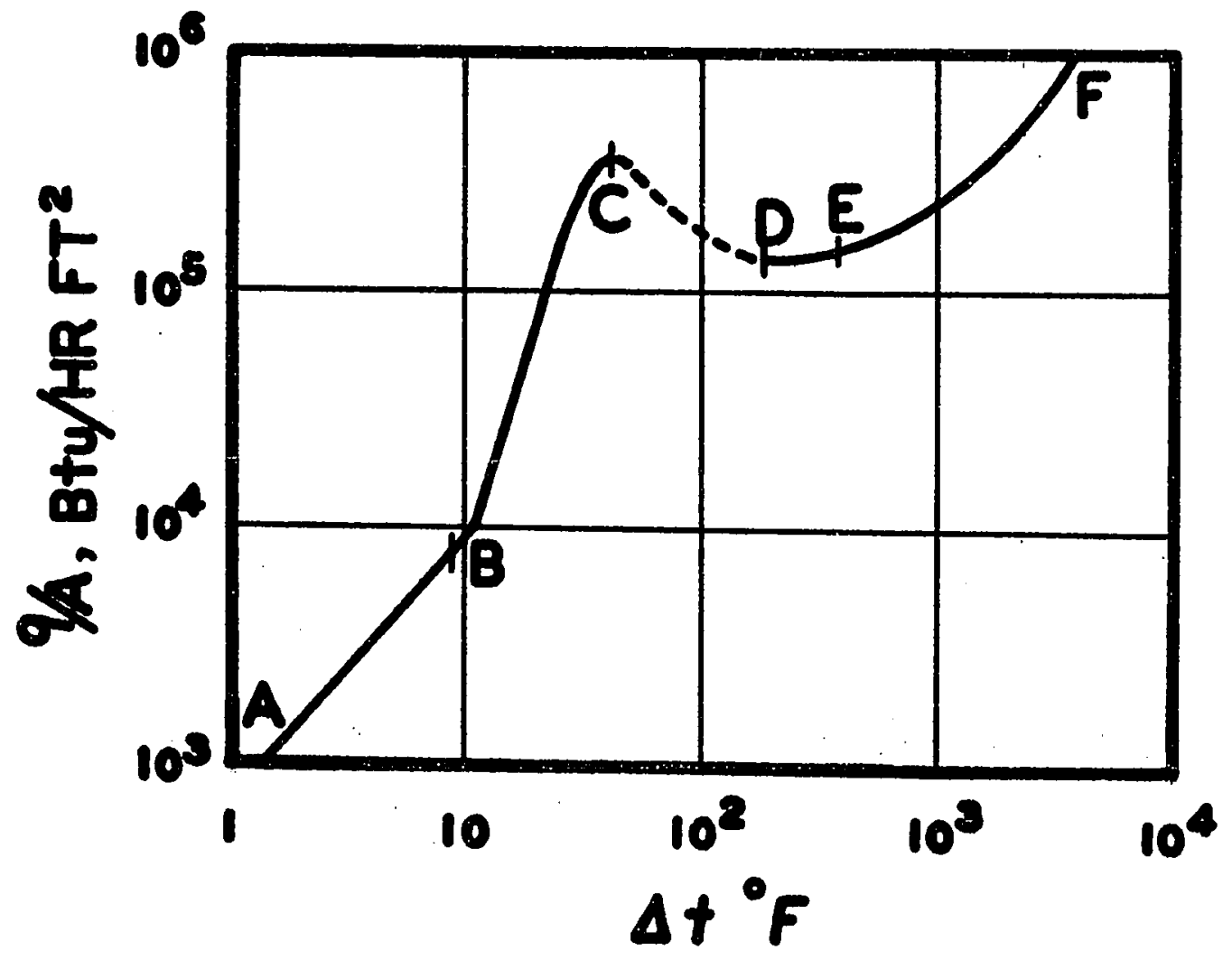


vapor film by conduction, convection and radiation.

The heat flux corresponding to the value at point $\mathrm{C}$ on the boiling curve sometimes is referred to as the burnout heat flux. In systems where heat is supplied by an electric heater or where the energy-generation rates are relatively independent of material temperatures as in the case of a pressurized-water nuclear reactor, an increase in heat flux beyond the peak value causes the temperature of the heater to jump suddenly to a very high value which usually exceeds the melting point of the heating element.

In spite of the extensive studies that have been made on boiling heat transfer, there exists today no consistent analytical method for predicting nucleate boiling heat fluxes and the peak value. Recent studies $(2,3,4,5)$, however, have Indicated that at lower heat fluxes, the important heat transfer mechanism is the agitation and stirring action of single bubbles in the superheated liquid layer adjacent to the heating surface. At higher heat fluxes, the mechanism of latent heat transport predominates and it is believed that in the vicinity of the peak heat flux, latent heat transport alone accounts for the total flux. It becomes obvious that the heat flux at a certain $\Delta t$ is directly proportional to the frequency of bubble emission and the number of nucleation sites on the heating surface. One is thus led to the conjecture on the effect of a sound field on these two varlables, and hence the effect of this fleld on bolling heat transfer rates.

In the case of natural convective heat transfer, it is expected that the heat transfer rates will be increased under the 
influence of a sound fleld. The imposition of acoustic pulsation should create disturbances in the relatively stagnant film of liquid near the heating surface.

It has been mentioned that wide discrepancy exists in the published data on the effects of acoustic vibrations on heat transfer by convection as well as by boling. The confusion is partly due to the various methods used to measure and report the values of the amplitude of vibration. In the case of a liquid, this in turn is due to the difficulty in measuring the amplitude of vibration directly. The interaction of the sound waves with the heat transfer surface and the container walls may set up a certain standing wave pattern. The effects of vibrations on heat transfer in many cases, may depend on the location of the heat transfer surface in the sound field. As a result, it is very difficult to compare these data on a common basis. In order to determine the mechanism which may be important in affecting the rate of heat transfer in a sound field, it is advantageous to review some concepts and definitions. 


\section{BACKGROUND INFORMATION}

"Ultrasonic vibrations" refers to vibrations of sound waves at frequencles above the frequencies of audible sound which generaliy ranges from 30 to $20,000 \mathrm{cps}$. When a liquid is subjected to ultrasonic vibrations, small bubbles may be generated. The collapse of these bubbles may bring about drastic effects such as chemical reaction, erosion, emission of light (sonoluminescence) and radiation of sound. In fact, the formation and collapse of these small bubbles, which is called acoustic cavitation, can be expected to have a pronounced effect upon any boundary layer in which they are found. The amount of acoustic energy necessary to cause cavitation is termed the "cavitation threshold".

The tensile strength of a homogeneous liquid may be defined as the limiting negative pressure that such a liquid will withstand before it ruptures to form a new stable phase. Theoretical studies (6) based on the kinetic theory of liquids show that the tensile strength within a liquid is very large, for example in water of the order of $10^{3}$ atm. These values are exceedingly high compared with the acoustic cavitation threshold values which range from 1 to 40 atm. under varying experimental conditions. Most liquids, unless they are specially treated, contain dissolved gases or other inhomogeneities which are generally called "nucle1" or "microbubbles". They are belleved to be small airor vapor-filled cavities stabılized in cracks on the surface of sma 11 particles suspended in the liquid, and are weak spots within the Iiquid. In order to have cavitation, it would be necessary only to overcome the surface tenston forces of these nuclei rather than the intermolecular 
bonding forces of the liquid. The strength of a nucleus depends very much on its size. As a result, the gas content of the liquid is an important variable in the study of acoustic cavitation. Other parameters include hydrostatic pressure, frequency, temperature, viscosity and other 1iquid properties.

\section{Gaseous Cavitation}

With water and using a focussing system at $60 \mathrm{kcps}$, Blake ${ }^{(7)}$ has shown that there are three distinct types of cavitation. At very low pressures, large visible bubbles, which do not produce sound are formed in gassy water (water more or less saturated with gas). This is termed quiet degassing. At higher pressures, a more or less continuous stream of smaller gas bubbles is observed. These stable bubbles are originated at the focus of the sound field and they are accompanied by a soft hissing sound. Blake has observed that there is a critical pressure, or threshold, for the formation of these streamers and that the rate of formation is very sensitive to changes in the sound pressure amplitude. This second type of cavitation is called gaseous cavitation. Like the quiet degassing, gaseous cavitation only occurs in water that is almost saturated with gas. For a sound field of $60 \mathrm{kcps}$, Blake reported a sound pressure amplituda of about 0.25 atm. to be the threshold value for quiet degassing and about $1.25 \mathrm{~atm}$. for gaseous cavitation. The boundary where the two types of cavitation are divided is not too well defined. Many investigators $(8,9,10)$ have combined the two and termed them as gaseous cavitation. 
As mentioned above, cavitation nuclei are small air- or vapor-filled cavities stabilized in cracks on the surface of smal1 particles suspended in 1iquid. On the basis of a microscopic examination of water, Rosenberg ${ }^{(11)}$ reported that these particles are mainly dust particles ranging from $0.5 \mu$ to $10 \mu$ in diameter. It appears that some mechanism must exist by which a nucleus can increase its air content and grow to a large visible bubble when it is situated in an acoustic pressure field. In a recent study by Barger ${ }^{(8)}$ on the effect of suspended particle size on cavitation threshold, the water used was filtered through a $0.45 \mu$ filter. It was assumed that the diameter of the particles remaining in the water must have been less than about $0.5 \mu$ and that the radius of the small bubbles that were drawn from the cracks was less than about $0.2 \mu$. With a sound pressure of $0.45 \mathrm{~atm}$. and a frequency of $27 \mathrm{kcps}$, the resulting cavitating bubbles had a mean radius of about $40 \mu$.

A theory called rectified diffusion was first proposed by Blake $(7)$ and later elaborated by Hsleh and Plesset ${ }^{(12)}$ to explain the growth of a cavity by a net influx of gas as it oscillates in the acoustic pressure field. According to this theory, a small bubble filled with gas is assumed to pulsate in phase with the pressure amplitude of the acoustic field. For this phase relationship to occur, the bubble resonance frequency must be larger than the driving frequency. If the bubble was initially in equilibrlum with its surroundings, gas will tend to diffuse out when the bubble is compressed and In when the bubble is expanded. This is because the pressure of the air in the bubble is less 
than the equilibrium air saturation pressure in the surrounding liquid when the bubble is expanded beyond its equilibrium radius and greater than the equilibrium air saturation pressure when the bubble is compressed. Since the surface area of the bubble is larger when the bubble is expanded, the bubble experiences a net gain of alr during each cycle of motion.

$$
\text { Several equations }(7,12,13) \text { have been proposed to deter- }
$$

mine the mass transfer rate of gas into the bubble by rectified diffusion. The most complete derivation has been presented by Hsleh and Plesset (12) and the final equation is as follows:

$$
\frac{d m}{d t}=\frac{8 \pi}{3} \& c_{s} R_{0}\left(\frac{P}{P_{0}}\right)^{2}
$$

where $\Phi=$ diffusivity of the gas through the liquid, $\mathrm{cm}^{2} / \mathrm{sec}$

$c_{s}=$ saturation gas content of the liquid at $\mathrm{P}_{0}, \mathrm{cc} / 1$ it

$P_{0}=$ amblent pressure in the liquid, atm

$P_{p}=$ peak acoustic pressure, atm

$\mathrm{R}_{\mathrm{o}}=$ mean bubble radius, $\mathrm{cm}$.

Eq. (1) was derived under the essumption that the applied acoustic pressure is small, that is, for small-amplitude linear oscillations. The effect of frequency is also assumed to be negligible.

Eq. (1) was used by Strasberg ${ }^{(14)}$ to obtain the threshold pressure for rectified diffuston. The threshold pressure is taken to be the critical pressure for which the rate of air diffusing into the bubble is equal to the rate of air diffusing out of the bubble. The result can be expressed as 


$$
\frac{P_{c v}}{P_{0}}=\left[\left(\frac{3}{2}\right)\left(1+\frac{2 \sigma}{R_{0} P_{0}}-\frac{C_{A}}{C_{S}}\right)\right]^{1 / 2}
$$

where $\mathrm{P}_{\mathrm{cv}}=$ threshold pressure for rectified diffusion, atm

$\sigma=$ surface tension, dyne/cm

$\mathrm{C}_{\mathrm{A}}=$ actual gas content of the liquid, cc/1it

$P_{0}, R_{0}$ and $C_{s}$ are defined as before.

Strasberg compared the threshold pressure values predicted

by Eq. (2) with a Iimited amount of experimental data and showed that they have the same order of magnitude. However, in deriving Eq. (1), Hsieh and Plesset have emphasized the assumption of $\left(P_{p} / P_{0}\right) \ll 1$ so that the Iinearization procedure may be carried out. Eq. (2) is thus subjected to the same limitation. In fact, for water that is saturated with air at $t=20^{\circ} \mathrm{C}$ and $P_{0}=1$ atm., one can easily show that the inequality $R_{0} \geqslant 220 \mu$ must hold for $\left(P_{p} / P_{0}\right) \leqslant 0.10$. For partially degassed water, Eq. (2) is limited to even larger values of $R_{0}$. On the other hand, cavitation bubbles have been observed to grow from sub-visible size $(8,10)$. It is evident that Eq. (2) cannot give rellable quantitative results.

\section{Vaporous Cavitation}

In degassed water, vaporous cavitation will occur. This is characterized by sporadic ruptures of cavities and sharp snapping sounds. According to Blake ${ }^{(7)}$, the small explosive ruptures can be observed when the sound pressure amplitude is about $4 \mathrm{~atm}$. (at $60 \mathrm{kcps}$ ). The ruptures are caused by the violent collapse of very short-lived bubbles, each bubble producing an audible snap at the climax of its 
cycle of growth and collapse. The gas content of the liquid is again an important variable. While Blake used completely degassed water, Barger ${ }^{(8)}$ was able to achieve vaporous cavitation with water of gas concentration half of the saturation value. The threshold pressure found by Barger for frequencies smaller than $200 \mathrm{kcps}$, was larger than $3 \mathrm{~atm}$.

The growth of vaporous cavitation bubbles cannot be explained by rectified diffusion. The complete collapse of bubbles in this region indicates that the gas content of the bubbles must be negligible with respect to the amount of gas that would be necessary to stabilize the final pre-collapse bubble radius.

The first theoretical treatment of the dynamics of a sub-visible nucleus in a sound field was given by Noltingk and Neppiras $(15,16)$. They assumed that the 1 iquid is incompressible, the gas content in the bubble is constant and that there is no vapor in it. The applied acoustic pressure wave is taken to be sinusoidal, and the diameter of a bubble is always much less than the wavelength. Numerical solutions of the equation of motion relating the kinetic energy of the associated mass of 1 iquid and the total work done in overcoming surface tensior, the pressure of the gas and that of the liquid have been calculated for a number of values of the parameters: acoustic pressure, frequency, inftial bubble radius. All calculations were for an ambient pressure of 1 atm. The results are presented in curves of radius versus time for the growth and collapse of the bubble. These solutions show that the bubble (nucleus) initially increases in size to a maximum radius during the tension phase of the acoustic cycle, and then collapses 
during the compression phase. At the end of the first acoustic cycle, the bubble radius is calculated to be equal or less than the initial radius. Noltingk and Neppiras did not continue their calculations beyond this point because the calculated bubble interface velocity became larger than the speed of sound in water, a condition that invalidates the incompressibility assumption.

Their results also showed that the maximum radius of the bubble is inversely. proportional to the driving frequency, and directly proportional to the applied acoustic pressure. For a specified driving frequency and acoustic pressure, it is shown that there exists a minimum and maximum bubble radius for which cavitation can set in. Bubbles with radil smaller than the minimum value are bubbles for which the surface tension forces are not exceeded by the applied acoustic pressure. The maximum value of the bubble radius should not exceed the resonant size of the bubble. Noltingk and Neppiras have shown that bubbles with radil larger than the maximum value exhibit a complex oscillation, but do not collapse.

It should be noted that because of the complexity of the problem, many simplifying assumptions have been made. Dissipative effects such as sound radiation, heat conduction and viscosity have been ignored by Noltingk and Neppira.9. Recent1y, Flynn ${ }^{(17)}$ has shown these dissipative effects have a pronounced effect on the motion of a bubble. Calculations of Noltingk and Neppiras show that the lifetime of a bubble is less than an acoustic cycle. This contradicts most experimental observations. Using high-speed photography, Willard ${ }^{(10)}$, as well as 
Barger ${ }^{(8)}$, observed the lifetime of a vaporous cavitation bubble to be hundreds of acoustic cycles. Consequently, results of Noltingk and Neppiras may be taken as qualitative.

\section{Experimental Determinations of Cavitation Threshold}

A great number of papers has been published on the dependence of acoustic cavitation threshold on the state of the liquid, the acoustic frequency, liquid properties, etc. Frequently, the measured threshold values have been inconsistent. This is mainly due to the various definitions of cavitation used by different experimenters, different experimental procedures, and poor control of the exact state of the 1iquid. It should be noted, however, that such control is generally very difficult to accomplish in practice.

As was discussed in the theory of acoustic cavitation, the gas content of the liquid is the most important variable affecting the cavitation threshold. The most complete study of this variable was given by Galloway ${ }^{(9)}$ who used a focussed system with frequencies ranging from 20 to $40 \mathrm{kcps}$. The sound pressure at the focus was determined from the reading taken by a pressure probe which was positioned at the secondary maxima of the standing pressure wave. The cavitation threshold depended heavily upon the gas content of the liquid for gas contents greater than $5 \%$ of the saturation value. The results were presented in graphical form for distilled water and petroleum ether. Whether the gaseous cavitation or vaporous cavitation occurred depended on the gas content of the 1iquid. When the gas content was of the order of $10 \%$ of 
the saturation value, vaporous cavitation occurred. Strasberg ${ }^{(14)}$ has also studied the effect of gas content on acoustic cavitation threshold. Various empirical equations are shown in Table $I$.

$$
\text { Galloway }{ }^{(9)} \text { also studied the effect of temperature on }
$$

the cavitation threshold of distilled water, synthetic seawater, petroleum ether, and a 0.1 mole fraction dioxane-water mixture for different degrees of gas content over a range of $0^{\circ}$ to $50^{\circ} \mathrm{C}$. The cavitation threshold of all samples decreased linearly with increasing temperature. Similar results for water at $60 \mathrm{kcps}$ were obtained by Blake ${ }^{(7)}$, whose empirical equation is given in Table $I$.

A change in the temperature of the 11quid changes the surface tension, the vapor pressure, the viscosity, as well as the degree or sasuration of the liquid. The cemperature dependence of cavitation threshold, however, cannot be attributed to viscosity, since viscosity has a hyperbolic rather than linear dependence on temperature. Galloway (9) also attempted to correlate cavitation threshold with the surface tension of the 1iquid without success. He concluded that the temperature dependence of cavitation threshold was due to the dependence of gas solubility on temperature.

The effect of temperature was also studied by Connolly and Fox ${ }^{(18)}$ using both focussed waves and plane progressive waves at 1 mcps for gassy water at temperatures between $0^{\circ}$ and $30^{\circ} \mathrm{C}$. The gas content of water was kept constant at the saturation value at $30^{\circ} \mathrm{C}$. It . was found that the measured value of cavitation threshold was not a Iinear function of temperature, but increased by a factor of 2.5 between 
TABLE I

CORRELATIONS FOR ACOUSTIC CAVITATION THRESHOLD

BLAKE

$$
P_{c v}=0.07\left(T_{s}-T\right)+1 \text { atm } \quad\left(T=10^{\circ} \text { to } 50^{\circ} \mathrm{C}\right)
$$

GALLOWAY

$$
P_{c v}=P_{z}(1-T / 273)
$$

$$
\left(\mathrm{T}=0^{\circ} \text { to } 50^{\circ} \mathrm{C}\right)
$$

CONNOLLY AND FOX

$$
P_{c v}=1.75+0.176\left(C_{s}-C_{A}\right) \quad\left(T=0^{\circ} \text { to } 30^{\circ} \mathrm{C}\right)
$$

STRASBERG

$$
P_{c v}=2+4.8\left(1-C_{A} / 20\right)
$$

$$
\begin{aligned}
& \text { where } T=\text { temperature, in }{ }^{\circ} \mathrm{C} \\
& \begin{aligned}
T_{s}= & \text { saturation temperature } \\
& \text { of the liquid, in }{ }^{\circ} \mathrm{C}
\end{aligned} \\
& P_{z}=P_{c v} \text { evaluated at } 0^{\circ} \mathrm{C} \\
& \mathrm{C}_{\mathrm{A}}=\text { actual gas content in cc/liter } \\
& C_{s}=\text { gas content when the liquid } \\
& \text { is saturated, in cc/liter. }
\end{aligned}
$$


$30^{\circ}$ and $0^{\circ} \mathrm{C}$. A method of correlation based on the degree of undersaturation of the 1 iquid was proposed by Connolly and Fox. As the temperature is decreased, water becomes less and less saturated. The undersaturation is then defined as the difference between the saturated gas content and the actual gas content present in the liquid. The measured values of cavitation threshold varied linearly with the degree of undersaturation. The final equation is shown in Table $I$.

$$
\text { Briggs et al. (19) studied the effect of variation of }
$$

viscosity on cavitation threshold in liquids at a frequency of $25 \mathrm{kcps}$. The cavitation threshold changed by less than a factor of 3 over a range of viscosities from 0.007 poise to 8.0 poise, the threshold increasing with increasing viscosity. On the basis of these data, it appears that the viscosity of the liquid is not a very important parameter in determining the cavitation threshold.

The first complete study on the frequency dependence of the acoustic cavitation threshold was made by Esche ${ }^{(20)}$. Nine different experimental arrangements were set up to determine the threshold at nine frequencies from dc to 3.3 mcps. The water was described as distilled, filtered, and degassed, but the actual gas content was not measured. The results were presented graphically ${ }^{(21)}$. For degassed water the cavitation threshold remains nearly constant at 1 atm. for frequencies below $10 \mathrm{kcps}$, and increases rapidly above $100 \mathrm{kcps}$. At $5 \mathrm{mcps}$ Esche reported a value of $100 \mathrm{~atm}$. for cavitation threshold. These results, however, have been shown to be in wide discrepancy with those reported by other experimenters ${ }^{(8)}$. Consequently, Esche's results are only qualitative. 
Recently, a more elaborate study has been made by Barger ${ }^{(8)}$ using water at seven different frequencies varying from 27 to $1,160 \mathrm{kcps}$. The gas content of water covered a very wide range and the suspended particle size was carefully controlled. As expected, the cavitation threshold depended heavily on the gas content of the liquid. The cavitation threshold increases rapidly for frequencies above $350 \mathrm{kcps}$. The effect of gas content became negligible when the frequency was $350 \mathrm{kcps}$ or above. With the same gas content, there was no measurable difference In the cavitation thresholds of the samples of water that had been filtered through a filter with pore size of $0.45 \mu$ and those that had not been filtered.

Finally, on the effect of the hydrostatic pressure, Galloway ${ }^{(9)}$ showed that for saturated liquids cavitation threshold was directly proportional to the hydrostatic pressure. The cavitation threshold was 1 atm. peak acoustic pressure at 1 atm. hydrostatic pressure. With undersaturated water the cavitation threshold was independent of the hydrostatic pressure from 1 atm. down to $0.05 \mathrm{~atm}$.

\section{Cavitation Damage}

Cavitation damage is one of the phenomena resulting from the motion of a cavitation bubble. Plesset and E1lis ${ }^{(22)}$ studied the cavitation damage on metal surfaces by means of micro-photographs and $\mathrm{X}$-ray diffraction patterns. Both methods showed that plastic deformation occurred whenever there was cavitation damage. The damage to a nickel specimen in water was compared to the damage to a similar nickel 
specimen in liquid toluene, free of air and covered by a helium atmosphere. They found that essentially the same type and the same extent of plastic deformation had taken place in both liquids. Specimens with un1ike chemical properties showed similar results. It was then postulated that cavitation damage starts with a plastic deformation of the material, which by repeated short stresses leads to work hardening, fatigue, and eventual fallure of areas on the specimen. Plesset and Ellis concluded that the cause of cavitation damage was the mechanical stress from rapid collapse of cavitation bubbles. The chemical effects were not of primary significance.

There are at least two different situations in which a collapsing bubble may bring high stresses to a solid surface. In the first case, a bubble which has grown from a nucleus in the liquid is only a few radil from the surface. When it collapses, a shock wave would be emitted and the damage to the surface would arise from an interaction between the shock wave and the surface. Sutton ${ }^{(23)}$ measured the stresses set up by cavitation bubbles collapsing on a photoelastic surface by high-speed photography. The resulting strain waves in the photoelastic solid showed that stresses as high as 13,000 atm. may have been generated by cavitation. Jones and Edwards $(24)$ who measured the stresses set up in a bar by bubbles collapsing on one end of the bar reported the stresses at the point of collapse must have been at least 10,000 atm.

Cavitation bubbles can also grow from certain selective spots on the solid surface which are microscopic imperfections containing 
trapped gas. When they collapse, the damage to the surface may be due either to the high pressures and temperatures of the compressed gases and vapors within the contracting bubbles, or to the impact of part of the liquid interface on the surface. The latter mechanism, first proposed by Kornfeld and Suvorov ${ }^{(25)}$ and by Eisenberg ${ }^{(26)}$, involves an unsymmetrical collapse of an attached bubble with 1 iquid jets being formed at the contracting interface. The damage to the solid would then be ascribed to the high-speed liquid jets impinging on the surface. High-speed photographs taken by Naudé and E11is ${ }^{(27)}$ of bubbles collapsing on photoelastic solids confirmed that this is the controlling mechanism. Their experiments also indicated that surface instabilities leading to the generation of high-speed jets can occur both in pulsating gaseous bubbles as well as in collapsing vaporous bubbles.

Since cavitation damage is directly related to the cavitation phenomena, factors affecting cavitation threshold are expected to affect the cavitation damage as well.

The temperature dependence of cavitation damage was first studied by Bebchuk $(28,29)$ who measured the weight loss from a standard specimen of aluminum plate at a frequency of $8 \mathrm{kcps}$ using a number of liquids, including water, ethyl alcohol and carbon tetrachloride, with temperature ranging from $10^{\circ}$ to $90^{\circ} \mathrm{C}$. The cavitation damage first increased to a maximum and then decreased with increasing temperature. Similar experiments by Devine and Plesset ${ }^{(30)}$ using various metals also showed that a maximum exists in the damage rate and that it is independent of the material. According to Devine and Plesset, the existence 
of a maximum is due to the increase of vapor pressure and the decrease of the equilibrium concentration of dissolved gas in a liquid as the temperature is increased. Increase in vapor pressure tends to decrease the damage while the cavitation bubbles would collapse more violently as the gas content of the liquid decreases. A maximum would be formed as the more violent bubble collapse tends to oppose the cushioning effect of rising vapor pressure. Devine and Plesset reported that the damage correlated directly with the change in vapor pressure of the 1 iquid and inversely with the concentration of dissolved air.

The cavitation damage was found by Bebchuk to be much greater in water than in any organic 11quid. For example, the damage maximum in water is approximately six times that in ethyl alcohol and carbon tetrachloride. Bebchuk and Rosenberg ${ }^{(29,31)}$ ascribed this difference to the effect of gas solubility. The solubility of gases in carbon tetrachloride and ethyl alcohol is almost an order of magnitude greater than that in water.

The effect of surface tension on cavitation damage was studied by Antony ${ }^{(32)}$ using 11quids of different surface tensions and approximately the same vapor pressure. His results show cavitation damage varies almost linearly with the surface tension of the liquid.

Since it is established that cavitation damage is primarily a mechanical process, it might be expected that there is a relation between the weight loss in a fixed time interval and the intensity of the sound radiated by the collapsing bubbles. Experiments by Bebchuk et a1. (33) showed that the weight loss increased as the square of the 
radiated sound pressure amplitude. This leads to the conjecture that cavitation damage may be used as a measure of cavitation activity at a surface. The findings of Bebchuk ${ }^{(28)}$ that, after an initial nonlinear period, the weight loss is a linear function of time in a steady field of cavitation indicate the reliability of this method. The initial nonlinear period reflects the surface inhomogeneities of the specimen. Recently, it has been proposed by Crawford ${ }^{(34)}$ and Antony ${ }^{(32)}$ that this method be used to measure the cavitation activity in a commercial ultrasonic cleaning tank.

\section{Acoustic Streaming}

Acoustic streaming is due to the interaction of sound waves with the fluid and boundary surfaces. In addition to the oscillating flow that would be anticipated, a steady, directed flow in the body of irradiated fluid is often observed. There are two types of streaming. When the streaming is caused by the interaction of sound waves with the fluid only, it is called the quartz wind. When the streaming is the result of the interaction of the sound waves with the fluid as well as with boundaries or obstacles, it is called the surface streaming.

When a beam of plane waves radiates into a liquid with a plane absorber some distance from the source, it can be shown experimentally that a reaction force acts on the source which is proportional to the energy density of the sound field. This force is called the radiation pressure. Since there is absorption of sound in liquids, an 
exponential drop of energy density, and thus the radiation pressure, along the axis of the sound beam would occur. If the sound beam fills the bounding container, there will be no circulation and a static pressure gradient will exist in the liquid. If the source is small so that the sound beam does not fill the container, there will be regions in which absorption does not occur. The resulting forces will cause an acceleration of the 1 lquid until viscous forces maintain an equilibrium flow. The resulting streaming is the quartz wind. Eckert ${ }^{(35)}$ has made a theoretical study of the problem and showed that for water, the streaming will have a negligible velocity at frequencies below 1 mcps. If the medium is air, it is appreciable at frequencies above several hundred cycles per second.

Surface streaming is a more complex phenomenon as it depends on the geometry of the surface or obstacle as well as on the properties of the fluid and the characteristics of the vibratory motion. Andrade ${ }^{(36)}$ was one of the pioneer workers who made a photographic study of surface streaming using tobacco smoke. The first mathematical solution was given by Schlichting ${ }^{(37)}$ who predicts two regions of streaming in each quadrant, a thin layer next to the cylinder, called the $D-C$ boundary layer, with streaming toward the surface along the propagation axis, and an outer streaming with direction away from the surface along this axis. Holtsmark et a1. ${ }^{(38)}$ conducted an extensive experimental and theoretical investigation and found two regions of streaming on the pattern of the Schlichting predictions. Good agreement was obtained between the predicted values and the observed values of the streaming velocity. 
According to the Schlichting theory, the thickness of the $D-C$ boundary layer $\left(\delta_{D-C}\right)$ is independent of the amplitude of vibration and directly proportional to the A-C boundary layer thickness $\left(\delta_{A-C}\right)$ which is defined by $(\delta / \omega)^{1 / 2}$ where $\checkmark$ is the kinematic viscosity and $\omega$ is the angular frequency of the vibration. Recently, Raney et al. (39) have shown experimentally that for small amplitudes of vioration, the D-C boundary layer thickness may be correlated with the diameter of the cylinder and the A-C boundary layer thickness as defined by Schlichting. The resulting correlation which includes data obtained by Holtsmark et a1. is one in which the $D-C$ boundary layer thins rapidly as the A-C boundary layer is also thinned, that is, when the frequency increases or viscosity decreases. Their experimental work also confirms theoretical predictions that for small amplitudes, the streaming pattern will be the same whether the cylinder oscillates in a quiescent fluid or is fixed in an oscillating fluid. These treatments are based on the assumptions that the radius of the cylinder is small compared to the wave length of the sound and large compared to the displacement amplitude of the sound wave. 
III. HEAT TRANSFER IITERATURE

Natural and Forced Convection - Air

Acoustically Vibrated Systems

Kubanskii ${ }^{(41)}$ studied the natural convective heat transfer from the outside of an electrically heated horizontal cylinder in air subjected to a sound field with frequencies ranging from 8 to 30 $\mathrm{kcps}$ and intensities ranging from 0.03 to 0.16 watts $/ \mathrm{cm}^{2}$ (approximately 145 to $152 \mathrm{db}$ re 0.0002 microbar). The direction of sound propagation was parallel to the axis of the cylinder which had a diameter of $2.4 \mathrm{~cm}$. An increase up to $75 \%$ in the heat transfer coefficient was reported. He concluded from shadowgraph studies that acoustic streaming was responsible for the increase of heat transfer.

$$
\text { Fand and Kaye }{ }^{(42)} \text { also investigated the effects of a }
$$

horizontal transverse sound field on free convection from a $3 / 4$ in, diameter, electrically heated, horizontal cylinder. The frequency of vibration varied from 1100 to $6120 \mathrm{cps}$ and the temperature difference between the cylinder and the air varied from $0^{\circ}$ to $250^{\circ} \mathrm{F}$. Their data showed that a "critical sound pressure level" exists below which the influence of sound is negligible and above which the rate of heat transfer is markedly increased by sound. From a flow-visualization study using smoke as the indicating medium ${ }^{(43)}$, they concluded that the Increase of heat transfer was due to a new type of boundary layer flow called "thermoacoustic streaming" resulting from the interaction of the transverse sound field with the heated cylinder. This streaming was more intense than the isothermal streaming and was evidenced by a pair of vortices above the cylinder but not below. The flow pattern resembled 
vortex shedding behind a cylinder in forced flow normal to the axis. For the same temperature difference, the superposition of a sound field increased the heat transfer coefficient by a factor of 3 . Recently, Fand and Peebles ${ }^{(44)}$ have observed similar flow patterns around a heated and mechanically vibrating cylinder in otherwise still air at a frequency of $104 \mathrm{cps}$. For $f \leqslant 1500 \mathrm{cps}$ and $\ell / D \geqslant 6(\ell$ is the half wavelength of sound and $D$ is the diameter of the test cylinder), Fand and Kaye (42) proposed the following correlation to evaluate the heat transfer coefficient

$$
h_{v}=0.722\left[\Delta t(a f)^{2}\right]^{1 / 3}
$$

where $h_{v}$ - heat transfer coefficient with vibration, BTU/hr $\mathrm{ft}^{2}{ }^{\circ}$ F $\Delta t$ - temperature difference, ${ }^{O} F$

$f$ - frequency of vibration, cps

a - sinusoidal displacement amplitude of vibration, ft.

The local heat transfer coefficients for the heated cylinder in a similar experimental set-up used by Fand and Kaye ${ }^{(42)}$ have been measured by Fand et a1. ${ }^{(45)}$ in a sound field of $146 \mathrm{db}$ (re 0.0002 microbar) and a frequency of $1500 \mathrm{cps}$. The results show that the maximum increase in the local heat transfer coefficient on the lower portion of the cylinder is approximately $250 \%$ and that on the upper portion of the cylinder is approximately $1,200 \%$. The increase on the upper portion is attributed to the vortex flow which is characteristic of the so-called thermoacoustic streaming, while that on the lower portion is attributed to an increase in laminar boundary layer velocities in this region and a modification of the boundary layer temperature profile due to 
acoustically induced oscillation within the boundary layer.

Holman and Mott-Smith ${ }^{(46)}$ measured convective heat transfer coefficients on a $3 / 4$ in.diameter, electrically heated cylinder in air between 2780 and 4710 cps. Wall temperatures of the cylinder ranged from $208^{\circ}$ to $270^{\circ} \mathrm{F}$. It was observed that increase in the heat transfer coefficient did not occur until the sound pressure level was greater than approximately $135 \mathrm{db}$ (re 0.0002 microbar). A $100 \%$ increase was obtained when the sound pressure level was $147 \mathrm{db}$. For the range of values studied, the effect of frequency was negligible. The increased heat transfer was taken to be the result of the thinning of the D-C boundary layer. No correlation was proposed.

The effects of forced convection in a standing sound field were studied by Kubanskii ${ }^{(50)}$. The direction of propagation of the sound wave was perpendicular both to the axis of the cylinder and to the direction of the forced flow. The velocities of the forced flow varied from 1.45 to $1.77 \mathrm{~m} / \mathrm{sec}$, which corresponded to Reynolds numbers of 1450 to 1770 . He was able to either increase or decrease the heat transfer rate by changing the axis of the cylinder with respect to the nodes of the sound field. It was observed that changes in the boundary layer flow and thus the heat transfer rate occurred if the acoustic particle velocity was equal to or greater than the forced flow velocity. A maximum increase of about $50 \%$ was observed in the heat transfer rate. The same problem has been studied recently by Fand and Cheng ${ }^{(51)}$. The ranges of experimental variables are as follows: Reynolds number of the forced flow, $590-10,750$; temperature difference, $50^{\circ}-360^{\circ} \mathrm{F}$; 
sound pressure level, $130-150 \mathrm{db}$ (re 0.0002 microbar); and sound frequency, 1100 and $1500 \mathrm{cps}$. However, the increase in the heat transfer coefficient did not exceed $25 \%$ in all cases.

Jackson et al. (52) studied free and forced convection to air inside a steam-heated vertical tube in the presence of a sound field. The sound field was superimposed from a loudspeaker located near the bottom of the tube. Their results indicated that sound pressure levels below approximately $118 \mathrm{db}$ (re 0.0002 microbar) had little effect on the heat transfer coefficient. The sound pressures, however, were measured at the entrance to the tube and did not reflect conditions within the tube. Increases in the heat transfer coefficient of up to $80 \%$ were found for frequencies varying from 250 to $2,400 \mathrm{cps}$ and the Graetz number from 40.2 to 1,633. The following correlation was proposed:

$$
\operatorname{Nu}(\mathrm{Re})^{1 / 4}(\mathrm{Gz})^{-1 / 2} f^{1 / 8}=5.7 \mathrm{e}^{\mathrm{SPL} / 69.5}
$$

where Nu - Nusselt number, dimensionless

$$
\begin{aligned}
& \text { Re - Reynolds number, dimensionless } \\
& \text { Gz - Graetz number, dimensionless } \\
& \text { SPL - } \text { sound pressure level, db (re to } 0.0002 \text { microbar). } \\
& \quad \text { Mathewson and Smith }{ }^{(53)} \text { studied the effects of pulsa- }
\end{aligned}
$$
tions on forced convective heat transfer by cooling pulsed air in a 1 in, vertical double-pipe heat exchanger. The pulses were generated by a motor-driven, flat-plate siren set in the exchanger Inlet line. Pulse frequencies ranged from 50 to $330 \mathrm{cps}$ and pulse amplitudes between 10 and $250 \mathrm{lb} / \mathrm{ft}^{2}$ were used. It was observed that the improvement in heat 
transfer coefficient increased with frequency and that amplitude had no effect. A maximum increase of $44 \%$ in heat transfer coefficient at $R e=$ 2,300 was obtained, but the increase became negligible when the Reynolds number exceeded 4,000. The range of Reynolds number covered was from 1,600 to 4,000. Using the same equipment, Mathewson and Smith studied the effects of pulsations on film condensation of isopropanol and observed increases in heat transfer rate by 10 to $60 \%$. The increase depended on the vapor flow rate which varled from 1 to $2.5 \mathrm{lb}$ mole/hr and was almost independent of pulse frequency where the same frequency range was used for air. A critical pulse amplitude was required before any increase in heat transfer rate was observed. At amplitudes just greater than the critical value, the heat transfer coefficient increased rapidly with the amplitude, becoming independent of amplitude at very high pulse amplitudes. No correlation was proposed.

The effect of vibration on forced convective heat transfer was also studied by Lemlich and Hwu ${ }^{(49)}$ who used a $25 \mathrm{in.}$ long, horizontal, double pipe, steam to air heat exchanger. Vibration was induced acoustically with frequencies from 198 to 322 cps and superposed directly onto the air stream at Reynolds numbers of 560 to 5900. Increases in Nusselt number of up to $51 \%$ in the normally laminar region and up to $27 \%$ in the normally turbulent region were reported. Their data were correlated with the following equations:

For $\operatorname{Re}<1500$

$$
\frac{N u}{N u}-1=1.3 \times 10^{-6}\left(\bar{H}_{p} f\right)^{2}
$$


For $\operatorname{Re}>2500$

$$
\frac{N u}{N u}-1=0.047\left(\frac{\bar{H}_{p} f}{R^{2}}\right)^{0.8}
$$

$\overline{\mathrm{H}}_{\mathrm{p}}$ is the root mean square pressure rise along the heated section resulting from vibration in $1 \mathrm{~b}$. force $/ \mathrm{ft}^{2}$.

\section{Mechanically Vibrated Systems}

$$
\text { Lemlich }{ }^{(40)} \text { studied the effect of transverse vibrations }
$$

on natural convective heat transfer from electrically heated, horizontal wires to air, with wire diameters ranging from 0.0253 to 0.0810 in. The amplitude of vibration ranged from 0.028 to 0.116 in. The frequency varied from 39 to $122 \mathrm{cps}$ end the temperature difference between the wire and the ambient air varied from $7^{\circ}$ to $365^{\circ} \mathrm{F}$. Up to a $400 \%$ increase in the coefficient of heat transfer was observed. Both the amplitude and the frequency of vibration has a positive effect on heat transfer rates. The effect of vibration was correlated in terms of a vibrational Reynolds number in which the velocity term was defined as twice the product of amplitude and frequency of the vibration. The following equation was used to correlate the data:

$$
\frac{h \mathrm{v}}{\mathrm{h}}=0.75+0.0031 \frac{\operatorname{Re}_{\mathrm{v}}^{2.05}(\beta \Delta \mathrm{t})^{0.33}}{G \mathrm{r}^{0.41}}
$$

where $h$ - heat transfer coefficient without vibration, BTU/hr ft ${ }^{\circ} \mathrm{F}$

$h_{v}$ - heat transfer coefficient with vibration, BTU/hr $\mathrm{ft}^{2} \mathrm{o}_{\mathrm{F}}$

$B$ - thermal coefficient of volumetric expansion, ${ }^{\circ} F^{-1}$

$\Delta t$ - temperature difference, ${ }^{\circ} F$ 


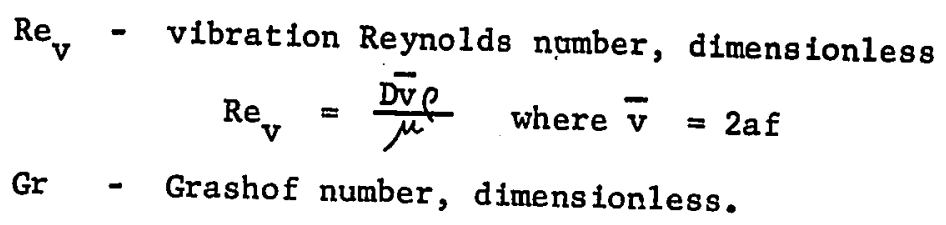

Lemlich reported that the above equation correlated data for vertical vibration as well as for horizontal vibration. In order to account for his observations, the concept of a "stretched film" surrounding the entire path of vibration was proposed. An attempt was made to observe the "stretched film" by placing a lighted cigarette under the heated wire, but the results were inconclusive.

Fand and Kaye ${ }^{(47)}$ studied the effects of vertical mechanical vibrations on natural convective heat transfer from a horizontal $7 / 8 \mathrm{in}$. cylinder to air. The frequency range varied from 54 to $225 \mathrm{cps}$ with amplitudes of vibration up to $0.16 \mathrm{in}$. were used. The range of temperature difference was from $25^{\circ}$ to $185^{\circ} \mathrm{F}$. It was shown that the effect of vibration becomes appreciable only when the intensity of vibration defined as the product of amplitude and frequency of vibration exceeds a value of $0.3 \mathrm{ft} / \mathrm{sec}$. The flow visualization study using smoke indicates a turbulent type of boundary later flow rather than the vortex type flow which was observed with horizontal vibrations.

Anantanaryanan and Ramachandran ${ }^{(48)}$ investigated the effect of vibration on heat transfer from an electrically heated nichrome wire to parallel air streams. An increase as high as $130 \%$ was obtained. It was shown that both frequency and amplitude increased the heat transfer coefficients. The frequencies of vibration ranged from 75 to 120 cps and air flow rates from 34 to $64 \mathrm{ft} / \mathrm{sec}$ were used. 


\section{Natural and Forced Convection - Liquids}

\section{Acoustically Vibrated Systems}

Robinson et al. (58) made an experimental study on the effects of ultrasonic vibrations at $400 \mathrm{kcps}$ on heat transfer from water and transformer oil to a solid brass cylinder acting as a heat sink. Their results were shown by a plot of $\Delta t$, the temperature difference between the heated oil or water and the cylinder surface, versus the electrical power input to the transducer. A reduction of about $18 \%$ in $\Delta t$ for the transformer oil was obtained when ultrasonic vibration was applied. For water, only a $4 \%$ reduction was reported. The sound pressure level involved in the case of water was much lower than that for the ofl so that a meaningful comparison of the relative effects in the two liquide is not possible. Whether the increase in heat transfer is due to cavitation is not mentioned by the authors. Since only the electrical power inputs to the transducer are reported, it is impossible to tell if the cavitation threshold for the transformer oil or water had been reached.

$$
\text { Larson and London }{ }^{(57)} \text { studied the effects of ultrasonic }
$$
vibrations on natural convective heat transfer from a 1 in.electrically heated copper sphere to water and toluene. The sphere was located at the center of a 3-inch diameter glass pipe cross with the transducer located at the lower opening. The frequency range varied from 20 to 1,000 kcps. As much as a four-fold increase in heat transfer coefficient could be obtained. At lower frequencies, it was concluded from shadowgraph studies that the increase was due to the ultrasonic 
cavitation. The increases in heat transfer coefficient were correlated with the parameter $\left[\left(I / I_{C}\right)^{0.5}\left(C_{A} / C_{S}\right)^{1.5}\right]$ with some success (here $I$ is the sound intensity at the transducer surface, $I_{c}$ is the cavitation threshold intensity of the gas-saturated liquid, $\mathrm{C}_{\mathrm{A}}$ is the actual gas content of the liquid, and $C_{S}$ is the gas content of the gas-saturated 1iquid). For frequencies above $100 \mathrm{kcps}$, the increase was taken to be the result of quartz wind streaming. No attempt was made to correlate these data.

It should be emphasized that the sound intensity values used to correlate the heat transfer data are the intensities at the transducer and not the intensities at the sphere surface which are of prime interest. The sound intensity at the transducer was calculated from the electrical power input to the transducer and would be proportional to the sound intensity at the copper sphere surface. But the exact relationship between these two quantities depends on the geometry of the system, the fluid used, the nature of the sound field, etc. In general, it is impossible to convert one to another.

Larson and London also studied the forced convective heat transfer with the same equipment. It was found that for frequencies below $125 \mathrm{kcps}$, depending on the sound intensity at the transducer, up to $60 \%$ increase in the Nusselt number could be obtained when the flow Reynolds number was 400. The flow Reynolds number was defined as (W/D $\mu$ ) where $W$ is the mass flow rate of the liquid, $D$ is the diameter of the sphere and $\mu$ is the viscosity. The increase became small as the flow Reynolds number was increased, and was negligible when the flow Reynolds 
number was approximately 6,000. For frequencies above $400 \mathrm{kcps}$, no measurable increase was found for flow Reynolds numbers over 1,000. Mechanically Vibrated Systems

One of the earliest studies on the effect of vibration on heat transfer to liquids was made by Martinelli and Boelter (54). A 0.75 in.horizontal cylinder was vibrated in water at frequencies up to $40 \mathrm{cps}$ and amplitude up to 0.1 in. The data were correlated by means of a dimensionless equation relating the Nusselt number with the Grashof number, PrandtI number, and a vibrational Reynolds number in which the velocity term was taken to be the root-mean-square velocity of the vibration of the cylinder. For vibrational Reynolds numbers below 1,000, there was no change in heat transfer. An improvement was observed with higher vibrational Reynolds numbers, and as much as $500 \%$ increase in heat transfer coefficient was obtained with Reynolds numbers of about 7,000. However, attempts to reproduce these data have been unsuccessful (40) West and Taylor ${ }^{(55)}$ studied the effect of pulsation on heat transfer in turbulent flow of water inside tubes. The pulsations were generated by a reciprocating pump. An increase of up to $70 \%$ in heat transfer coefficient was reported when a pulsation rate of 1.7 pulses/sec was applied to water flowing at Reynolds numbers of 30,000 to 85,000 . No appreciable improvement was observed for other flow rates. The effects of normal surface vibration on laminar forced convective heat transfer were studied by Scalan (56), who used a system where degassed water flowed by gravity through a chamber which contained the vibrating heat transfer surface. Frequencies up to $600 \mathrm{cps}$ and 
amplitudes of vibration up to $0.004 \mathrm{in}$, were used. A maximum increase in heat transfer coefficient was observed when the frequency was in the range of 50 to $80 \mathrm{cps}$. The increase, however, became almost negligible at high frequencies when the amplitude of vibration was sma11. According to Scalan, the decreasing effect of vibration at higher frequencies was due to cavitation. In the words of Scalan, "the resulting blanketing effect (from cavitation) would be expected to counteract the increase in coefficient caused by mixing. Below a certain combination of amplitude and frequency, this blanketing effect will not occur. Above this point, the blanketing will increase with increased amplitude and frequency as that portion of a cycle during which the critical acceleration is exceeded becomes larger." The critical frequency was observed to be about $70 \mathrm{cps}$ for the range of frequency and amplitude studied. If cavitation is responsible, one would expect some variation in the critical frequency as there was a fourfold increase in amplitude. Larson and London ${ }^{(57)}$ have proposed that the maximum in the heat transfer coefficient observed by Scalan at about $70 \mathrm{cps}$ is probably due to the fact that the resonant frequency of the system is also at about $70 \mathrm{cps}$. At higher frequencies and amplitudes, the cavitation which could occur can satisfactorily explain the increase in heat transfer rate reported by Scalan.

Deaver, Penney and Jefferson ${ }^{(59)}$ measured heat transfer rates from an oscillating horizontal wire to water. A platinum wire of 0.007 in. diameter was vibrated mechanically in an otherwise still tank of water in the frequency range of 0 to $4.25 \mathrm{cps}$ and amplitudes up to 
2.76 in. Temperature differences between the wire and the water varled from $0^{\circ}$ to $140^{\circ} \mathrm{F}$. For large-amplitude vibrations ( $\sim 1$ in), the data were correlated by an equation which is almost identical to the equation for heat transfer for flow of liquid normal to single bodies. The velocity term in the Reynolds number, however, is based on the mean velocity of the wire, which is taken as the total distance through which the wire moved per cycle divided by the period of the oscillation. The correlation is as follows:

$$
\frac{\mathrm{Nu}}{(\mathrm{Pr})^{0.3}}=0.35+0.48(\operatorname{Re})^{0.52}
$$

It is unfortunate that Deaver et al. did not attempt to observe the boundary layer flow around the wire so that it could be compared with that for flow of liquid normal to a heated cylinder.

Raben $(60)$ studied the effects of transverse vibration on forced convective heat transfer. The vibration was induced mechanically to a pipe of 1 in O. D. at frequencies from 32 to 84 cps with water flowing on the outside of the pipe in an annular space. The maximum amplitude of vibration was $0.150 \mathrm{in}$. The Reynolds number for the water flow ranged from 541 to 23,600 . It was shown that increases in heat transfer coefficlent varied from $450 \%$ at a Reynolds number of 540 to $11 \%$ at a Reynolds number of 16,000. For Reynolds numbers greater than 5,000 the data were correlated by the following equation:

$$
\left(\frac{\mathrm{h}_{\mathrm{v}}}{\mathrm{h}}-1\right)=0.115\left[\operatorname{Re}_{\mathrm{v}} / \operatorname{Re}\right]^{1.69}
$$


The vibrational Reynolds number was defined to be the same as in Equation (7).

In the laminar region, no single correlation could be obtained.

$$
\text { Recently, Bergles }{ }^{(61)} \text { made an experimental study of forced }
$$
convective heat transfer from an electrically heated stainless steel tube to water flowing inside the tube with vibration applied to degassed water at the downstream end by an electrodynamic vibrator. The frequency of vibration was $80 \mathrm{cps}$ with amplitudes varying from 0.05 to $0.14 \mathrm{in}$. The velocity of water was $11 \mathrm{ft} / \mathrm{sec}$. It was shown that there was a critical temperature difference between the water and the heating surface, below which the effect of vibration on heat transfer was negligible. As the amplitude of vibration was increased, the critical temperature difference was reduced. An increase of up to $100 \%$ was obtained in heat transfer rate. No correlation was proposed.

\section{Bolling Heat Transfer}

Acoustically Vibrated Systems

Isakoff ${ }^{(62)}$ studied the effect of vibration at a frequency of $10 \mathrm{kcps}$ on boiling heat transfer. An electrically heated platinum wire of 0.008 in. diameter was suspended horizontally in water at the saturation temperature. The transducer was located at the bottom of a tank measuring 6 in. $x 10$ in. $\times 3$ in. deep. The sound intensity was estimated to be approximately 2 watts $/ \mathrm{cm}^{2}$ at the transducer surface. The sound pressure or intensity in the boiling water was not measured. It 
was concluded that the use of a sound field could increase the burnout heat flux by about $60 \%$. In the nucleate bolling region, at a given $\Delta t$, it was found that the effect of acoustic vibration on the heat transfer rate was negligible. Isakoff also observed that film boiling could be made to revert to nucleate boiling by applying the acoustic vibrations. No mechanism was proposed to account for the increase in the burnout heat flux.

A similar pool-boiling experiment at atmospheric pressure was performed by Ornatskii and Shcherbakov ${ }^{(63)}$ who used distilled water and a nichrome wire heater with a diameter of $0.4 \mathrm{~mm}$. The quartz transducer which was vibrating at the frequency of $1000 \mathrm{kcps}$ was also located at the bottom of the glass vessel. It was stated that the intensity of the ultrasound in the water was approximately 1.5 to 2 watts $/ \mathrm{cm}^{2}$. But the method used to obtain these values was not given. Experiments were performed in water temperatures of $20^{\circ}, 35^{\circ}, 50^{\circ}, 70^{\circ}$ and $97^{\circ} \mathrm{C}$. It was shown that the value of burnout heat flux with ultrasonic vibrations increased with the increase of the subcooling of the liquid. For example, when the subcooling was $80^{\circ} \mathrm{C}$ (water temperature $=20^{\circ} \mathrm{C}$ ), the increase in burnout heat 1.ux was $80 \%$. It dropped to $30 \%$ when the water was at the saturation temperature. The increase was attributed to an increase in the frequency of bubble generation from the wire as the result of ultrasonic vibrations.

Markels, Durfee and Richardson (65) studied the effects of acoustic vibrations on the burnout heat flux of saturated pool boiling of isopropanol. A horizontal, steam heated copper tube with 
dinmeter of $3 / 8 \mathrm{in}$ and length of $3 \frac{1}{4}$ in, was used as heater. Sound waves were generated by a barium titanate transducer located in the bottom of the tank. The sound pressure was measured by a second transducer placed near the heating surface. Frequencies were varied from 20 to 38,000 cps. It was found that acoustic energy did not affect significantly either the burnout heat flux or the critical temperature difference. No data were taken for nucleate boiling. For the range of frequency used, the effect of frequency was also negligible. It should be noted, however, that except for the case when the frequency was $38,000 \mathrm{cps}$, which was the resonant frequency of the transducer, the sound pressures measured by the second transducer located near the heating surface were very sma11. For example, the sound pressure was $7 \mathrm{psi}$ when the frequency was $38,000 \mathrm{cps}$, but it varied between $2.5 \times 10^{-3} \mathrm{psi}$ and $400 \times 10^{-3} \mathrm{psi}$ for frequencies from 200 to $18,000 \mathrm{cps}$ when the electrical power input to the transducer in each case was about the same. Thus, except when the transducer was operating at its resonant frequency, the acoustic power output from the transducer at any other frequency was so low that one would not expect it to have any effect on heat transfer.

A note of caution concerning the sound pressure data of Markels et a1. must be introduced here. As mentioned above, a second transducer was placed near the heating surface to probe the sound pressure. The exact position of this transducer probe as well as its size were not given. Furthermore, there was no mention of the possible variation of sound pressure along the length of the copper tube. Although the dimensions of the tank were not given, it is expected that there 
would be a standing wave pattern in the tank with a wide spatial variation of sound pressure. The sound pressure value used for correlating heat transfer data should be the time-space average at the heating surface. Values of sound pressure reported by Markels et al. apparently were those measured at a specific point near the heating surface. While these measurements are useful for comparing data obtained in their equipment, they do not represent the true sound pressure exerted on the entire heating surface.

Romie and Aronson ${ }^{(66)}$ made an experimental investigation of the effects of ultrasonic vibrations on the burnout heat flux for forced convection, subcooled boiling. In their experiment, water flowed at atmospheric pressure through an annulus formed by a $1 / 4 \mathrm{in}$. diameter, electricaily heated tube and a concentric glass tube of $3 / 4$ in. I. D. The length of the heating element was $5 \frac{1}{2}$ in. The ultrasonic transducer, which was operated at $25 \mathrm{kcps}$ and an electrical power input of 300 watts, was located at the inlet end of the annulus. The ultrasonic waves were propagated in the same direction as the flow, and thus were parallel to the heating surface. The velocity of the water varied from 1.61 to $6.25 \mathrm{ft} / \mathrm{sec}$ and the degree of subcooling from $16^{\circ}$ to $28^{\circ} \mathrm{F}$. No measurement of acoustic power at the transducer surface or in the water was made. It was found that the effect of ultrasonic vibrations on burnout heat flux was negligible. Romie and Aronson also reported that at heat fluxes appreclably below the burnout level, the presence of an ultrasonic field did have some effect on the bubble activity surrounding the heating element, provided the flow velocities were low. The 
average bubble size appeared to have been decreased and the frequency of bubble generation increased. They also reported that the number of nucleation points for bubble generation did not appear to be influenced by the ultrasonic field. However, it is not clear whether there was . cavitation in the water close to the heating element. No quantitative result in this range of heat flux was presented. As the flow velocity increased, the effect of ultrasonic vibrations decreased.

\section{Mechanica11y Vibrated Systems}

Recently, an experimental investigation has been carried out by Nangia and Chon ${ }^{(64)}$ to determine the effects of vibration of the heat transfer surface in saturated pool boiling of water at atmospheric pressure. Platinum wires of 0.01 in. diameter were heated electrically and vibrated electro-magnetically at frequencies between 35 and $115 \mathrm{cps}$ and amplitudes from 0.030 to $0.178 \mathrm{~cm}$. The heat flux with vibration was always higher than the flux from a stationary wire. At frequencies below $35 \mathrm{cps}$, the heat flux increased with frequency for a constant amplitude and temperature difference. Between $35-45 \mathrm{cps}$, the heat flux decreased with frequency while the expected increase with frequency was observed for frequencles above $45 \mathrm{cps}$. The above results were confirmed by varying the amplitude at a fixed frequency. Results from high speed motion pictures taken at 4800 frames/sec showed that the increase was due to a decrease in the average bubble size and an increase in the frequency of bubble generation, The bubble growth rate for a pulsating wire was also lower than that of a stationary wire. No satisfactory explanation was given for the reversing trends in the heat flux 
for frequencies between 35 to $45 \mathrm{cps}$. A more detalled study is currently underway to determine the reason for such behaviour.

The effect of flow vibrations on forced convection, subcooling boiling was also studied by Bergles ${ }^{(61)}$ with degassed water flowing in an electrically heated stainless steel tube. Vibrations were applied to the water at the downstream end by an electrodynamic vibrator at $80 \mathrm{cps}$ with amplitudes of $0.08 \mathrm{in}$. The temperature of water was kept at $50^{\circ} \mathrm{F}$ and the flow velocities varied from 7 to $28 \mathrm{ft} / \mathrm{sec}$. It was found that vibrations had no detectable effect on burnout heat flux as well as on the heat transfer rates in the region of fully developed surface boiling. However, at lower heat fluxes, increases up to $70 \%$ in heat transfer rate were obtained. As it was reported by Romie and - Aronson (66), the improvement in heat transfer decreased as flow velocity increased. The pressure amplitude of the vibration which was probed by a diaphragm-type pressure transducer near the vibrator was $15 \mathrm{psi}$. It was attenuated to $2 \mathrm{psi}$ at the upstream end. Bergles mentioned that he was doubtful there was cavitation in his system at such pressure amplitude levels. 
IV. GENERAL COMMENTS

It can be seen that although considerable work has been done on the effects of vibrations on heat transfer, the published data are far from being conclusive as wide discrepancies can be found between them. This is usually due to the different experimental conditions and ranges of variables which have been used.

The effects of vibrations on heat transfer by convection and by boiling have been studied experimentally either by vibrating the fluid or by vibrating the heating surface. The two methods are directly comparable if the wavelength of sound is large relative to the characteristic dimension of the heating surface $(44,51)$. Another important experimental variable is the ratio of the amplitude of vibration to the characteristic dimension of the heating surface. For isothermal conditions, Raney et a1. (39) have observed that the D-C boundary layer thickness is independent of $(a / d)$, the ratio of the amplitude of vibration (a) to the diameter of the test cylinder (d), when (a/d) is about 0.25 or less. At higher values of $(\mathrm{a} / \mathrm{d})$, the $\mathrm{D}-\mathrm{C}$ boundary layer thickness begins to shrink, and decreases to zero at sufficiently high amplitudes of vibration. As a result, the boundary layer flow pattern around a heated cylinder for small values of $(a / d)$ is expected to be different from that for large values of $(a / d)$ and hence the effects of vibrations on heat transfer. For values of $(\mathrm{a} / \mathrm{d})$ about 0.017 and 1 ess, Fand and Raye $(42,43)$ have observed the so-called "thermoacoustic streaming" which is characterized by the development of two vortices above the cylinder. Similar flow patterns were obtained by Fand and Peebles (44) with a value of 
(a/d) of 0.16. Experiments Involving large values of $(a / d)$ have been performed by Lemlich ${ }^{(40)}$ and Deaver et al. (59). While Lemlich employed values of $(a / d)$ up to 4 , Deaver et al. used values of $(a / d)$ almost up to 200. Using smoke, Lemlich observed a stretched film around the entire vibrating path of the heated wire. However, Lemlich mentioned that his observation was not conclusive. Deaver et al.did not attempt any observation of the boundary layer flow around the heated wire.

For systems where the heat transfer surface is vibrating, the measurement of the amplitude of vibration is usually accomplished by means of a calibrated microscope $(40,56)$. In cases where the heat transfer surface is stationary and the fluid vibrates, the measurement of the amplitude of vibration is also simple provided the fluid is a gas. It is usually measured by a microphone gystem and the results expressed as sound pressure level (SPL) $(42,53)$. It should be emphasized here that the effect of vibrations on the heat transfer rate depends very much on the location of the heat transfer surface in the sound field. Thus, Fand and Kaye ${ }^{(42)}$ obtained a $300 \%$ increase in heat transfer coeffictent when the heated cylinder was located on the plane of pressure antinodes of a stationary sound field. When the heated cylinder was positioned at the node of the same sound field, the resulting heat transfer coefficient had the same value as that for the analogous case without vibration. Kubanskif $(50)$ also reported that he was able to either increase or decrease the convective heat transfer rate by moving the cylinder relative to the nodes of the stationary sound field. As a result, measurements of sound pressure must be made in the vicinity 
of the heat transfer surface. It can be seen that the sound pressure data reported by Jackson et a1. (52) were not the actual sound pressures exerted on the heat transfer surface as the sound level meter was located beside the loudspeaker at the entrance to the steam heated vertical tube. For systems where the vibrating fluid is a liquid, depending on the intensity of the sound field, measurement of the sound pressure can be a problem. For sound pressures below the cavitation threshold of the liquid, they can be measured by a pressure sensitive microphone $(67,68)$. The specific requirements that must be achieved for probes of this type have been discussed $(67,69,70)$. For sound pressures near the cavitation threshold or above, the microphone cannot be used as it can easily be damaged by the cavitation action. Other methods for measuring the sound field include the calorimetric method where the rate at which the sound energy introduced into the liquid is degraded into heat is measured $(69,71)$ and the radiation pressure float method where the radiation pressure is measured in terms of the buoyancy of a float $(69,72,73)$. The calorimetric method requires isolation of the system to avold heat gain or loss from and to its environment. This is very difficult, if not impossible, to achieve in experiments involving heat transfer. The radiation pressure float method is applicable if small probes are used. However, these probes are also subjected to cavitation damage in a high intensity sound field. Because of these difficulties, most investigators $(57,58,62)$ reported only the electrical power input to the transducer(s) or the acoustic power output from the transducer(s). It has been mentioned that standing waves are usually set up with a non-uniform distribution 
of pressure and particle velocity in the sound field. This is further complicated by cavitation. The presence of the cavitation bubbles tends to scatter and dissipate a part of the sound energy. The knowledge of the acoustic power output from the transducer(s) does not reflect the conditions of sound pressure in the vesse1. Furthermore, it has been pointed out that for the same acoustic power output, depending on the location of the heat transfer surface, the resulting vibration can cause an increase or decrease in the heat transfer rate. As a result, it is difficult to compare the experimental data of various investigators as they are strongly dependent on the geometry of the test. Larson(75) was one of the investigators who realized this limitation of his work and emphasized this point in the following manner:

"It is to be emphasized that this investigation is for a single geometry -- that of a 1 in. diameter sphere located at the center of a 3 in. diameter vertical circular tube 5 in.above the sound source, which is located at the lower end."

In all the works that have been reviewed, an empirical method is used to determine the governing parameters of these systems. The mathematical formulation of coupled sound vibration and convective heat transfer problems is very difficult and has not been attempted even in the simpler case where the fluid is a gas. For systems where a liquid is involved, the problem becomes more complicated because of the cavitation phenomena. For systems where the fluid is a gas, it is apparent that there exists a sound pressure level below which the effect of vibrations on heat transfer is negligible. An attempt, based on the 
work of Raney et al (39), has been made by Westervelt ${ }^{(74)}$ to determine this critical value. Raney et al. have observed under isothermal conditions that acoustical streaming patterns in the vicinity of a cylinder deviate strikingly from theory when the ratio $\left(a / \delta_{A C}\right)$ is appreciably greater than unity. ( $a=$ amplitude of vibration, $\delta_{A C}=A-C$ boundary layer thickness). As $\left(a / \delta_{A C}\right)$ increases beyond the value 1 , the thickness of the streaming boundary layer increases slightly for a while and suddenly, at a critical value of $\left(a / \delta_{A C}\right)$, the layer appears to collapse entirely. At the collapsed stage, the regular streaming motion appears to be replaced by a vigorous and chaotic motion. Westervelt ${ }^{(74)}$ postulated that the effect of sound waves is mainly a result of the alteration of the streaming configuration. The condition $\left(a / \delta_{A C}\right)=1$ is taken as a criterion for determining the critical sound pressure level (SPL crit $_{\text {). }}$. For air at atmospheric conditions, the criterion has been expressed as follows:

$$
\begin{array}{r}
\mathrm{SPL}_{\text {crit. }}=136+10 \log \left(\frac{\mathrm{f}}{1000}\right) \mathrm{db} \\
\\
\text { (re } 0.0002 \text { microbar })
\end{array}
$$

where $f=$ frequency of the sound wave in cps. Values of critical SPL predicted by Equation (11) compare favourably with those reported by Fand and Kaye ${ }^{(42)}$ and Holman and Mott-Smith ${ }^{(46)}$. When the fluid is a liquid, the mathematical formulation of the problem becomes more complicated because of the cavitation phenomenon. A study of the physical mechanism for such systems has been made only by Larson and London ${ }^{(57)}$. They have shown that for frequencies above $400 \mathrm{kc}$, the increase in convective heat transfer rates for water 
is the result of the quartz wind streaming. At low frequencies, the controlling mechanism is the acoustic cavitation in water near the heat transfer surface. It is apparent that the cavitation threshold of the liquid can be used as a criterion in determining the effects of ultrasonic vibration on heat transfer in 1iquids. The threshold value, however, should correspond to the liquid at a temperature equal to that of the liquid near the heat transfer surface. It is unfortunate that experimental data of cavitation threshold for liquids near the saturation temperature are very scarce. A value of 1 atm is predicted by Blake ${ }^{(7)}$ for water at its saturation temperature (Table I). The value from Galloway's equation ${ }^{(9)}$ is $4.4 \mathrm{~atm}$, if the threshold value of saturated water at $0^{\circ} \mathrm{C}$ is taken to be 6.9 atm as measured by Connolly and Fox ${ }^{(18)}$. All equations 1 isted in Table $I$ are based on experimental data for the narrow temperature ranges listed. As pointed out by Blake ${ }^{(7)}$, his empirical equation should not be used for temperatures above $50^{\circ} \mathrm{C}$, the upper temperature limit of his experiment. One of the limitations of these equations is that the vapor pressure has not been taken into consideration.

The fact that quartz wind streaming is the controlling mechanism at high frequencies is also expected. The cavitation threshold of water has been found to increase rapidly for frequencies above 350 kcps $^{(8)}$. Before acoustic cavitation can be induced, the streaming vèloclty as the result of the high intensity ultrasonic waves becomes appreclable and is an important contributor in increasing the heat transfer. Based on the published data on the effects of ultrasonic 
vibrations on boiling heat transfer, the following conclusions can be drawn. First of all, the results on burnout heat flux are rather inconsistent. While Isakoff ${ }^{(62)}$ and Ornatskil et al. ${ }^{(63)}$ reported an increase of $60 \%$ and $30 \%$ respectively, Markels et $21 .^{(65)}$, as well as Romie and Aronson (66), have shown that the effect of ultrasonic vibration on burnout heat flux is negligible. Secondly, the amount of data on nucleate boiling is very limited. Several investigators, however, have discussed the possible effects of ultrasonic vibrations on nucleate boiling. Isakoff suggested that cavitation and microagitation induced by ultrasonic vibrations might accelerate the formation and evolution of vapor bubbles from the heating surface. In other words, there would be an increase in the number of active nuclei on the heating surface for vapor bubbles and in the frequency of bubble generation. Romie and Aronson as well as Ornatskii and Shcherbakov have mentioned that the effect of an ultrasonic field is a reduction in mean bubble size and an increase in frequency of bubble formation. However, these proposed mechanisms cannot be taken as conclusive as they are based on visual observations. 


\section{NOMENCLATURE}

ROMAN SYMBOLS

a

C

$\mathrm{C}_{\mathrm{p}}$

D

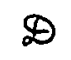

f

h

$\overline{\mathrm{H}}_{\mathrm{p}}$

I

k

L

$\ell$

$$
\text { Po }
$$

$P_{p}$

$\mathrm{P}_{\mathrm{CV}}$

$\mathrm{P}_{\mathbf{z}}$

Ro

SPL

$\mathrm{T}$

V

W amplitude of vibration

gas content of liquid

specific heat at constant pressure

diameter

diffusivity

frequency of vibration

heat transfer coefficient

root mean square pressure rise

sound intensity

thermal conductivity

length of tube

half wavelength of sound

ambient pressure in liquid

peak acoustic pressure

cavitation threshold pressure

$P_{c}$ evaluated at $0^{\circ} \mathrm{C}$ and atmospheric pressure

mean bubble radius

sound pressure leve1

temperature

velocity

mass flow rate 
GREEK SYMBOLS

$\begin{array}{ll}B & \text { thermal coefficient of volumetric expansion } \\ \Delta t & \text { temperature difference } \\ \delta_{A-C} & \text { A-C boundary layer thickness, A-C }=\left(\frac{v}{\omega}\right)^{1 / 2} \\ \delta_{D-C} & \text { D-C boundary layer thickness } \\ \mu & \text { viscosity } \\ \sqrt{:} & \text { kinematic viscosity } \\ \rho & \text { density } \\ \sigma & \text { surface tension } \\ \omega & \text { angular frequency }\end{array}$

\section{DIMENS IONLESS GROUPS}

$\begin{array}{ll}\text { Gr } & \text { Grashof number, } g \beta \rho^{2} D^{3} \Delta t / \mu^{2} \\ \text { Gz } & \text { Graetz number, }{ }^{2} C_{\mathrm{p}} / \mathrm{kL} \\ \mathrm{Nu} & \text { Nusselt number, } \mathrm{hD} / \mathrm{k} \\ \mathrm{Pr} & \text { Prandtl number, } \mu \mathrm{C}_{\mathrm{p}} / \mathrm{k} \\ \mathrm{Re} & \text { Reynolds number, } \mathrm{Dv} \rho / \mu\end{array}$

\section{SUBSCRIPTS}

A

$\ell$

$\mathbf{s}$

v

$\mathbf{w}$ actual

1iquid

saturation condition

with vibration

based on wall temperature. 


\section{REFERENCES}

1. Nukiyama,. S. J.Soc.Mech.Engrs. (Japan), 37, No. 206, 367 (1934).

2. Gaertner, R.F. General Electric Research Laboratory, Rept. No. 63-RL-3357C. June, 1963.

3. Westwater, J.W. and Kirby, D.B. Paper presented at the 16 th National Heat Transfer Conference, Boston, Aug. 1963, AIChE Preprint No. 14.

4. Moisis, R. and P.J. Berenson. J.Heat Transfer, Trans.Am.Soc. Mech. Engrs., 프, 222 (1963).

5. Westwater, J.W. and J.G. Santangelo. Ind.Eng.Chem., 47, 1005 (1955).

6. Frenke1, J. "Kinetic Theory of Liquids" Oxford, The Clarendon Press (1964).

7. Blake, F.G. Jr. Tech.Memo. No. 12, Acoustic Research Lab., Harvard U., September (1949).

8. Barger, J.E. Tech.Memo. No. 57, Acoustic Research Lab. Harvard U., April (1964).

9. Galloway, W.J. J.Acoust.Soc.Am., 26, 849 (1954).

10. Willard, G.W. J.Acoust.Soc.Am., 25, 669 (1953).

11. Rosenberg, R.D. Tech.Memo. No. 26, Acoustic Research Lab., Harvard U. (1953).

12. Hsieh, D.Y. and M.S. Plesset. J.Acoust.Soc.Am., 33, 206 (1961).

13. Pode, L. Rept. No. 854, David W. Taylor Model Basin, Washington, D.C., May (1953). 
14. Strasberg, M. J.Acoust.Soc.Am., 33, 359 (1961).

15. Noltingk, B.E. and E.A. Neppiras. Proc.Phys.Soc. (London) B $\underline{63}$, 674 (1950).

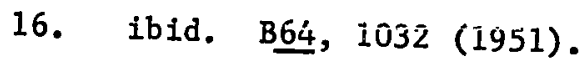

17. Flynn, H.G. "Physics of Acoustic Cavitation in Liquids". Physical Acoustics, Vol. 1B. Academic Press. W. P. Mason,ed. 1964.

18. Connolly, W. and F.E. Fox. J. Acoust.Soc.Am., 26, 843 (1954).

19. Briggs, H.B., J.B. Johnson and W.P. Mason. J.Acoust.Soc.Am., 19 , 664 (1947).

20. Esche, R. Akust.Beihefte 4 , 208 (1952).

21. Heuter, T.F. and R.H. Bolt. "Sonics" John Wiley, New York, p.230 (1955).

22. Plesset, M.S. and A.T. E11is, Trans.Am.Soc.Mech.Engrs. 77, 1055 (1955).

23. Sutton, G.W. J.App1.Mech., 24, 340 (1957).

24. Jones, I.R. and D.H. Edwards. J.Fluid Mech., I, $S 96$ (1960).

25. Kornfeld, M. and L. Suvorov. J.App1.Phys. 15, 495 (1944).

26. Eisenberg, P. Rept. 712, David W. Taylor Model Basin, Washington, D.C. (1950).

27. Naudé, C.F. and A.T. E11is. Trans.Am.Soc.Mech.Engrs. D83, 648 (1961).

28. Bebchuk, A.S. Soviet Phys. - Acoustics, $\underline{3}, 95$ (1957).

29. ibid. 3 , 395 (1957).

30. Devine, R.E. and M.S. Plesset. Rept. No. 85-27. Div.Eng. and App.Sci., California Inst. of Tech., Pasadena, April (1964). 
31. Rosenberg, L.D. and A.S. Bebchuk. Soviet Physics - Acoustics, $\underline{6}$, 496 (1961).

32. Antony, O.A. Ultrasonics, 1, 194 (1963).

33. Bebchuk, A.S., In.Ia. Borisov and L.D. Rosenberg, Soviet Physics Acoustics, 4, 372 (1958)。

34. Crawford, A.E. Ultrasonics, 2, 120 (1964).

35. Eckert, C. Phys.Rev., 7368 (1948).

36. Andrade, E.N. Proc.Roy.Soc. (London) A134, 445 (1931).

37. Schlichting, H. Physik Z., 33, 327 (1932).

38. Holtsmark, J., I. Johnson, T. Sikkeland and S. Skavlem, J.Acoust. Soc.Am., 26, 26 (1954).

39. Raney, W.P., J.C. Corelli, P.J. Westerve1t. J.Acoust.Soc.Am., 26, 1006 (1954).

40. Lemlich, R. Ind.Eng.Chem. 47, 1175 (1955).

41. Kubanskii, P.N. Trans. USSR Academy of Science, 82, 585 (1952).

42. Fand, R.M. and J. Kaye. J.Heat Transfer, Trans. ASME, 83, 133 (1961).

43. Fand, R.M. and J. Kaye. J.Acoust.Soc.Am., 32, 579 (1960).

44. Fand, R.M. and E.M. Peebles. J.Heat Transfer. Trans. ASME, 84 , 268 (1962).

45. Fand, R.M., J. Roos, P. Cheng and J.Kaye. J.Heat Transfer, Trans. ASME, 84, 245 (1962).

46. Holman, J.P. and T.P. Mott-Smith, J.Aero/Space Science, $\underline{26}, 188$ (1959).

47. Fand, $R_{1} M_{\odot}$ and J. Kaye. International Developments in Heat Transfer. Part I. 490-498 (1961). 
48. Anantanaryanan, R. and A. Ramachandran, Trans.ASME, 80, 1426 (1958).

49. Lemlich, R. and Hwu, C.K. Am.I.Ch.E.J. I, 102 (1961).

50. Kubanski1, P.N. J.Tech.Phys. USSR, 22, 593 (1952).

51. Fand, R.M. and P. Cheng. Int.J.Heat Mass Transfer, 6, 571 (1963).

52. Jackson, T.W., W.B. Harrison and W.C. Boteler. J.Heat Transfer, Trans. ASME, $\underline{81}, 68$ (1959).

53. Mathewson, W.F. and J.C. Smith. Chem.Eng.Prog.Sym.Series, 59, No. 41,173 (1963).

54. Martine11i, R.C. and L.M.K. Boelter. Proc.5th Int.Congr. of Applied Mechanics, 578 (1938).

55. West, F. and A. Taylor. Chem. Eng. Progr. 48, 39 (1952).

56. Scalan, J.A. Ind.Eng.Chem., 50, 1565 (1958).

57. Larson, M.B. and A.L. London. ASME. Paper 62-HT-44 (1962).

58. Robinson, G.C., C.M. McClure, and R. Hendricks. Bull.Am. Ceramic Soc., 37, 399 (1958).

59. Deaver, F.K., W.R. Penney and T.B. Jefferson. J.Heat Transfer, Trans, ASME, 84, 251 (1962).

60. Raben, I. Proc.Heat Transfer and Fluid Mech. Institute, Stanford University, p. 90 (196்1).

61. Bergles, A.E. J.Heat Transfer, Trans. ASME, 86, 559 (1964).

62. Isakoff, S.E. Proc.Heat Transfer and Fluid Mech. Institute, Stanford University, p.15 (1956).

63. Ornatski1, A.P. and V.K. Shcherbakov, Teploenergetika, 6, 84 (1959). Translation appears in (65). 
64. Nangia, K. K. and W.Y. Chon. Paper presented at the 15 th Canadian Chemical Engineering Conference, Quebec City, October, 1965.

65. Markels, M., R. L. Durfee and R. Richardson. United States Atomic Energy Commission, NYO 9500, September, 1960.

66. Romie, F.E. and C.A. Aronson. Advanced Technology Laboratories, Report ATL-A-123, July, 1961.

67. Goldman, R. "Ultrasonic Technology", Reinhold, p. 278-280 (1962)

68. Heuter, T.F. and R.H. Bolt. "Sonics". John Wiley, p. 146-152 (1955).

69. Henry, G.E. IRE Trans. PGUE 6,17 (1957).

70. Massa, F. J.Acoust.Soc.Am., 17, 29 (1945).

71. Goldman, R. "Ultrasonic Technology". Reinhold, P. 277-278 (1962).

72. ibid, p. 276-277 (1962).

73. Fox, F.E. and V. Griffing, J.Acoust.Soc.Am., 20, 352 (1948).

74. Westerve1t, P.J. J.Acoust.Soc.Am., 32, 337 (1960).

75. Larson, M. B. Tech.Rept. No. 48, Dept. of Mechanical Engineering, Stanford University, California, September 30, 1960. 
PRESENT INVESTIGATION 


\section{INTRODUCTION}

This investigation was concerned with the effects of ultrasonic vibrations on heat transfer to distilled water and methanol by natural convection and by surface bolling, specifically, a study on the important variables and the possible mechanisms of these processes. In addition, a technique to measure a high intensity sound field in a cavitating liquid was to be developed.

In Part I of this study, a method using cavitation damage to measure the cavitation activity of a liquid under strong ultrasonic vibrations was developed.

In Part II, the natural convective heat transfer and surface boiling heat transfer rates from a platinum wire to distilled water and methanol at three different acoustic intensity levels were measured. Other variables including the degree of subcooling and frequency were also studied. High speed photography was used to study the mechanisms of these processes.

In Part III, the effects of ultrasonic vibrations on burnout heat flux and critical temperature difference were studied. 


\section{PART I}

MEASUREMENT OF SOUND FIELD IN LIQUIDS

\section{INTRODUCTION}

The method used to measure a liquid sound fleld depends on the type of data required. In general, the experimental quantities that are of interest are sound pressure, sound intensity, and the rate at which acoustic energy is delivered from the ultrasonic transducer to the liquid load. These quantities are inter-related where there is a free sound field. However, the usual laboratory set-up is one in which a great deal of interference exists, giving rise to various irregular standing wave patterns. At sound pressures above the cavitation threshold, the presence of cavitation bubbles further complicates the picture as they scatter and dissipate a part of the acoustic energy. Consequently, most investigators reported the acoustic power output from the transducer. In studying the effects of ultrasonic vibrations on processes such as heat transfer, it is expected that the boundary layer flow pattern around the heated surface would be changed. The resulting data could then be correlated with local acoustic variables on the heated surface. Such information is not available from a knowledge of the acoustic power output of the transducer.

The difficulty in obtaining local acoustic varlables in a high intensity liquid sound field is primarlly due to the erosive nature of the cavitation phenomena which tends to damage the probes normally used in non-cavitating liquids. It becomes more practical to 
attempt to measure the cavitation activity in the liquid since direct measurement of acoustic variables, such as sound pressure and sound intensity, becomes rather difficult.

Acoustic cavitation bubble fields may be characterized either by the motions of the cavitation bubbles or by the physical effects that such motions bring about. Cavitation damage is one of the phenomena resulting from these effects. It has been mentioned in the Literature Review section of this thesis that the damage on metal surfaces in a cavitating Iiquid increased as the square of the sound pressure $^{(1)}$. Further studies by Bebchuk ${ }^{(2)}$ and other investigators $(3,4)$ have shown that the weight loss, or cavitation damage, is a linear function of the time of exposure in a cavitation bubble field. Since cavitation damage has been interpreted as a mechanical process, it seems logical to use the rate of cavitation damage for measuring the cavitation activity of a liquid under strong ultrasonic vibrations.

The objective of the present study was to provide information on the sound field in which heat was being transferred. Measurement of the cavitation activity was directed toward the liquid around the heated surface which was a platinum wire about 1 in. long with diameter of 0.007 and 0.010 in. When the applied acoustic energy was below the cavitation threshold level, the sound pressure on the platinum wire was measured by a probe microphone. 
EXPERIMENTAL

\section{Equipment}

An overall schematic diagram of the equipment including that for studying heat transfer rates in a sound field is shown in Figure 1. Figure 2 is a photograph of the apparatus. Two ferrite transducers with a resonant frequency of about $20 \mathrm{kcps}$ were cemented directly onto the bottom of an open stainless steel tank ( $7 \frac{1}{2}$ in, $\times 4 \frac{1}{2}$ in. $\times 6$ in.deep). A glass window was installed on the front of the tank and there was a jacket surrounding the remaining three sides. Three 250-watt strip heaters were placed in the jacket, one in each side, to control the temperature of the liquid in the tank through a powerstat. The remaining space of the jacket was filled with an asbestos slab.

The transducers were driven by a sine-wave form signal generator, whose output was amplified by a custom-built power amplifier. The amplifier had a frequency range of 15 to $500 \mathrm{kcps}$ with a power output rating of 200 watts.

Two types of transducer were used in this study. For the low frequency work, namely for $20 \mathrm{kcps}$ and $44 \mathrm{kcps}$, magnetostrictive transducers made of ferroxcube 7A2 manufactured by Philips were used. For the higher frequencies, $108 \mathrm{kcps}$ and $306 \mathrm{kcps}$, ceramic transducers made of lead zirconate and manufactured by Gulton Industries were used. Other information concerning transducers such as the number of transducer used, the cementing procedures, the impedance matching, etc. is given in Appendix A. 
FIGURE 1

SCHEMATIC DIAGRAM OF APPARATUS 


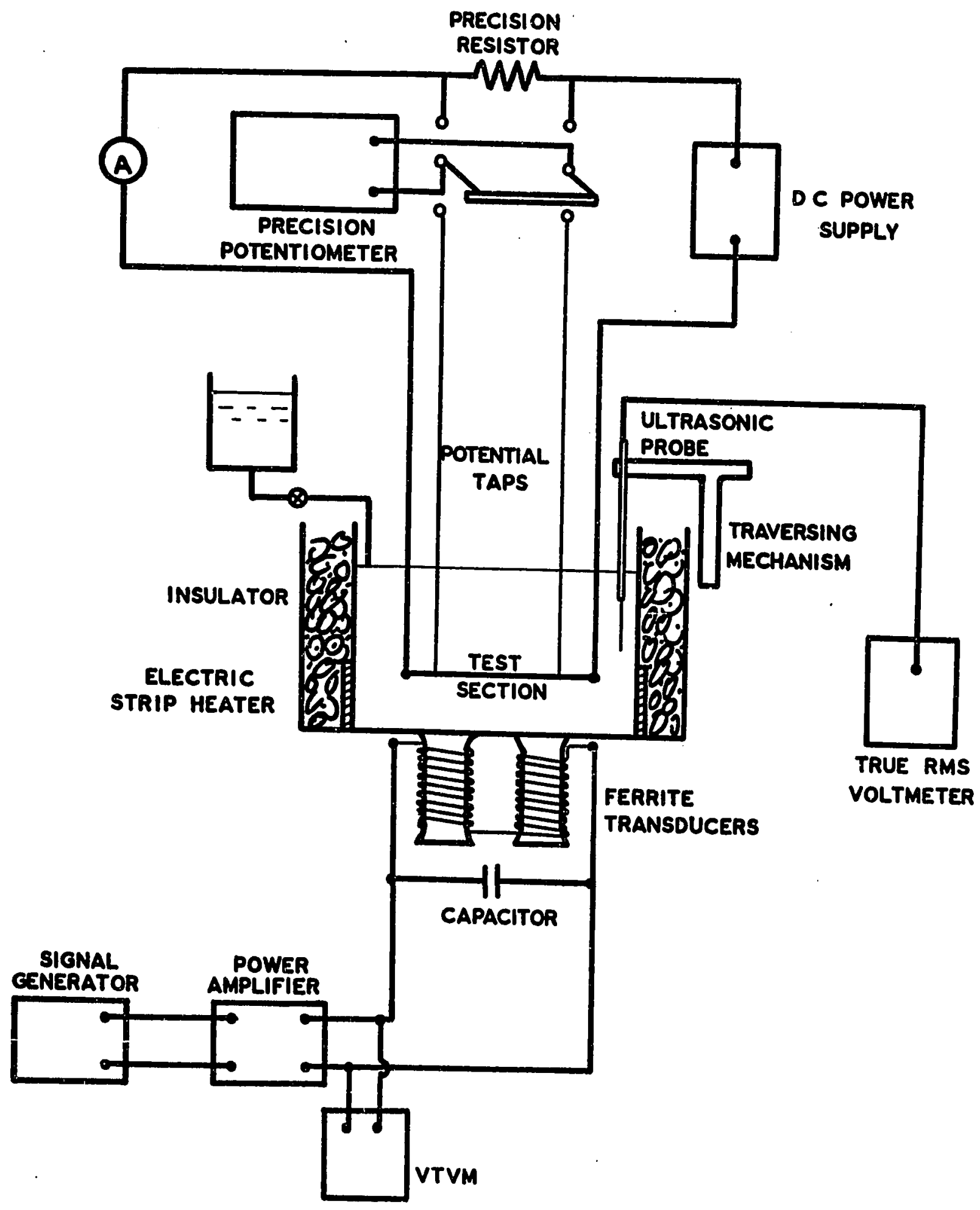


FIGURE 2

PHOTOGRAPH OF THE EXPERIMENTAL APPARATUS 


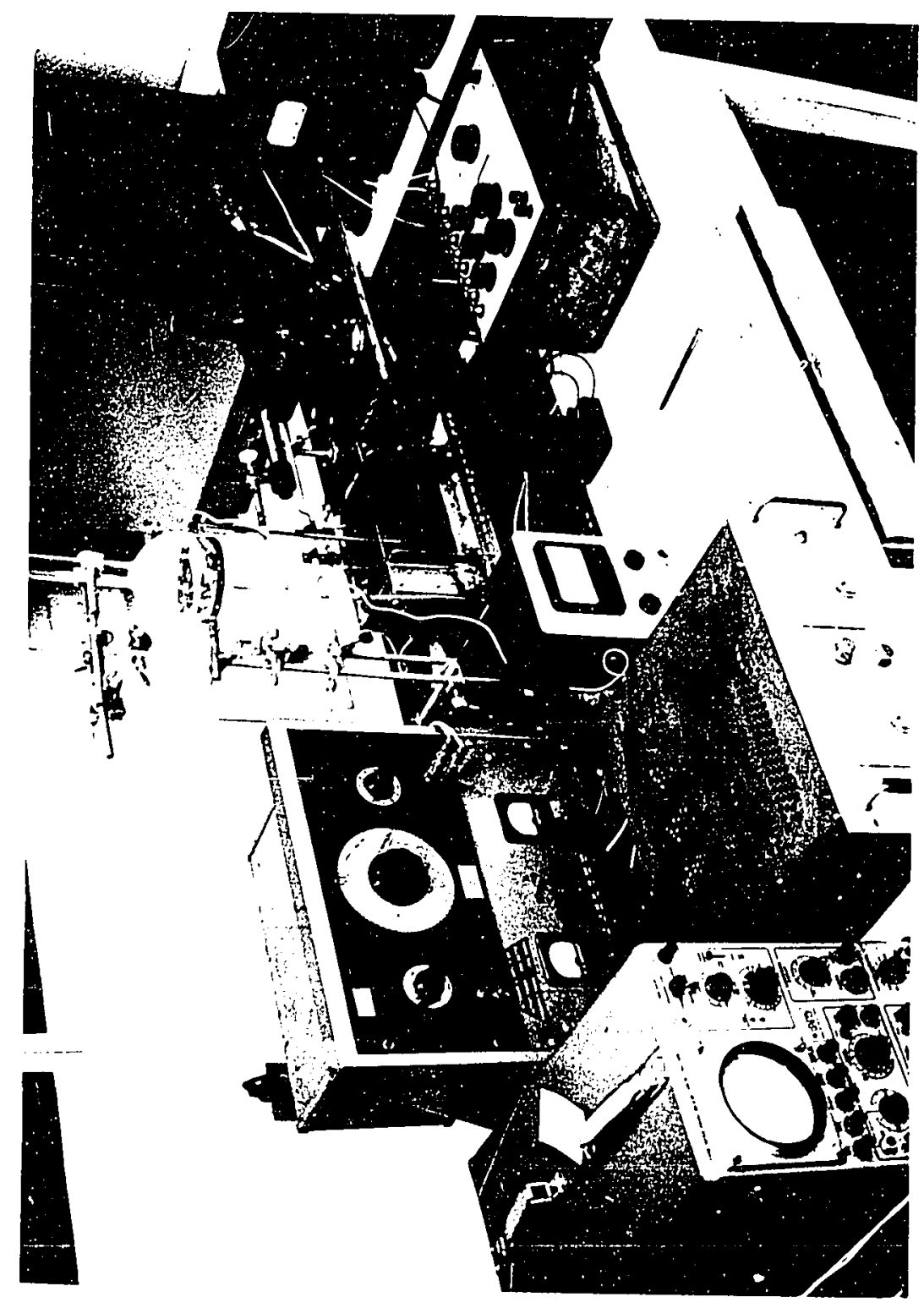


The voltage drop across the transducerswas measured by a Hewlett-Packard vacuum-tube voltmeter model 400D, A standard resistor (Type 1682), having a resistance of 0.02 ohm and manufactured by Guildline Instruments Ltd., was connected in series with the transducers to measure the current. The purpose was to obtain the apparent power $\left(W_{A}\right)$, which is the product of the effective values of voltage and current ${ }^{(5)}$. No attempt was made to determine the power factor of the circuit.

The cavitation damage specimen was an 18 gauge $(D=0.0403$ In.) copper wire, $1 \frac{1}{2}$ in.long, and coated with a radioactive soil. It was clamped at each end in a groove between brass blocks, as shown in Figure 3 (the two small brass blocks and the electrical wires in the background of the photograph were for heat transfer experiments). The frame was fastened to a support so that the specimen was $1 \frac{1}{2}$ In. from the bottom and midway from the sides of the tank.

The radioactivity of the specimen was measured by a we11type gamma ray scintillation detector (model 810B) manufactured by Baird Atomic Company. A scalar-timer (model 135) manufactured by the same company was used to register the measurement from the scintillation detector. Since the well of the detector is $1 \frac{35}{64}$ in. deep and the length of the specimen is $1 \frac{1}{2}$ in., the entire specimen could be introduced into the well.

When the applied acoustic energy was below the cavitation threshold level, the sound pressure along the specimen was measured by a Glennite ultrasonic probe (model UP-800C), manufactured by Gulton Industried Ltd. The sensitive element of the probe is a barium titanate 
FIGURE 3

SUPPORTING FRAME FOR CAVITATION DAMAGE

SPECIMEN AND PLATINUM WIRE 
O

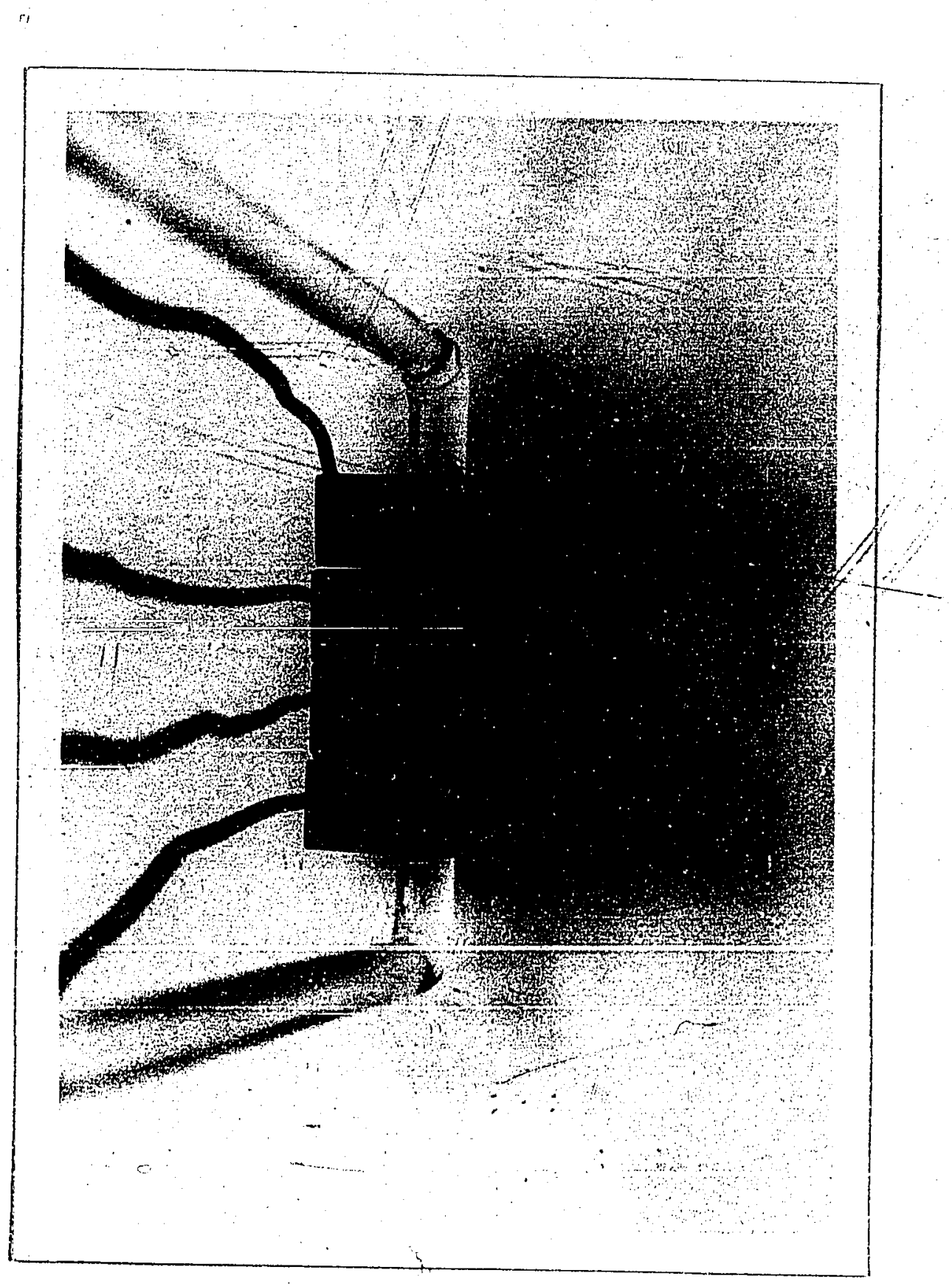




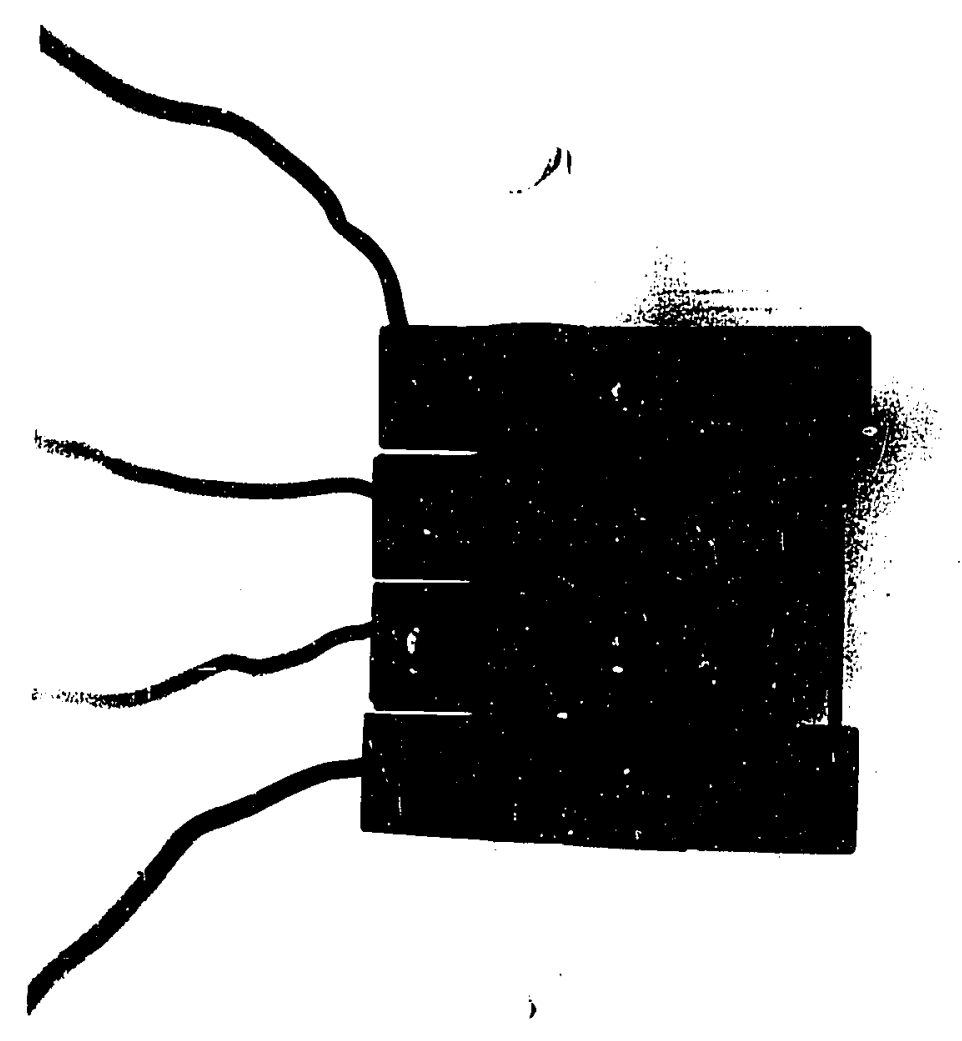


ceramic cylinder $1 / 16$ in. In diameter by $1 / 16$ in, long. The calibration, made at five points between $100 \mathrm{kcps}$ and $1000 \mathrm{kcps}$, was supplied by the manufacturer. Below $100 \mathrm{kcps}$, the frequency response curve was assumed to be flat. The probe which was connected to a Brülel and Kjaer vacuum tube voltmeter (type 2409) was mounted in a traversing device capable of giving an accuracy of $1 / 1000$ in. When the frequency of the system was $306 \mathrm{kcps}$, the Hewlett-Packard voltmeter described earlier was used.

\section{Materials}

Cobalt-60 was the tracer materlal and approximately $10 \mathrm{~g}$. of cobalt oxide was shipped to the Atomic Energy of Canada Ltd. for irradiation. The total activity after irradiation was given as approximately 100 microcurie.

The binder materials for the soll were Esso MP grease $H$ and carbon black.

Distilled water and methanol were used in this study. The absolute methanol was supplied by Anachemia Chemical Ltd.

\section{Preparation of Specimen}

After a number of trials, the following procedures were established.

1. Into a Kimax test tube with plastic cap (length $\times 0 . D_{0}=125 \times 16 \mathrm{~mm}$ ), 0.45 g. of carbon black, 4 g. of radioactive cobalt oxide and 2 g. of Esso MP grease H were introduced. Ten m1. of benzene was then added into the test tube. 
2. The test tube was capped and placed into a 1 in. pipe jacket, whose purpose was to protect the test tube from breaking and act as $z$ radiation shield. The jacket was picked up by a clamp and it was then shaken vigorously until a smooth mixture was obtained. It was found that a more homogeneous mixture could be obtained if the test tube was exposed to a cavitating liquid for a few minutes to disperse the carbon black.

3. Tinned copper wire, gauge 18, from Birnback Radio Co. was cut into lengths of approximately $6 \frac{1}{2} \mathrm{in.}$ They were thoroughly cleaned by successively dipping them into test tubes containing dilute HCl, distilled water, acetone and benzene.

4. The clean wire was dipped into the test tube containing the mixture three times. The second and third dippings were made only after fanning the wire in the air for approximately 30 seconds after each dipping so that the benzene would be evaporated. For all dippings, care was taken not to have the wire touch any part of the test tube when it was introduced into the test tube or taken out from it. The mixture was shaken again to ensure its homogeneity after 4 to 6 lengths of wire were prepared.

5. The wire was then clamped horizontally from the portion of the wire that was bare in an oven of $120^{\circ} \mathrm{F}$ for $20 \mathrm{hr}$. The length of wire covered with soil was about 4 in,, out of which $1 \frac{1}{2}$ in.was cut out to make a specimen. Since the specimen would be subsequently clamped at each end in a groove between the two blocks, a protective coating of $1 / 4 \mathrm{in.}$ in length was put on both ends of the spectmen. This procedure is described in 6 ). 
6. Specimens to be used in distilled water were dipped 3 times into a mixture consisting of 3 parts by volume of Ambroid liquid cement to 2 parts of acetone. For specimens to be used in methanol, Armstrong epoxy A12T was used directly. These coatings were found to be sufficiently strong to resist the stresses due to the brass blocks as well as the damaging action of a cavitating liquid for a short period of time. It was found that the counting rate of a completely damaged specimen, that is, a specimen on which the unprotected portion of the soil was completely eroded away by the cavitation action, was, within experimental error, one third of the original counting rate. The active length of each specimen was then 1 in.

7. The specimen stored in a small polyethylene bag was placed in the well of the scintillation detector to measure its radioactivity. All specimens whose radioactivity did not fall in the range of 35,000 - 50,000 counts per minute were rejected as it was found in preliminary studies that the sensitivity of the test depended very much on the soil thickness.

8. It was found that the results were morereproducible if new specimens were prepared fresh for each test sequence. During the course of the experiment which lasted for 3 months, two batches of soil were made. The soll did not appear to become aged. Al1 specimen preparation work was done in a Fisher isolator. The specimen was handled only with tweezers after it was cut to the length of $1 \frac{1}{2} \mathrm{in}$. Figure 4 shows a specimen with the polyethylene bag used to store it. 
FIGURE 4

CAVITATION DAMAGE SPECIMEN WITH POLYETHYLENE BAG 


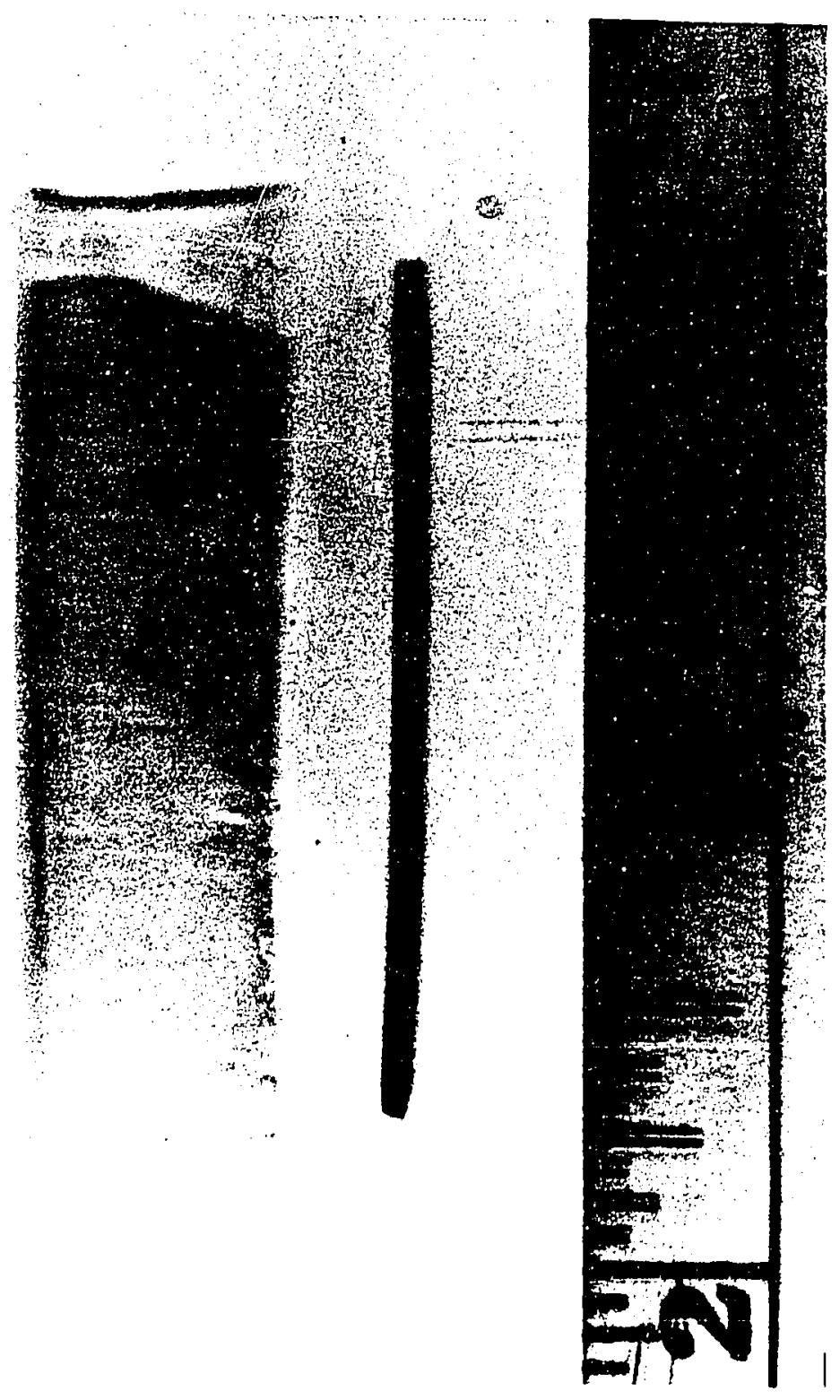


$\underline{\text { Procedure }}$

In all experiments, the tank was filled with distilled water or methanol to a depth of $4 \frac{3}{4}$ in. and maintained at this level. The temperature of the liquid was controlled by the powerstat and the three strip heaters. The liquid temperature was always brought up slowly so that the dissolved air content in the test liquid would be at its equilibrium value. The cavitation damage determination was started $1 \mathrm{hr}$ after the 1 iquid attained the desired temperature. No measurements were made of the air content of the liquid at the various. test temperatures.

The specimen was clamped in place in the brass block with Its active portion properly exposed. The specimen assembly was installed into its place. The ultrasonic probe mounted on the traversing mechanism was used to measure the sound pressure along the specimen at intervals of 0.20 in,at different apparent electrical power input levels until cavitation was observed to be occurring near the probe. The probe was then withdrawn, and the cavitation damage for a finite time interval was measured after the specimen was replaced by a new one.

The time for which a specimen was exposed to the cavitating liquid depended on the electrical power input. The possible error of the final result, that is, the percentage of soil removed, would be very much reduced if the exposed time was selected to give a value of soil removed of 20 to $30 \%$ for a specific electrical power input. For ressons which will become obvious later, the exposure time should be kept below a value which would yield a soil removal value of more than $35 \%$. 
Before using the scintillation detector for radioactivity measurements, the scintillation plateau region of the detector was first determined using a standard source of cobalt-60 supplied by Baird Atomic Company. The plateau curve is shown in Appendix C. The voltage of the scaler-timer was then set at the voltage corresponding to the plateau region which was 1,400 volts and the background was measured before and after each test. The counting time for all specimens as well as the background was 6 minutes.

The test 1iquids were distilled water and methanol. When the frequency was $20.6 \mathrm{kcps}$, the temperatures of distilled water at which measurements were made were $113^{\circ} \mathrm{F}, 149^{\circ} \mathrm{F}$, and $180^{\circ} \mathrm{F}$. For methanol, they were $95^{\circ} \mathrm{F}$ and $113^{\circ} \mathrm{F}$. Other frequencles at which measurements were made were $44.1,108$, and $306 \mathrm{kcps}$. The temperature of distilled water was $149^{\circ} \mathrm{F}$ and that of methanol was $113^{\circ} \mathrm{F}$ for these frequencles. Little difficulty was encountered in maintaining the temperature at the desired level to within $\pm 1^{\circ} \mathrm{F}$.

RESILTS

When the applied acoustic energy levels are below the cavitation leve1, the root-mean-square values of sound pressure along the specimen were measured by the ultrasonic probe. Figure 5 shows some typical sound pressure profiles. The distance between two sound pressure readings was chosen to be 0.02 in. A smaller interval was not used because subsequent heat transfer experiments showed that the motion of the cavitation bubbles on the platinum wire did not appear to be 
C

FIGURE 5

SOAE TYPICAL SOUND PRESSURE PROFILES ON THE CAVITATION DAMAGE SPECIMEN 


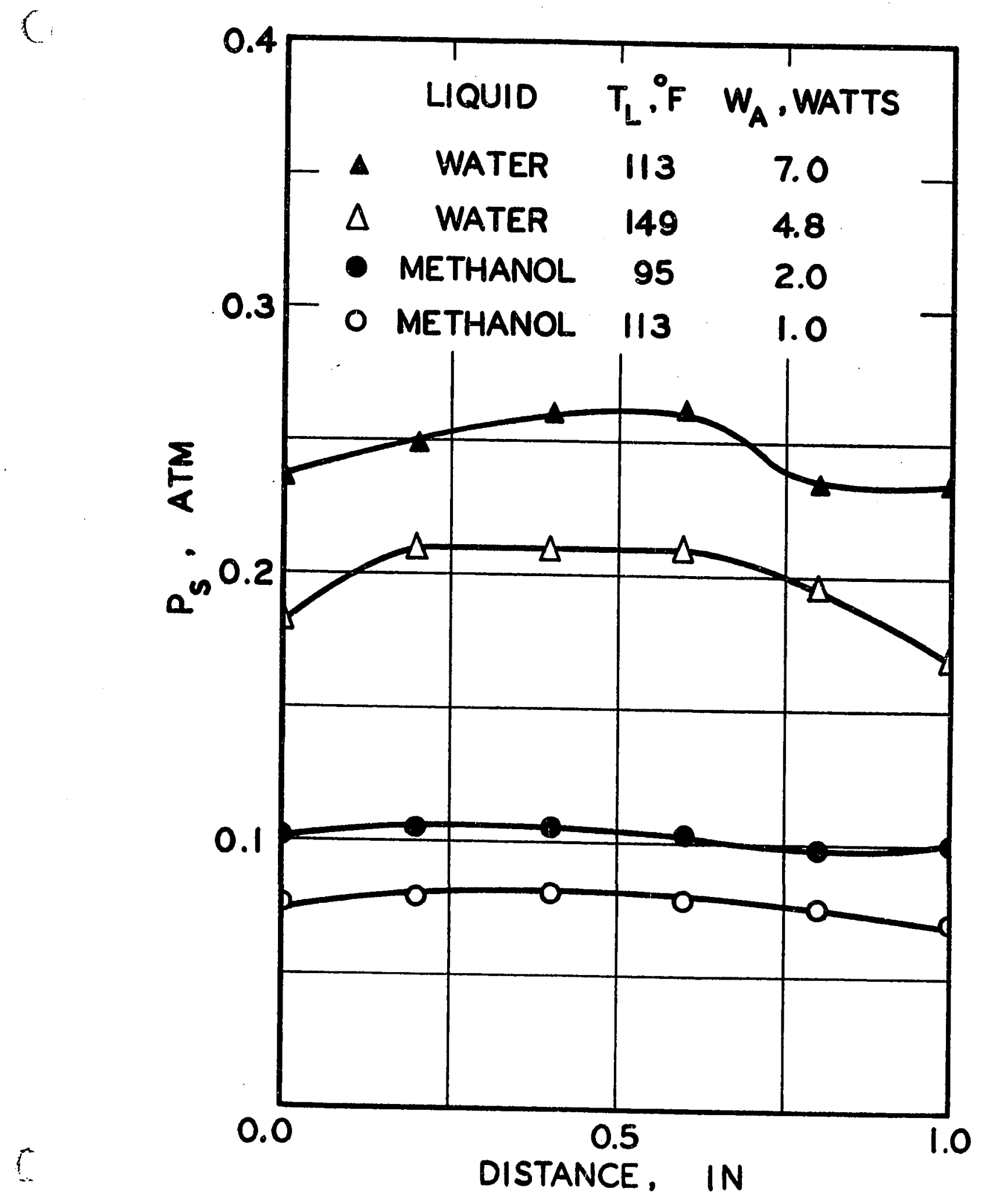


dependent on the sound pressure profile.

The effective value of sound pressure for the active portion of the specimen was calculated by taking the square root of the average of the squares of the individual sound pressure values along the specimen. The calculated results of sound pressure values for experiments at different frequencies are shown in Tables 1, 2, 3 and 4. The value of $P_{8}$ which is underlined indicates the sound pressure at which cavitation began to occur in the test liquid, Where there are two values underlined,cavitation occurred somewhere between the two values. The criterion used to determine this value was that when the first cavitation bubble was observed to appear anywhere in the test 1iquid. In Tables B-1 to B-10 in Appendix B where experimental data on sound pressure are shown, the corresponding peak sound pressures are also included. The peak values were measured directly by the Brüel and Kjaer voltmeter and each value represents the maximum peak sound pressure that was recorded on the active portion of the specimen. They should not be taken as the cavitation threshold of the test 1iquid, as the occurrence of the first cavitation bubble was usually not on or near the specimen surface. In these tables, each value of the voltage signal $\left(E_{s}\right)$ picked up by the ultrasonic probe was the average of three or four readings. The reproducibility was always within $15 \%$.

In measuring the sound pressure, it was assumed that the variation in the radial direction of the specimen was small. The assumption was justified since the sensitive element of the probe was a $1 / 16$ in. by $1 / 16$ in. cylinder, while the diameter of the specimen was approximately 
TABLE 1

Effective Value of Sound Pressure on the Specimen

$\mathrm{W}_{\mathrm{A}}$

watts

1.0

2.0

4.8

7.0

15.6 $\underline{f=20.6 \mathrm{kcps}}$

$P_{s}(\mathrm{~atm})$

$\frac{\mathrm{P}_{S}(\mathrm{~atm})}{\frac{\text { Water }}{\mathrm{T}_{\mathrm{L}}=149^{\circ} \mathrm{F} \quad \mathrm{T}_{\mathrm{L}}=113^{\circ} \mathrm{F}} \quad \frac{\text { Methano1 }}{\mathrm{T}_{\mathrm{L}}=113^{\circ} \mathrm{F} \quad \mathrm{T}_{\mathrm{L}}=95^{\circ} \mathrm{F}}}$

.092

.085

.076

.072

.16

.14

.20

.18

.11

.10

.14

.12

.27

.25

.16

.14

12

\section{TABLE 2}

$\underline{f}=44.1 \mathrm{kcps}$

$\underset{A}{\mathrm{w}_{\mathrm{A}}}$

0.5

1.3

3.2

4.6

9.5

23.2

.34

.34

$-$ 
(.)

TABLE 3

$\underline{f}=108 \mathrm{kcps}$

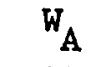

watts

16.0

24.0

34.2

47.0

10.0

$\frac{\mathrm{P}_{8}(\mathrm{~atm})}{\frac{\text { Water }}{\mathrm{T}_{\mathrm{L}}=149^{\circ} \mathrm{F}}} \frac{\text { Methano1 }}{\mathrm{T}_{\mathrm{L}}=113^{\circ} \mathrm{F}}$

.35 .$\underline{.34}$

.45

.$\underline{.53}$

.63

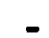

TABLE 4

$\underline{f}=306 \mathrm{kcps}$

$\begin{array}{cc}\mathrm{W}_{\mathrm{A}} & \frac{\mathrm{P}_{8} \text { (atm) }}{\text { Methanol }} \\ \text { watts } & \frac{\mathrm{T}_{L}=113^{\circ} \mathrm{F}}{22} \\ 54 & - \\ 74 & .57 \\ 92 & .71 \\ 125 & .83 \\ 165 & .92 \\ \end{array}$


$0.04 \mathrm{in}$. In fact, most of the sound pressure measurements were made along the platinum wire whose diameter was even smaller.

The results of experiments on cavitation damage are shown in Figures 6 to 11. The percentage of soil removed $\left(S_{R}\right)$ was based on the amount of soll on the active portion of the specimen before it was exposed to a cavitating 1iquid. Consequently, the percentage of soil removed was calculated by the following expression:

$$
S_{R}=\frac{\mathrm{CPM}_{1}-\mathrm{CPM}_{f}}{\frac{2}{3}\left(\mathrm{CPM}_{1}\right)} \times 100 \%
$$

where $\mathrm{CPM}_{i}$ - counting rate of the specimen per minute before cavitation damage

$\mathrm{CPM}_{f}$ - counting rate of the specimen per minute after cavitation damage.

It is to be noted that the active portion of the specimen was equal to two-thirds of the total length.

Figure 6 shows the percentage of soll removed for distilled water at $149^{\circ} \mathrm{F}$ and at various exposure times with apparent electrical power input to the transducers as parameter. Bebchuk ${ }^{(2)}$ and other investigators $(3,4)$ who studied cavitation damage on metal surfaces have shown that the cavitation damage is a linear function of time. The non-linearity of the results of present work was due to the finite thickness of the soil on the tinned copper wire. It was observed that when the percentage of soil removed was about 40 , the specimen became partially bare so that one could actually see the tinned copper wire surface. 
F IGURE 6

DETERMINATION OF THE TIME OF EXPOSURE OF A SPECIMEN

IN A CAVITATING LIQUID 
1

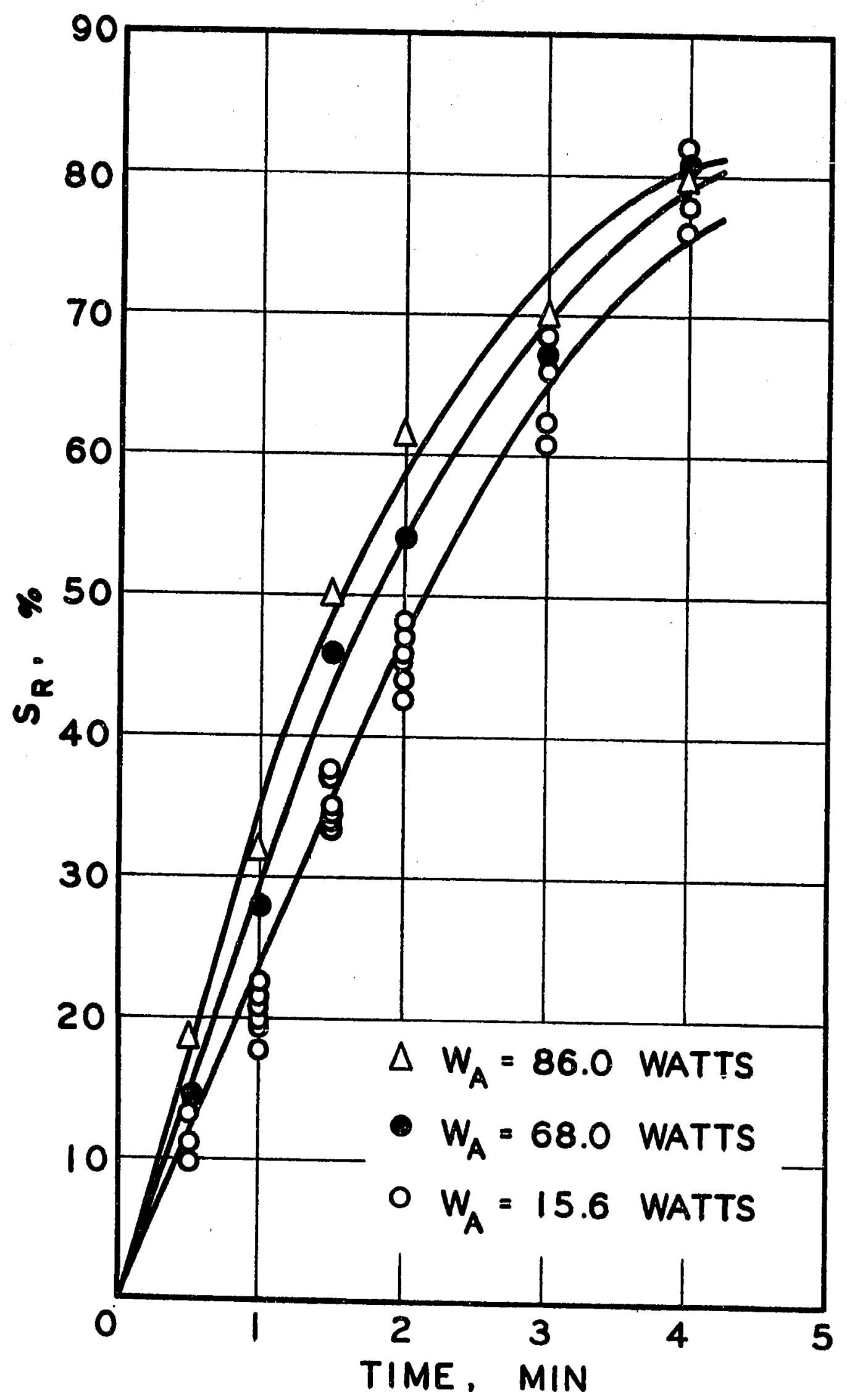


PERCENT SOIL REMOVAL AS A FUNCTION OF APPARENT ELECTRICAL POWER INPUT TO TRANSDUCERS AT 20.6 kcPs WITH AN EXPOSURE TME OF I MINUTE

FIGURE 7 Dist11led Water at $113^{\circ} \mathrm{F}, 149^{\circ} \mathrm{F}$ and $180^{\circ} \mathrm{F}$ FIGURE 8 Methanol at $95^{\circ} \mathrm{F}$ and $113^{\circ} \mathrm{F}$ 
1

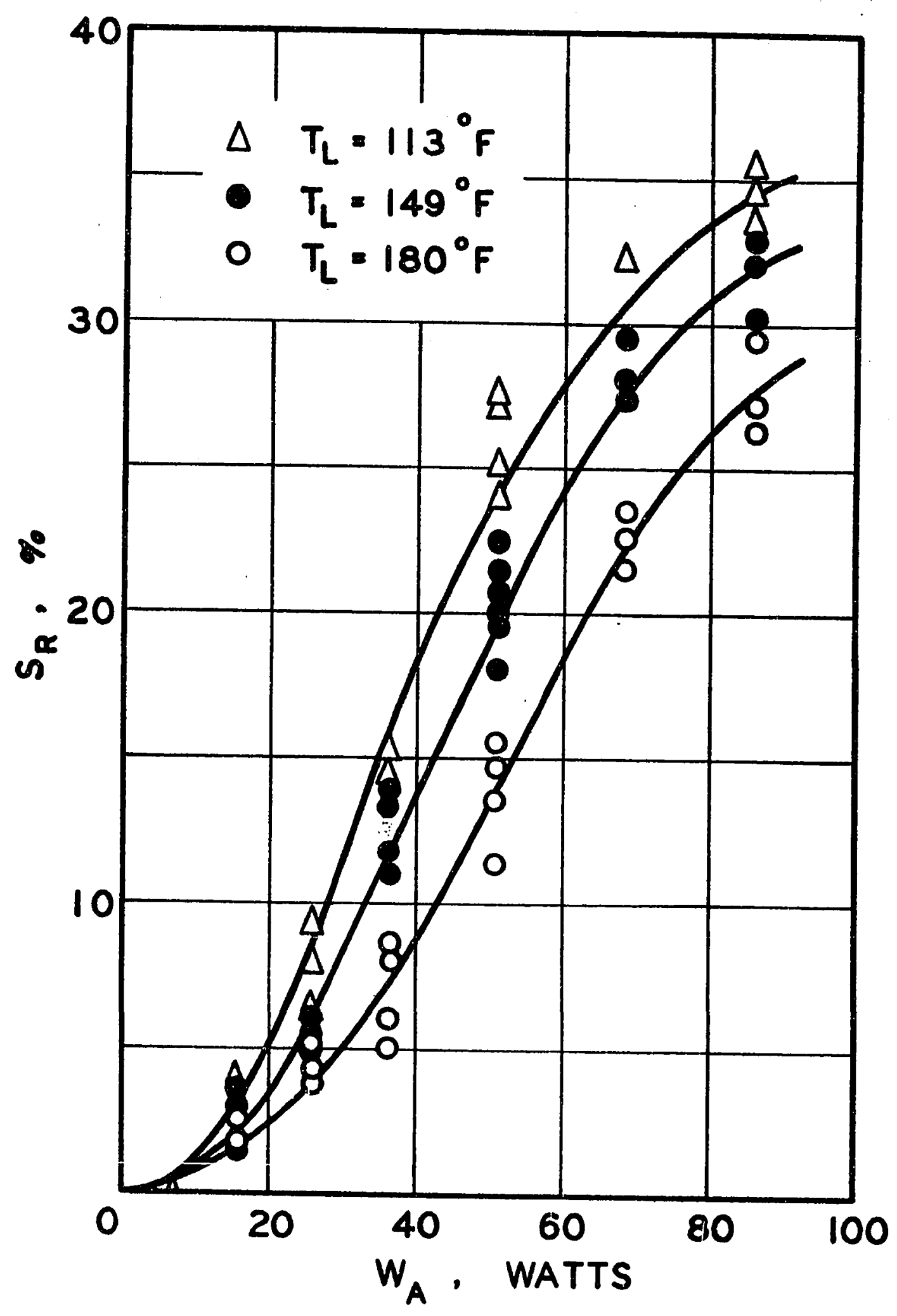


?

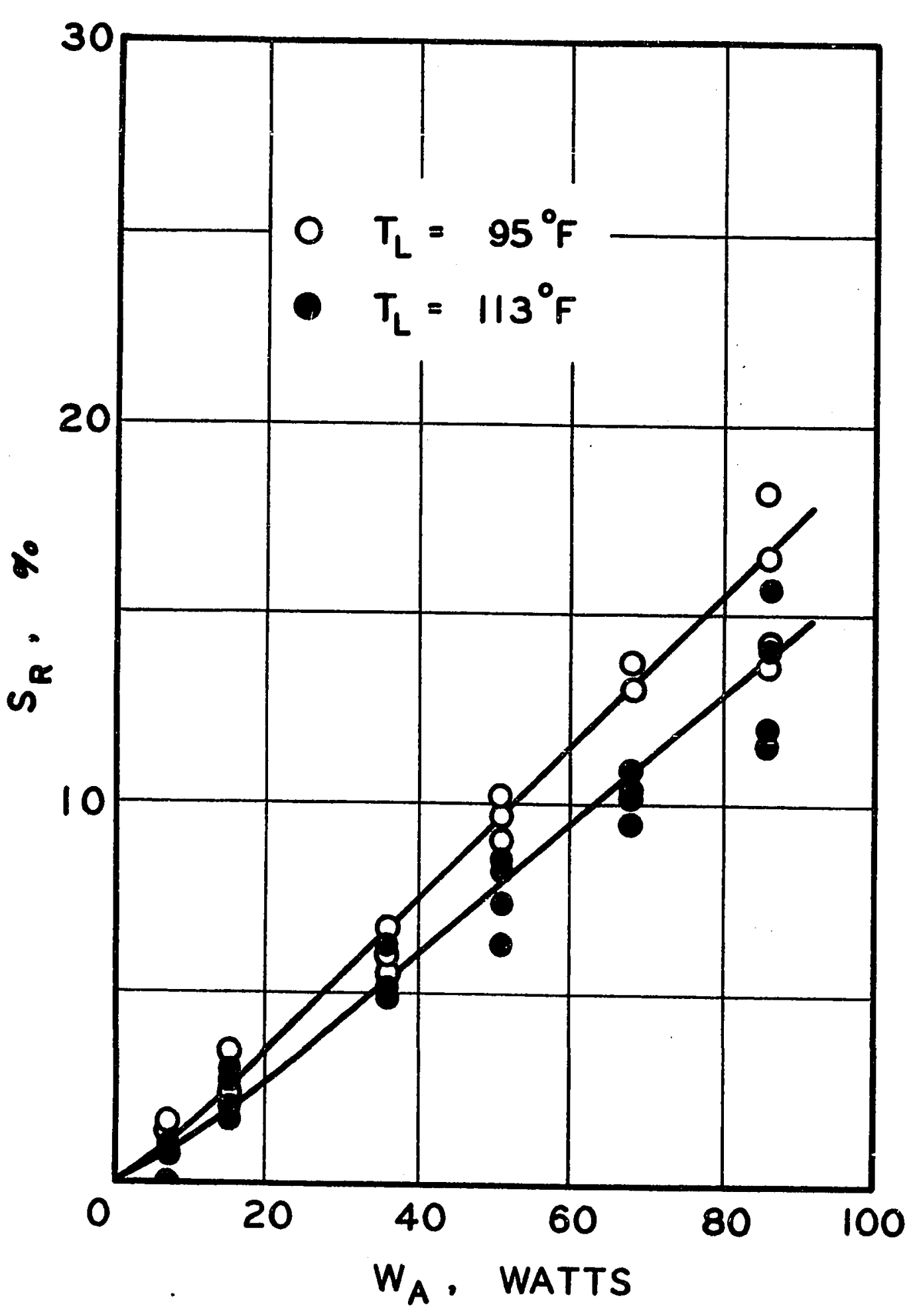


PERCENT SOIL REMOVAL AS A FUNCTION OF APPARENT ELECTRICAL POWER INPUT TO THE TRANSDUCERS FOR DISTILLED WATER AT $149^{\circ} \mathrm{F}$ AND METHANOL AT $113^{\circ} \mathrm{F}$

$\begin{array}{llcl}\text { FIGURE } 9 & f=44.1 \mathrm{kcps} & \text { Exposure time }=1 \mathrm{~min} \\ \text { FIGURE } 10 & f=108 \mathrm{kcps} & " & " 1 " \\ \text { FIGURE } 11 & f=306 \mathrm{kcps} & " & " 1 "\end{array}$


$\tau$

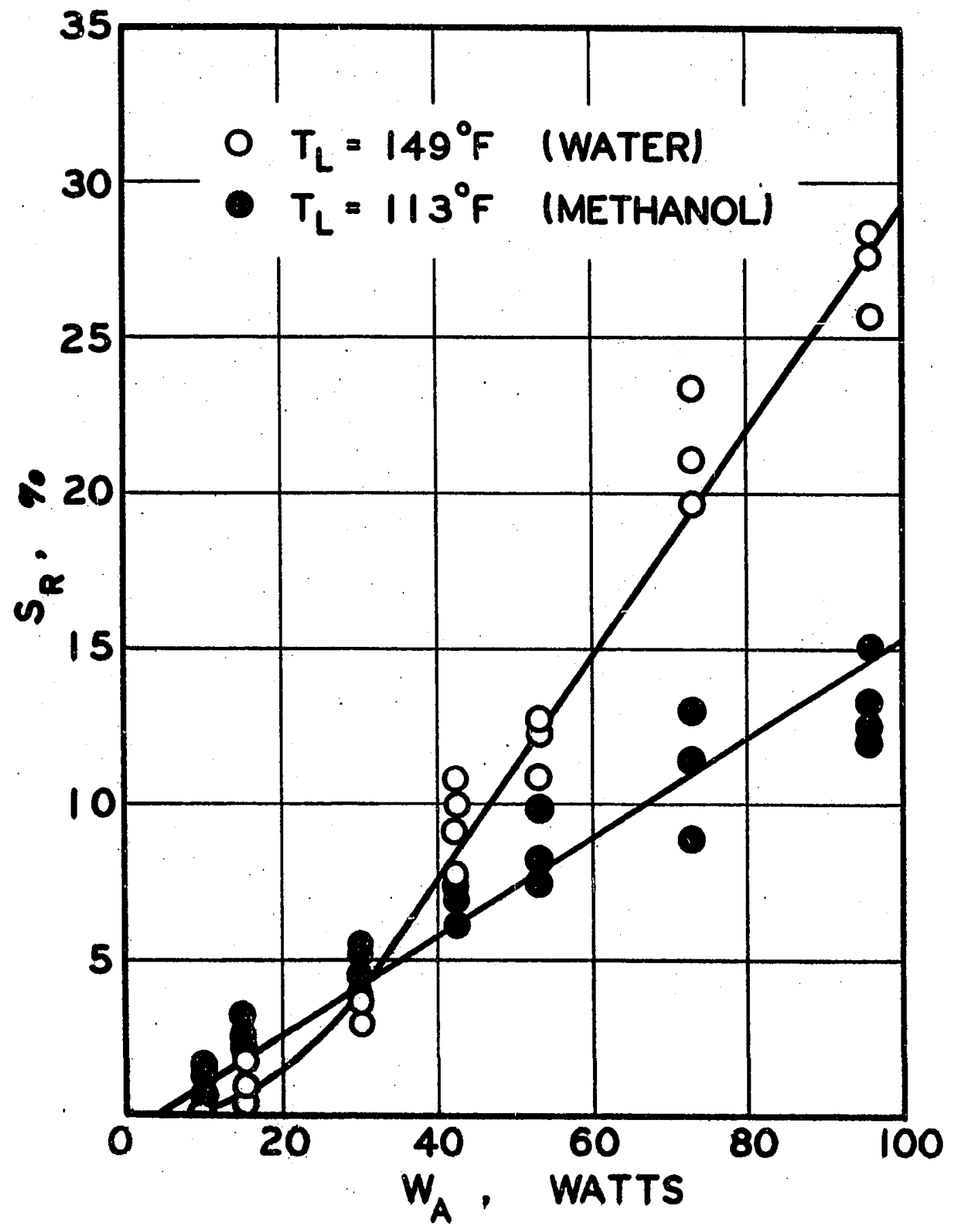


c

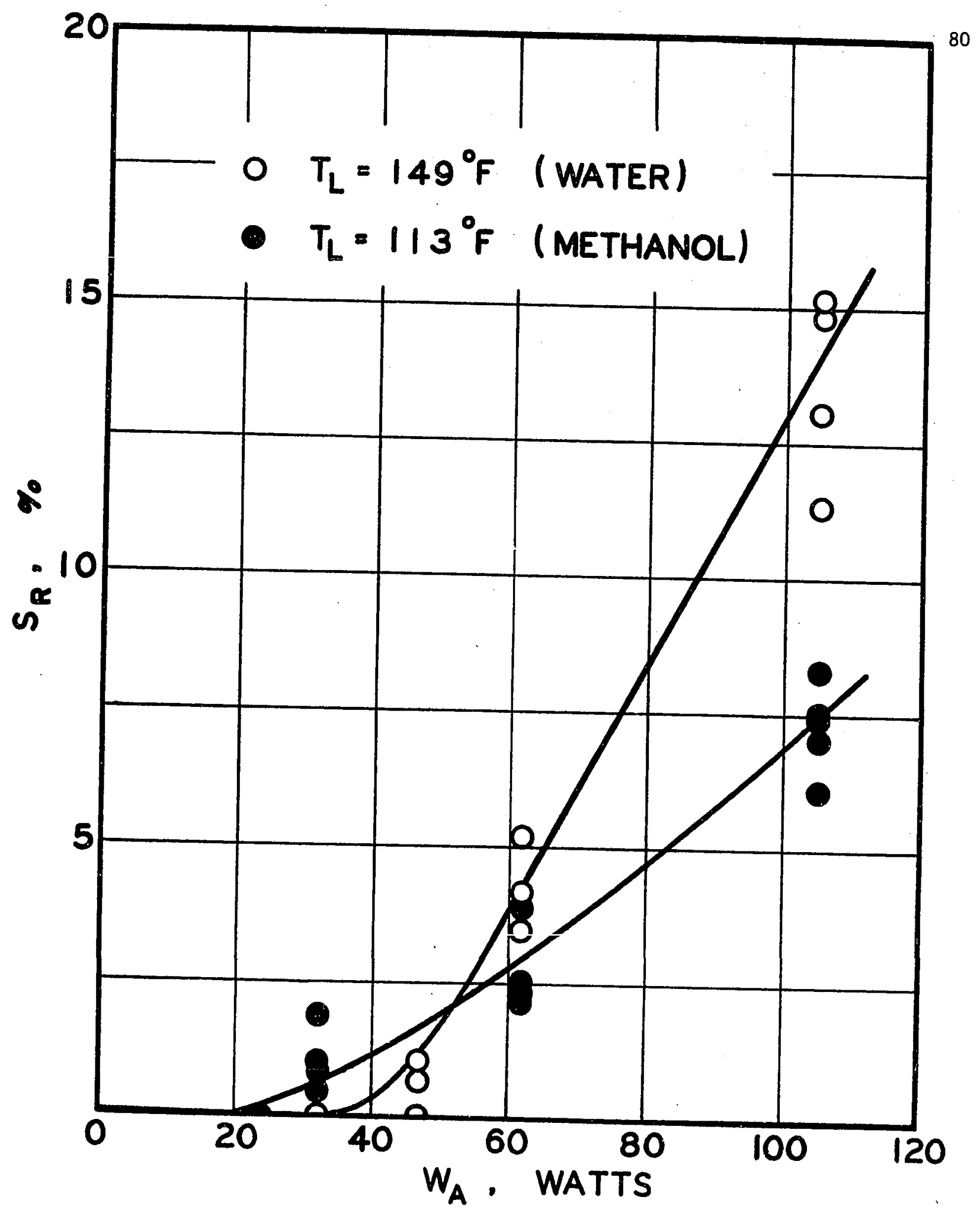




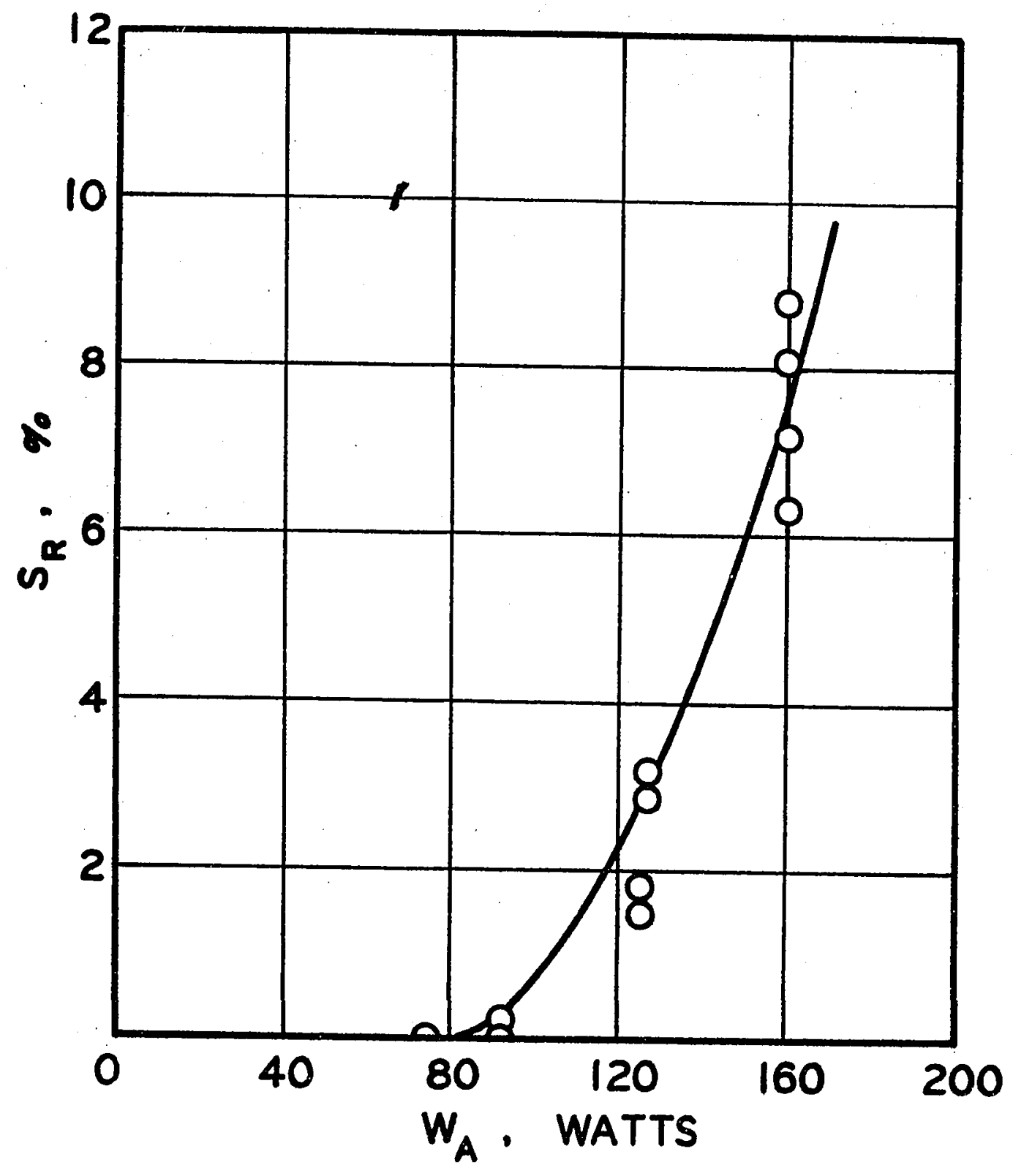


However, when the percentage of soil removed was below 35 , a linear relationship was indeed obtained. In order that the results of a cavitation damage experiment should reflect the cavitation activity of the liquid near the specimen, the time of exposure of a specimen in a cavitating liquid should be chosen so that at the maximum value of apparent electrical power input, it would lie within the linear portion of the curve. The exposure time basis of one minute that was used in preparing Figures 7 to 11 was chosen under these considerations. In actual experiments, the exposure time was dependent on the electrical power input to the transducers. A longer exposure time was used for small electrical power Inputs as this would decrease the possible error of the final result, provided the value of the percentage of soll removed did not exceed 35 . An independent study on exposure time for methanol was not necessary because the cavitation damage was observed to be always lower than that of distilled water.

Figures 7 and 8 summarlze the percentage of soll removed at the frequencies of $20.6 \mathrm{kcps}$ for distilled water and methanol respectively at different apparent electrical power inputs with the temperature of the test 1 iquid as parameter. The percentage of soil removed for frequencles of $44.1 \mathrm{kcps}, 108 \mathrm{kcps}$, and $306 \mathrm{kcps}$ are shown in Figures 9, 10 and 11 respectively. In all the figures, each point represents an experimental data point, except in Figure 6 where the average values were plotted when the apparent electrical power inputs were 86 watts and 68 watts. For any run with eight to twelve measurements, the mean deviation of each measurement from its average for the entire run is in the 
range \pm 10 to $15 \%$. Individual deviation of more than $30 \%$ occurred about once in perhaps twelve measurements.

In Figures 9 and 10 where the cavitation damage for the two test liquids are superimposed on one another, the percentage of soil removed for methanol at $113^{\circ}$ was higher than that for distilled water at $149^{\circ} \mathrm{F}$ at low apparent electrical power input. This is because the cavitation threshold for methanol at $113^{\circ} \mathrm{F}$ is much lower than the cavitation threshold for distilled water at $149^{\circ} \mathrm{F}$. For example, as shown in Figure 9, cavitation took place in methanol and the value of percentage of soil removed was about $1.5 \%$ when the apparent electrical power input was 9.6 watts. For the same electrical power input, there was no cavitation in distilled water.

\section{DISCUSSION OF RESULTS}

It has been established that the cause of cavitation damage is the mechanical stress arising from the motion of cavitation bubbles ${ }^{(6)}$. Both the pulsating stable gaseous cavitation bubbles and the collapsing vaporous cavitation bubbles are capable of generating high mechanical stresses. The extent of cavitation damage would then give a measure of the cavitation activity of the cavitating liquid. Attempts have been made in industry to assess the activity of ultrasonic cleaning tanks by using strips of lead or aluminum foil and measuring the weight loss due to erosion. Due to the relatively low rate of erosion on metal surfaces, it would be difficult to obtain accurate results. 
In the present work, a soil containing cobalt-60 powder was used. Cobalt-60 was chosen because of its relatively long half-life (5.3 years), its high gamma-energy level (1.2 Mev average) and the low scattering property. It has been mentioned that the reproducibility of data was within $15 \%$. This is quite acceptable taking account of the difficulty in reproducing the position of the specimen in the sound field. For applications $b=10$ $100 \mathrm{kcps}$, the use of the specimen has the further advantage that it will not disturb the sound field as the diameter of the specimen is small compared to the value of $0.58 \mathrm{in.,}$ which is the wavelength of sound in water at $100 \mathrm{kcps}$. The radioactivity level involved was sufficiently low so that it would not present much hazard.

In studying the cavitation damage on metal surfaces, a number of investigators $(2,3,4,6)$ have reported that an initial nonlinear period is always present as a result of surface Inhomogeneities. Although the non-linear period was observed in the present work, the interval was relatively short, indicating the uniformity of the specimen surface.

The diameter of the platinum wire which was used as heater in the heat transfer experiments varied from 0.007 to 0.010 in. The specimen for measuring the cavitation activity of the liquid should have similar diameter size. Preliminary experiments showed that it was extremely difficult to put a uniform coating of soll onto a wire of such dlameter: Tinned copper wire, gauge $18(D=0.0403 \mathrm{in})$ was subsequently used. It has been mentioned that the specimen diameter is small compared 
to the wavelength of sound fields used in present work except for the case of $308 \mathrm{kcps}$. The cavitation activity measured by the specimen should be applicable to the platinum wire which was mounted on the same position as the specimen in the test liquid.

The percentage of soil removed for distilled water, as seen from Figures 7 to 10, was always higher than that for methanol except for very low electrical power inputs. This is in accordance with the findings of Bebchuk and Rosenberg $(7,8)$ who attributed the difference to the effect of gas solubility. Cavitation bubbles would collapse more violently when the gas content in the 1iquid is small and thus increase the damage. The solubility of gases in methanol is more than an order of magnitude greater than the solubility of gases in water. The reversing trend at low electrical power input was due to the lower value of cavitation threshold of methanol.

It should be noted that values of percentage soil removed at different frequencies should not be compared even when the apparent electrical power inputs to the transducers were the same. The efficiencles of the transducer system were not determined and the effective sound pressures on the specimen as shown in sound pressure data were not the same in every case.

The effect of temperature on cavitation damage is shown in Figures 7 and 8 . Bebchuk ${ }^{(2)}$ measured the weight loss from a specimen of aluminum plate in water at a frequency of $8 \mathrm{kcps}$ with temperature ranging from $50^{\circ}$ to $194^{\circ} \mathrm{F}$. His results show that the cavitation damage first increases to a maximum which is located at approximately $120^{\circ} \mathrm{F}$ 
and then decreases with increasing temperature. Similar experiments carried out by Devine and Plesset ${ }^{(9)}$ have shown that the maximum. is in the temperature range $105^{\circ}$ to $120^{\circ} \mathrm{F}$, depending on the type of metal surface used. The results shown in Figure 7 are in agreement with these findings. As mentioned in the Literature Review section, the existence of the maximum can be explained as the result of the increase in the vapor pressure and the decrease of the equilibrium concentration of dissolved gas in a liquid as the temperature is increased. Increase in vapor pressure tends to decrease the damage while the cavitation bubbles would collapse more violently as the gas content of the liquid decreases. A maximum would be formed as the more violent bubble collapse tends to oppose the cushioning effect of rising vapor pressure. Devine and Plesset have shown that the temperature dependence of the cavitation damage in water is similar to a plot of

$$
\left[1-\frac{P_{V}(T)}{P_{v}\left(212^{\circ} F\right)}\right]\left[\frac{C_{s}\left(32^{\circ} F\right)}{C_{S}(T)}\right]
$$

versus the water temperature with the maximum located at approximately $120^{\circ} \mathrm{F}$. There are no data available in the literature for methanol.

$$
\text { Recently, Koontz and Amron }{ }^{(10)} \text { and Heim (11) have studied }
$$
the rate of cavitation damage of a specially prepared soil applied to a metal surface. Similar work has been reported by Romero and Stern (12) who used a soil labelled with carbon 14. The purpose of these studies was primarily to determine the cleaning efficiency of an ultrasonic cleaning unit as compared to other methods of cleaning. They were concerned with the total time required to clean the specimen completely 
and studied it as a function of frequency, temperature of the cleaning liquid, the electrical energy input to the system as well as the type of detergent used. This is in contrast to the objective of this investigation which was concerned with the development of a technique using the rate of cavitation damage to measure the acoustic intensity of a liquid under strong ultrasonic vibrations, The success of their work, however, gives further support to the rellabllity of the present technique.

CONCLUS IONS

The proposed method provides an accurate and reliable means using cavitation damage to measure the cavitation activity of a liquid sound field. While smaller specimens may be prepared, the use of present specimens will not interfere with any sound fleld at a frequency of $100 \mathrm{kcps}$ or lower. The radiation level involved is sufficiently low that it does not involve much hazard. 


\section{NOMENCLATURE}

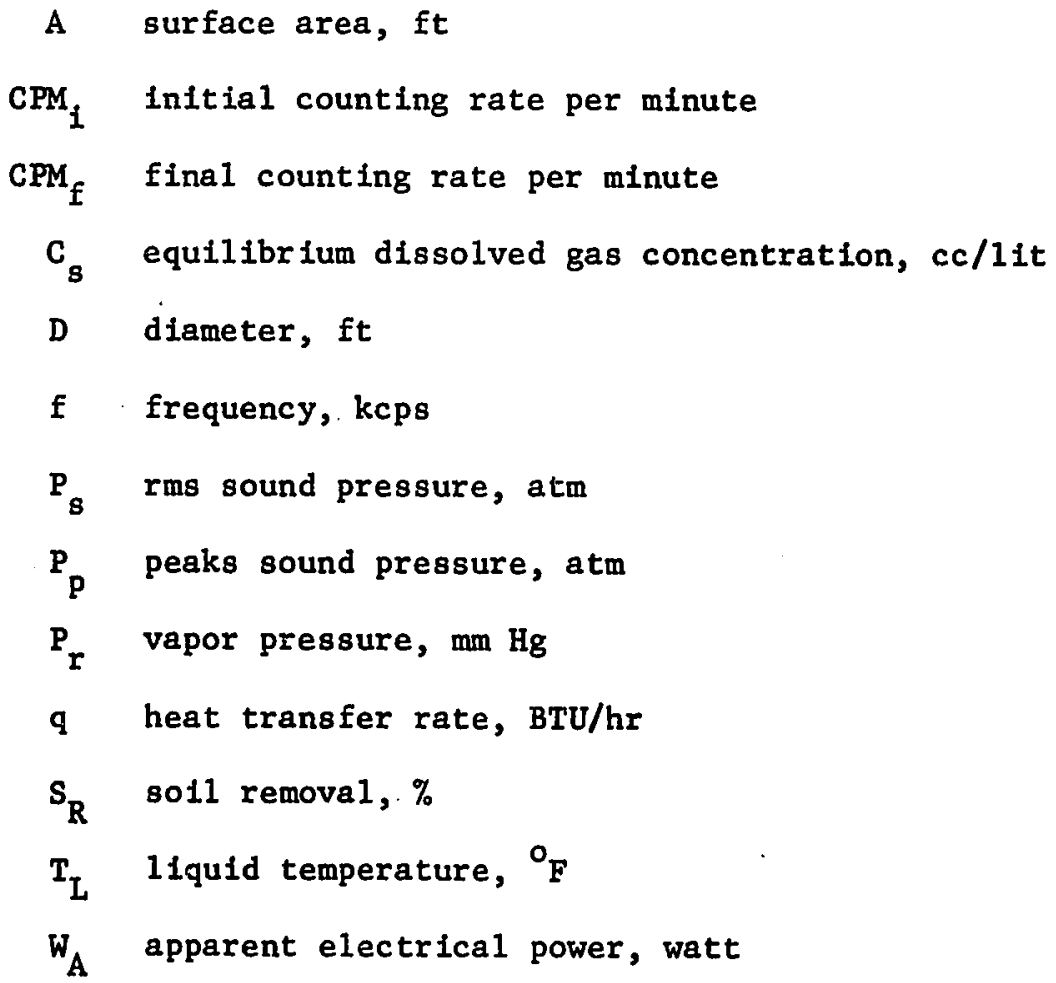




\section{REFERENCES}

1. Bebchuk, A.S., Iu. Ia. Borisov, and L.D. Rosenberg, Soviet Physics - Acoustics, 4, 372 (1958).

2. Bebchuk, A.S. Soviet Physics - Acoustics, 3, 95 (195.7).

3. Crawford, A.E. Ultrasonics, 120, July-September (1964).

4. Antony, 0.A. Ultrasonics, 194, October-December (1963).

5. Gray, A. and G.A. Wallace. "Principles and Practice of Electrical Engineering", McGraw-H111, p.. 281 (1955).

6. Plesset, M.S. and A.T. Ellis. Trans.Am.Soc.Mech.Engrs. 77, 1055 (1955).

7. Bebchuk, A.S. Soviet Physics - Acoustics, 3 , 395 (1957).

8. Rosenberg, L. D. and A.S. Bebchuk. Soviet Physics - Acoustics, 6, 496 (1961).

9. Devine, R.E. and M.S. Plesset, Rept. No. 85-27, Div.Eng. and App1. Sc1., California Institute of Technology, April (1964).

10. Koontz, D.E. and I. Amron. ASTM Speclal Technical Publication, No. 246, pp. 22-31 (1958).

11. Heim, R.C. Inst.Radio Engrs.Convention Record, Part 6, 219 (1960).

12. Romero, E.L. and H.A. Stern, ibid, Part 6, 225 (1960). 


\section{PART II}

EFFECTS OF ULTRASONIC VIBRATIONS ON HEAT TRANSFER TO

LIQUIDS BX NATURAL CONVECTION AND BY BOILING

\section{INTRODUCTION}

In Part I of this section, a technique has been developed to measure the cavitation activity of a liquid under intense ultrasonic vibrations. This technique was used to obtain the cavitation activity of the 11quid near the heat transfer surface and subsequently, using this information, to correlate the heat transfer results. Applied sound pressure amplitudes below the cavitation threshold level were measured by the ultrasonic probe.

Platinum wires with diameters of 0.007 in. and 0.010 in. were used as heating elements because of the following advantages: 1) Since the diameters of the wire are small compared with the wavelength of the ultrasound, one can assume that there is no variation of sound pressure in the radial direction; 2) platinum can be used as an accurate resistance thermometer,

To study the mechanism of the heat transfer processes, high speed photography was used. 
EXPERIMENTAL

$\underline{\text { Equipment }}$

The same apparatus described in Part I was used except that the specimen for measuring the cavitation activity was replaced by a platinum wire. In order to minimize the end conduction effects, only the central portion (approximately $3 / 4$ in.) of the heating element was made to serve as the test section by use of platinum potential leads having smaller diameters relative to that of the heating element.

A regulated DC power supply, Model 520A (0-36 V, 0-25A) manufactured by Harrison Laboratorles was used to energize the heating circuit. The heating current was obtained by measuring the drop in electric potential across the 0.02 ohm standard resistor described earlier, with a Tinsley Model 3184E precision potentiometer and a Tinsley galvanometer (Type SR-1). The Tinsley potentiometer and galvanometer combination was capable of reading to $0.01 \mathrm{mv}$ at $1 \mathrm{mv}$. The accuracy of the readings, however, was limited by the stability of the boiling and the cavitation phenomena rather than by the instruments. The voltage drop across the test section was also measured with the same potentiometer and galvanometer. 


\section{Materials}

Ail platinum wires Including the 0.0045 in. diameter and 0.0002 in. diameter wires used as potential leads were $C P$ platinum wires, reference grade, manufactured by Engelhard Industrles.

The 1 iquids used were distilled water and methanol, described earlier.

\section{Procedure and Observations}

The platinum potential leads were spot-welded to the heating element which was then annealed at red heat in a1r for 15 minutes with alternating current. The test section of the heating element was calibrated in water at $212^{\circ} \mathrm{F}$ by using very low DC current and measuring the voltage drops across the standard resistor and the test section. This was done after the temperature coefficients of resistivity of platinum obtained from a number of calibrations performed at both $32^{\circ} \mathrm{F}$ and $212^{\circ} \mathrm{F}$ were in good agreement with the known values. At least ten sets of readings were taken at $212^{\circ} \mathrm{F}$ for each wire to obtain its average value of resistance. The length of the test section was measured by a scale capable of giving an accuracy of 1/64 in. For the wire diameter, the value given by the manufacturer was used.

The calibrated platinum wire assembly was placed in the same location as the specimen used in Part $I$. The temperature of the test liquid was brought slowly up to the desired level so that the 
dissolved air content in the test liquid would be at its equilibrium value. The liquid level in the tank was the same as before.

\section{Heat Transfer Experiments Without Vibration}

The current from the DC power supply was passed through the wire, and readings of voltage drop across the standard resistor and the test section were taken. It was then efther increased or decreased, depending on the initial value used, by small steps so that measurements were made in the whole region of natural convection and nucleate boiling. When the test 1 iquid was methanol at $113^{\circ} \mathrm{F}$, the amperage of the power supply was sufficient to burnout the wire. Subsequently, the effects of ultrasonic vibrations on burnout heat flux and the critical temperature differences were also studied as described in Part III of this section. With distilled water at $149^{\circ} \mathrm{F}$ as the liquid, the maximum available current was insufficient to burnout the wire. For reasons which will become obvious later, saturated pool bolling or subcooled pool bolling with smaller values of the degree of subcooling are undesirable. Using smaller diameter wires as the heating element would also require less current to achleve burnout. Preliminary experiments had shown, however, that a heating element made of smaller diameter wires $(0.0045$ and 0.002 in.) vibrated at high heat fluxes under intense ultrasonic vibrations.

\section{Determination of the Critical Sound Pressure}

A sma11 DC current was passed through the wire and the acoustic energy was imposed upon the system, starting with a very low 
value of apparent electrical power input to the transducers. The apparent electrical power input was increased in small steps. The voltage drops across the standard resistor and the test section as well as the apparent electrical power input were recorded after each increment. It was observed that the potential across the test section remained the aame until at some value of apparent electrical power input a sudden drop was recorded indicating a decrease in the wire temperature. Simultaneously cavitation bubbles appeared on the wire. These cavitation bubbles were very unstable and began to roll on the wire surface soon after they were formed. The root mean square sound pressure on the wire measured at this value of apparent electrical power input to the transducers is then called the critical sound pressure. It can be defined as the sound pressure at which the applied sound pressure field begins to have an effect on the heat transfer rate. For values of sound pressure below the critical value, the heat transfer rate was the same as in the case where there was no vibration.

The following procedure was adopted in determining the critical sound pressure. The voltage drop across the transducers was increased in small steps of 1 minute duration. The actual value of increase in voltage depended on the frequency of the sound field. For example, when the frequency was $20.6 \mathrm{kcps}$, the voltage increment was 1 volt. At $108 \mathrm{kcps}$, the increment was increased to 25 volts. When a drop in the potential across the test section was recorded, the voltage drop across the transducers was decreased by one step, that is 1 volt if $f=20.6 \mathrm{kcps}$. If the potential drop across the test wire returned to 
its vibration-free value after a 5-minute interval, the sound pressure measured prior to the decrease in transducer voltage was taken as the critical sound pressure. If the potential across the test section did not return to its value without vibration, the voltage drop across the transducers was further reduced by one step for 5 minutes. In all cases, the lowest sound pressure for which a drop in the voltage across the test section occurred was taken to be the critical sound pressure. The 5-minute interval criterion was checked by waiting for periods of as much as 30 minutes. It was found that the 5-minute interval was sufficlent in 10 out of the 11 cases checked. The critical sound pressures were reproductble to within $12 \%$.

\section{Heat Transfer Experiments with U1trasonic Vibrations}

It was found that the critical sound pressure was a function of the wire temperature as well as the frequency of the sound field. , In order to be able to compare directly the heat iransfer results witi ultrasonfc vibrations, it was necessary to select values of apparent electrical power input to the transducers so that for the whole range of the wire temperature used, the resulting sound pressures on the wire surface would exceed their corresponding critical values. When the frequency was $20.6 \mathrm{kcps}$, the three values of voltage drop across the transducers used were 15,25 and 40 volts, corresponding to values of apparent electrical power input of $15.6,36.2$ and 86.0 watts respectively. After the critical sound pressure was determined, the voltage drops across the transducers were changed to the above values. The $D C$ current 
passing through the wire was then increased in small steps. For each new wire temperature, measurements were made first without imposing vibration.

The liquids used and the experimental variables studied were the same as in Part I. When the frequency was $20.6 \mathrm{kcps}$, two different liquid temperatures were used for both liquids; namely, $113^{\circ} \mathrm{F}$ and $149^{\circ} \mathrm{F}$ for distilled water, and $95^{\circ} \mathrm{F}$ and $113^{\circ} \mathrm{F}$ for methanol. For the three remaining frequencles ( $44.1,108$ and $306 \mathrm{kcps}$ ): the temperature of distilled water was $149^{\circ} \mathrm{F}$ and that of methanol was $113^{\circ} \mathrm{F}$. A thermometer located near one end of the wire was used to measure the temperature of the liquid. The temperature was always maintained at the desired level to within $1^{\circ} \mathrm{F}$.

All platinum wires were used as received. It was found however that, after two or three tests, it became rather difficult to reproduce the heat transfer results using the same wire. Microscopic studies showed that the wire surface conditions had changed considerably after two or three tests. In Appendix $G$, the change of surface conditions is shown in three photographs taken through a microscope. The change of surface conditions of the platinum wire was taken to be the result of cavitation damage. It has been established that the surface condition is an important varlable in the study of nucleate bolling $(1,2,3)$. Subsequently, each platinum wire was not used for more than three tests. 
RESULTS

\section{Critical Sound Pressure}

The results of the critical sound pressure measurements are shown in Figures 1 to 5 . Figure 1 shows some typical temperature history curves used in the determination of the critical sound pressure. For a given value of heat flux, the temperature difference between the wire and the bulk. Ilquid remained almost constant until the critical sound pressure was reached when it dropped rather abruptly to a lower value. The DC current passing through the wire was maintained at the same value. The heat flux value dropped slightly due to the decrease in platinum wire resistance as the wire temperature decreased. The change, however, was less than $2 \%$, and the values reported In Figure 1 are the mean values.

Figure 2 shows the critical sound pressure for distilled water ac two different 1iquid temperatures at a frequency of $20.6 \mathrm{kcps}$. The effect of irequency on critical sound pressure is shown in Figures 4 and 5 for distilled water at $149^{\circ} \mathrm{F}$ and for methanol at $113^{\circ} \mathrm{F}$, respectively. Figure 3 gives the same information for methanol at $95^{\circ} \mathrm{F}$ and $113^{\circ} \mathrm{F}$, as Figure 2 does for distilled water. The critical sound pressure shows a minimum in the temperature range of $235^{\circ}$ to $245^{\circ} \mathrm{F}$ for distilled water and $170^{\circ}$ to $180^{\circ} \mathrm{F}$ for methanol, both corresponding to temperatures for the Inciplence of boiling of the two liquids. 
()

FIGURE' 1

SOME TYPICAL. TEMPERATURE HISTORY CURVES DURING THE DETERMINATION OF CRITICAL SOUND PRESSURE

C 
0

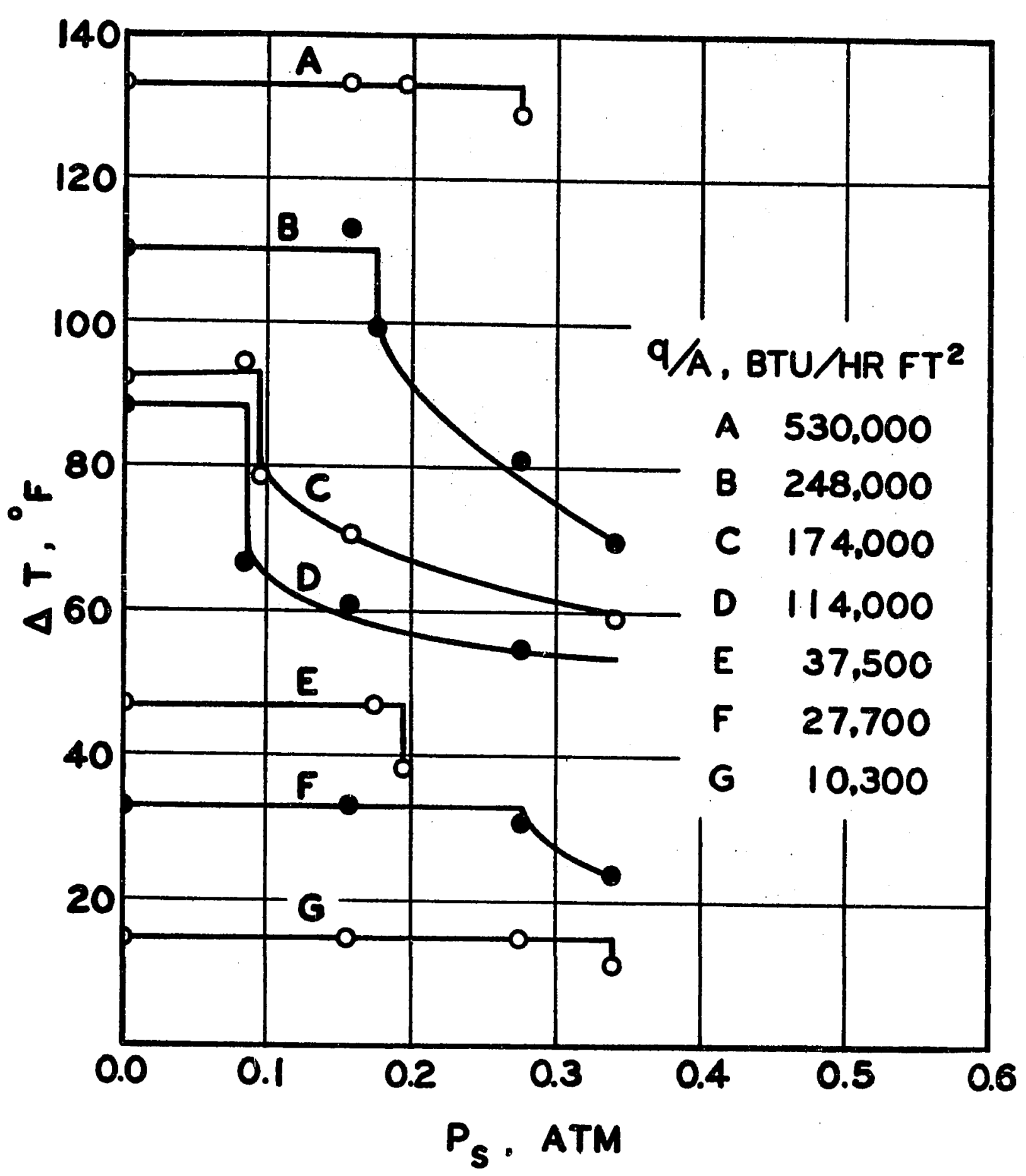


VARIATION OF CRITICAL SOUND PRESSURE AS A FUNCTION OF THE WIRE TEMPERATURE AT $20.6 \mathrm{kcps}$

FIGURE 2 DISTILLED WATER AT $113^{\circ} \mathrm{F}$ AND $149^{\circ} \mathrm{F}$ FIGURE 3 METHANOL AT $95^{\circ} \mathrm{F}$ AND $113^{\circ} \mathrm{F}$. 
I

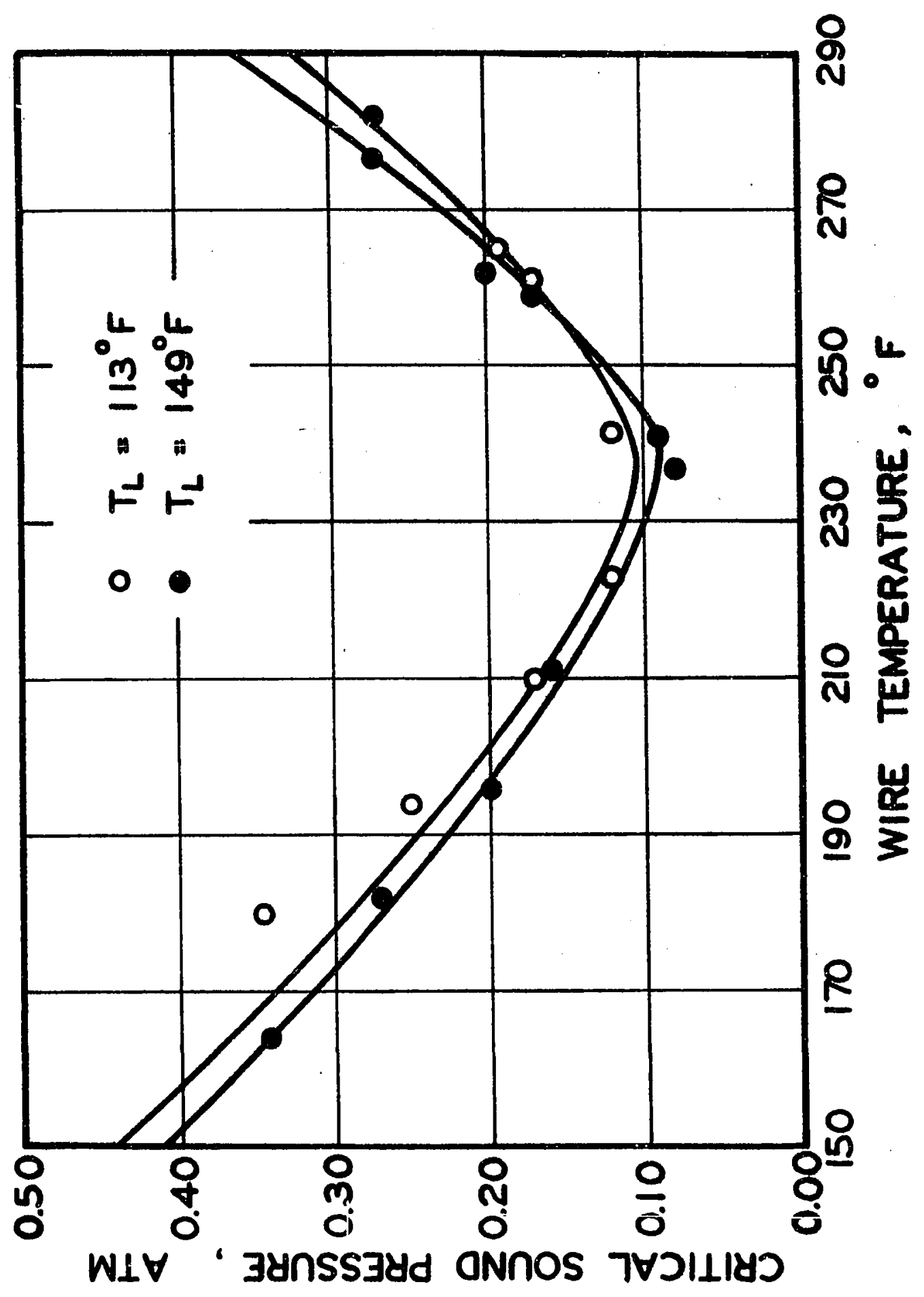




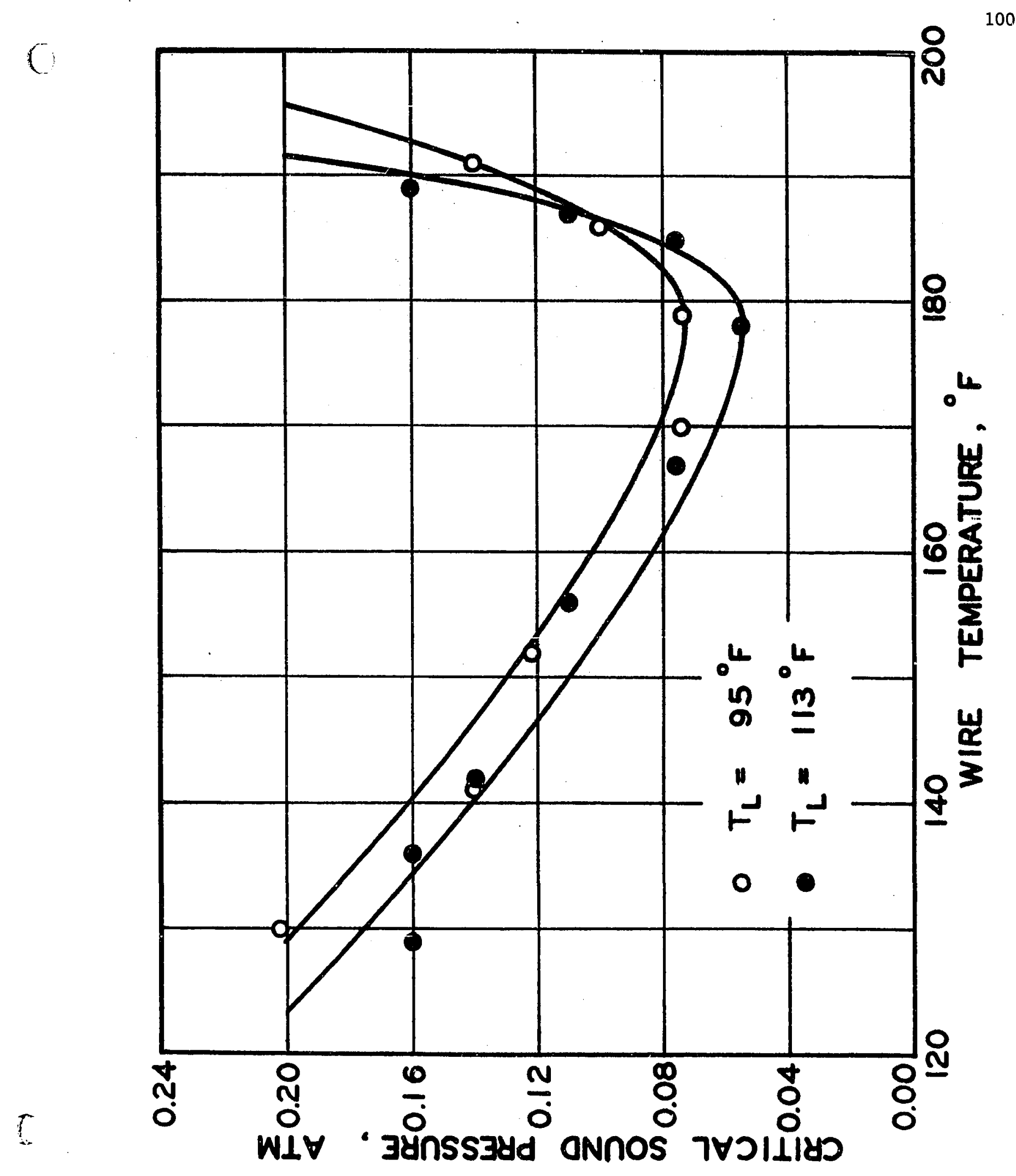


VARIATION OF CRITICAL SOUND PRESSURE AS A FUNCTION OF THE WIRE TEMPERATURE AT DIFFERENT FREQUENCIES

FIGURE 4 DISTILLED WATER AT $149^{\circ} \mathrm{F}$

FIGURE 5 METHANOL AT $113^{\circ} \mathrm{F}$. 
1

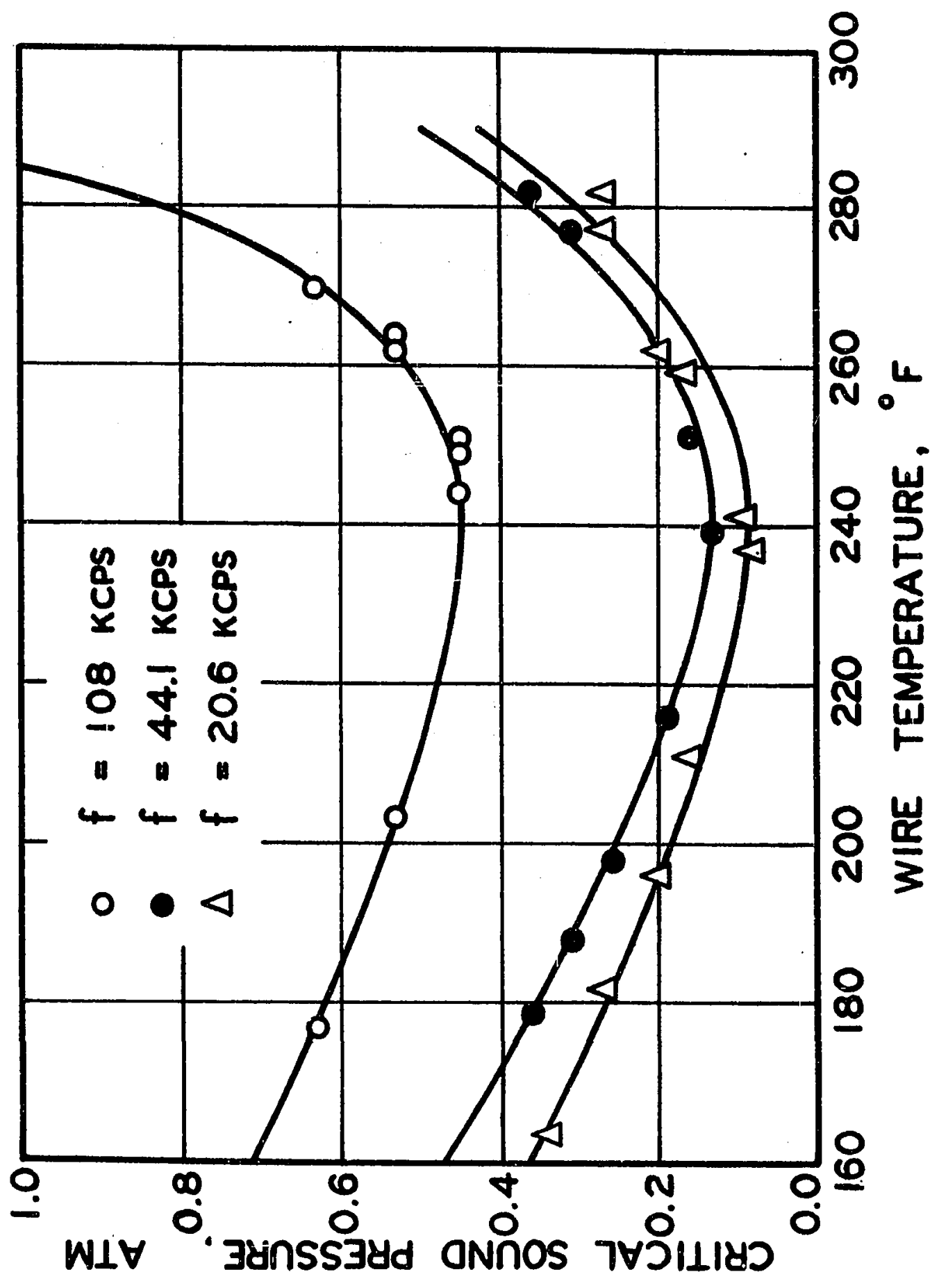




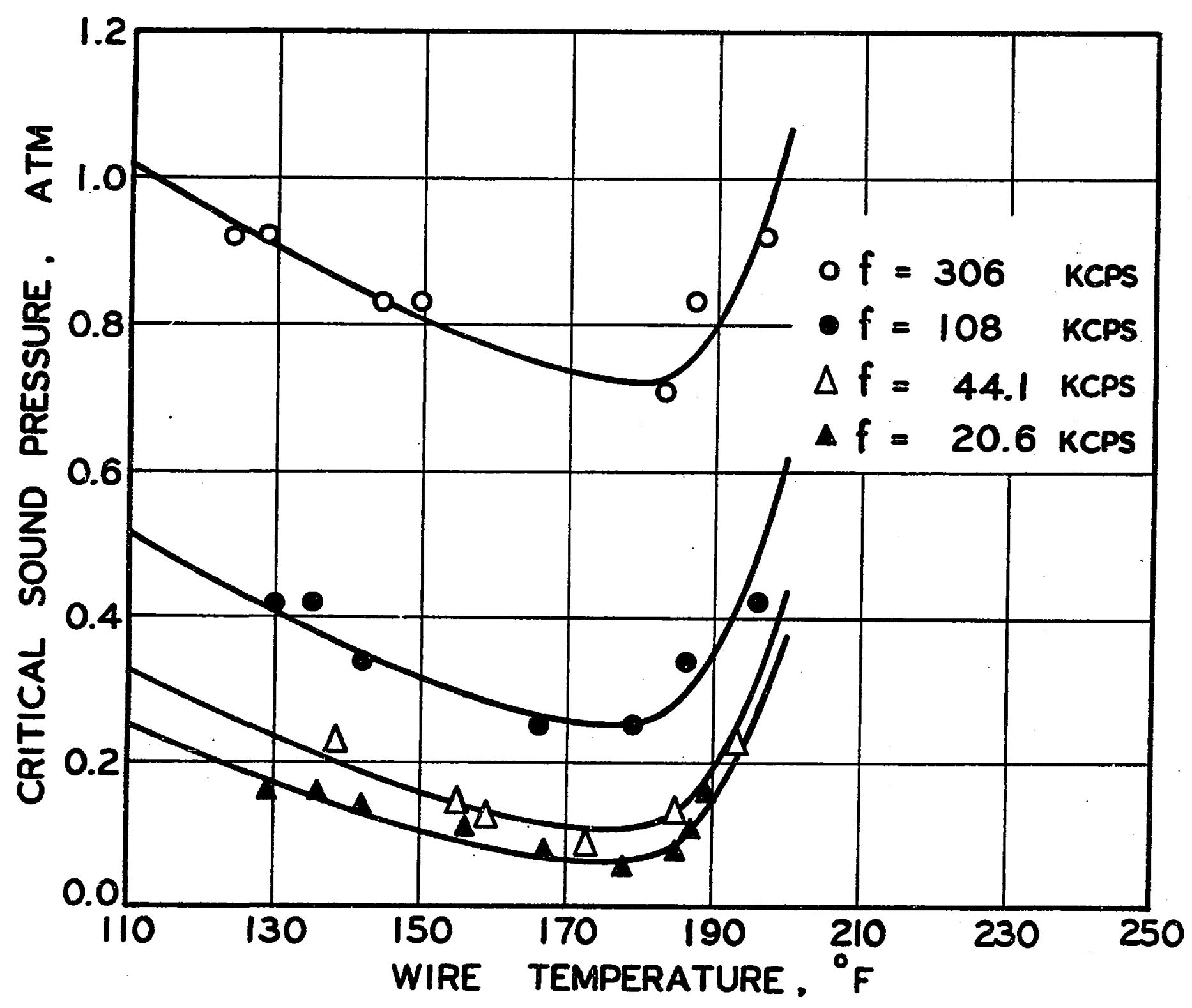


Heat Transfer Data

The results of heat transfer experiments with and without ultrasonic vibrations are presented in.Figures 6 to 14. In each figure, the heat fluxes are shown at three different acoustic energy levels except in Figures 11, 13 and 14 for frequencies of 108 and $306 \mathrm{kcps}$ where they were measured at two levels.

Because of the high precision of the potentiometergalvanometer combination, the values of heat flux were measured to within $1 \%$ accuracy. However, the small fluctuations in voltage as the result of the instability of the boiling and cavitation phenomena might have increased the error up to $5 \%$. The errors in $\Delta t$ caused by these fluctuations were more serious as they were calculated to be as large as $2^{\circ} \mathrm{F}$ in some cases. Subsequently, heat transfer data with $\Delta t$ smaller than $10^{\circ} \mathrm{F}$ were neglected and less emphasis was put on data with $\Delta t$ smaller than $20^{\circ} \mathrm{F}$.

The radial temperature gradient within the platinum wire was calculated according to an equation given by McAdams et al. (4). The correction was not made as the error Involved was less than $2 \%$ in all cases. The calculations are given in Appendix F. The temperature difference $(\Delta t)$ in all figures is the temperature difference between the platinum wire and the bulk liquid.

The acoustic energy levels were expressed in terms of the apparent electrical power input to the transducers, which could be translated from the results obtained in Part I to the percentage of soil removed. Table 1 shows the corresponding percentage soil removed for 
EFFECT OF $20.6 \mathrm{kcPs}$ ULTRASONIC VIBRATIONS ON HEAT TRANSFER RATES IN DISTILLED WATER
FIGURE 6
DISTILLED WATER AT $149^{\circ} \mathrm{F}$
FIGURE 7
DISTILIED WATER AT $113^{\circ} \mathrm{F}$ 
1

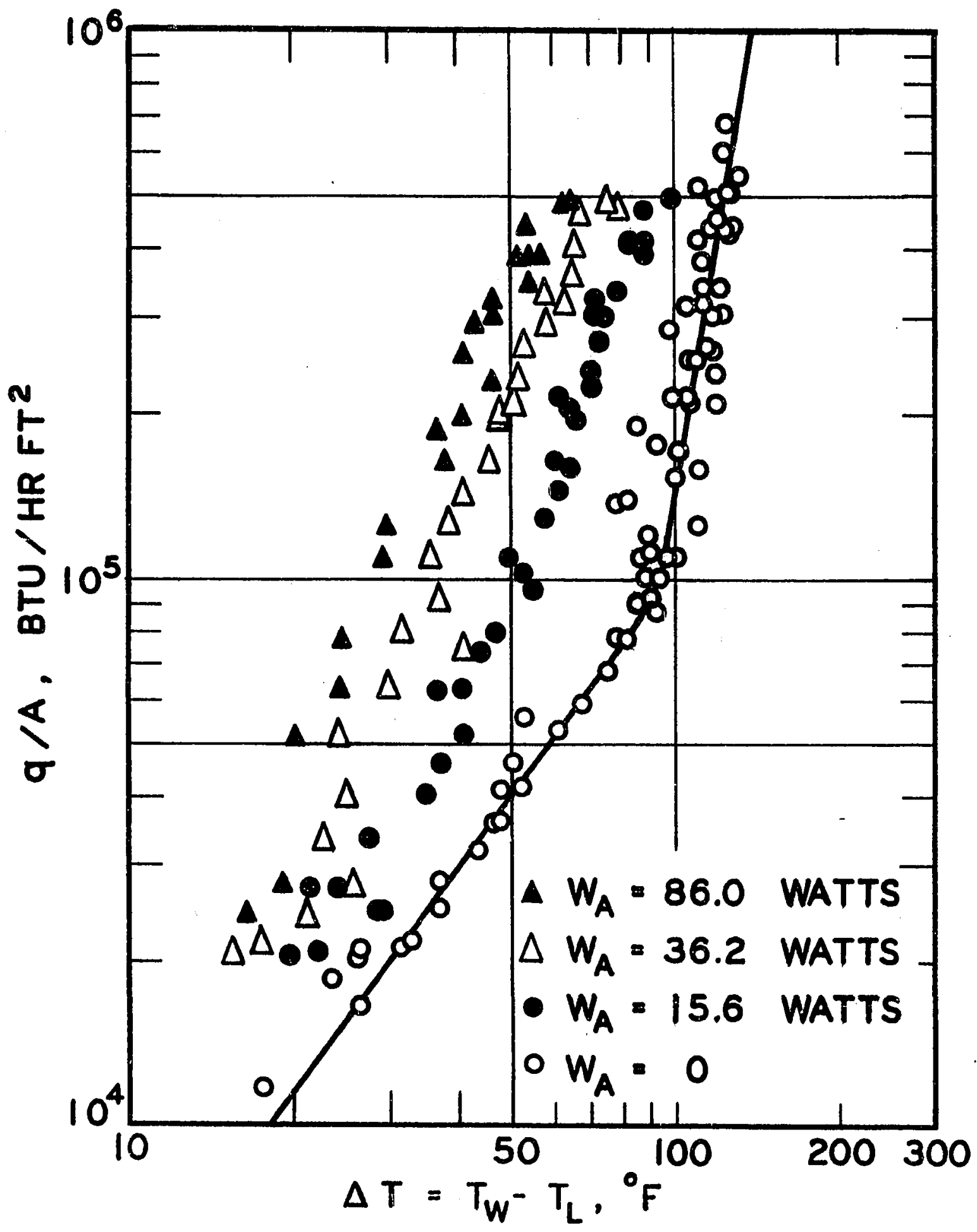


蛋

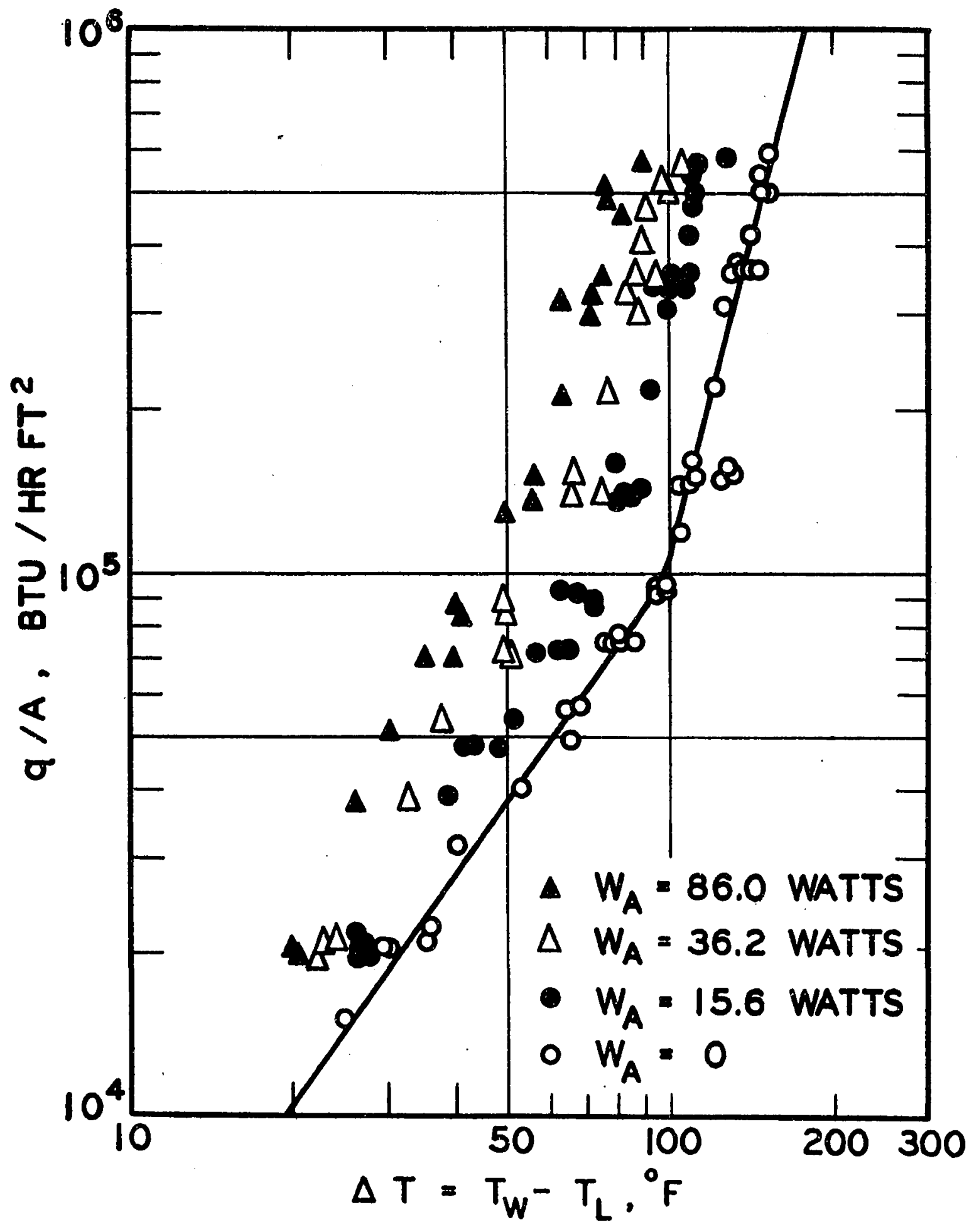


EFFECT OF $20.6 \mathrm{kcPs}$ ULTRASONIC VIBRATIONS ON HEAT TRANSFER RATES IN METHANOL
FIGURE 8
METHANOL AT $113^{\circ} \mathrm{F}$
FIGURE 9
METHANOL AT $95^{\circ} \mathrm{F}$ 


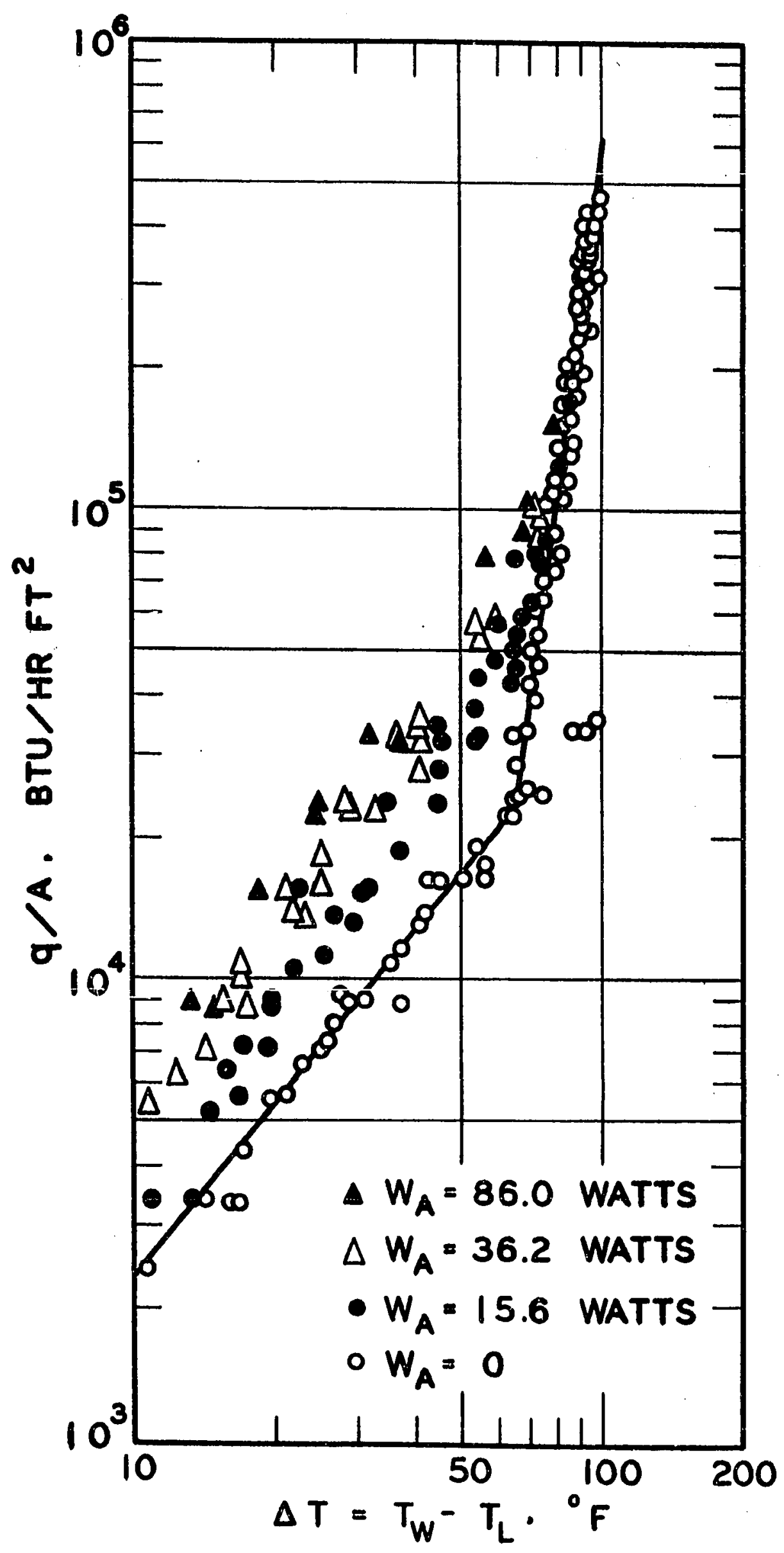


is

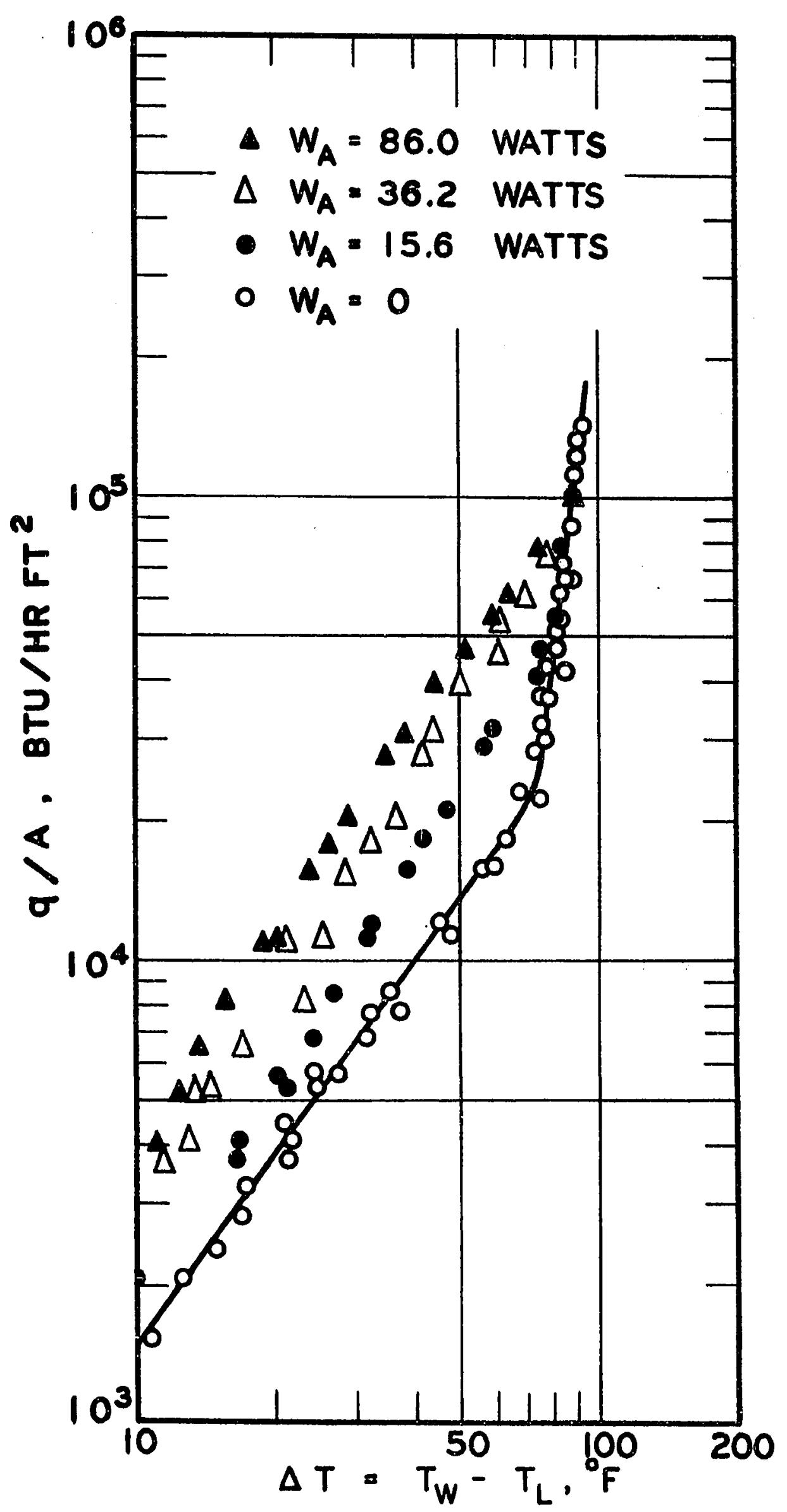


EFFECT OF ULTRASONIC VIBRATIONS ON HEAT TRANSFER RATES IN DISTILLED WATER AT $149^{\circ} \mathrm{F}$

$\begin{array}{ll}\text { FIGURE } 10 & \text { FREQUENCY }=44.1 \mathrm{kcps} \\ \text { FIGURE } 11 & \text { FREQUENCY }=108 \mathrm{kcps}\end{array}$


I

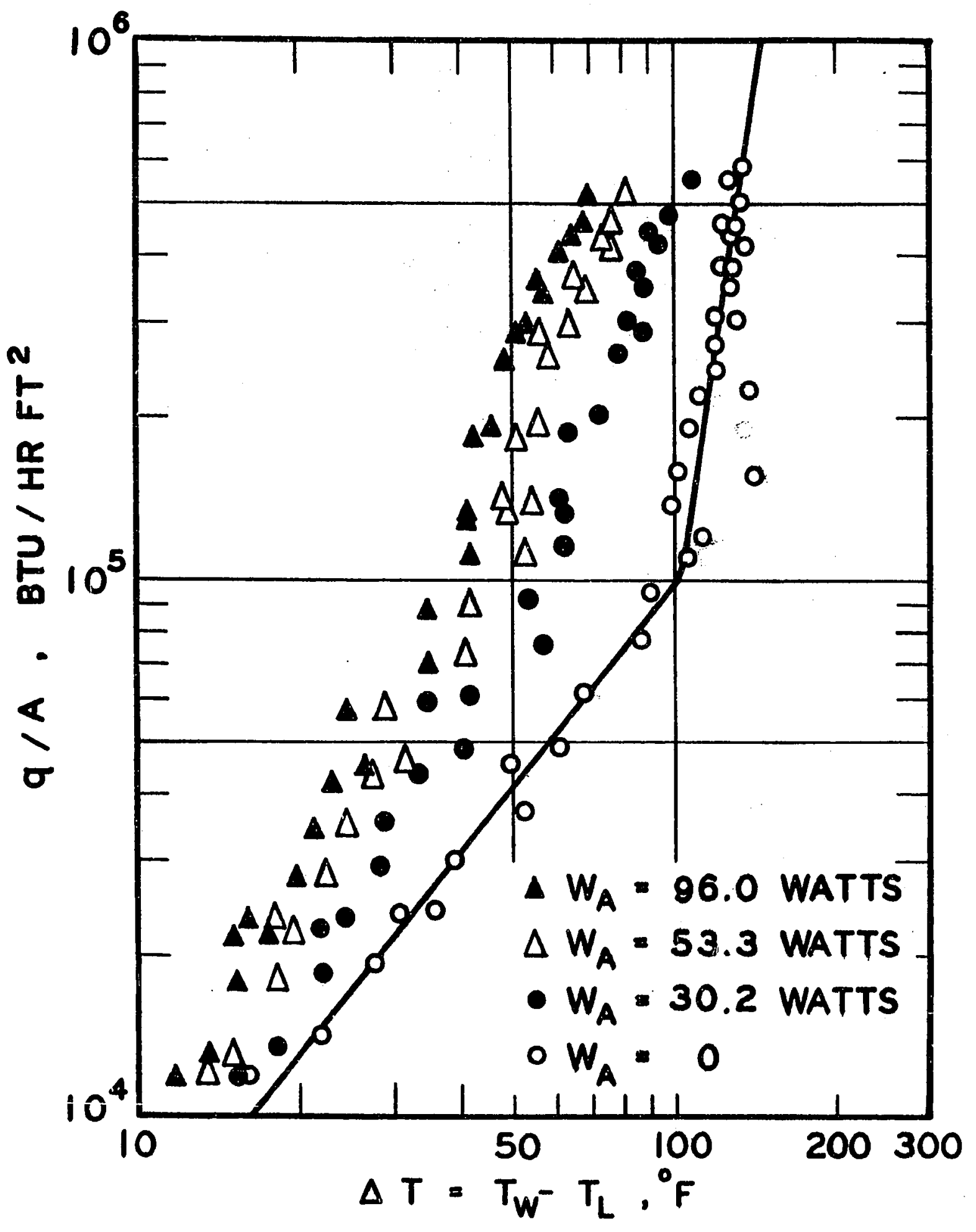


i

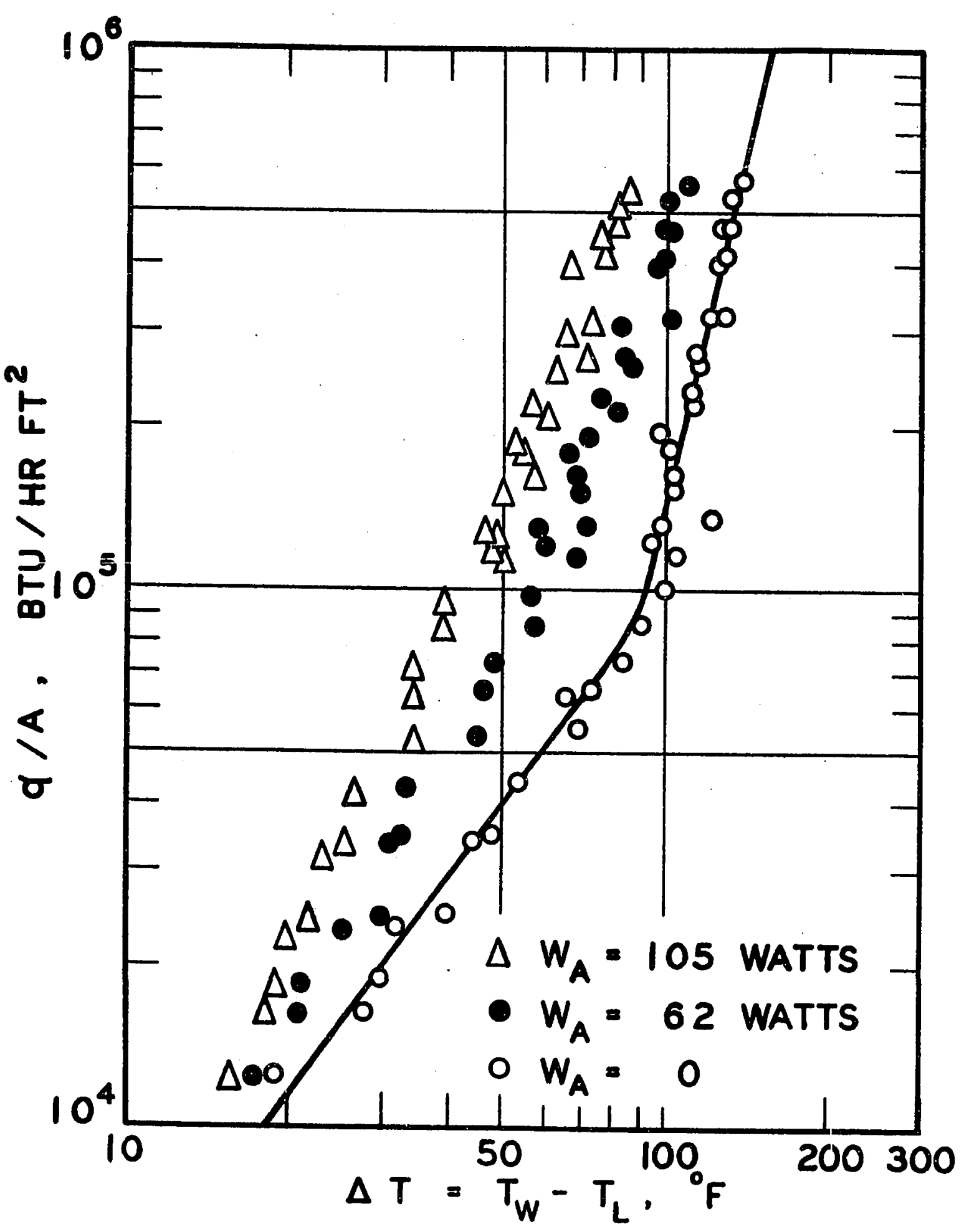




\section{EFFECT OF ULTRASONIC VIBRATIONS ON HEAT TRANSFER \\ RATES IN METHANOL AT $113^{\circ} \mathrm{F}$}

FIGURE 12

FREQUENCY $=44.1 \mathrm{kcps}$

FIGURE 13

FREQUENCY $=108 \mathrm{k.cps}$

FIGURE 14

FREQUENCY $=306 \mathrm{kcps}$ 
C

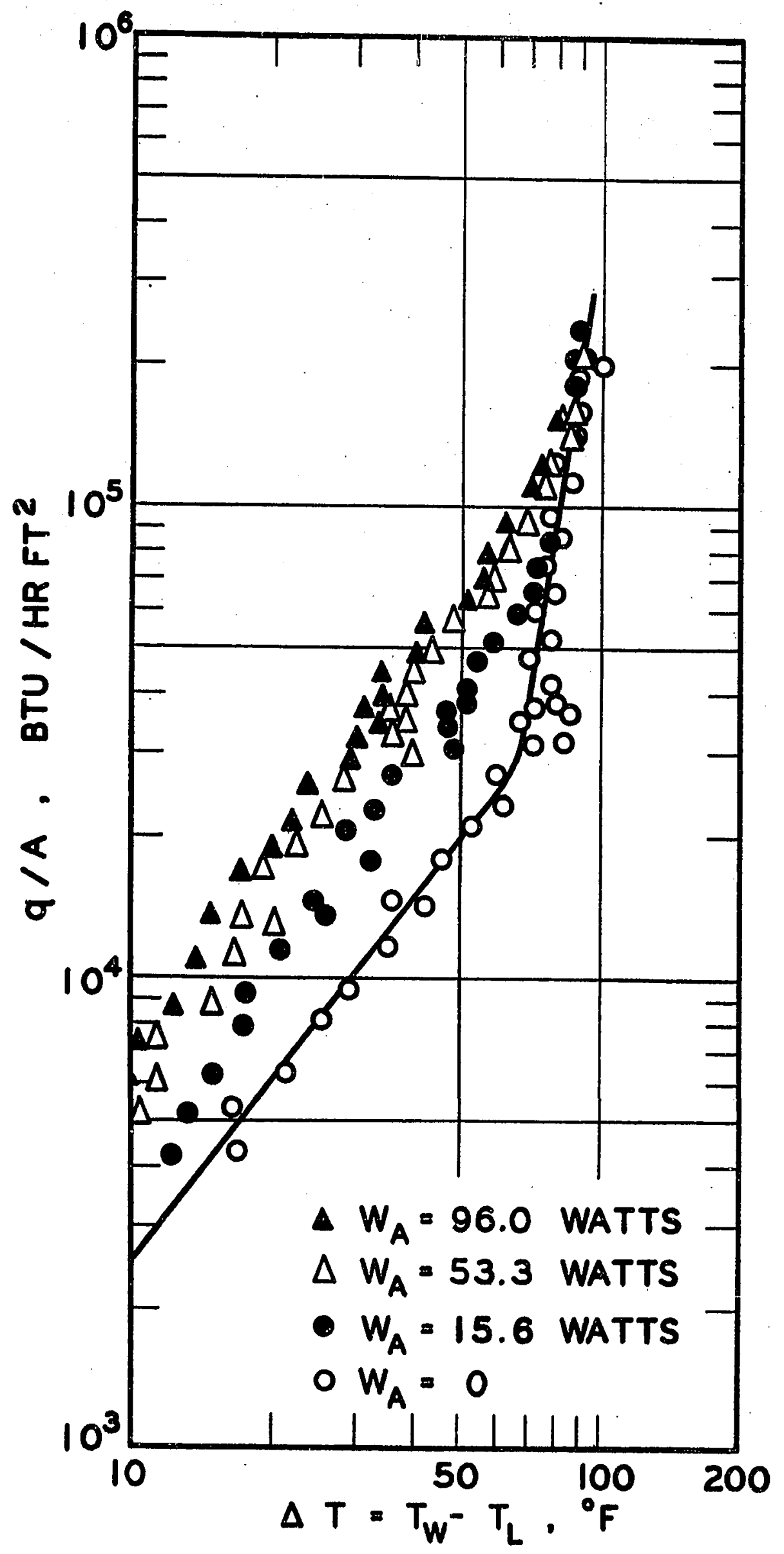




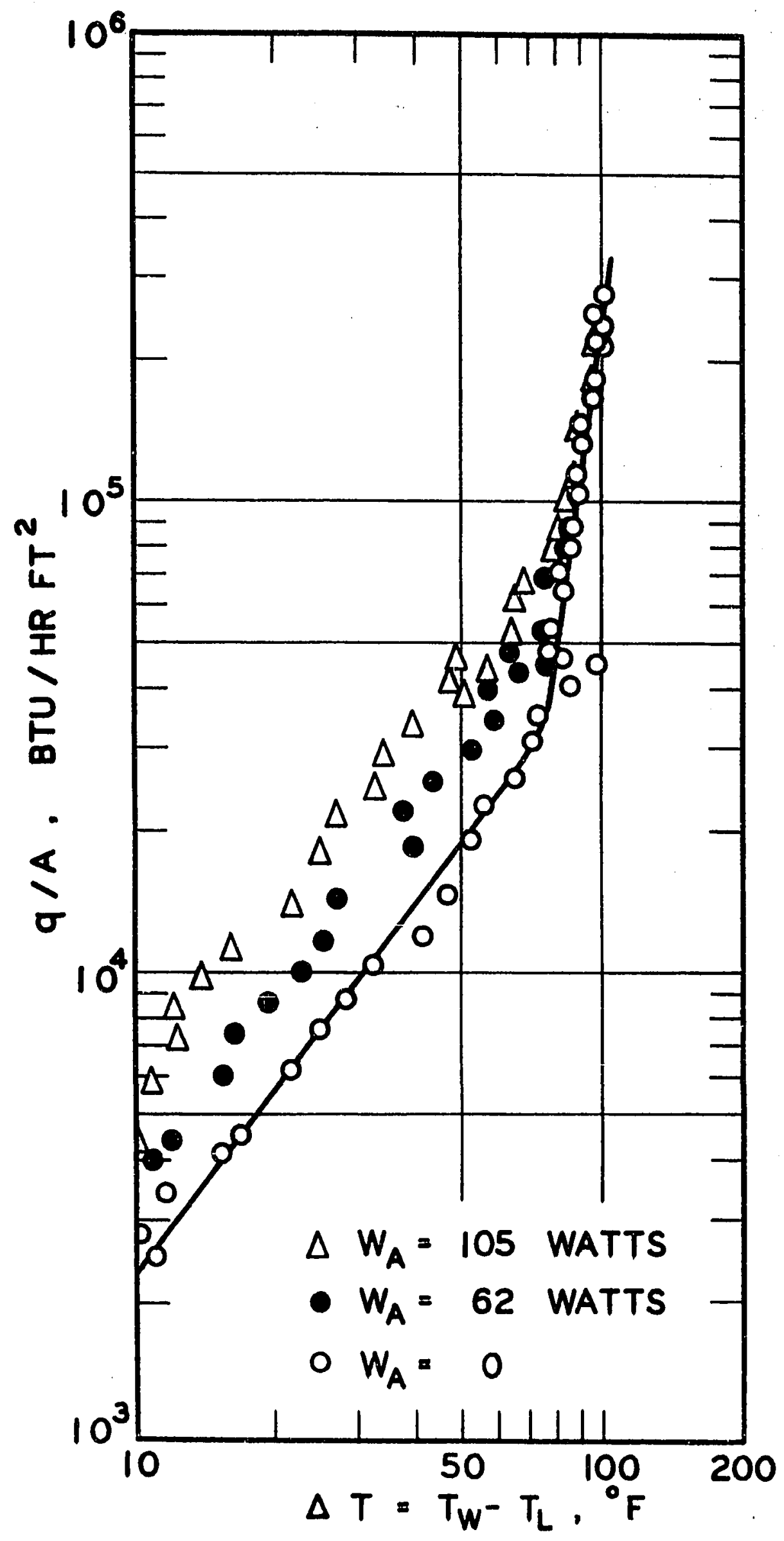

111 
1

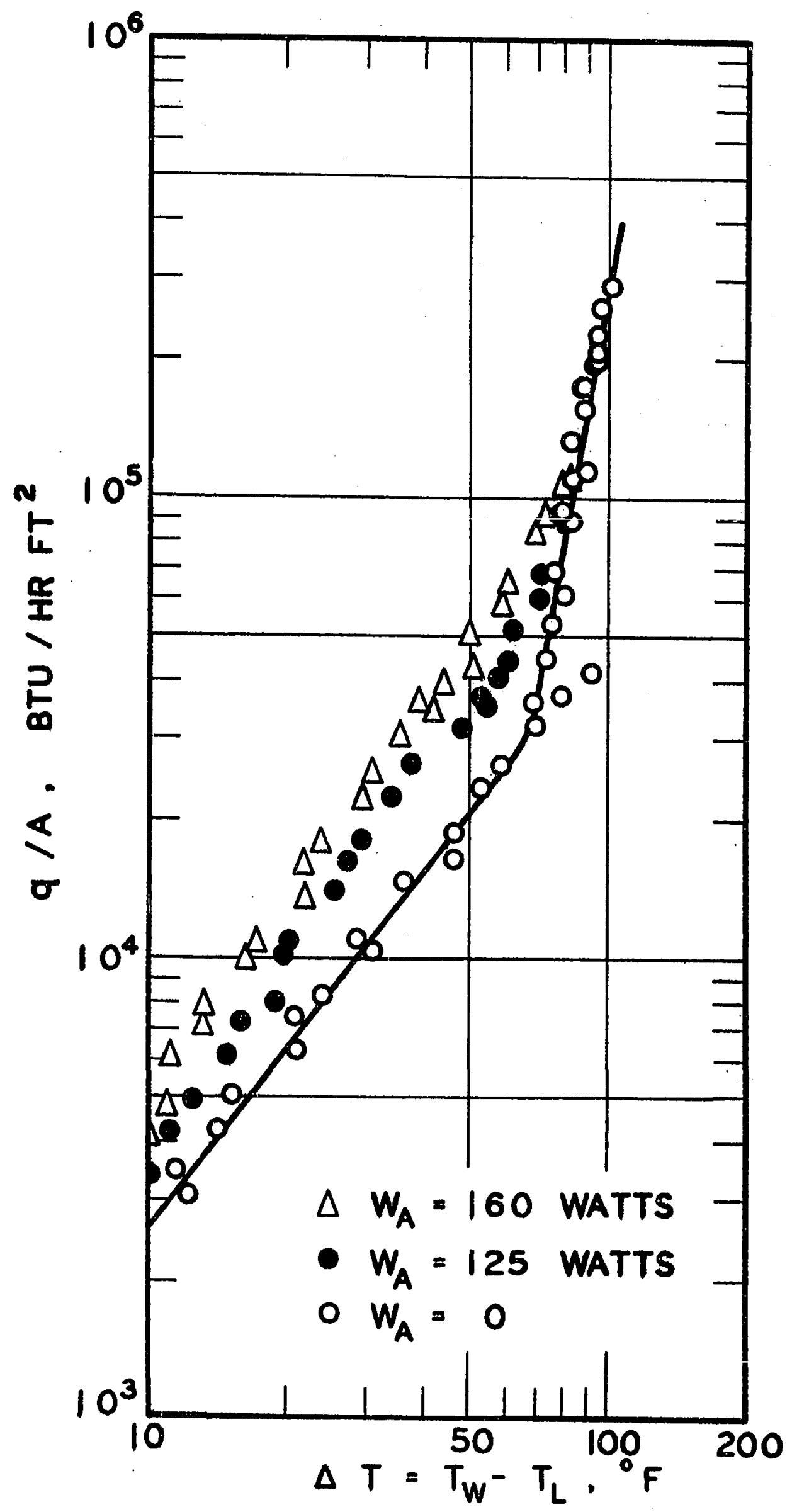

112 
TABLE 1

Values of Percentage Soll Removed at Which

Heat Transfer Data Were Measured

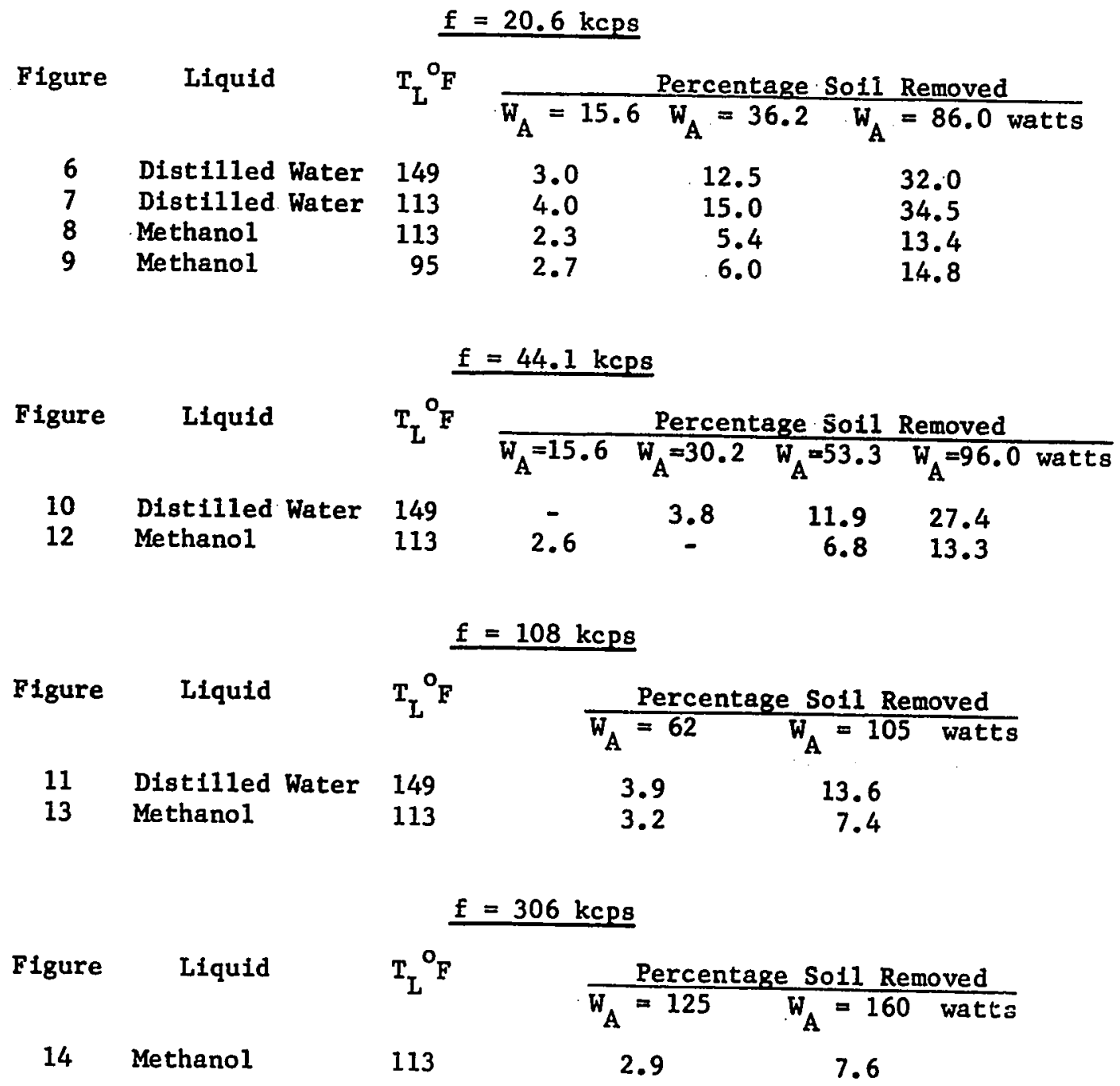


values of apparent electrical power input used in Figures 6 to 14. The experimental data for these figures are given in Appendix $D$.

Heat transfer experiments without vibration were performed in order to check the experimental techniques and to establish a reference relation with which to compare results when ultrasonic vibrations were used. For data in the natural convection region, the GrashofPrandt 1 product and the Nusselt number were calculated and are presented as a plot of Nu versus (Gr $x \cdot \mathrm{Pr}$ ) in Figure.15. The solid line is the best-fitted straight line for the data points and the dashed line is the recommended correlation for single horizontal cylinder in the same range of Grashof-Prandt1 product (10 to 150) given by McAdams (5). The difference in Nusselt numbers from the two 1 ines does not exceed $4 \%$.

The effects of ultrasonic vibrations, as shown in Figures 6 to 14, were to increase the heat transfer rates, and hence the heat transfer coefficients at a given $\Delta t$. Depending on the apparent electrical power Input as well as the temperature difference, up to $800 \%$ increase in heat transfer rates could be obtained. When the test liquid was methanol, regardless of the frequency of the sound field or the liquid temperature, the effects of ultrasonic vibrations diminished as the wire temperature was increased. At wire temperatures corresponding to well-developed nucleate boiling, the effects of ultrasonic vibrations became negligible. It is expected that similar results would be obtained for distilled water if the DC power supply had a largeramperage output. The highest value of heat flux from the wire to distilled water at $149^{\circ} \mathrm{F}$ was about $6 \times 10^{5} \mathrm{BTU} / \mathrm{hr} \mathrm{ft}^{2}$ at a wire current of about $23 \mathrm{amp}$. 
FIGURE 15

NATURAL CONVECTIVE HEAT TRANSFER FROM HORIZONTAL

PLATINUM WIRES TO IIQUIDS 
C

115

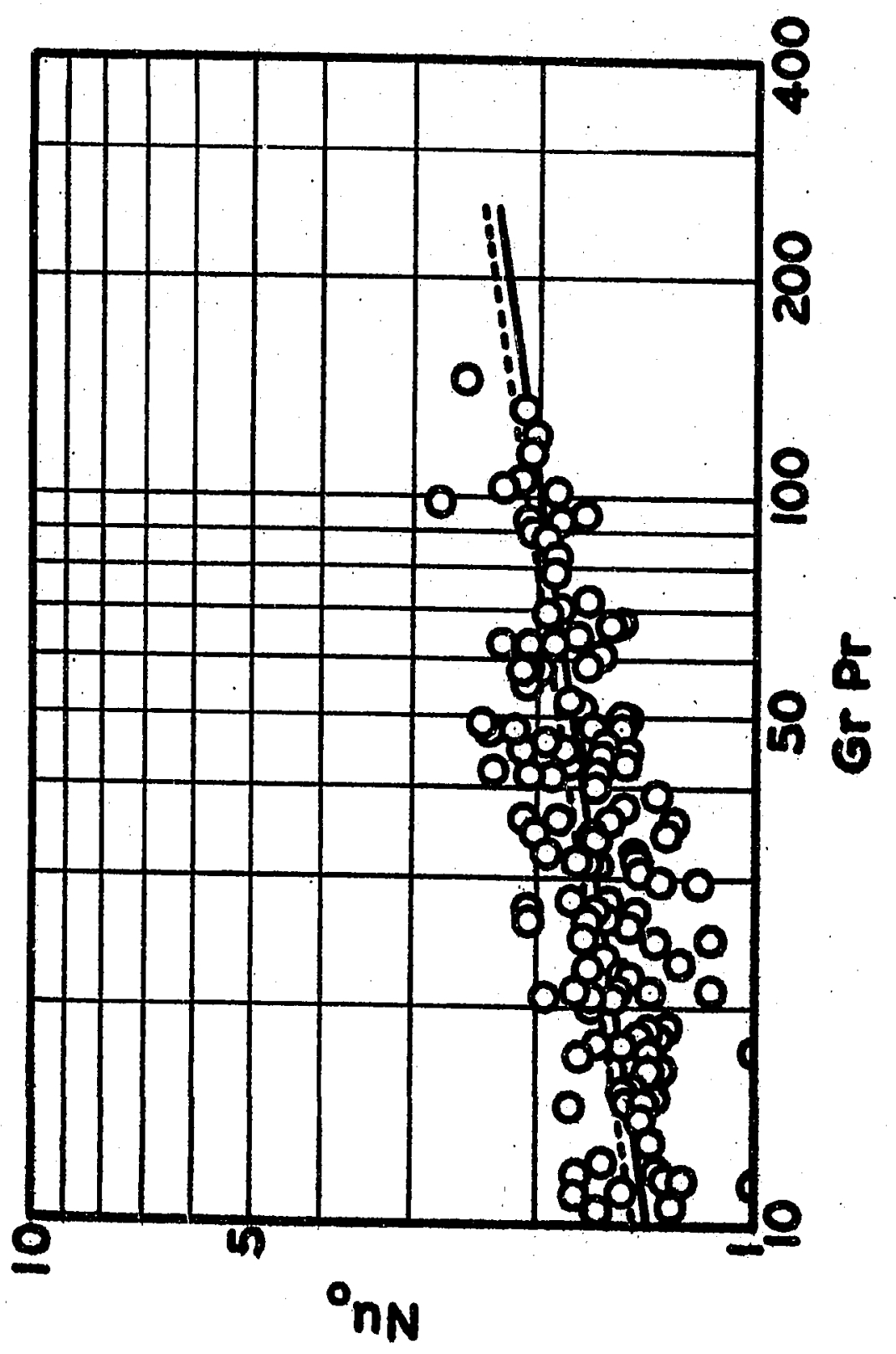


The effect of liquid temperature on heat transfer rates in an ultrasonic field can best be observed by comparing their values in the natural convection region. As shown in Figure 6 where the water temperature was $149^{\circ} \mathrm{F}$, the heat flux was increased from. $3.0 \times 10^{4} \mathrm{BTU} / \mathrm{hr} \mathrm{ft}^{2}$, where there was no vibration, to $6.2 \times 10^{4} \mathrm{BTU} / \mathrm{hr} \mathrm{ft}^{2}$ when the soll removed was $3.0 \%$, both at a temperature difference of $40^{\circ} \mathrm{F}$. Namely, the increase was about $100 \%$. For water temperature of $113^{\circ} \mathrm{F}$ (Figure 7), the heat flux of $2.9 \times 10^{4} \mathrm{BTU} / \mathrm{hr} \mathrm{ft}^{2}$ without vibration was increased to $4.2 \times 10^{4} \mathrm{BTU} / \mathrm{hr} \mathrm{ft}^{2}$ with a $4.0 \%$ soll removal, resulting in an increase of only $45 \%$. Simllar results were obtained for methanol although the increases were lower in the latter case.

The effect of frequency on heat transfer rates in an ultrasonic field cannot be evaluated from the apparent electrical power input to the transducers. The arrangement of transducers at the bottom of the tank was not the same in each case and the efficlency of the transducer system had not been determined. On the basis of cavitation damage, or the percentage of soll removed, higher frequency results in only a slight decrease in heat transfer rates. For the two lower frequencies (20.6 and $44.1 \mathrm{kcps})$, the effect of frequency was negligtble. The increase in heat transfer rate for distilled water at $149^{\circ} \mathrm{F}$ and at $20.6 \mathrm{kcps}$ with $3.0 \%$ soll removal was approximately $100 \%$. At the same 11quid temperature and the temperature difference of $40^{\circ} \mathrm{F}$, the increase was approximately $70 \%$ at $108 \mathrm{kcps}$ with a $3.9 \%$ soll removal. Thus, for a fivefold increase in the frequency of the sound field, only a $30 \%$ decrease in heat transfer rates resulted for approximately the same value of percentage soll removal. It should be noted, however, that to achieve the 
same degree of cavitation damage, more acoustic energy was required at the higher frequency.

\section{High Speed Photography Study}

A Fastex High-Speed $16 \mathrm{~mm}$ camera (Model WF-3) was used in this study. The framing speed was 4000 frames/sec. The motion picture was taken through the glass window with illumination coming from the top.

In order to make a thorough study on the mechanisms of the heat transfer processes in a sound field, high speed motion pictures were taken at the four different conditions summarized in Table 2. For each set of experimental conditions, motion pictures were taken for both cases, 1.e. with and without vibration. Some representative frames from the motion picture are shown in Figures 16 to 19. A $5 \times$ enlargement of the image in the motion picture negative which is clage to the actual size was made in the printing process. The pictures shown in each figure are from successive frames from the motion picture.

The apparent electrical power input to the transducers was 36.2 watts, in all cases. The resulting sound pressure on the platinum wire therefore exceeded the critical sound pressure. It is to be noted that sound pressure was also much higher than the cavitation threshold of both test 11quids so that cavitation bubbles were formed in the bulk liquid as well. The results of the high speed photographic study for methanol will be given first. 
TABLE 2

Experimental Conditions Selected for High Speed Photography Study

Apparent electrical power input $=36.2$ watts

Frequency of vibration $=20.6 \mathrm{kcps}$

Filming speed $\quad=4000$ frames $/ \mathrm{sec}$

Platinum wire diameter $=0.007$ in.

Test Liquid Without

Liquid Temp. Vibration

$\stackrel{\Delta t}{{ }_{\mathrm{o}}} \quad \stackrel{\mathrm{q} / \mathrm{A}}{\mathrm{BTU} / \mathrm{hr}} \mathrm{ft}^{2}$

A Methanol 113

B Methanol 113

C Methano1

113

D Distilled

Water
Remarks

Natural Convection

Nucleate Boiling (Isolated Bubbles)

Nucleate Boiling

(Wel1-developed)

Nucleate Boiling

(Isolated Bubbles)
With

Vibration

$\Delta_{\mathrm{O}} \mathrm{t} \quad \mathrm{BTU} / \mathrm{hr} \mathrm{ft}^{2}$

22 18,700 (Fig. 16)

$42 \quad 37,700 \quad$ (Fig.17)

$81 \quad 167,000 \quad$ (Fig. 18)

$50 \quad 209,000 \quad$ (Fig. 19) 
FIGURE 16

CAVITATION BUBBLE MOTION ON A HEATED WIRE WIRE DIAMETER $=0.007 \mathrm{in}$.

FREQUENCY OF VIBRATION $=20.6 \mathrm{kcps}$, $\mathrm{W}_{\mathrm{A}}=36.2$ watts; METHANOL AT $113^{\circ} \mathrm{F}$ WITH $\Delta t=22^{\circ} \mathrm{F}$ AND HEAT FLUX $=18,700 \mathrm{BTU} / \mathrm{HR} \mathrm{FT}^{2}$ 


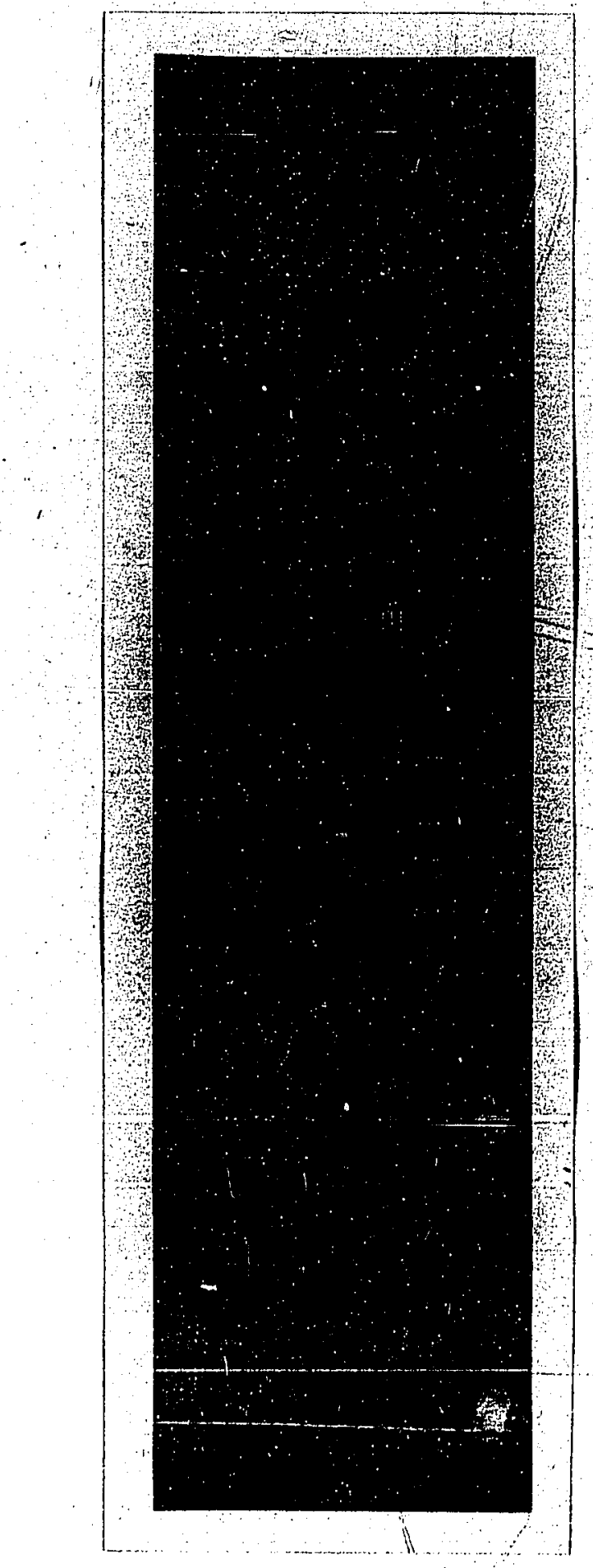

()

Al

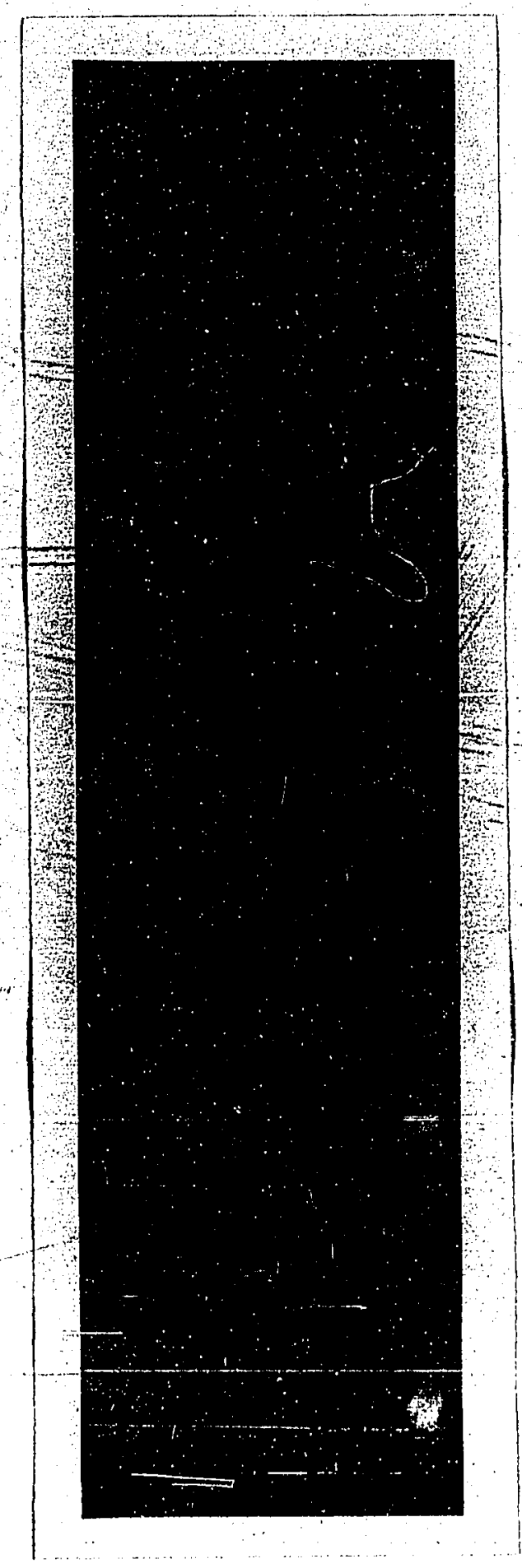

A2 

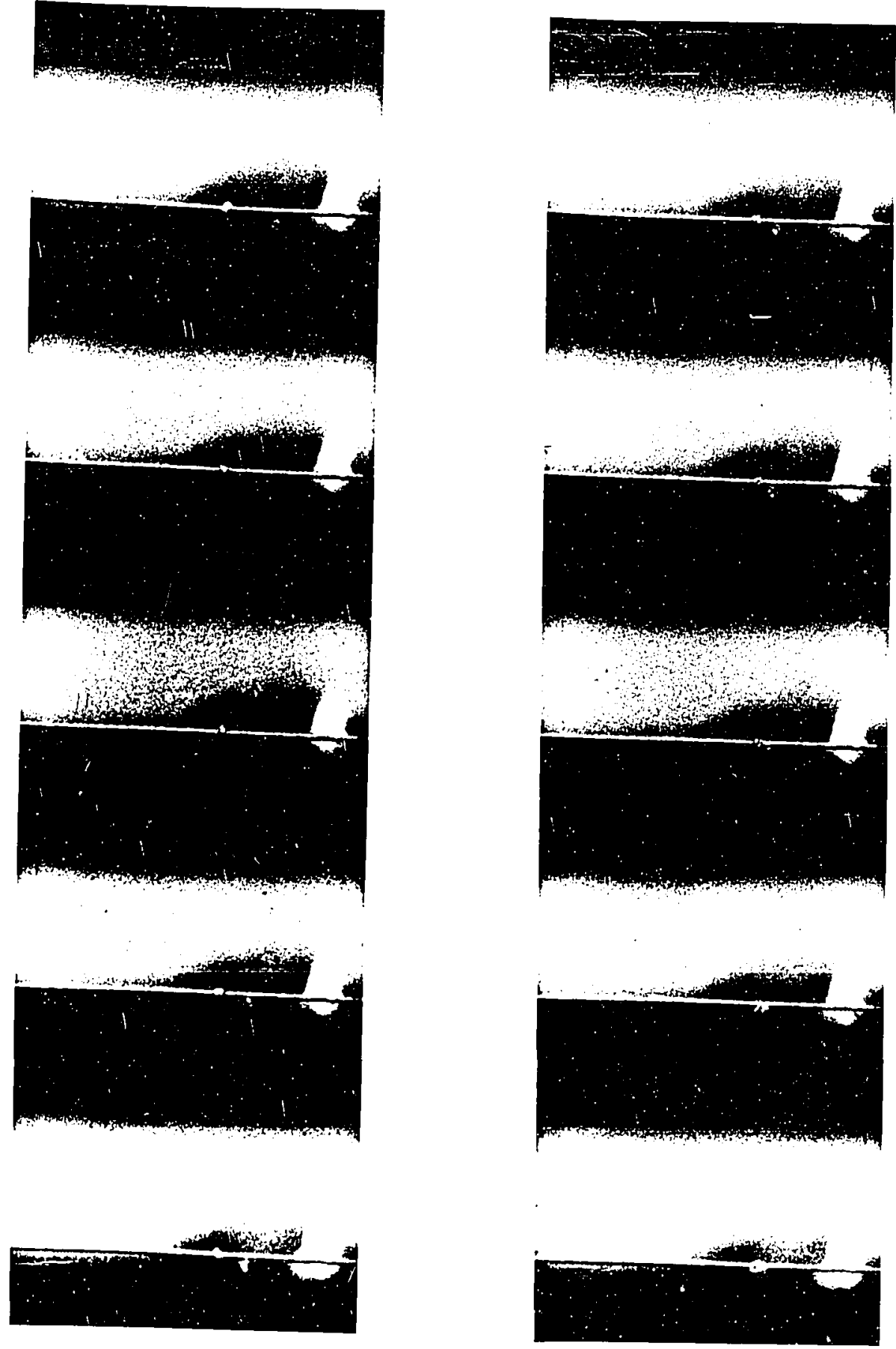
0
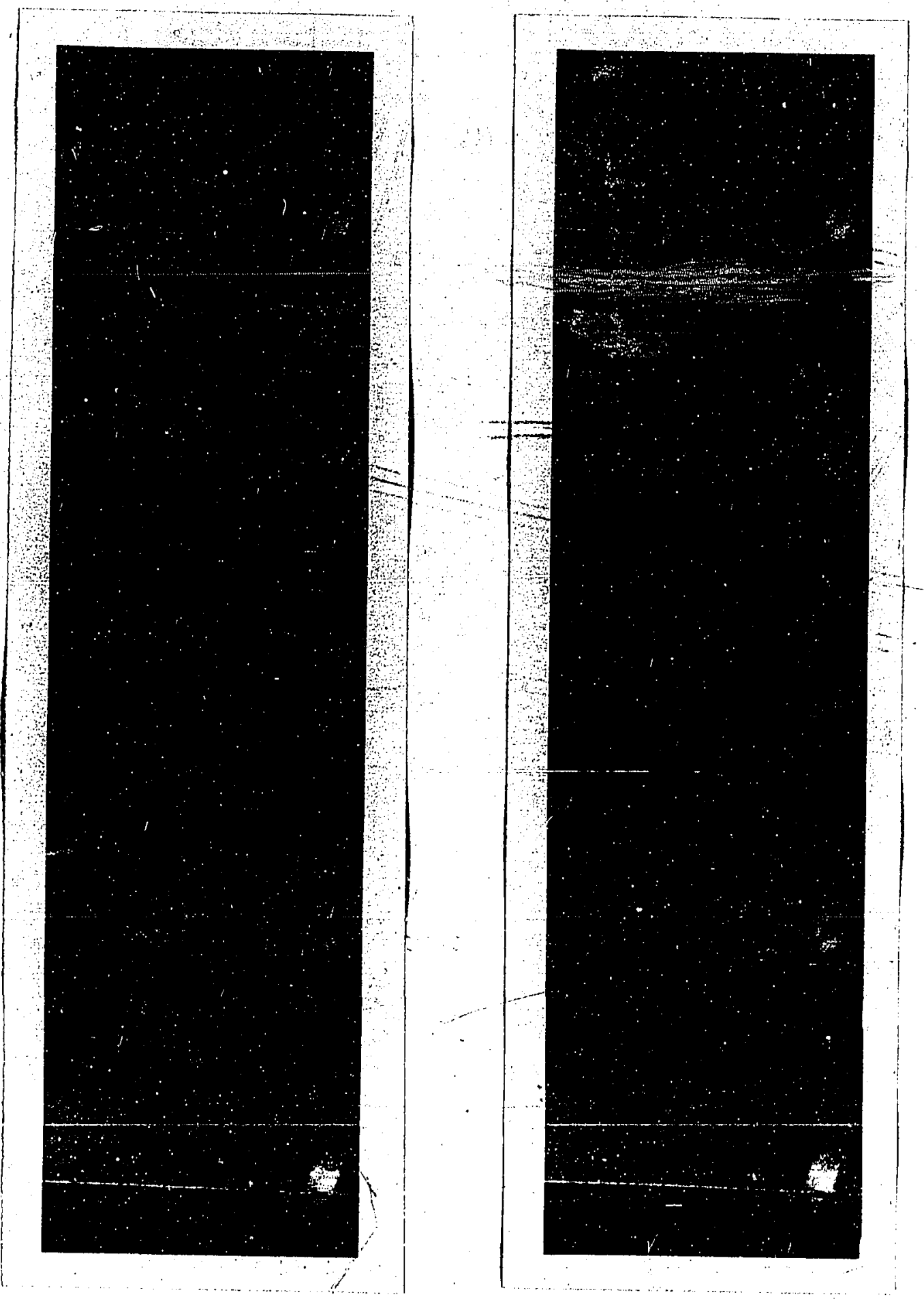

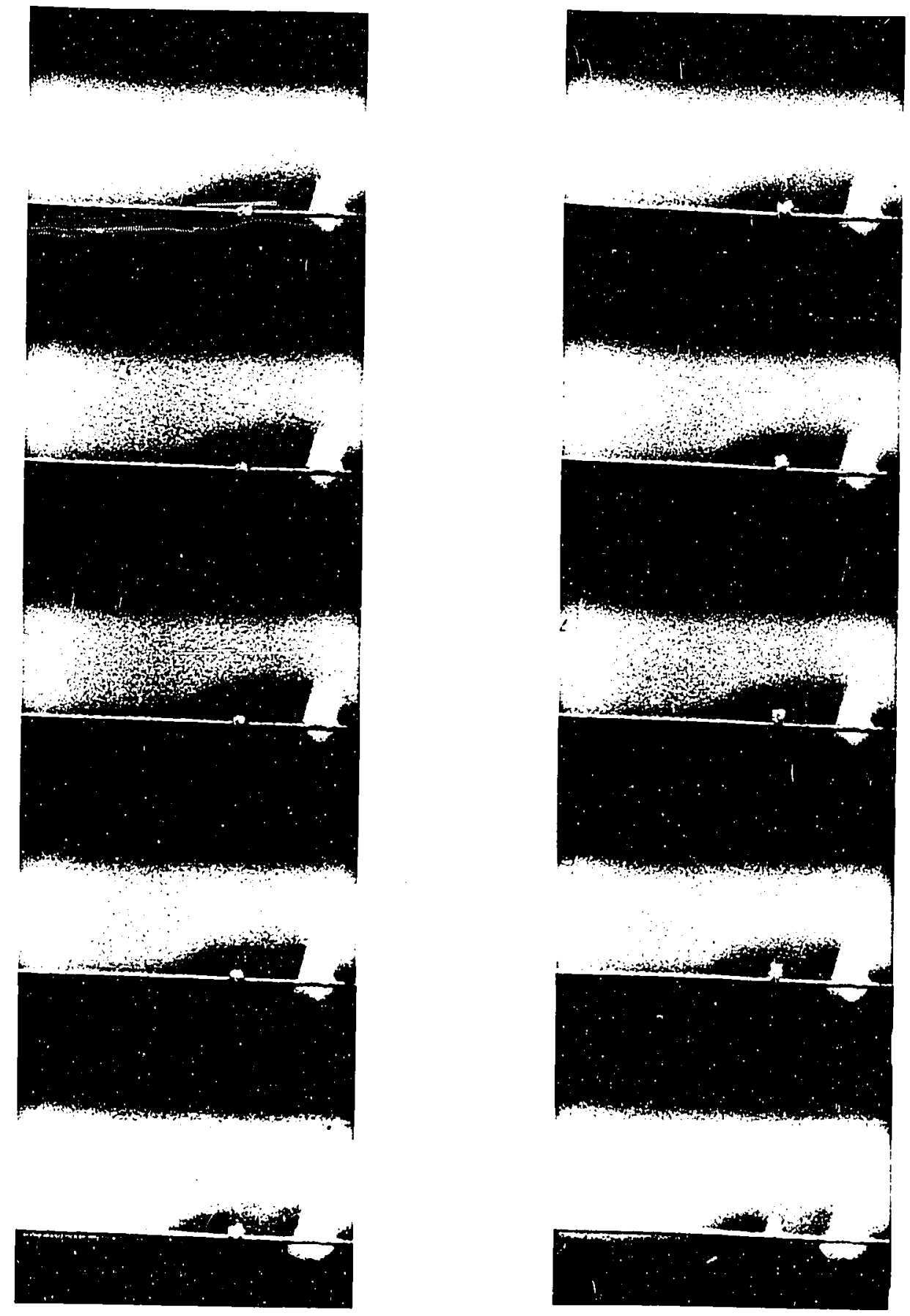
FIGURE 17

CAVITATION BUBBLE MOTION ON A HEATED WIRE

WIRE DIAMETER $=0.007 \mathrm{in}$.

FREQUENCY OF VIBRATION $=20.6 \mathrm{kcps}$,

$\mathrm{W}_{\mathrm{A}}=36.2$ WATTS. METHANOL AT $113^{\circ} \mathrm{F}$ WITH

$\Delta t=42^{\circ} \mathrm{F}$ AND HEAT FLUX $=37,700 \mathrm{BTU} / \mathrm{HR} \mathrm{FT}^{2}$ 


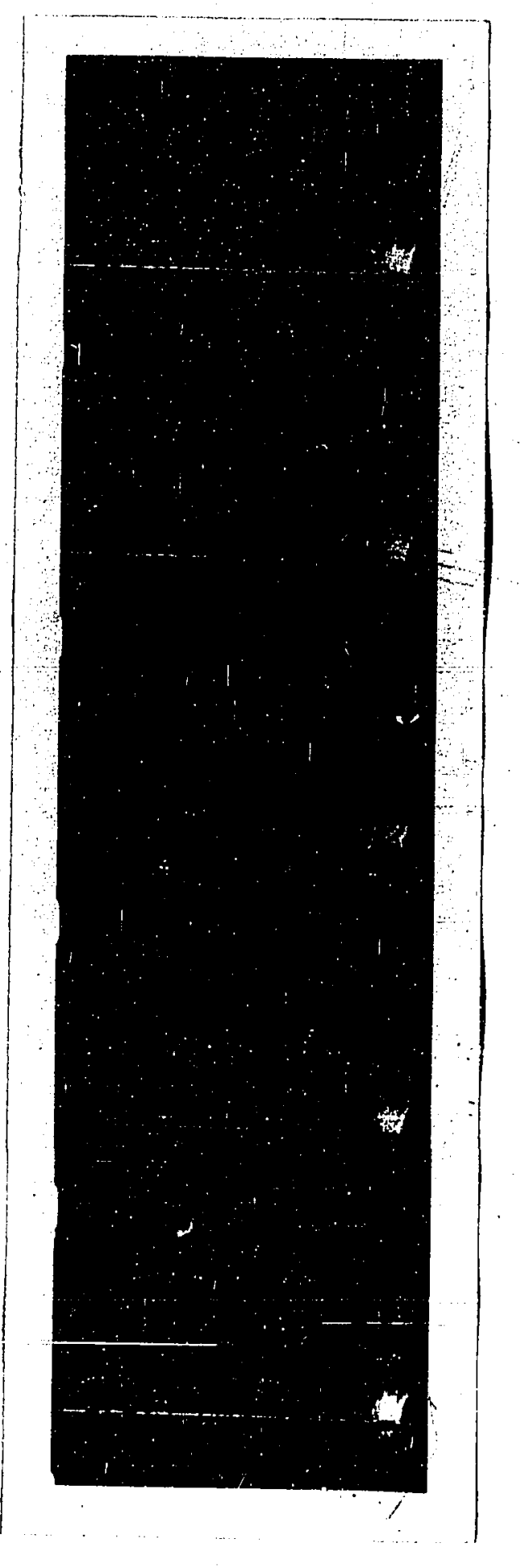

B1

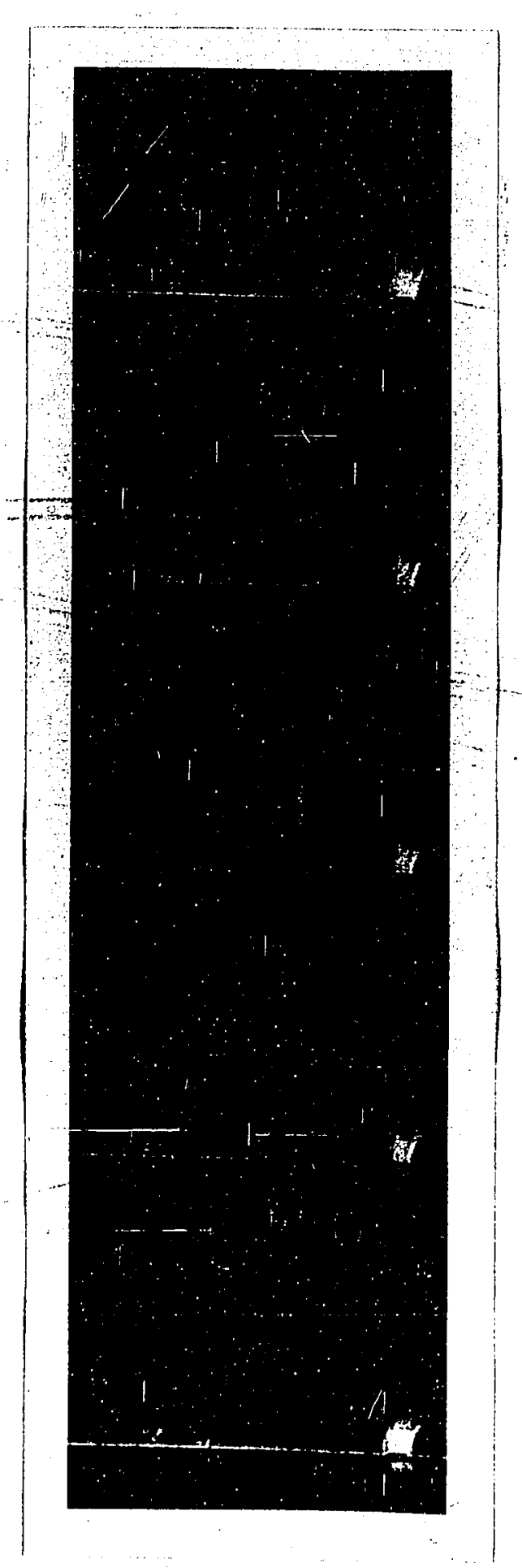

B2 


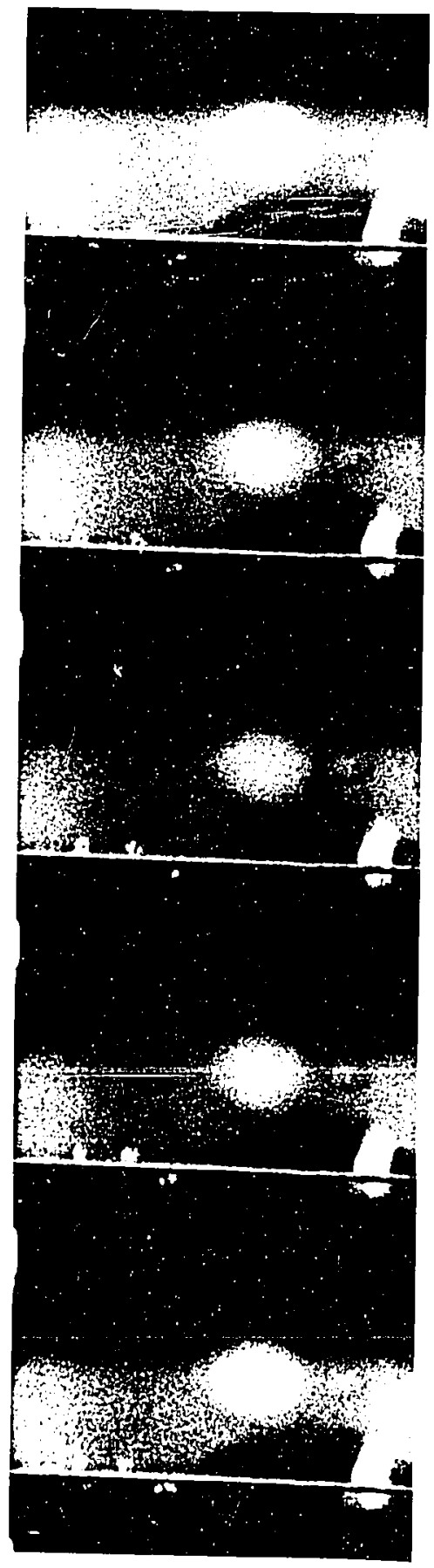

B1

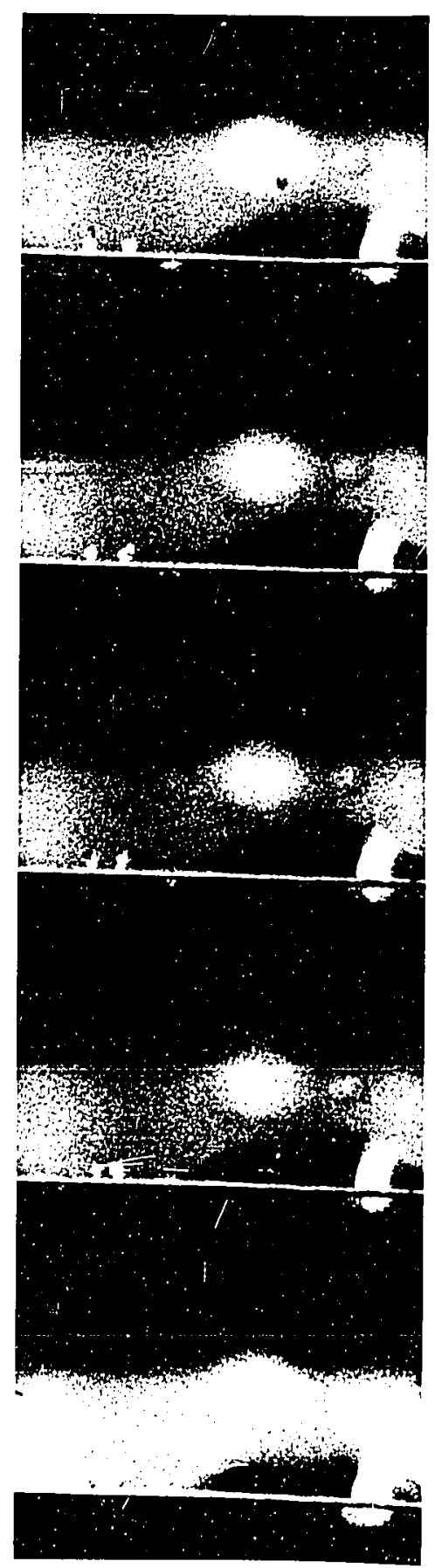


( )

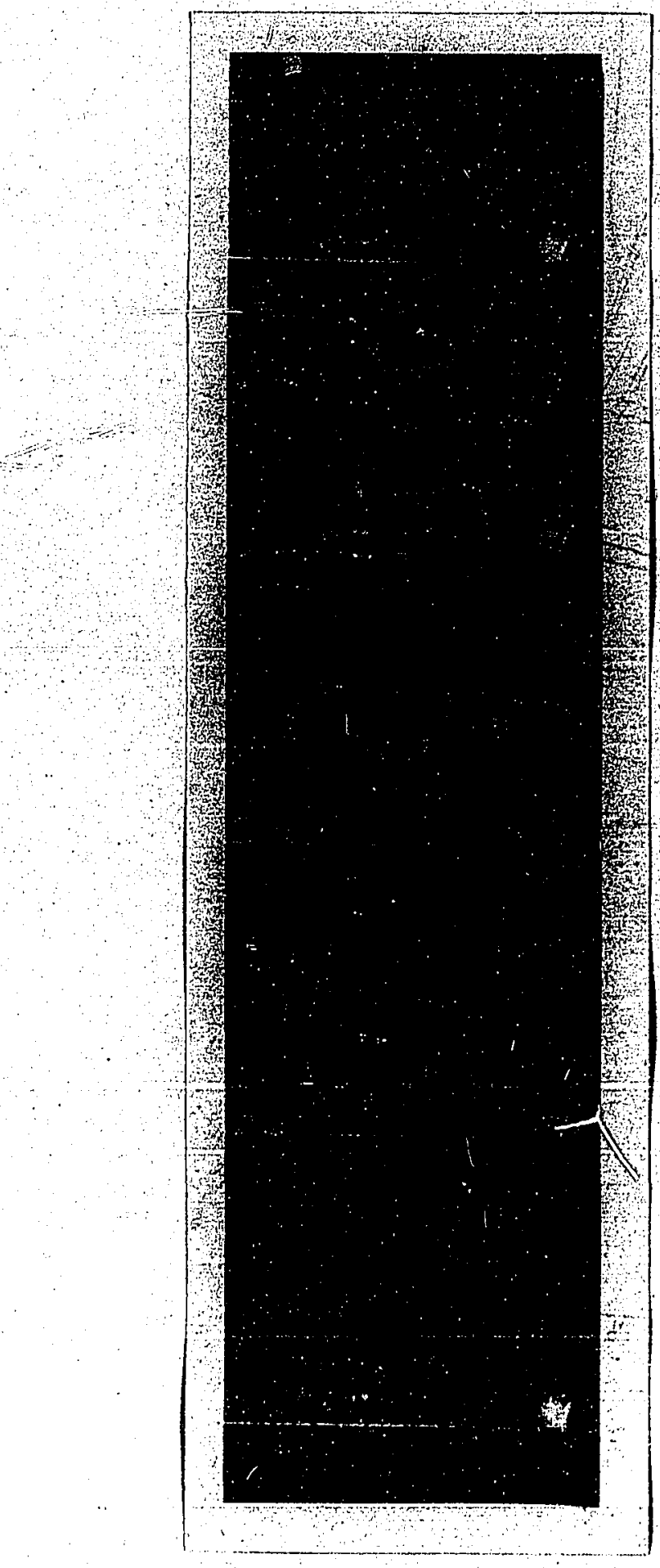

B3

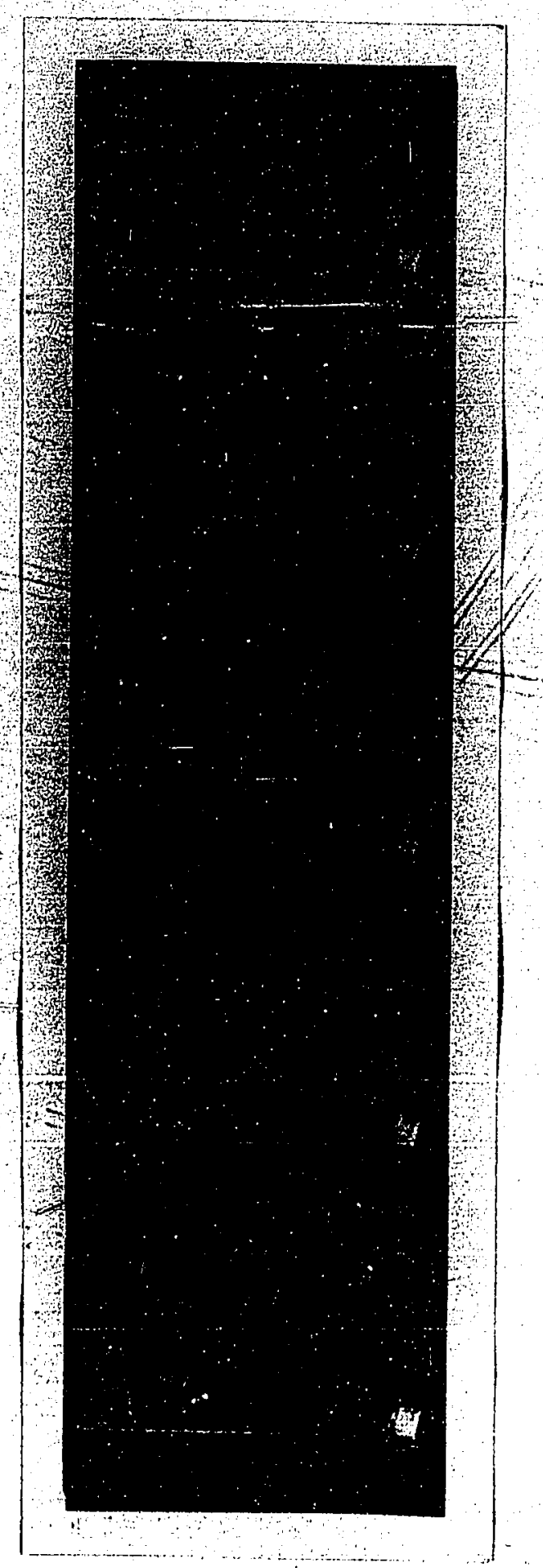

B4 


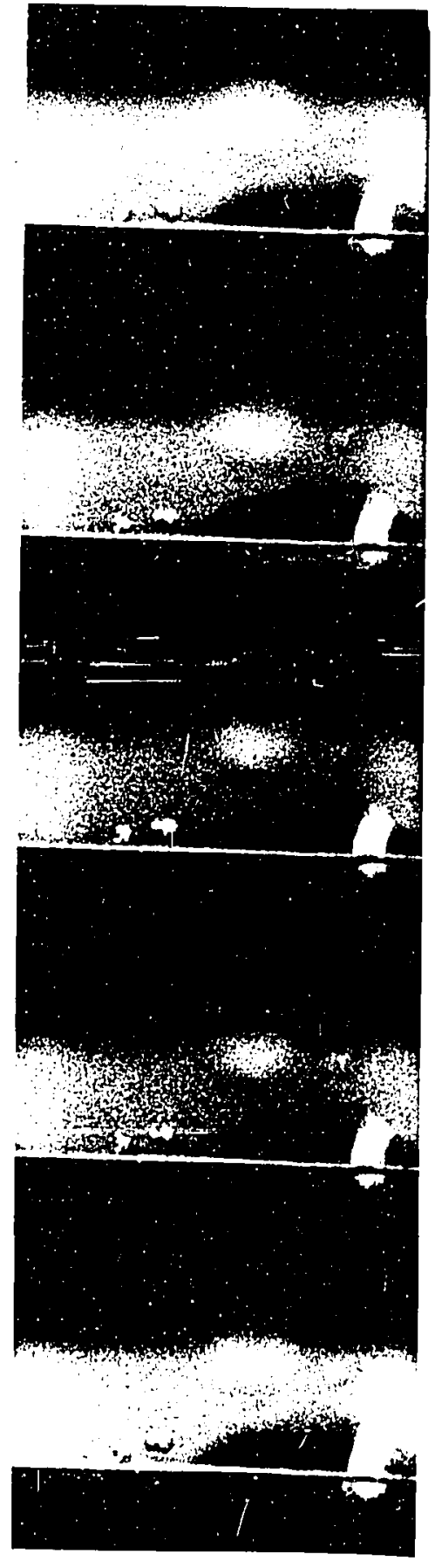

B3

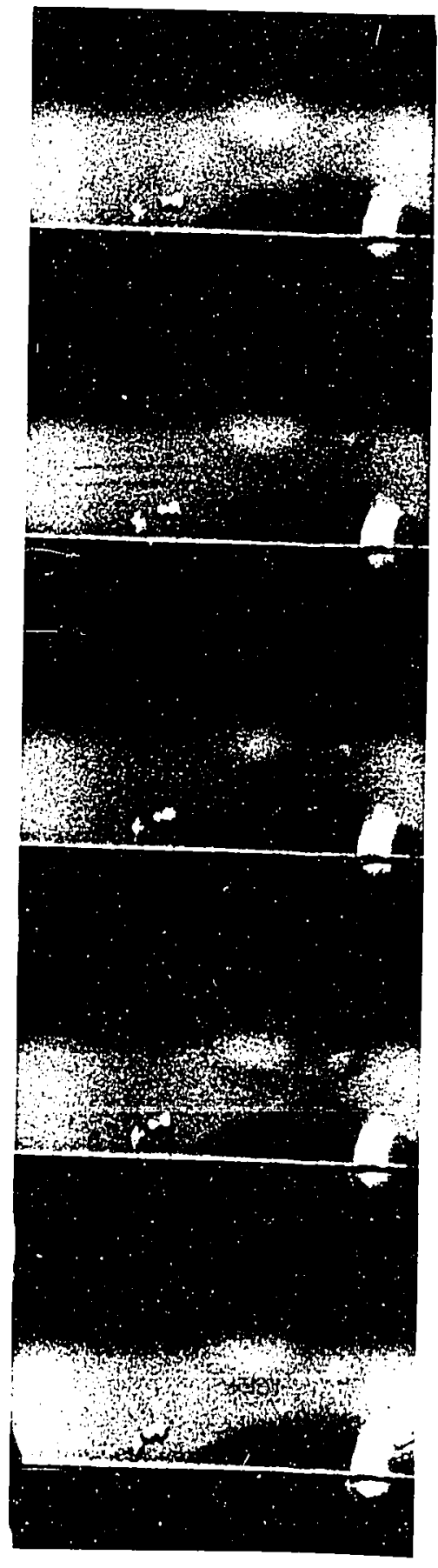


FIGURE 18

CAVITATION BUBBLE MOTION ON A HEATED WIRE

WIRE DIAMETER $=0.007 \mathrm{in}$.

FREQUENCY OF VIBRATION $=20.6 \mathrm{kcPs}$,

$\mathrm{W}_{\mathrm{A}}=36.2$ WATTS: METHANOL AT $113^{\circ} \mathrm{F}$ WITH

$\Delta \mathrm{t}=81^{\circ} \mathrm{F}$ AND HEAT FLUX $=167,000 \mathrm{BTU} / \mathrm{HR} \mathrm{FT}^{2}$ 


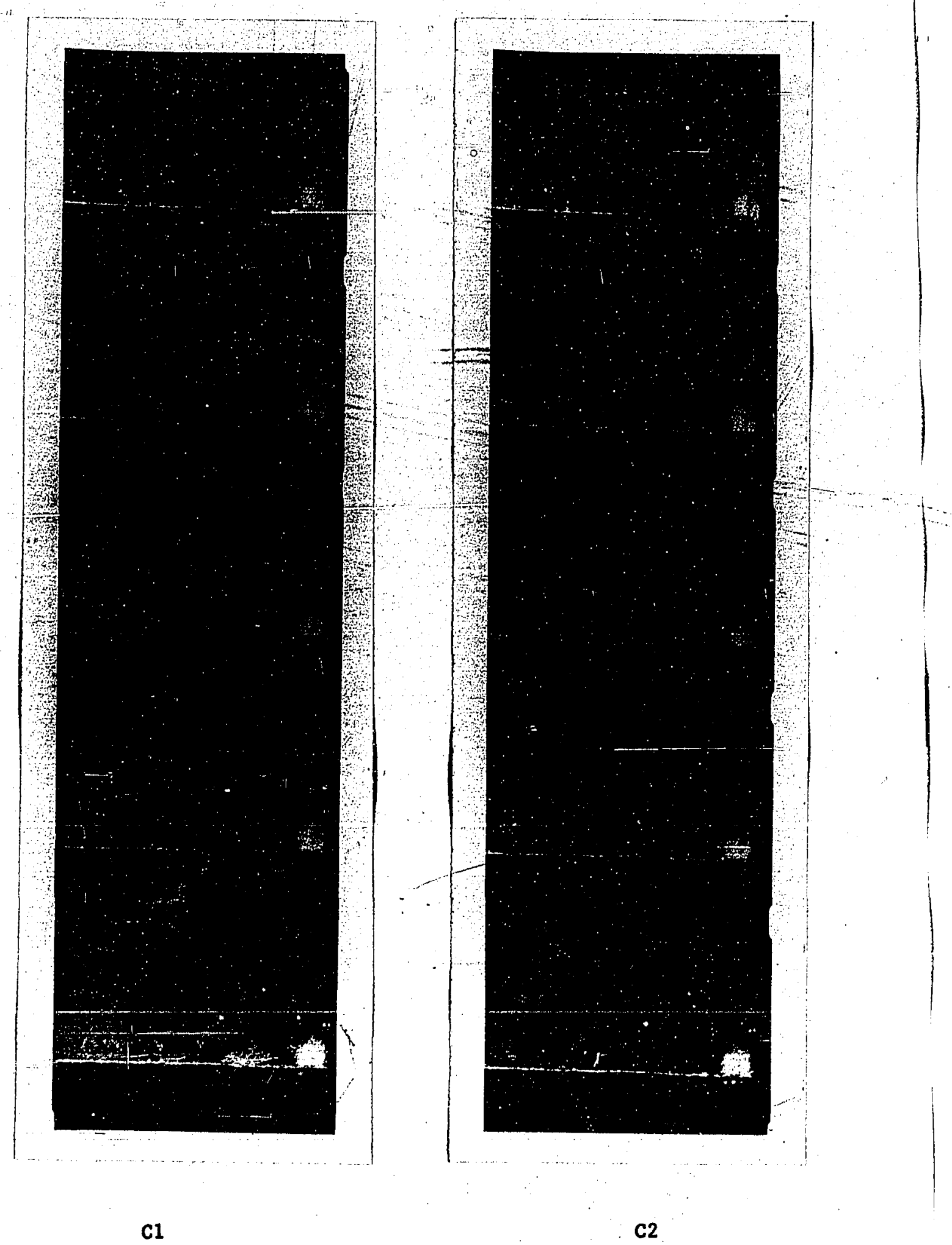




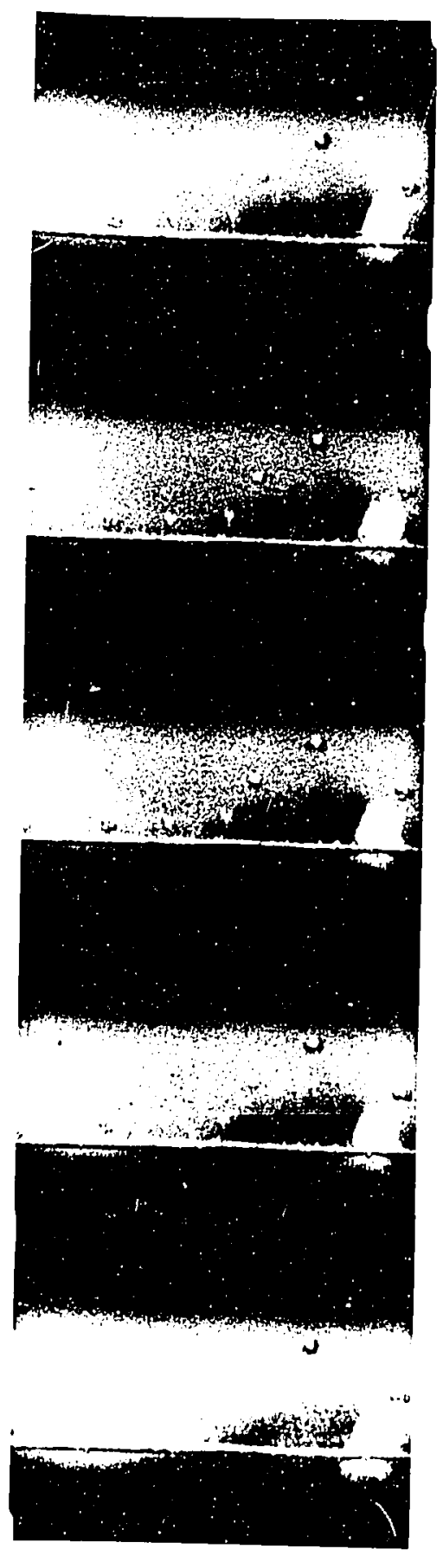

C1

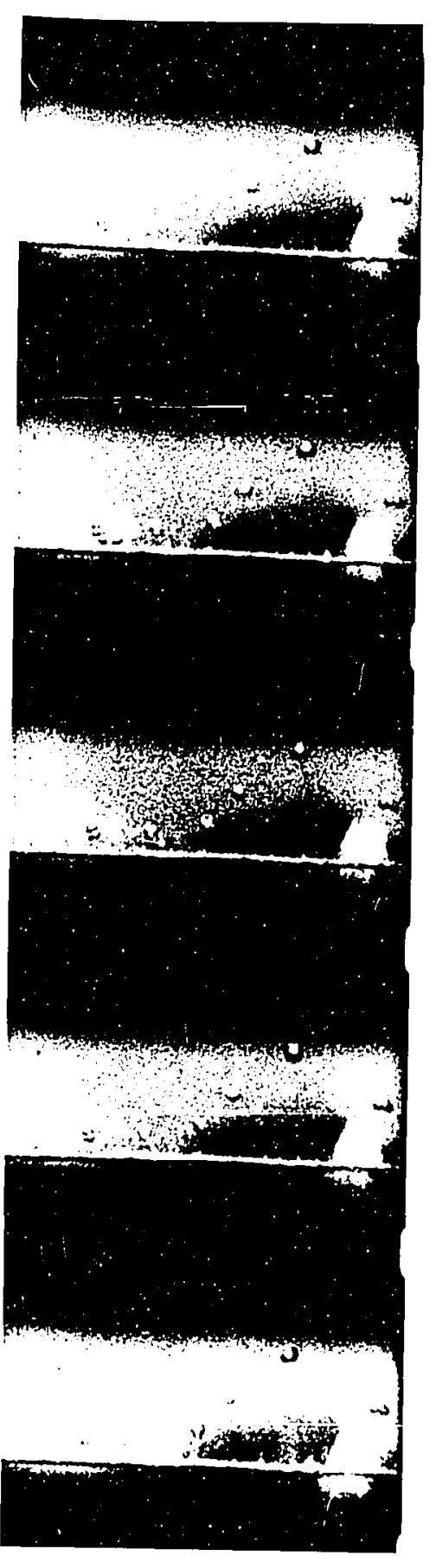

C2 


$$
\text { || }
$$



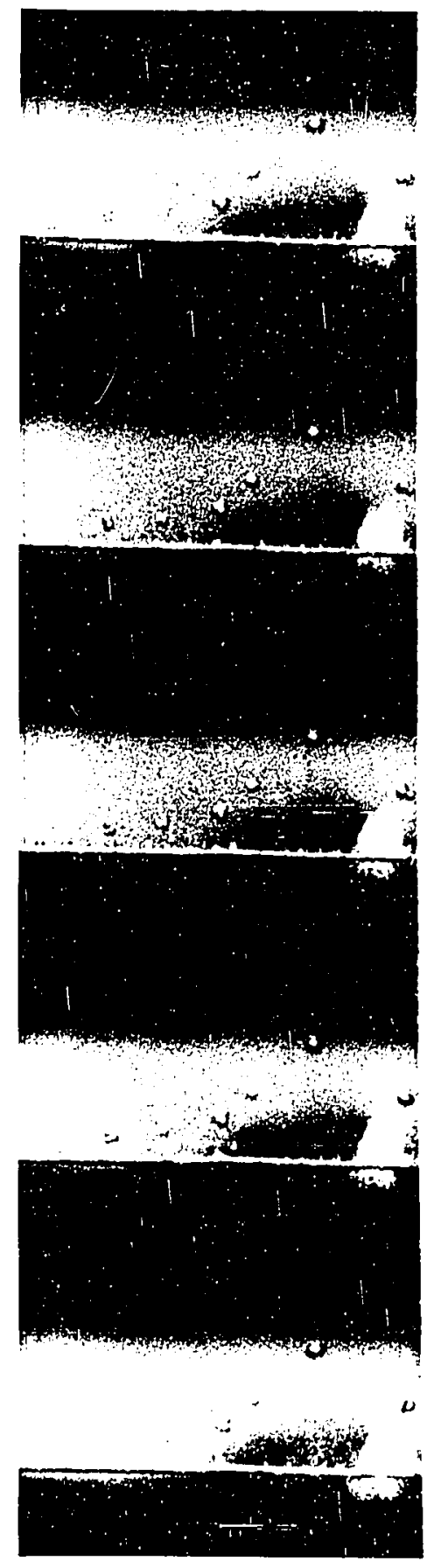

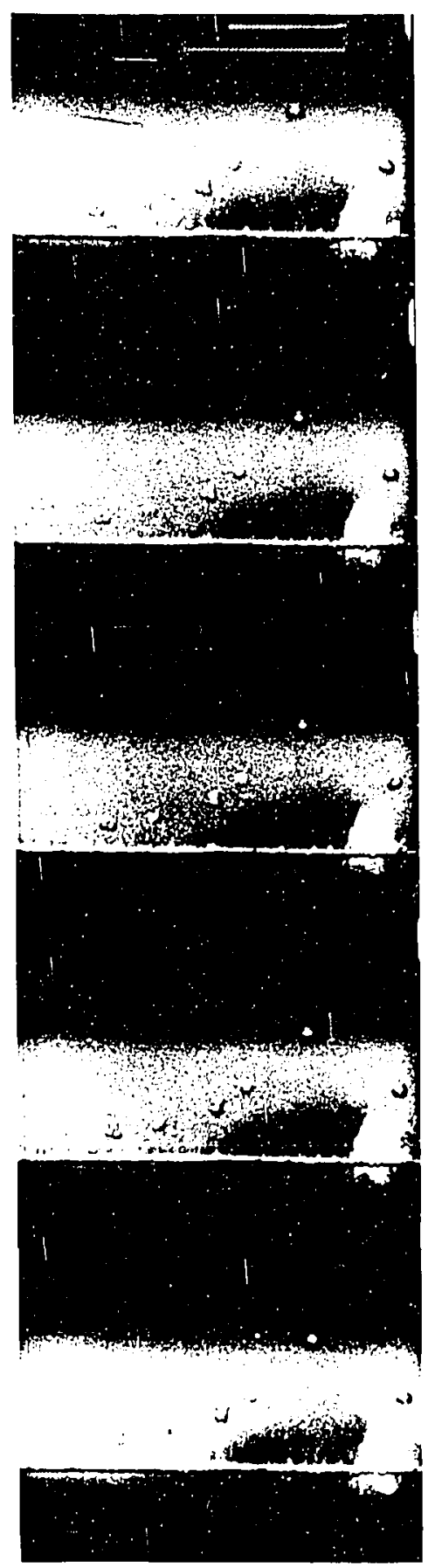

C4 
FIGURE 19

CAVITATION BUBBLE MOTION ON A HEATED WIRE WIRE DIAMETER $=0.007 \mathrm{in}$. FREQUENCY OF VIBRATION = $20.6 \mathrm{kcps}$; $\mathrm{W}_{\mathrm{A}}=36.2$ WATTS : DISTILLED WATER AT $149^{\circ} \mathrm{F}$ WITH $\Delta t=50^{\circ} \mathrm{F}$ AND HEAT FLUX $=20,900$ BTU/HR FT ${ }^{2}$ 


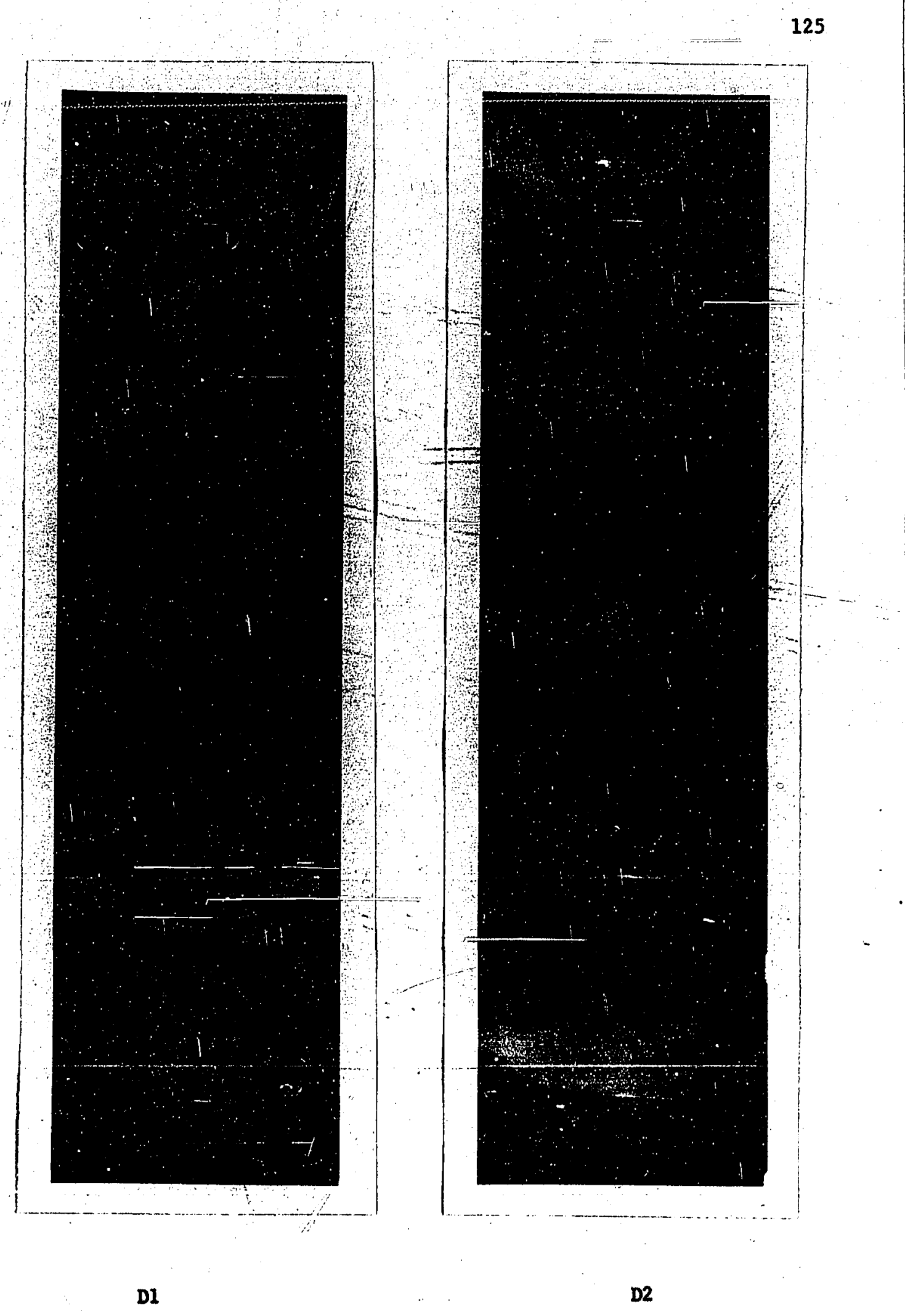



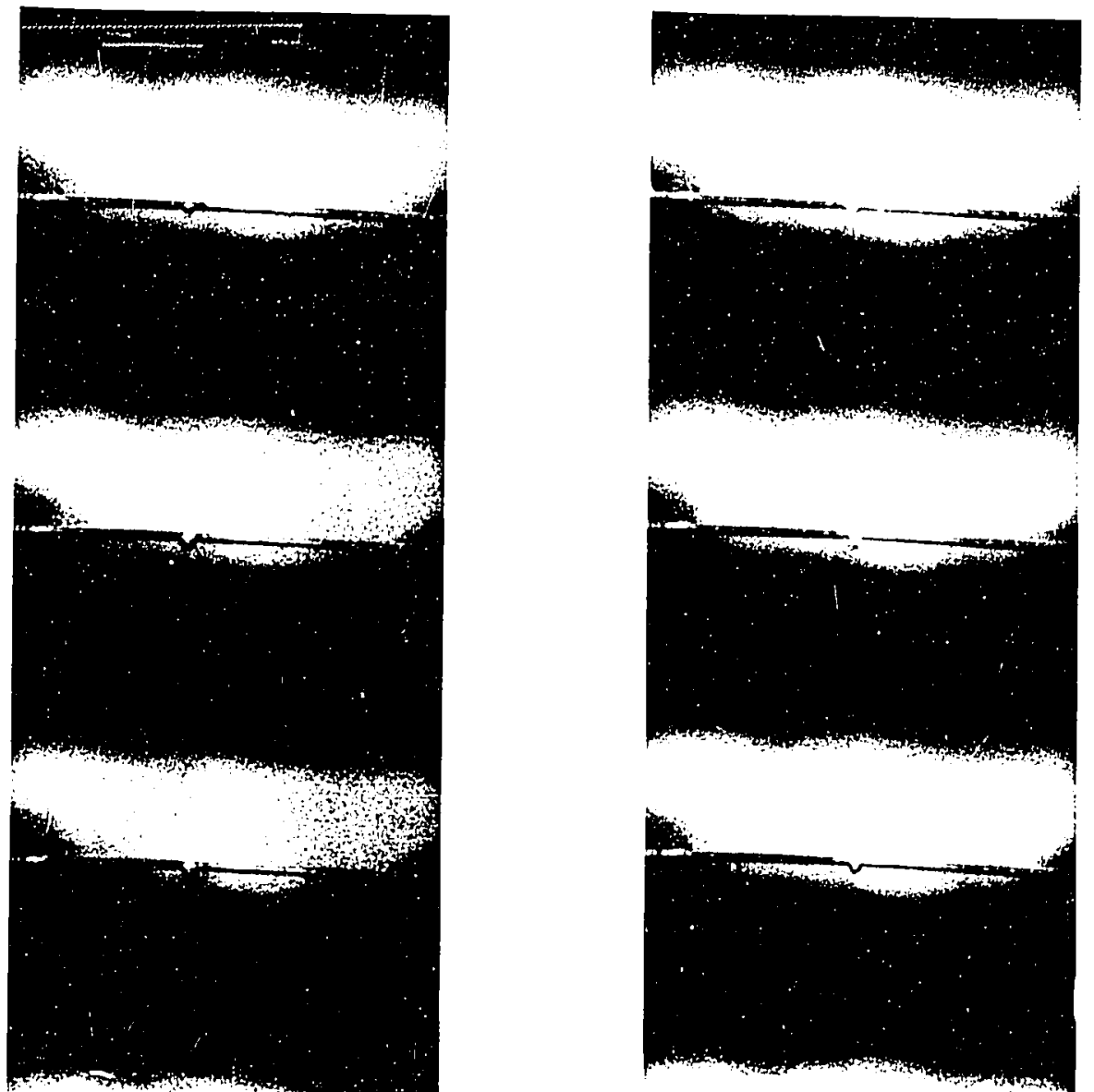

sis
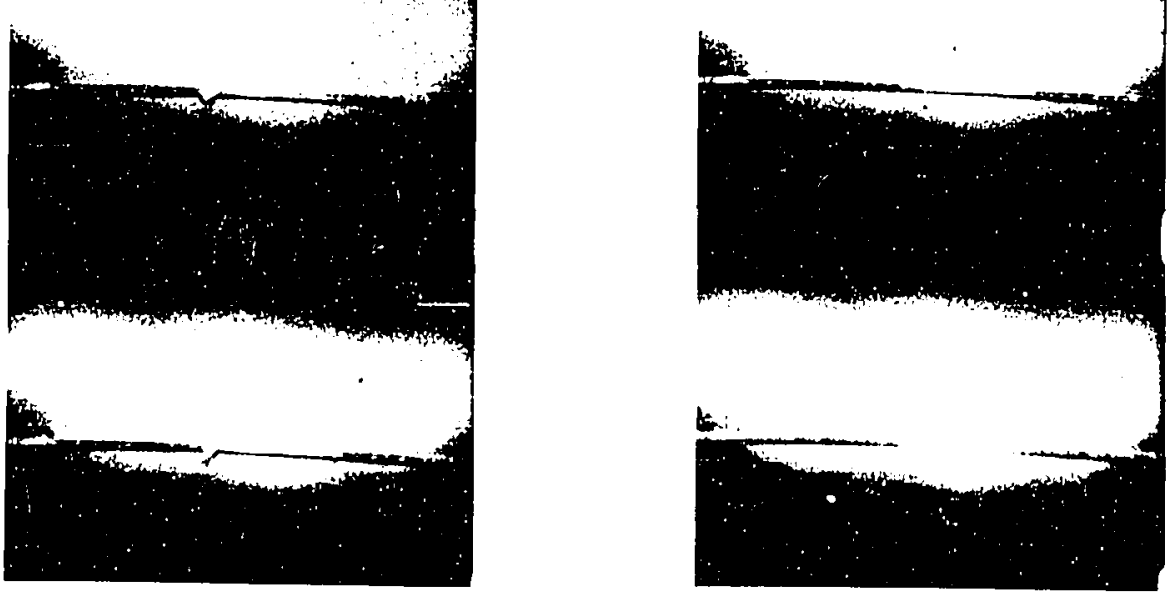


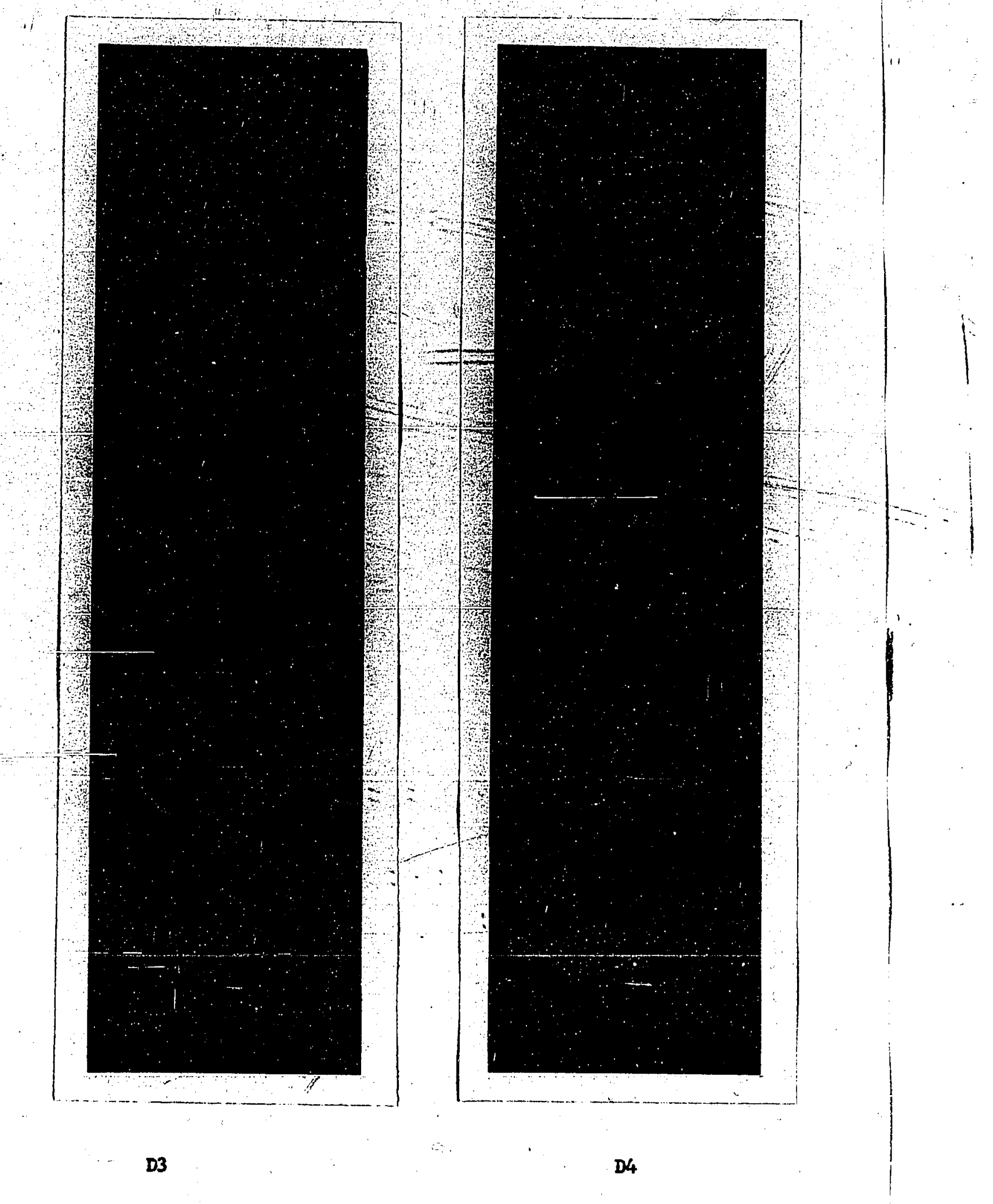



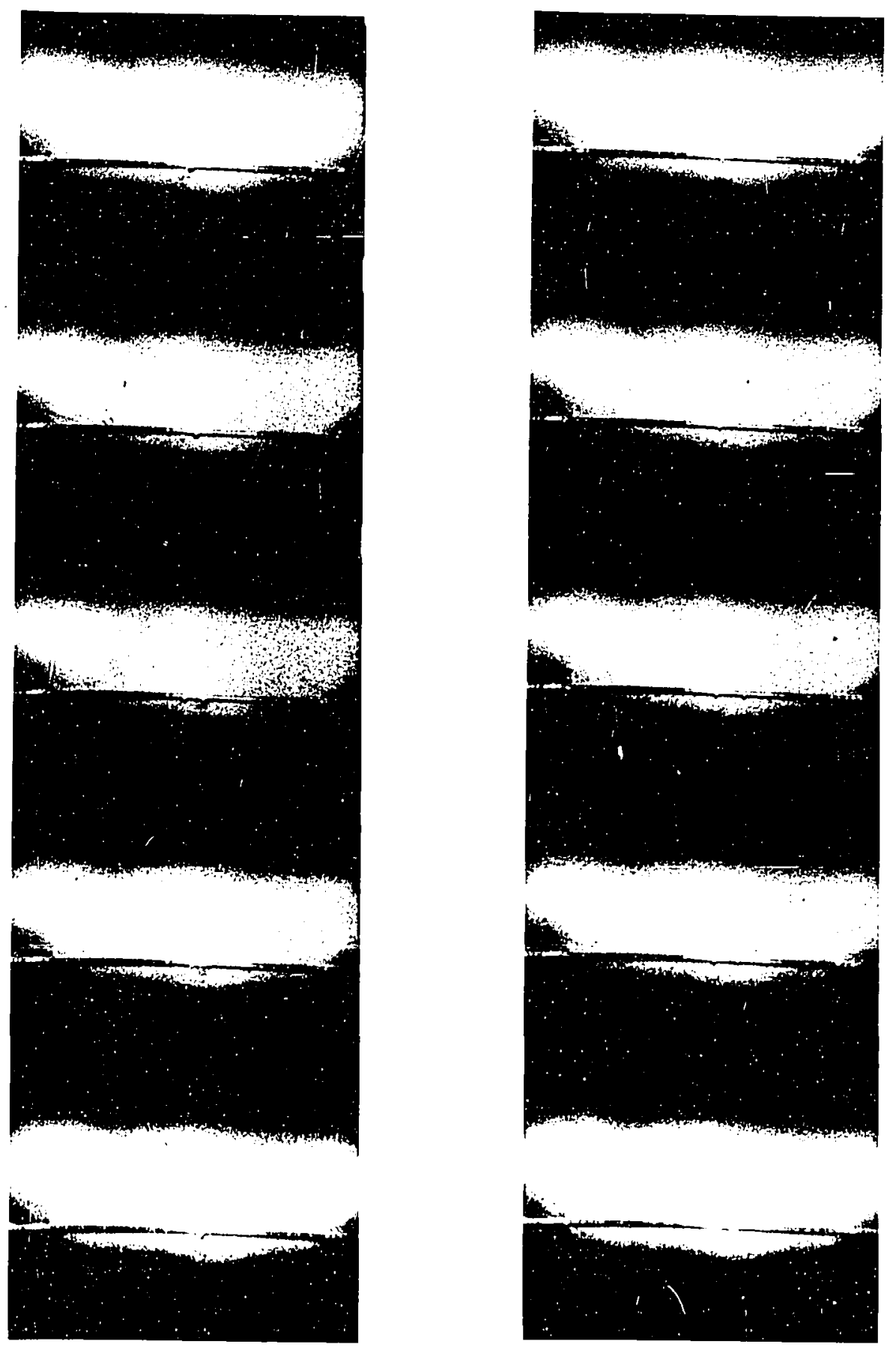
It appeared that there was no particular site from which cavitation bubbles would grow. Small cavitation bubbles usually appeared first on the lower portion of the wire, and as they grew larger, moved to the upper portion of the wire. Small cavitation bubbles usually grew to larger sizes and left the wire by one of the following mechanisms :

(1) They rolled along the wire, grew in size by agglomerating with other smaller cavitation bubbles, and eventually left the wire. This is illustrated in Figure 17. The two cavitation bubbles on the wire in B1 moved toward each other, agglomerated In the last frame of B2, and left the wire surface $3.8 \mathrm{msec}$ later, that is, five frames after the last frame in B4 where the 'big' cavitation bubble - a cluster of cavitation bubbles sticking together - further agglomerated with another cavitation bubble.

(2) While they were rolling along the wire and agglomerating with small cavitation bubbles, a cavitation bubble originated from the bulk IIquid migrated to the wire, agglomerated with the cavitation bubble on the wire, and the resulting 'big' cavitation bubble left the wire. This process is illustrated in Figure 16. The lower bubble in the first frame of $\mathrm{Al}$ was a cavitation bubble originating in the bulk 1iquid. It agglomerated with the cavitation bubble on the wire in the third frame of $\mathrm{A} 2$ and left the wire after $4 \mathrm{msec}$. The same process is also illustrated in Figure 17 where the cavitation bubble which appeared underneath the wire in the first frame of $B 1$ was originated from the bulk Iiquid. 
The motion of cavitation bubbles on the wire surface was rather erratic and rapid. The directions of rolling were not always the same. A cavitation bubble could start rolling in one direction on the wire and then in the opposite direction a moment later, or it could settle on a particular spot after rolling along the wire for a short distance. Consequently, it was impossible to establish any definite pattern of the bubble motion. Also, the cavitation bubble did not necessarily roll on the upper surface of the wire. This can be seen In Figure 16 -Al where the cavitation bubble was on the lower surface of the wire. It began to move around the wire and was on the upper surface in A4. As the temperature of the wire increased, the population of cavitation bubbles on the wire and their activities also increased. The bubbles were moving at a great speed and their motion was much more erratic. However, at wire temperatures corresponding to the well developed nucleate bolling region, as shown in Figure 18, the growth and collapse of vapor bubbles which was observed when there was no vibration were still occurxing on the wire surface. It appears that the formation of cavitation bubbles only took place above the wire which was partially covered with vapor bubbles.

Another point of interest is that there existed a high degree of radial oscillation in all cavitation bubbles as they rolled on the wire surface. This is shown by the frosted appearance and the non-spherical shape oi cevitetion bubbles in $\varepsilon .11$ photographs. It can be seen that 'big' cavitation bubbles were composed of clusters of small bubbles sticking together. The clusters of small cavitation bubbles 
would coalesce and become smooth and spherical only after they left the wire surface. This is illustrated in Figure 18. In the first frame of C1, a 'big' cavitation bubble, whose previous history was similar to the three cavitation bubbles which appeared near the wire in the same frame, can be seen above the wire surface and near the right end of the wire. They did not coalesce together unt1l after the third frame of C3, although partial coalescence did occur somewhere in the last frame of $\mathrm{Cl}$. Unlike vapor bubbles due to boiling, the smooth spherical bubbles so generated did not appear to collapse into the 11quid.

Since nopreferential site from which a cavitation bubble would grow could be observed, it would be impossible to determine the frequency of generation of the cavitation bubbles. A frame-to-frame analysis showed that, regardless of the wire temperature, the diameter of the cavitation bubbles when leaving the surface was quite constant. The diameters of eight cavitation bubbles which were measured after they had left the wire surface and coalesced to form smooth spheres were all within the range of 0.018 to $0.021 \mathrm{in}$. They were larger than the diameters of vapor bubbles due to boiling which varied from 0.01 to 0.02 in. The determination of the vapor bubble diameters, however, was much more difficult since most of the vapor bubbles collapsed on the wire surface. An effort was also made to determine the speed of the motion of cavitation bubbles in the natural convection region (Case $A$ ). It was found that the smaller the bubble, the higher the speed. When the diameter was approximately $0.02 \mathrm{in}$., the speed which was measured when the cavitation bubble was moving continuously in one direction only, 
varied from 0.8 to $1 \mathrm{ft} / \mathrm{sec}$.

Figure 17 also provides an opportunity of studying the characteristics of the young cavitation bubbles. The first one which was present throughout the twenty frames of Figure 17 was a small bubble which appeared on the lower surface and near the center of the wire. The second one seemed to appear first in the first frame of B3, growing from the lower surface of the wire about midway between the two 'big' cavitation bubbles. It became quite visible in the last frame of $B 3$. In both bubbles, the radial oscillation which was characteristic of the 'big' cavitation bubbles did not seem to exist. However, the lifetimes of these young bubbles were usually very short as they soon agglomerate with other bubbles rolling on the wire.

When distilled water at $149^{\circ} \mathrm{F}$ was used and there was no vibration, the vapor bubbles due to bolling were larger and they collapsed more rapidly. The average vapor bubble diameter assuming a hemispherical bubble was about $0.03 \mathrm{in}$. The 11 fetimes which varied from 0.25 to 0.5 msec were about half of that for vapor bubbles in methanol at $113^{\circ} \mathrm{F}$.

The cavitation bubble behaviour in water was radically different from that in methanol as the cavitation bubbles collapsed almost completely on the wire surface. It differed from the case without vibration in that small bubbles with diameters from 0.002 to 0.005 in. were always observed to remain on the wire surface after the collapse of a cavitation bubble, serving as nucleus from which a new cavitation bubble began to grow. It was observed that, before its collapse, the bubble was also travelling on the wire at a relatively high speed. The 
result was a local explosion in the superheated liquid layer around the wire. One could see in the high speed motion pictures the turbulence generated in the liquid as the result of such explosions. Occasionally, a cavitation bubble originating in the liquid migrated to the wire and coalesced with a bubble on the wire. The resulting bubble also collapsed. The average size of a cavitation bubble before its collapse was about 0.015 in., but some of them were as large as 0.03 in. The lifetime varled from 0.7 to $2 \mathrm{msec}$. The speed based on three bubbles varied from 2 to $3 \mathrm{ft} / \mathrm{sec}$.

Figure 19 illustrates some of the phenomena described above. The cavitation bubble which was in the first frame of DI grew in size and at the same time moved toward the center of the wire until in the third frame of D2 it collapsed. It can be seen, however, that it did not collapse completely. A small bubble was observed in the same location where the big cavitation bubble had collapsed and it migrated to the wire surface almost immediately to form a new nucleus from which another cavitation bubble grew. Consequently, the same process was observed to repeat itself, starting from the last frame of D2 to the last frame of $\mathrm{D} 3$. The lifetimes of these cavitation bubbles varied widely as demonstrated by the two cavitation bubbles just mentioned. The distance that the first cavitation bubble travelled between the first frame of D2 to the second frame of D3 was about $0.035 \mathrm{in}$. The speed was then calculated to be approximately $2 \mathrm{ft} / \mathrm{sec}$. The cavitation bubbles also exhibited radial oscillations although the amplitudes were not as high as the cavitation bubbles in methanol. 
The results of the high speed photographic study then show that the formation as well as the motion of the cavitation bubbles on the heated wire surface were random and erratic processes. Under the present experimental conditions, it was difficult to make any statistical study of the cavitation bubble behaviour from the high speed motion picture. The numerical values given for. the diameters and the speed of the cavitation bubbles in this section are approximate values and should be regarded as a qualitative indication of magnitudes involved. 


\section{DISCUSSION OF EXPERIMENTAL RESULTS}

\section{High Speed Photography Study}

The cavitation bubble behaviour observed in methanol was radically different from that observed in distilled water. Before discussing some of the details of the results, it will prove convenient to establish first whether the cavitation bubbles generated in each liquid are gaseous or vaporous cavitation bubbles.

Barger $^{(7)}$ studied the acoustic cavitation of water in a focussed standing wave system and described his observations of gaseous cavitation in the following manner:

"The single bubble that was formed at the center (the focal region) gradually increased in size with time. It had a very clear spherical surface. This bubble seemed to grow even when no new small bubbles were being added to it. After a period of time, which could be as long as one minute, this bubble suddenly developed a frosted appearance and began to dance around, executing an erratic and rapid motion about the center of the sphere. This behaviour was observed to begin when the bubble radius was about equal to the resonance size at the driving frequency ${ }^{*}$. After a few seconds of this behaviour, this bubble was rapidly ejected from the center radially outward. It slowed down and came to rest at the nearest pressure node. As it came to rest its surface became smooth and clear again."

These observations compare favourably with the results obtained here for methanol.

* See Eq. (1), page 134 
It was observed that the young bubbles on the wire did exhibit a clear spherical surface. The lifetimes of these young bubbles were very short as they agglomerated with other cavitation bubbles rolling on the wire surface or migrated from the bulk liquid. The 'big' cavitation bubbles also exhibited a frosted appearance and rolled on the wire in a random and erratic manner. After they left the wire surface, coalescence of the bubbles took place and their surface became spherical and smooth again.

$$
\text { According to Barger (7), the erratic behaviour of the }
$$
bubble was observed when the bubble radius was about equal to the resonance size at the driving frequency. The resonance radius $R_{0}$ of an air bubble in a liquid is given to the first approximation by ${ }^{(8)}$

$$
R_{0}=\frac{0.326 \mathrm{P}_{0}^{1 / 2}}{f \rho_{\mathrm{L}}^{1 / 2}}
$$

$$
\begin{aligned}
& \text { where } R_{0} \text { equilibrium radius of the bubble, } \mathrm{cm} \\
& P_{0} \text { ambient pressure, atm } \\
& P_{L} \text { density of the liquid, } \mathrm{g} / \mathrm{cm}^{3} \\
& f \text { driving frequency, kcps. }
\end{aligned}
$$

Equation (1) involves the assumption of $P_{0} \gg 2 \sigma / R_{0}$ which is valid as all experiments were performed under atmospheric conditions $(\sigma$ is the surface tension of the liquid).

The resonance diameter based on Equation (1) for methanol at a frequency of $20.6 \mathrm{kcps}$ was calculated to be 0.014 in. It was difficult under the present experimental conditions to determine the bubble size at which the erratic behaviour of the bubble was first observed. 
The bubble diameter after leaving the wire surface should be greater than the resonance size and was measured to be approximately $0.02 \mathrm{in}$. It appears that the cavitation bubbles in methanol are similar to gaseous cavitation bubbles. As they did not collapse in the liquid, the contents of these bubbles must be mainly gas.

The interpretation of the results of the high speed photographic study for methanol becomes straightforward if the cavitation bubble was taken to be a gaseous cavitation bubble. A cavitation bubble is formed from a small surface crack or scratch on the wire surface. It may also have originated in the liquid containing a nucleus such as dust particles near the wire and then migrated to the wire. The latter mechanism seems to be the more important one as most cavitation bubbles appeared to have originated from the lower surface of the wire. This is because the temperature of the liquid near the lower surface of the wire is lower than that above the wire. The result is a higher dissolved gas content in the liquid near the lower wire surface. The bubble is believed to grow by the rectified diffusion mechanism as suggested by Hsieh and Plesset ${ }^{(9)}$, that is, gas will diffuse out of the bubble in the compression period of the acoustic cycle and diffuse into the bubble in the tension period of the acoustic cycle; a net increase of gas in the bubble resulted because the surface area in the tension period is larger than the compression period in an acoustic cycle. Before it grows to the resonance size, it usually agglomerates with other cavitation bubbles. As the bubble approaches the resonance size the amplitude of oscillation will increase. This corresponds to the observation that 
The bubble diameter after leaving the wire surface should be greater than the resonance size and was measured to be approximately 0.02 in. It appears that the cavitation bubbles in methanol are similar to gaseous cavitation bubbles. As they did not collapse in the Iiquid, the contents of these bubbles must be mainly gas.

The interpretation of the results of the high speed photographic study for methanol becomes straightforward if the cavitation bubble was taken to be a gaseous cavitation bubble. A cavitation bubble is formed from a small surface crack or scratch on the wire surface. It may also have originated in the liquid containing a nucleus such as dust particles near the wire and then migrated to the wire. The latter mechanism seems to be the more important one as most cavitation bubbles appeared to have originated from the lower surface of the wire. This is because the temperature of the liquid near the lower surface of the wire is lower than that above the wire. The result is a higher dissolved gas content in the liquid near the lower wire surface. The bubble is believed to grow by the rectified diffusion mechanism as suggested by Hsieh and Plesset ${ }^{(9)}$, that is, gas will diffuse out of the bubble in the compression period of the acoustic cycle and diffuse into the bubble in the tension period of the acoustic cycle; a net increase of gas in the bubble resulted because the surface area in the tension period is larger than the compression period in an acoustic cycle. Before it grows to the resonance size, it usually agglomerates with other cavitation bubbles. As the bubble approaches the resonance size the amplitude of oscillation will increase. This corresponds to the observation that 
the bubble surface developed a frosted appearance. The bubble becomes very unstable and starts its erratic and rapid motion on the wire surface. This is further complicated by the local temperature fluctuations as well as the uneven pressure distribution on the wire. Further agglomerations occurred and eventually the bubble leaves the surface. The bubble has now grown to be much larger than its resonance size, the amplitude of its oscillation is smaller, and the bubble becomes spherical and smooth again.

Attempts have been made to establish a pattern of the motion of the cavitation bubbles on the wire and were unsuccessful as the motion was rapid and erratic. The motion did not appear to be related to the sound pressure distribution on the wire although the latter might have affected them.

The cavitation bubbles generated in distilled water collapsed on the wire surface and their lifetimes were much shorter. The collapse of these bubbles indicated that their contents were mainly vapor. Barger ${ }^{(7)}$ also studied vaporous cavitation in water at $27 \mathrm{kcps}$ and described his visual observations of the vaporous cavitation bubble as a small comet whose total length was as long as 1.2 in. with a maximum diameter of 0.4 in. near the tall. Similar descriptions were given by Lieberman ${ }^{(10)}$ for a vaporous cavitation bubble at a frequency of 26.3 kcps. The dimensions of the vaporous cavitation bubbles were observed to be approximately inversely proportional to the square of the driving frequency. The diameters of the cavitation bubbles observed in this work were about $0.010 \mathrm{in}$. and the length which was calculated from 
the product of its lifetime and the speed was about $0.05 \mathrm{in.,}$ both of which are more than an order of magnitude smaller. The sound pressure levels employed in this work, although not measured directly, were much lower than the vaporous cavitation threshold reported by other investigators. It is then postulated that a new type of cavitation bubble is generated when it is formed on a heated surface in an acoustic pressure field. It has the characteristics of a gaseous cavitation bubble as was demonstrated by the behaviour of the cavitation bubble in methanol. The content of this new type of cavitation bubble which may be called the gaseous-vaporous cavitation bubble depends on the dissolved gas content as well as the vapor pressure of the 1iquid. Since both of these properties are temperature dependent, the bubble content becomes dependent on the temperature of the wire. When methanol was used as in cases $A$ and $B$, because of its high solubility of gas, the bubble content was mainly gas when the wire temperature was relatively low. Consequently, the bubble behaviour was similar to that of a gaseous cavitation bubble. With increasing wire temperature resulting in an increase in the vapor pressure of the liquid at the wire as in case $C$, it is unlikely that the bubble content continues to be mainly gas. It was observed that the cavitation bubbles did not collapse after they left the wire. The vapor in the bubbles might hav . been dissolved into the liquid before they left the wire so that the content of the observed bubbles was still mainly gas. On the other hand, when there was no vibration, methanol vapor bubbles were observed to leave the wire surface without collapsing at relatively high heat flux values. 
With distilled water and using relatively low wire temperatures as in case $D$, cavitation bubbles with diameter of about 0.015 in. were observed to have collapsed to less than one tenth of their original volumes. The content of the non-collapsible bubble must be gas. Tine high vapor content of the bubble can be ascribed to the low gas solubility of water which is about one fourth of that for methanol. With increasing wire temperature, a lower value in the gas content of the cavitation bubble would be expected. It is interesting to note that the resonance diameter of 0.013 in. calculated from Equation (1) compares favourably with the observed bubble diameter of 0.015 in. The results of the high speed photographic study of distilled water can then be interpreted as follows. A new cavitation bubble is formed from a crack containing trapped gas on the wire as in the case of methanol. The bubble grows to the resonance size, becomes unstable, and begins its erratic motion on the wire. When it reaches a certain critical size depending on the temperature of the liquid surrounding the bubble, the bubble collapses. The non-condensable gas in the bubble becomes a small bubble on the surface from which a new cavitation bubble will grow.

The purpose of the high speed photographic study was to establish the mechanisms of the heat transfer processes studied in the present work. At wire temperatures corresponding to the 1solated bubble region and below, the increase in heat transfer rates, and thus the heat transfer coefficients, was due to the erratic and rapid motion of the gaseous-vaporous cavitation bubbles which created intense turbulence in the superheated 1iquid layer on the heat transfer surface. The erratic 
and rapid motion of the bubbles was the result of the interaction of the bubbles with the acoustic pressure field, complicated further by the local temperature fluctuations of the liquid around the bubbles. The activity of the cavitation bubbles is a function of the applied sound pressure amplitude as well as the temperature of the heat transfer surface. The activity also depended on the gas solubility of the liquid which determines the content of the cavitation bubbles. As the heat transfer surface temperature increases, the population and the activity of the cavitation bubbles, as well as the vapor content of the cavitation bubbles, also increase. At surface temperatures corresponding to the well-developed nucleate boiling region where intense turbulence is already created by the growth and subsequent detachment (collapse) of the vapor bubbles, the effects of the motion of cavitation bubbles became negligible. This was observed experimentally using methanol at $95^{\circ} \mathrm{F}$ and $113^{\circ} \mathrm{F}$. In fact, the results of the high speed photographic study showed that under these conditions, the formation of cavitation bubbles appeared to be occurring only above the wire surface which was partially covered by vapor bubbles.

$$
\text { Isakoff(11) and Romie and Aronson }{ }^{(12)} \text { as well as Ornatskif }
$$

and Shcherbakov ${ }^{(13)}$ suggested that the effects of ultrasonic vibrations on boiling heat transfer were to increase the frequency of bubble formation and the number of active nuclei on the heat transfer surface. High speed photographic study indicated that with the application of ultrasonic vibrations, the controlling mechanism of the heat transfer process was the rapid and erratic motion and the subsequent collapse of the 
cavitation bubbles on the heat transfer surface. It was difficult to determine the active sites for the cavitation bubbles and their frequency of generation because of the agglomeration resulting from the motion of cavitation bubbles on the heat transfer surface.

\section{Critical Sound Pressure}

The critical sound pressure, as mentioned earlier, was defined as the sound pressure at which the applied sound pressure field begins to have an effect on heat transfer rates. Experimentally, it is the sound pressure at which the first drop of potential across the test section of the platinum wire was observed, indicating a drop in the wire temperature for the same heat flux density. At wire temperatures corresponding to the isolated bubble region of nucleate boiling or lower, the first appearance of a cavitation bubble on the wire was observed when the sudden drop of potential across the test section of the wire was recorded. The critical sound pressure is, in fact, the Itation threshold of the liquid at the wire. At higher wire temperatures, visual observation of the first occurrence of cavitation bubbles became difficult due to the increased vapor bubble activity on the wire. In the well-developed nucleate boiling region where the effect of ultrasonic vibrations was negligible, the determination of critical sound pressure from visual observations of the occurrence of a cavitation bubble was impossible. Subsequently, the criterion based on the potential drop across the wire test section was adopted.

The critical sound pressure, as shown in Figures 2 to 5 , 
was a function of the wire temperature, the temperature of the liquid and the frequency of the sound field. For both methanol and distilled water, at wire temperatures corresponding to the natural convection region, an increase in wire temperature resulted in a lower value of critical sound pressure. Although the cavitation threshold of the liquid at the wire surface depends on the gas content and the vapor pressure of the 1iquid, the latter appears to be the controlling variable as decreased gas content resulting from increasing temperature would increase the critical sound pressure instead of decreasing it as observed. The temperatures at which minimum values of critical sound pressure were observed were close to the values for the incipience of bolling. Consequently, little acoustic energy was necessary to induce the formation of cavitation bubbles. At temperatures above the point of incipient boiling, because of the increased vapor bubble activity, more acoustic energy was required to cause an increase in heat transfer rates. Since the vapor bubble density on the wire without vibration was very sensitive to the wire temperature in the nucleate boiling region, a rapid increase in critical sound pressure resulted. The plots of critical sound pressure versus wire temperature became asymptotic to the critical sound pressure. In the well-developed nucleate boiling region where the effect of ultrasonic vibrations on heat transfer rates was negligible.

The effect of liquid temperature on critical sound pressure is shown In Figures 2 and 3 for distilled water and methano1, respectively. At the same wire temperature, the critical sound pressures 
decreased with increased liquid temperature. This can be ascribed, again, to the higher value of vapor pressure of the liquid at a higher temperature. The minimum critical sound pressure, however, was constant for all liquid temperatures as it was observed to occur at the temperature of incipient boiling. The discrepancy in the values of minimum critical sound pressure was within the experimental error of $\pm 12 \%$. At wire temperatures above the incipience of boiling, the curves for two liquid temperatures crossed over in both Figures 2 and 3. The critical sound pressure for the liquid at lower temperature was lower because the vapor bubble activity at the same wire temperature when there was no vibration was lower. This was opposite to the results for wire temperatures below the point of incipient bolling and subsequently a reversing trend was obtained.

The critical sound pressure increased with frequency as expected, since it has been established by Esche ${ }^{(14)}$ and Barger (7) that the cavitation threshold of a liquid increases directly with frequency. Quantitative comparison of their results with those obtained in this work cannot be made as the temperature and the state of I1quid were different.

A comparison of the sound pressure data in Tables 1 to 4 in Part $I$ and the critical sound pressure data in Figures 2 to 5 shows that depending on the wire temperature, the critical sound pressure could be higher than the value of sound pressure at which a cavitation bubble would be generated in the bulk liquid. For example, the critical sound pressure for methanol at $113^{\circ} \mathrm{F}$, as shown in Figure 3 , varied from 
0.17 to $0.06 \mathrm{~atm}$. for wire temperatures between $130^{\circ} \mathrm{F}$ and $170^{\circ} \mathrm{F}$. The sound pressure at which cavitation bubble was observed to occur in the bulk 1iquid for methanol at $113^{\circ} \mathrm{F}$ was 0.11 atm (rms) as shown in Table 1 in Part $I$. This suggests that it was easier to induce cavitation in the bulk liquid than in the liquid at the wire surface which was at a higher temperature. It should be noted that the value of 0.11 atm was the sound pressure measured on the wire. The element of liquid in the bulk liquid where cavitation was first observed (owing to the interaction of sound waves with the container walls), might have a higher sound pressure, but this was not measured. It was also possible that there existed an active nucleus such as a dust particle which required much. lower sound pressure to induce cavitation. When the critical sound pressure was below the value at which cavitation would occur in the bulk liquid, cavitation bubbles were observed only on the wire.

It may be recalled that there were two mechanismsthrough which a small cavitation bubble could grow to larger size. The first mechanism was agglomeration resulting from the motion of cavitation bubbles which originated on the wire only, while the second one involved agglomeration on the wire of cavitation bubbles which originated in the bulk liquid and migrated to the wire. Consequently, it is possible that only the first mechanism is taking place if the applied sound pressure is sufficient to induce cavitation on the wire but not in the bulk 1iquid. In order to be able to compare the heat transfer results directly, the apparent electrical power input to the transducers was selected so that cavitation occurred in the test liquid as well as 
0.17 to $0.06 \mathrm{~atm}$. for wire temperatures between $130^{\circ} \mathrm{F}$ and $170^{\circ} \mathrm{F}$. The sound pressure at which cavitation bubble was observed to occur in the bulk liquid for methanol at $113^{\circ} \mathrm{F}$ was 0.11 atm (rms) as shown in Table 1 in Part $I$. This suggests that it was easier to induce cavitation in the bulk liquid than in the liquid at the wire surface which was at a higher temperature. It should be noted that the value of 0.11 atm was the sound pressure measured on the wire. The element of liquid in the bulk liquid where cavitation was first observed (owing to the interaction of sound waves with the container walls), might have a higher sound pressure, but this was not measured. It was also possible that there existed an active nucleus such as a dust particle which required much lower sound pressure to induce cavitation. When the critical sound pressure was below the value at which cavitation would occur in the bulk liquid, cavitation bubbles were observed only on the wire.

It may be recalled that there were two mechanismsthrough which a small cavitation bubble could grow to larger size. The first mechanism was agglomeration resulting from the motion of cavitation bubbles which originated on the wire only, while the second one involved agglomeration on the wire of cavitation bubbles which originated in the bulk liquid and migrated to the wire. Consequently, it is possible that only the first mechanism is taking place if the applied sound pressure is sufficient to induce cavitation on the wire but not in the bulk 1iquid. In order to be able to compare the heat transfer results directly, the apparent electrical power input to the transducers was selected so that cavitation occurred in the test liquid as well as 
on the wire for the whole range of wire temperature used.

\section{Heat Transfer Results}

The effects of ultrasonic vibrations on heat transfer rates have been found to be dependent on the liquid used and its temperature. The higher heat transfer rates obtained in distilled water appeared to be the result of its low value of gas solubility which controlled the cavitation bubble content. The cavitation bubbles in water were observed to have collapsed on the wire surface as the bubble content was mainly vapor. The turbulence so generated was much more intense than that by the motion of the non-condensable cavitation bubbles generated in methanol.

A change in water temperature from $149^{\circ} \mathrm{F}$ to $113^{\circ} \mathrm{F}$ resulted in a change in the increase in heat transfer rates from $100 \%$ to $45 \%$ for approximately the same value of soil removal. It may be recalled that the increase in heat transfer rates was evaluated at a temperature difference of $40^{\circ} \mathrm{F}$ in both cases. The critical sound pressures, as shown In Figure 2, were $0.23 \mathrm{~atm}$ for a water temperature of $149^{\circ} \mathrm{F}$ and $0.42 \mathrm{~atm}$ for $113^{\circ} \mathrm{F}$. At the same value of the percentage of soil removal, the liquid with a lower critical sound pressure showed an increased cavitation bubble activity on the wire surface. This explains the dependence of the increase in heat transfer rates on wire temperature at the same value of the percentage of soil removal. It is advantageous to use a liquid at its saturated condition since its cavitation threshold will be low and the critical sound pressure is close to the minimum value. 
The effects of ultrasonic vibrations on saturated pool boiling were not studied because the motion of vapor bubbles generated on the walls of the stainless tank from the strip heaters interfered with the sound field and rendered the measurements of sound pressure on the wire surface very difficult. In preliminary experiments using methanol at its bolling point, more than a $100 \%$ fluctuation was obtained in sound pressure measurements by the ultrasonic probe. The liquid temperatures used in this work were selected so that the strip heaters maintained the temperature at the desired level without formation of vapor bubbles on the tank walls. Since the ultrasonic probe depolarizes at a temperature of $170^{\circ} \mathrm{F}$, the temperature could not exceed this value.

Since only platinum wires of diameters 0.007 and $0.010 \mathrm{in}$. were used in this study, the range was too small to determine the effect of wire diameter.

The effect of frequency based on the percentage of soll removed has been shown to be relatively unimportant. The increase in heat transfer rates based on the same liquid temperature, the same temperature difference and approximately the same value of the percentage of soil removed was only lowered from $100 \%$ to $70 \%$ for a fivefold increase in frequency. According to Equation (1), the resonance size of the cavitation bubble was decreased by a factor of five as the frequency increased from $20.6 \mathrm{kcps}$ to $108 \mathrm{kcps}$. In order to have the observed effect on heat transfer rates, the smal1 cavitation bubbles must be as efficient as the larger cavitation bubbles in creating turbulence in the liquid at the wire surface. 
CORRELATION OF EXPERIMENTAL DATA

The mathematical formulation of the effects of coupled acoustic or ultrasonic vibrations and heat transfer in fluids is very difficult and has not been attempted. If the fluid is a liquid, the analysis is further complicated by cavitation phenomena. It does not appear possible to write an appropriate differential equation which could be used to search out the important non-dimensional parameters of the problem. Consequently, the parameters used to correlate the data have been based on proposed mechanisms and tested empirically.

The experimental variables studied in this work were the liquid temperature, acoustic energy input to the system, and frequency. The acoustic energy input to the system was expressed in terms of sound pressure when the levels were below the cavitation threshold of the liquid and in terms of the percentage of soll removed when the levels were above. The latter quantity has been shown to give a measure of the cavitation activity at the heater surface. It should be noted that both the sound pressure and the soil removal measurements were conducted in 1 iquids undex isothermal conditions.

The heat transfer coefficient was first calculated by the following equation

$$
h=\frac{q}{A \Delta t}
$$

where $h$ - heat transfer coefficient, BTU/hr $\mathrm{ft}^{2} \mathrm{o}_{F}$ $\mathrm{q} / \mathrm{A}$ - heat flux, BTU/hr $\mathrm{ft}^{2}$

$\Delta t$ - temperature difference between the wire and the bulk 1 iquid, ${ }^{\circ}$. 
An equation of the form shown as follows was used to correlate the heat transfer data at $20.6 \mathrm{kcps}$

$$
\mathrm{Nu}_{\mathrm{w}}=\emptyset\left(\mathrm{Gr}, \mathrm{Pr}, \mathrm{S}_{\mathrm{R}}, \mathrm{P}_{\mathrm{CR}}\right)
$$

where $\mathrm{Nu}_{\mathrm{w}}$ - Nusse1t number based on the wire diameter, dimensionless

Gr - Grashof number, dimensionless

Pr - Prandtl number, dimensionless

$S_{R} \quad$ - percentage soil removed, $\%$

$P_{C R}$ - critical sound pressure, atm.

In determining the dimensionless groups, all liquid properties were evaluated at the arithmetic mean temperature of the wire and the bulk 1iquid. A plot of $\mathrm{Nu}_{\mathrm{w}}$ versus $(\mathrm{Gr} \mathrm{Pr})^{0.65}\left(\mathrm{~s}_{\mathrm{R}}\right)^{0.5} / \mathrm{P}_{\mathrm{CR}}$ yielded a reasonably good correlation except for the data points taken at wire temperatures above the temperature for incipient boiling which were above the correlation. It was decided that at high values of wire temperature, different dimensionless groups (reflecting the boiling mechanism) should be used to correlate the heat transfer results.

The results from the high speed photographic study showed that the cavitation bubble activity and its content depended on the wire temperature. Since the percentage of soil removed indicated only the cavitation activity of the liquid at the wire when it was not heated, the wire temperature effect was included in the critical sound pressure term and partially in the Grashof number which explains the high exponent for the latter. As the wire temperature increased, the frequency of formation and the activity of cavitation bubbles were increased, the 
bubble content changing gradually from mainly gas to mainly vapor. The mechanism of heat transfer became similar to that in nucleate boiling without vibration. The wire temperature effect can no longer be accounted for by the critical sound pressure and the Grashof number. A Reynolds number for the cavitation bubbles was then postulated similar to that in nucleate boiling. The question which arises here is what criterion should be used to separate the heat transfer results into two groups. A convenient basis would be the cavitation bubble content which consists of $50 \%$ gas and $50 \%$ vapor. Since it was difficult to measure the actual bubble content, the heat flux value at the incipience of boiling was chosen. The choice was purely an arbitrary one and, in fact, data points with heat flux values $50 \%$ higher than the incipient boiling heat flux were included in the correlation for the low heat flux region. After the data were divided into two parts, the data of the graphs of heat flux $(q / A)$ versus temperature difference $(\Delta t)$ in a log-log plot for the low heat flux region could be better correlated using lines with smaller slope. Subsequently, a new exponent of 0.5 was obtained for the product of Grashof number and Prandtl number. Satisfactory correlations were also obtained when the same dimensionless groups were used to correlate data in the low heat flux region at other frequencies. The final correlation takes the form of

$$
\mathrm{Nu}_{\mathrm{w}}=\mathrm{C}_{1} \frac{(\mathrm{Gr} \mathrm{Pr})^{1 / 2}\left(\mathrm{~s}_{\mathrm{R}}\right)^{1 / 2}}{\mathrm{P}_{\mathrm{CR}}}+\mathrm{C}_{2}
$$

where $\mathrm{C}_{1}$ and $\mathrm{C}_{2}$ are constants. The results are shown in Figures 20 to 23 . The slope and the intercept 
of the straight line in each figure were obtained by the least squares method and are shown in Table 3 together with the $95 \%$ confidence limits based on the $t$ test. For each frequency, there was a set of constants. It was impossible to correlate heat transfer results from different frequencies with a single equation, because the exact relationship between the critical sound pressure and frequency of the sound field has not been found.

The plots of $\mathrm{Nu}_{\mathrm{W}} / \mathrm{Nu}_{\mathrm{o}}$ where $\mathrm{Nu}$ is the Nusselt number for the wire when there was no vibration, versus $(\mathrm{Gr} P r)^{1 / 2}\left(\mathrm{~S}_{R}\right)^{1 / 2} / \mathrm{P}_{\mathrm{CR}}$ were also prepared for the four frequencies and are shown in Figures 24 to 27. Although the degree of scatter was about the same, the data points from one test Iiquid temperature mixed better with data points from a different test liquid temperature. The slope and intercept are also summarized in Table 3.

To correlate the heat transfer results with vibrations in the high heat flux region, that is, the data points with heat flux values greater than that at the incipient boiling, a Reynolds number for cavitation bubbles would be used to account for the high cavitation bubble activity on the wire surface.

In nucleate pool boiling the volumetric flow rate of the vapor away from the surface is given by

$$
Q=\frac{g}{\rho_{v} \lambda}
$$

where $Q$ - volumetric flow rate of the vapor, $\mathrm{ft}^{3} / \mathrm{hr}$

$q$ - heat transfer rate, BTU/hr 
CORRELATION OF HEAT TRANSFER DATA IN THE LOW HEAT FLUX REGION
FIGURE 20 FREQUENCY $=20.6 \mathrm{kcps}$
FIGURE 21 FREQUENCY $=44.1 \mathrm{kcps}$
FIGURE 22 FREQUENCY $=108 \mathrm{kcps}$
FIGURE 23 FREQUENCY $=306 \mathrm{kcps}$ 


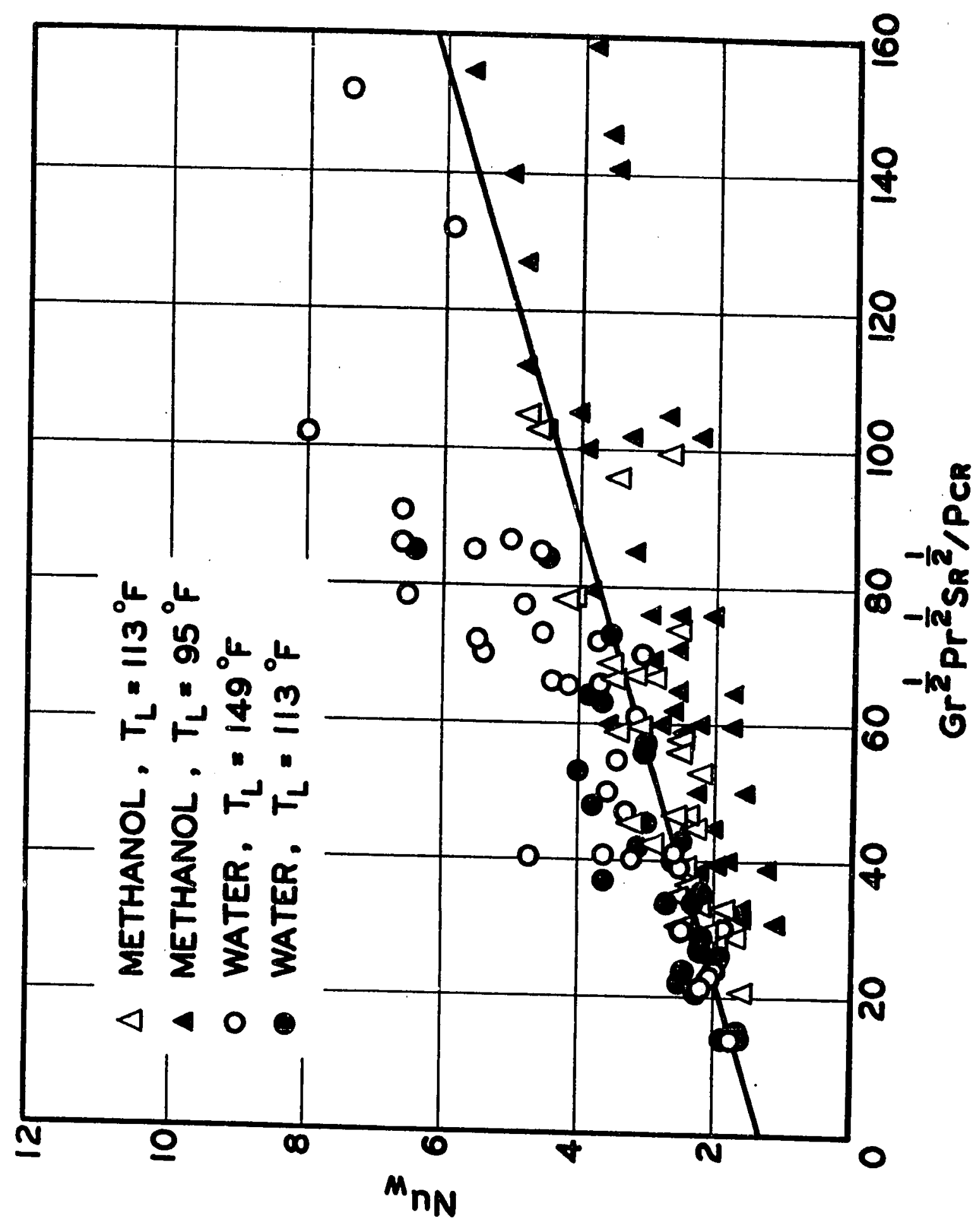




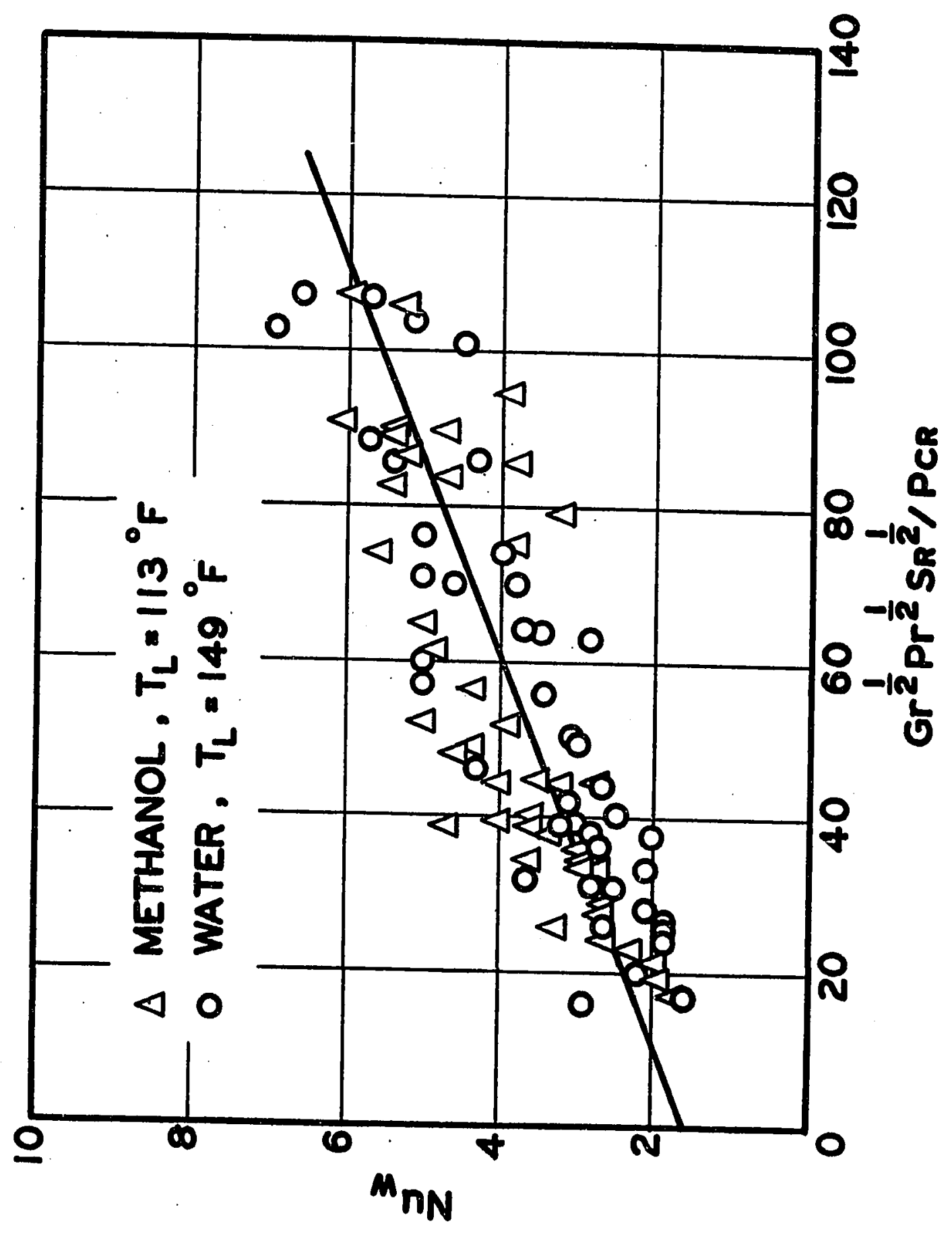




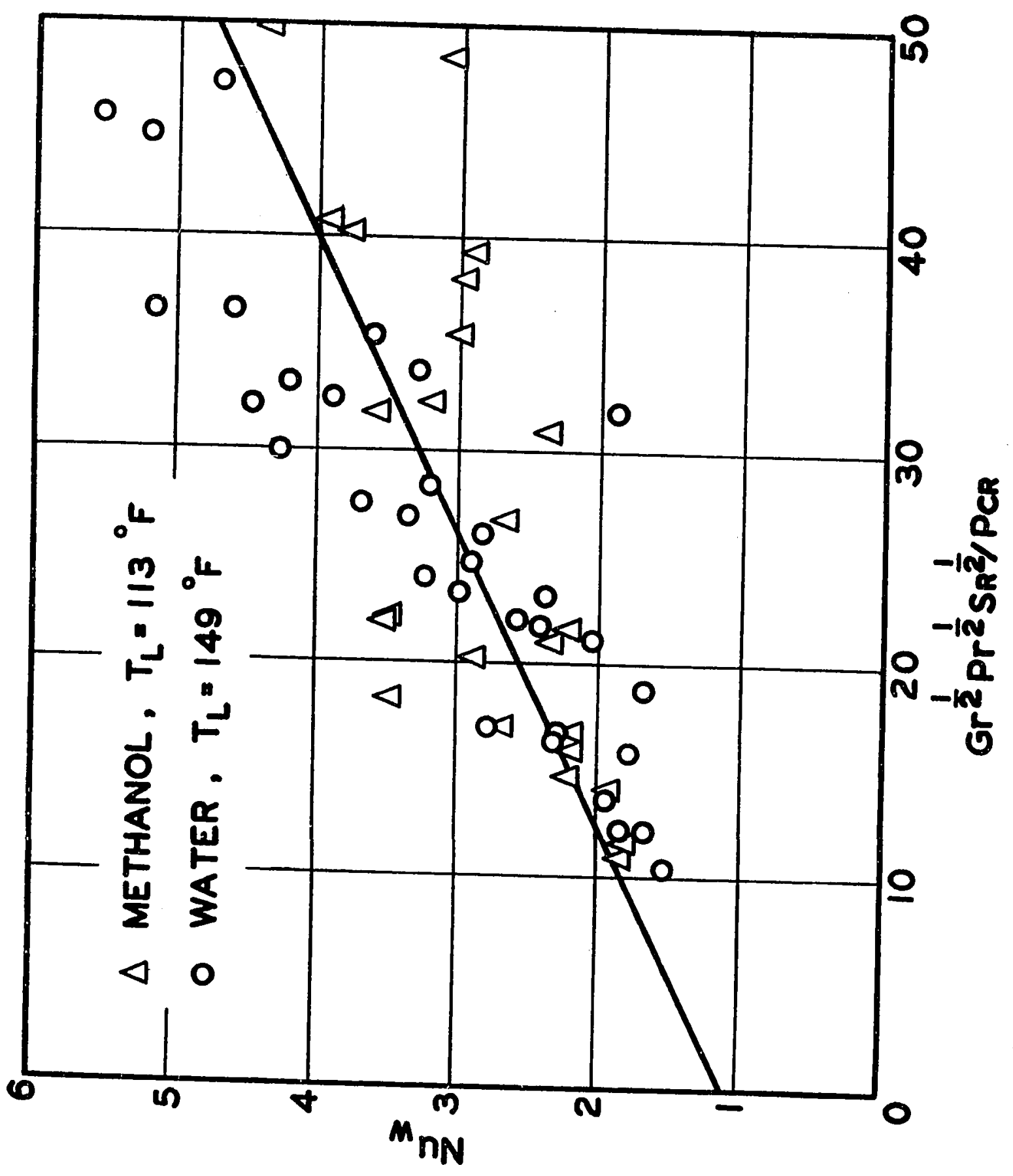




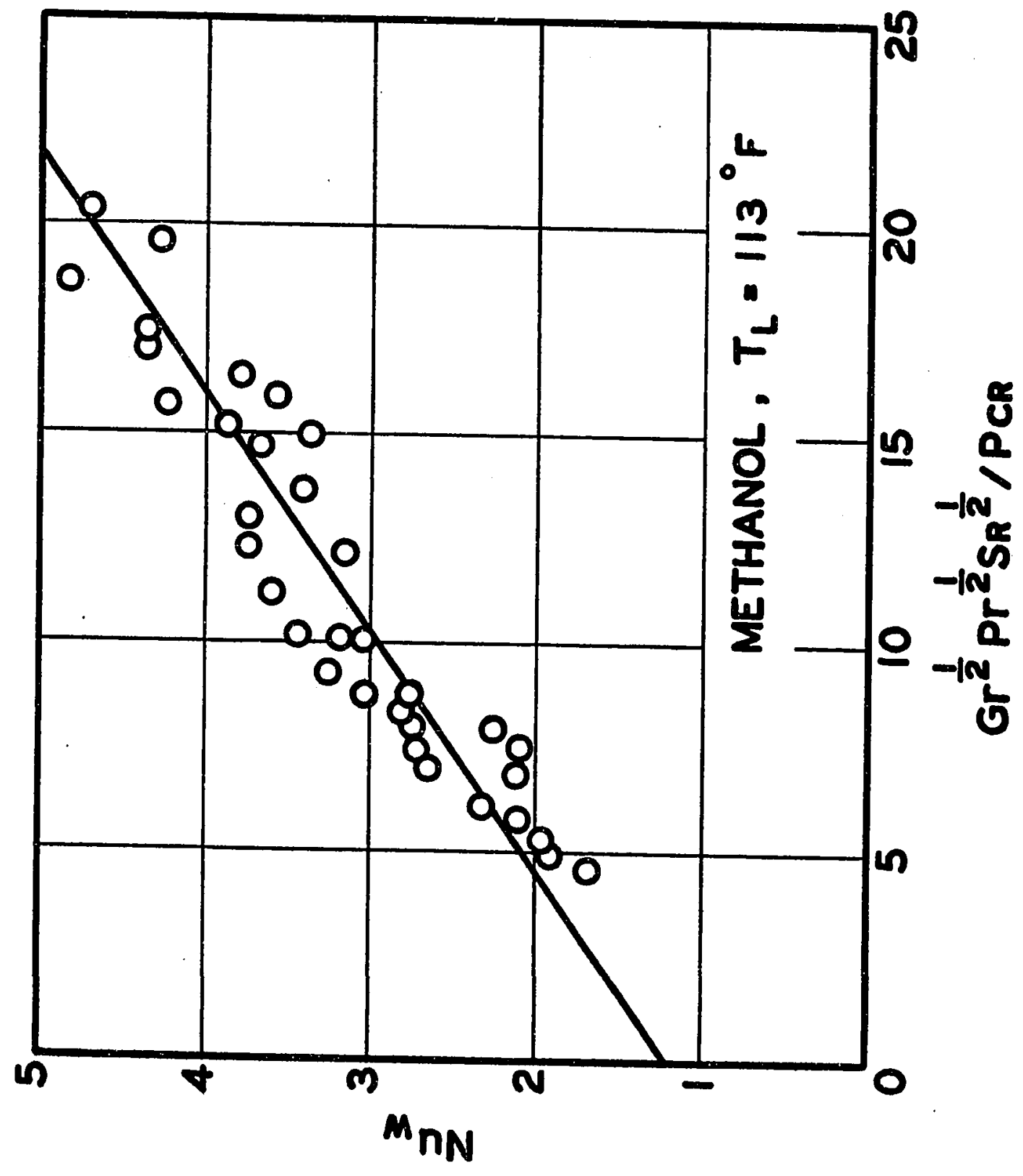


TABLE 3

Summary of Slope and Intercept of Correlations

\begin{tabular}{cccccc}
$\begin{array}{c}\text { FREQUENCY } \\
\text { kCPS }\end{array}$ & $\begin{array}{c}\text { FIGURE } \\
\text { NUMBER }\end{array}$ & SLOPE & INTERCEPT & \multicolumn{2}{c}{ THE 95\% CONFIDENCE LIMITES } \\
20.6 & 20 & 0.0305 & 1.34 & \pm 0.0048 & \pm 0.17 \\
44.1 & 21 & 0.0402 & 1.56 & \pm 0.0055 & \pm 0.16 \\
108 & 22 & 0.0732 & 1.09 & \pm 0.015 & \pm 0.22 \\
306 & 23 & 0.174 & 1.22 & \pm 0.022 & \pm 0.13 \\
20.6 & 24 & 0.0139 & 1.20 & \pm 0.0030 & \pm 0.093 \\
44.1 & 25 & 0.0191 & 1.48 & \pm 0.0047 & \pm 0.14 \\
108 & 26 & 0.0303 & 1.21 & \pm 0.011 & \pm 0.16 \\
306 & 27 & 0.0573 & 1.49 & \pm 0.020 & \pm 0.17 \\
20.6 & 28 & 0.00470 & 5.84 & \pm 0.00089 & \pm 0.63 \\
44.1 & 29 & 0.00471 & 2.96 & \pm 0.00058 & \pm 0.21 \\
108 & 30 & 0.00881 & 0.745 & \pm 0.0026 & \pm 0.19
\end{tabular}


CORRELATION OF HEAT TRANSFER DATA IN THE LOW HEAT

FLUX REGION IN TERMS OF A NORMALIZED NUSSELT NUMBER

$\begin{array}{ll}\text { FIGURE } 24 & \text { FREQUENCY }=20.6 \mathrm{kcps} \\ \text { FIGURE } 25 & \text { FREQUENCY }=44.1 \mathrm{kcps} \\ \text { FIGURE } 26 & \text { FREQUENCY }=108 \mathrm{kcps} \\ \text { FIGURE 27 } & \text { FREQUENCY }=306 \mathrm{kcps}\end{array}$




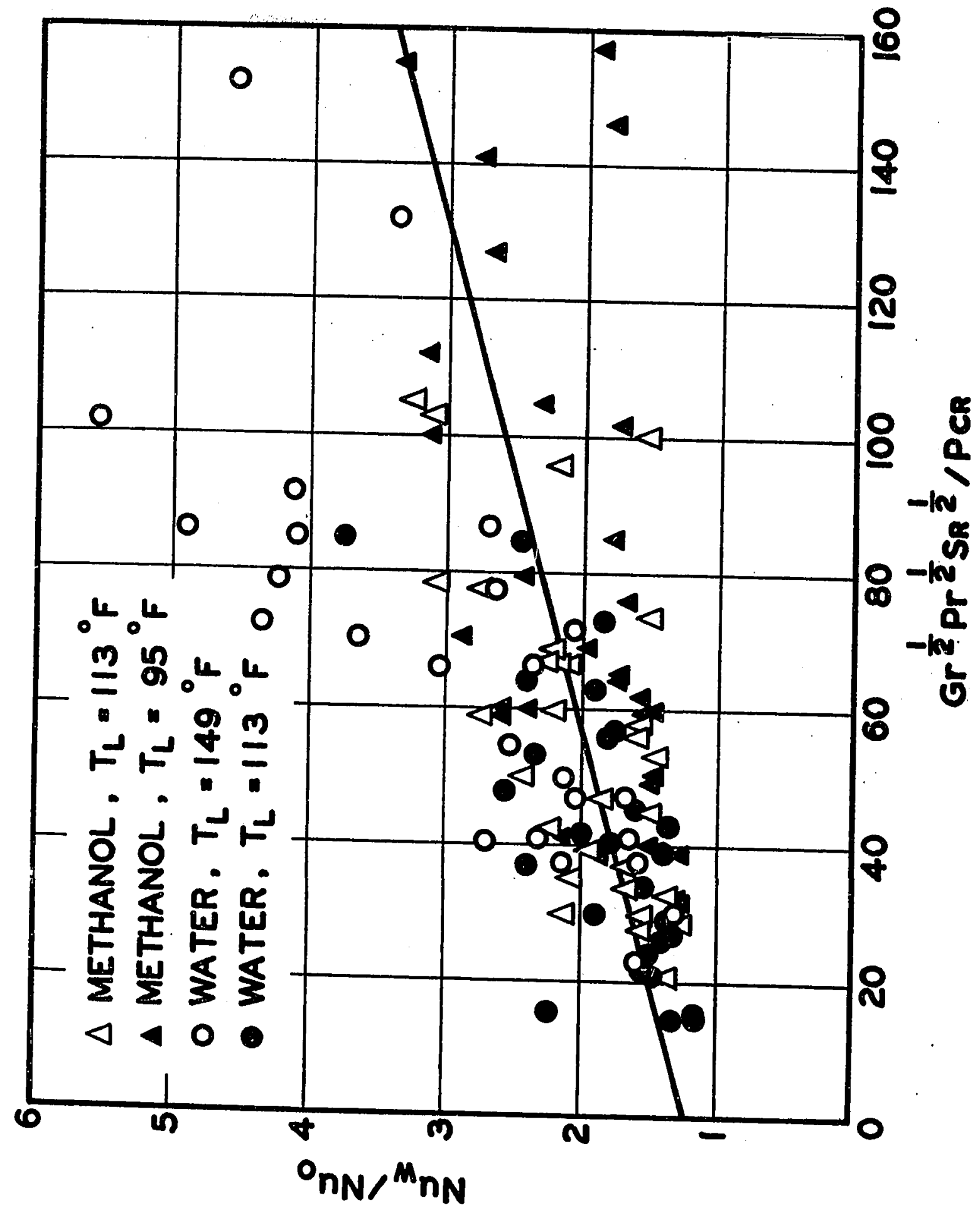




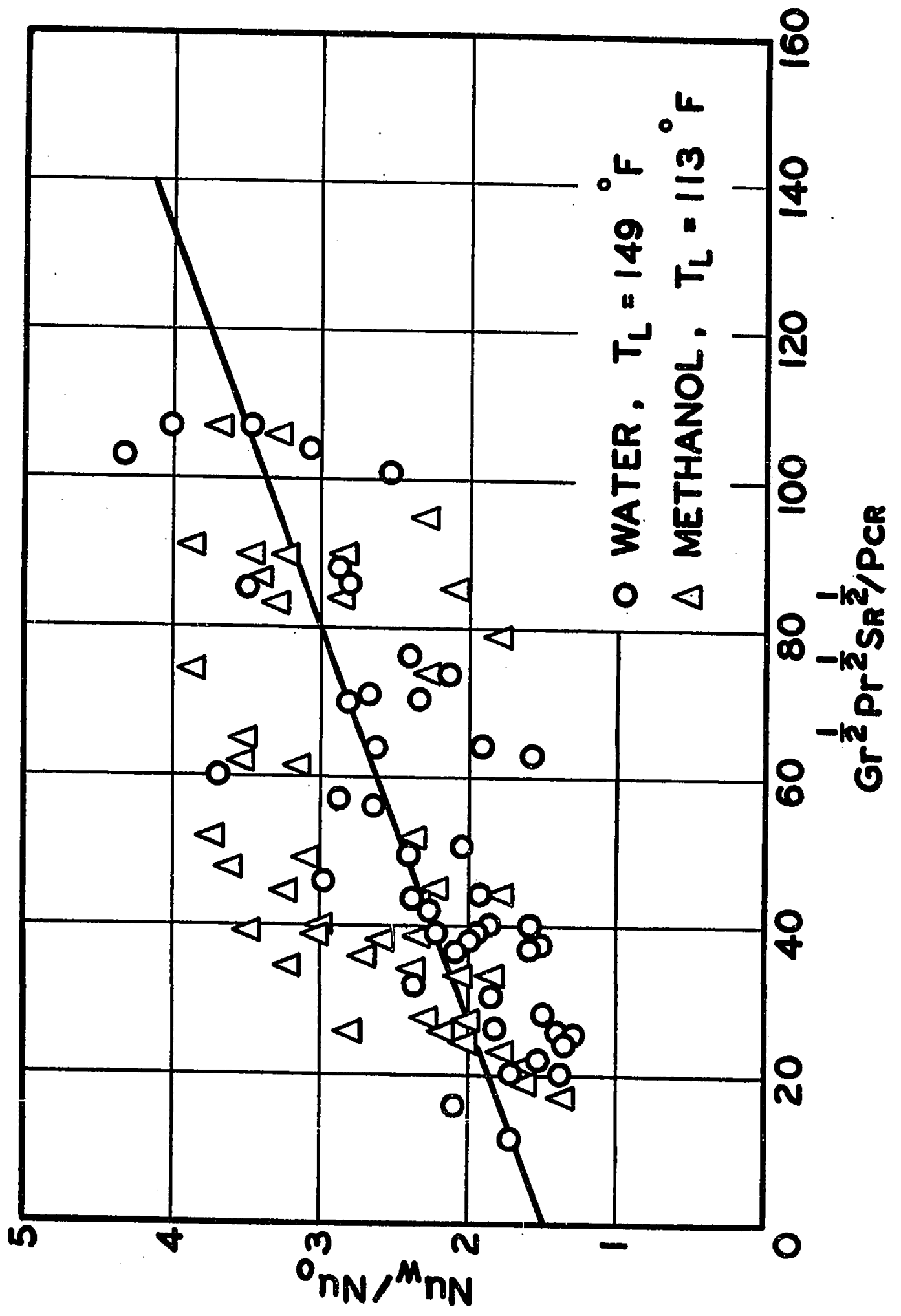




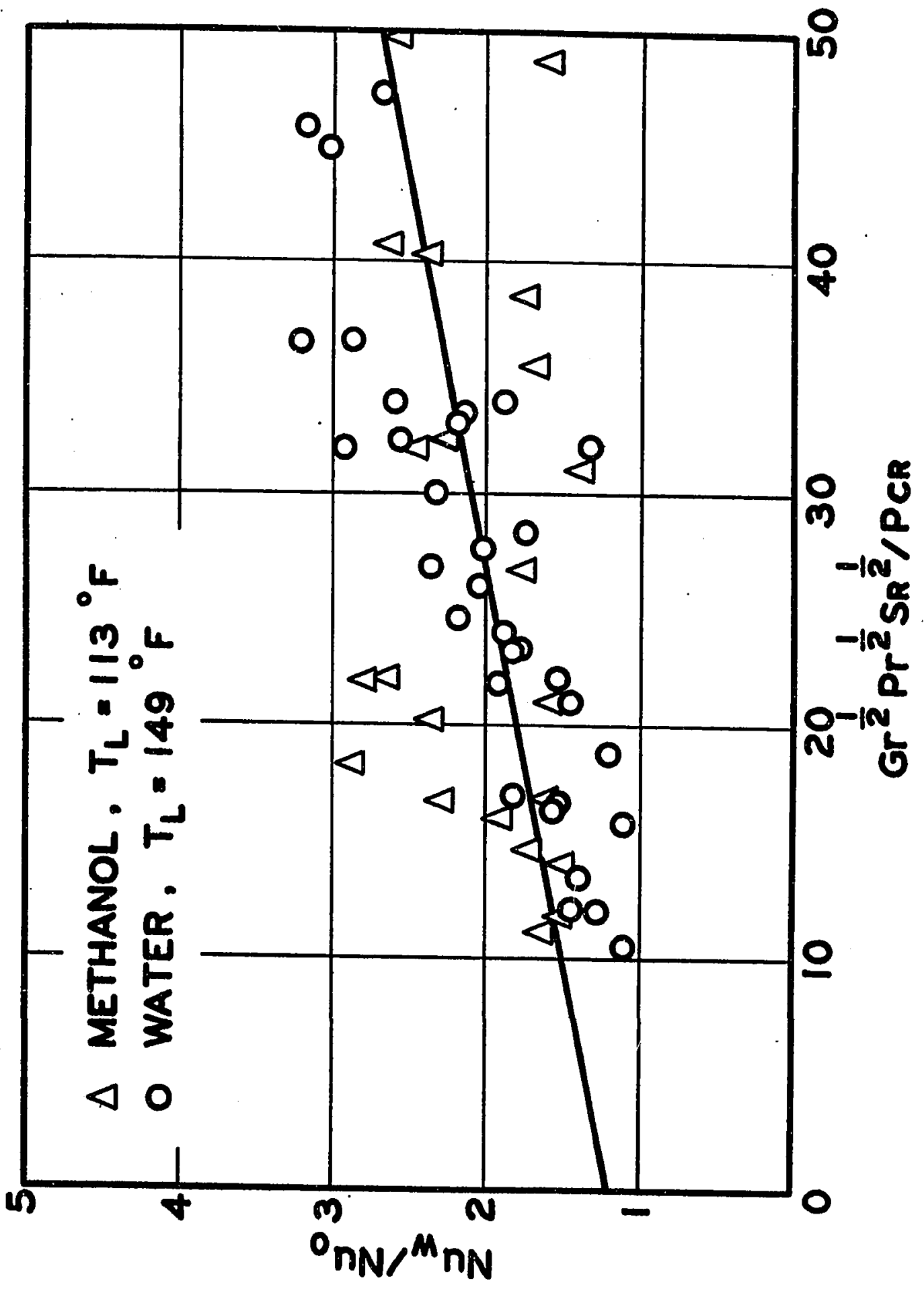




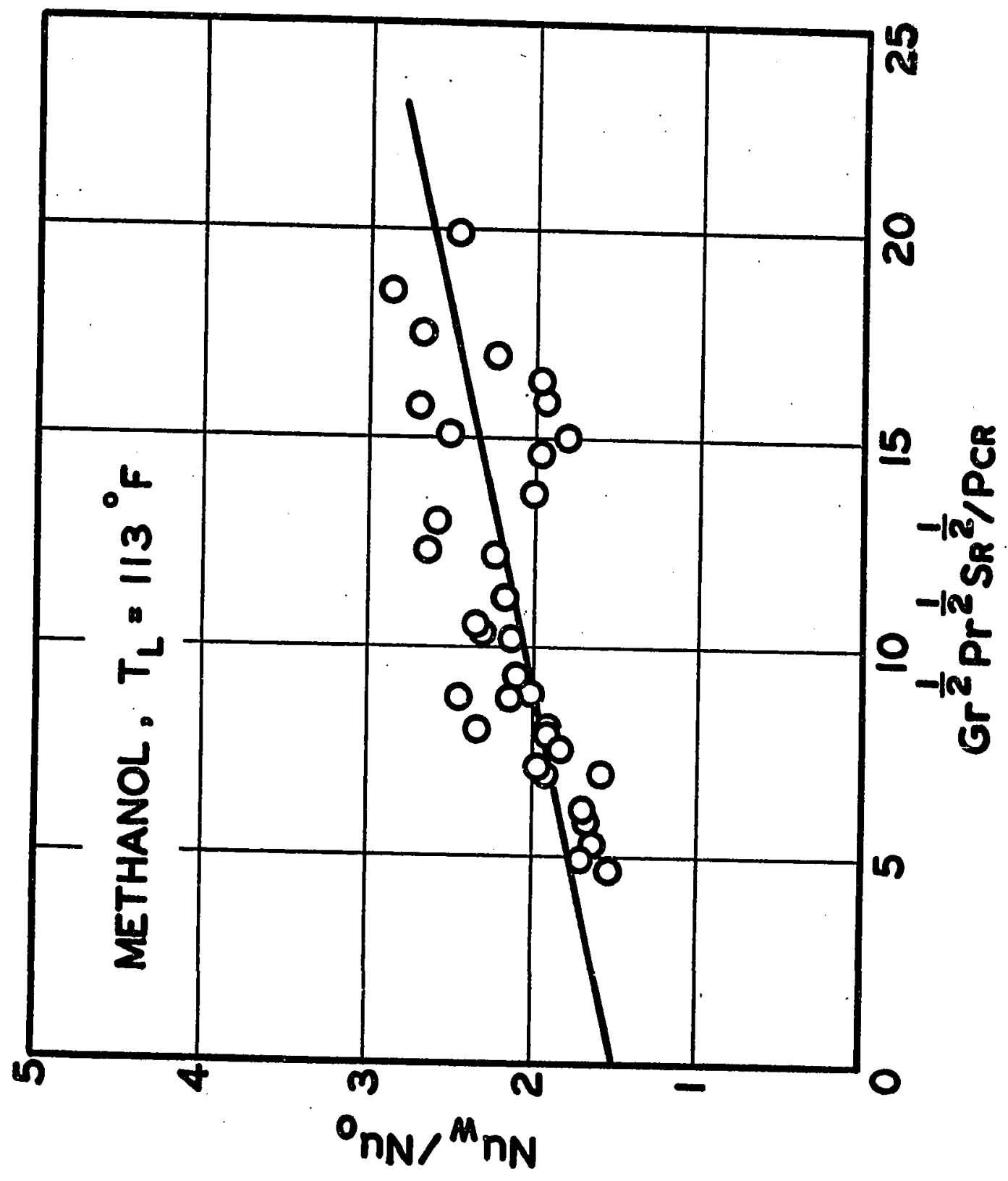


$C_{v}$ - density of the vapor, $1 \mathrm{~b} / \mathrm{ft}^{3}$

$\lambda$ - latent heat of vaporization, BTU/1b.

The superficial vapor velocity $\left(V_{S V}\right)$, that is, the velocity based on the total available cross section, is

$$
v_{S V}=\frac{q}{A \rho_{v} \lambda}
$$

where A - total available surface area, ft.

If it is assumed that the flow of the liquid toward the surface is determined by simple volumetric exchange, the superficial velocities of the liquid and the vapor are equal. Equation (6) has been used by a number of investigators as the velocity term in the Reynolds number for correlation of nucleate boiling data $(15,16,22)$.

Before defining the characteristic length in the Reynolds number, it may be recalled that the cavitation bubble size at which the erratic behaviour of the bubble was first observed, could be approximated by Equation (1) which relates the resonance size of an air bubble in a liquid to the frequency of the sound field. Comparison of the observed cavitation bubble size with the value predicted by Equation (1) for both methanol and distilled water at heat flux values in the region of 1solated bubbles of nucleate boiling showed good agreement. It is likely that Equation (1) can be used to approximate the cavitation bubble diameter formed on the wire at increased temperatures. At higher frequencies, visual observations also showed that the cavitation bubble sizes were much smaller than that at $20.6 \mathrm{kcps}$. The Reynolds number is then defined as 


$$
\operatorname{Re}=\frac{D_{B} q \rho_{L}}{A \rho_{v} \lambda \mu_{L}}
$$

where Re - Reynolds number for cavitation bubble, dimensionless

$$
\begin{aligned}
& D_{B}-\text { Diameter of cavitation bubble, ft. } D_{B}=2 R_{0} \\
& \text { where } R_{0} \text { is the resonance radius defined in Equation (1) } \\
& \rho_{L}-\text { density of liquid, } 1 \mathrm{~b} / \mathrm{ft}^{3} \\
& \mu_{L}-\text { viscosity of liquid, } 1 \mathrm{~b} / \mathrm{ft} \mathrm{hr} .
\end{aligned}
$$

Using a Nusselt number based on the cavitation bubble diameter (from Equation (1)), the data in the high heat flux region were correlated and the results are shown in Figures 28 to 30 . Because of the dependence of the critical sound pressure on the frequency of the sound field, a different correlation was obtained for each frequency. The final correlation is given as follows

$$
\mathrm{Nu}_{\mathrm{B}}=\mathrm{c}_{3} \frac{\operatorname{Re}^{1 / 2} \operatorname{Pr}^{2 / 3} \mathrm{~S}_{\mathrm{R}}^{1 / 2}}{\mathrm{P}_{\mathrm{CR}}}+\mathrm{c}_{4}
$$

where $C_{3}$ and $C_{4}$ are constants. The slope and the intercepts of the correlation for each frequency are given in Table 3 together with the $95 \%$ confidence limits.

The results at $306 \mathrm{kcps}$ were not correlated because few data points were available. The normalized plots of $\mathrm{Nu}_{\mathrm{B}} / \mathrm{Nu}$ o versus $\mathrm{Re}^{1 / 2} \mathrm{Pr}^{2 / 3} \mathrm{~S}_{\mathrm{R}}^{1 / 2} / \mathrm{P}_{\mathrm{CR}}$ were not prepared because an accurate determination of heat transfer coefficients in the nucleate bolling region without vibration was extremely difficult. While the normalized plots in the low heat flux region showed an increase in heat transfer coefficient 
CORRELATION OF HEAT TRANSFER DATA IN THE HIGH HEAT FLUX REGION
FIGURE 28
FREQUENCY $=20.6 \mathrm{kcps}$
FIGURE 29
FREQUENCY $=44.1 \mathrm{kcps}$
FIGURE 30
FREQUENCY $=108 \mathrm{kcps}$ 


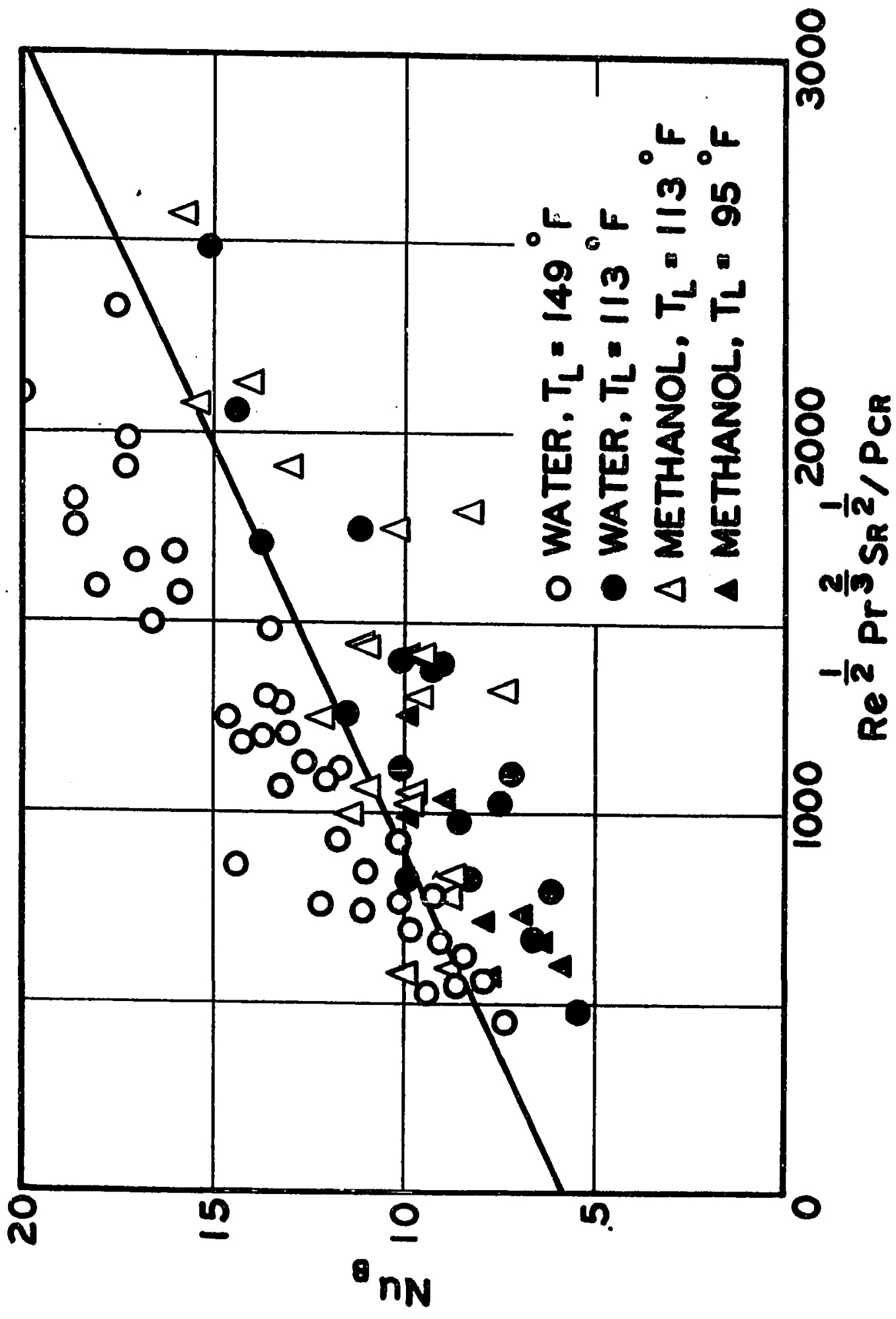




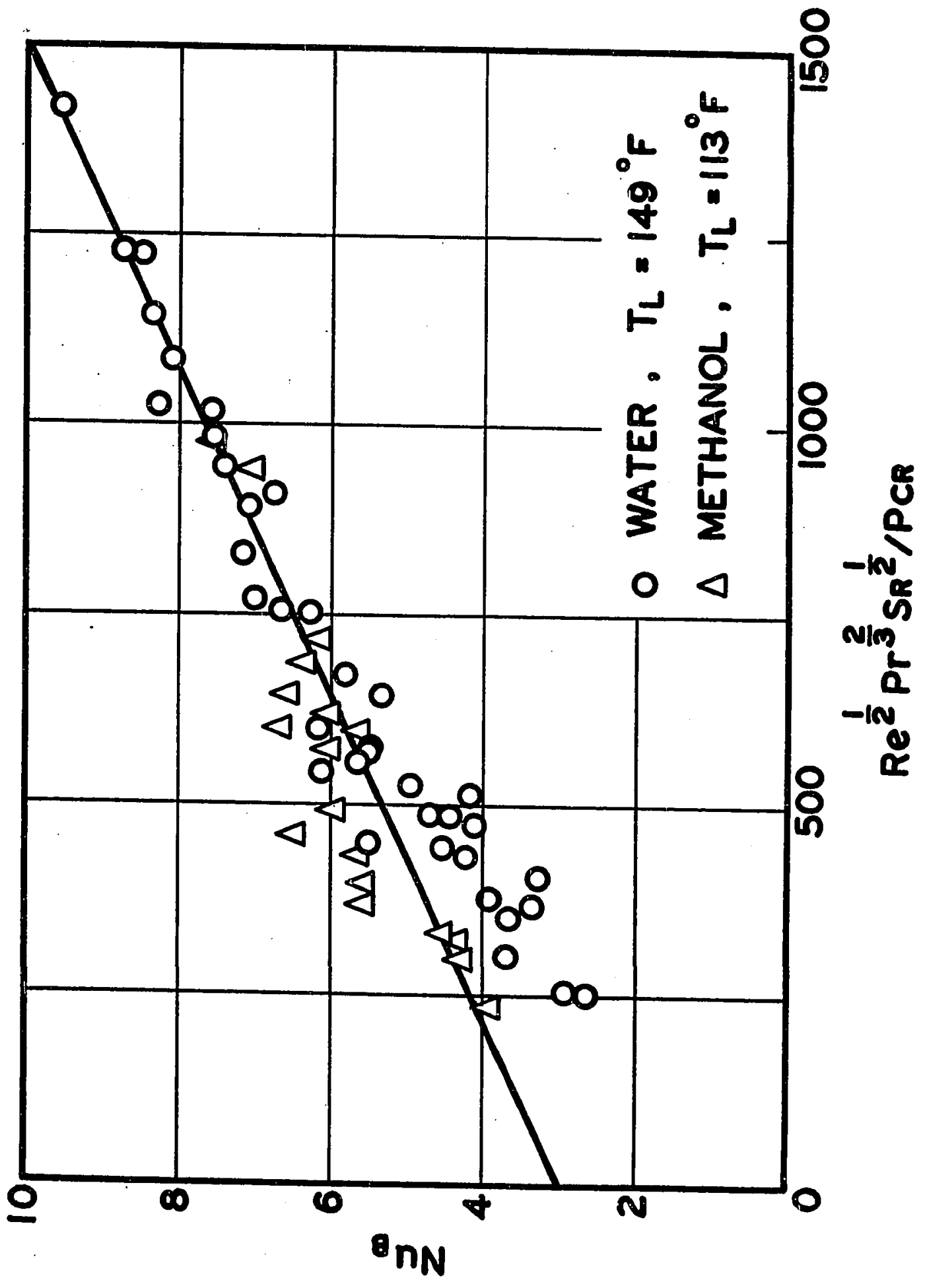




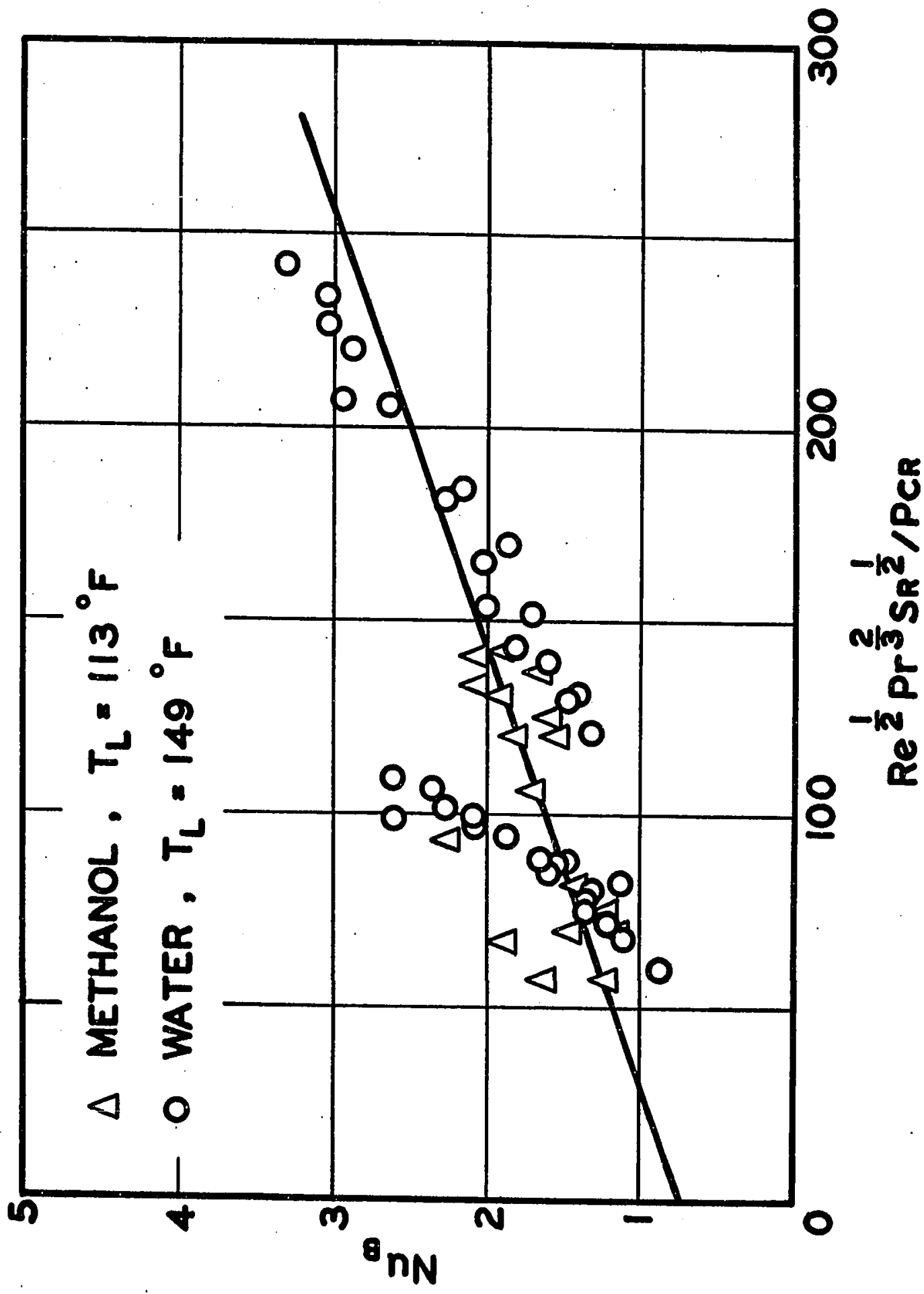


as wire temperature increased, the reverse would be expected in the high heat flux region. 
DISCUSSION OF CALCULATED RESULTS

As mentioned earlier, attempts have been made to correlate the heat transfer results at different frequencies with a single equation. They were unsuccessful because the exact relationship between the critical sound pressure and the frequency of the sound field has not been established. The values of the slope and intercept of the correlations for different frequencies, in fact, reflect the dependence of the critical sound pressure on the frequency of the sound field. The critical sound pressure values for distilled water and methanol at $44.1 \mathrm{kcps}$, as shown in Figures 4 and 5 , were only slightly higher than those for 20.6 kcps. Subsequently, a comparison of the slopes and intercepts at different frequencies shows that the values at 20.6 and $44.1 \mathrm{kcps}$ are much closer to each other than those at other frequencies.

The exponent of the Grashof number in the final correlation for heat transfer results in the low heat flux region is 0.5 which Is unusually high compared with the value of 0.17 , the exponent of the Grashof number found when there was no vibration (Figure 15). It has been mentioned that both the soll removal and the critical sound pressure measurements were made in a liquid, whose temperature was the same as that in the bulk 1iquid. In heat transfer experiments, the cavitation bubble activity on the wire was observed to increase directly with the wire temperature. The increase in cavitation bubble activity would cause an increase in the turbulence of the liquid at the wire, resulting in higher values of heat transfer coefficient. In correlating the heat transfer results in the low heat flux region, since this temperature 
effect was not accounted for in the cavitation damage data, that is, percentage of soil removed, it was combined with the temperature effect which produced the buoyancy force usually represented by the Grashof number in natural convective heat transfer. The result was the large value of the exponent of the Grashof number.

It should be pointed out that the critical sound pressure and the percentage of soil removed measured under 1sothermal conditions might not represent the actual values when the radioactive specimen was replaced by a heated platinum wire. The thermal gradient in the 1iquid near the wire, the formation and the motion of the cavitation bubbles on the wire would scatter sound waves. Since the ultrasonic probe cannot be used at temperatures above $170^{\circ} \mathrm{F}$ and since 1 was impossible to simulate the thermal gradient of the liquid near the specimen when the percentage of soil removed was measured, this represents one of the limitations of the present work.

The heat transfer coefficlents in both the low and high heat flux regions were found to be directly proportional to the square root of the percentage of soll removed which is a measure of the cavitation activity of the liquid at the heat transfer surface. In the penetration theory proposed by Danckwerts $(17,18)$, it is shown that the mass transfer coefficlent is inversely proportional to the square root of the time of contact between the liquid and the gas phase. The penetration theory assumes that the interface is contisuously replaced by eddies so that fresh surface will be formed continuously at a constant rate. The reciprocal of the contact time is then shown to be the 
fractional rate of surface renewal. Consequently, the mass transfer coefficient is proportional to the square root of the fractional rate of surface renewal, which depends on the degree of turbulence in the 1iquid. From the analogy of heat and mass transfer, it appears that the percentage of soil removed is directly related to the intensity of turbulence resulting from cavitation in a liquid under ultrasonic vibrations. The mechanism of cavitation damage, as mentioned earlier, is mainly due to the collapse of cavitation bubbles near and on a solid surface. The percentage of soil removed can then be interpreted as a measure of the rate of formation (collapse) of cavitation bubbles which becomes a measure of the turbulent intensity in the liquid.

The cavitation damage has been shown to increase directly with the square of the sound pressure amplitude ${ }^{(19)}$. This renders the term $(\mathrm{Gr} \mathrm{Pr})^{1 / 2}\left(\mathrm{~S}_{\mathrm{R}}\right)^{1 / 2} / \mathrm{P}_{\mathrm{CR}}$ in the correlation for the low heat flux region and the term $\operatorname{Re}^{1 / 2} \operatorname{Pr}^{1 / 2} \mathrm{~S}_{\mathrm{R}}^{1 / 2} / \mathrm{P}_{\mathrm{CR}}$ in the correlation for the high heat flux region dimensionless as the percentage of soll removed becomes directly proportional to the square of the sound pressure amplitude. The dimensionless term $\mathrm{S}_{\mathrm{R}}{ }^{1 / 2} / \mathrm{P}_{\mathrm{CR}}$ gives a measure of the cavitation bubble activity for different liquids at different temperatures.

The effects of quartz wind streaming and the surface streaming have been neglected in correlating the heat transfer results. Eckert ${ }^{(20)}$ has shown that the quartz wind streaming which is a volume effect resulting from sound absorption in a liquid will have a negligible velocity at frequencles below $1000 \mathrm{kcps}$. The frequency range of the present work is well below this value. 
Surface streaming is a local effect resulting from the interaction of the sound waves with a surface. Westervelt ${ }^{(21)}$ suggested a Reynolds number $\left(\mathrm{Re}_{s}\right.$ ) for correlating heat transfer results due to surface streaming. It is given as follows

$$
\operatorname{Re}_{s}=\frac{u^{2}}{\omega v}=\left(\frac{a}{\delta_{A C}}\right)^{2}
$$

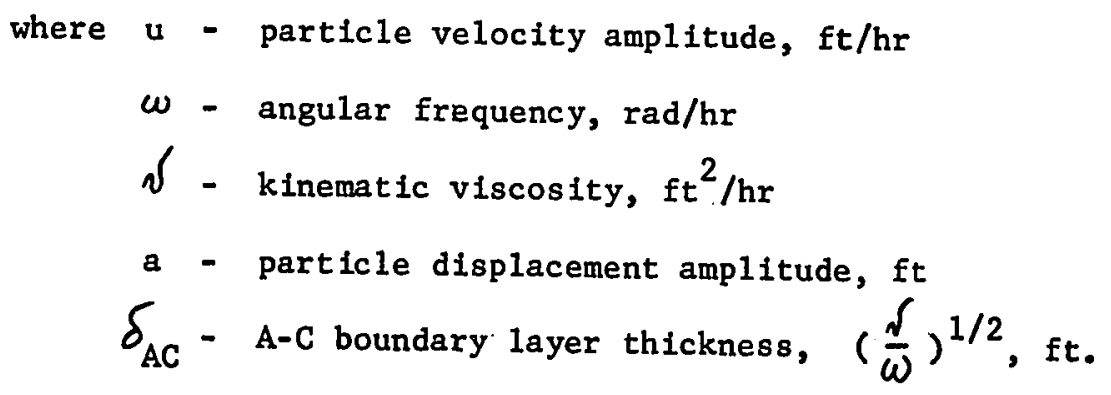

Westervelt predicted that the heat transfer will increase for values of $\operatorname{Re}_{s}>1$, but below unity no effect will be observed. As mentioned in theliterature Review section, Equation (9) has been successfully used to determine the critical sound pressure level - the sound pressure level at which the effect of sound on heat transfer becomes appreciable - when the fluid is air.

For progressive waves, Equation (9) may be written as

$$
\operatorname{Re}_{s}=\frac{2 \mathrm{P}_{\mathrm{s}}{ }^{2}}{{\rho \mathrm{c}^{2} \omega \mu}^{2} \omega}
$$

where $\mathrm{P}_{s}$ - effective sound pressure, atm

c - velocity of sound in the fluid, $\mathrm{ft} / \mathrm{hr}$

$\mu$ - viscosity of the fluid, $1 \mathrm{~b} / \mathrm{ft} \mathrm{hr}$.

In the present work, the Reynolds numbers were calculated 
to be 0.07 for water at $20.6 \mathrm{kcps}$ and 0.0048 at $306 \mathrm{kcps}$, taking the sound pressure to be $1 \mathrm{~atm}$. The success of the correlation of data also indicates that the effects of quartz wind and surface streaming were negligible. 
CONCLUSIONS

1. There existed a critical sound pressure, depending on the 1iquid used and its temperature, the acoustic frequency and the heat transfer surface temperature, below which the effects of ultrasonic vibrations on heat transfer were negligible.

2. Above the critical sound pressure, the effects of ultrasonic vibrations on heat transfer to liquids varied from a $800 \%$ increase in heat transfer coefficient in the natural convection region to a negligible increase in the well-developed nucleate boiling.

3. The Increase in heat transfer coefficient was due to the intense turbulence resulting from the radial oscillations as well as the rapid and erratic motion of the cavitation bubbles on the heat transfer surface. The characteristics of these cavitation bubbles resembled that of a gaseous cavitation bubble with content varied from mainly gas to mainly vapor, depending on the gas solubility of the liquid at the heat transfer surface temperature. An increase In the surface temperature also increased the population and the activity of the cavitation bubbles. Under the present experimental conditions, it was impossible to determine the frequency of generation of the cavitation bubbles and the number of active sites (1f there was any) on the heat transfer surface.

4. The cavitation damage results (percentage of soll removed) obtained in Part I were used successfully to correlate the heat transfer results. The dependence of the population and the activity of 
cavitation bubbles on the heat transfer surface temperature, however, was not accounted for by the cavitation damage measurements. Subsequently, it was necessary to separate the heat cransfer results into two regions using the heat flux value at the incipience of boiling as the criterion. In the low heat flux region, the wire temperature effect was reflected in the high exponent of the Grashof number while a cavitation bubble Reynolds number was defined to account for the wire temperature effect in the high heat flux region. The correlations for $f=20.6 \mathrm{kcps}$ are given as follows with the slopes and Intercepts for all frequencies summarized in Table 4. Low Heat F1ux Region

$$
\begin{aligned}
& \mathrm{Nu}_{\mathrm{w}}=0.0305 \frac{(\mathrm{Gr} \mathrm{Pr})^{1 / 2}\left(\mathrm{~S}_{\mathrm{R}}\right)^{1 / 2}}{\mathrm{P}_{\mathrm{CR}}}+1.34 \\
& \frac{\mathrm{Nu}}{\mathrm{Nu}}=0.0139 \frac{(\mathrm{Gr} \mathrm{Pr})^{1 / 2}\left(\mathrm{~S}_{\mathrm{R}}\right)^{1 / 2}}{\mathrm{P}_{\mathrm{CR}}}+1.20
\end{aligned}
$$

High Heat Flux Region

$$
N u_{B}=0.00470 \frac{\operatorname{Re}^{1 / 2} \operatorname{Pr}^{2 / 3} S_{R}^{1 / 2}}{P_{C R}}+5.84
$$

Since the reiationship between the critical sound pressure and the frequency of the sound field has not been established, it was impossible to combine the correlations at different frequencies into a single one. 
TABLE 4

Summary of Slope and Intercept for Correlations

at Different Frequencles

Frequency

(kcps)

$\frac{N_{w} / N_{0} \text { plot }}{\text { Slope }}$

Low Heat Flux Region

$\begin{array}{ccccc}20.6 & 0.0305 & 1.34 & 0.0139 & 1.20 \\ 44.1 & 0.0402 & 1.56 & 0.0191 & 1.48 \\ 108 & 0.0732 & 1.09 & 0.0303 & 1.21 \\ 306 & 0.174 & 1.22 & 0.0573 & 1.49\end{array}$

High Heat Flux Region

$\begin{array}{llllll}20.6 & 0.00470 & 5.84 & - & - \\ 44.1 & 0.00471 & 2.96 & - & - \\ 108 & 0.00881 & 0.745 & \vdots & - & -\end{array}$


The exponent of 0.5 for the percentage of soil removed in all correlations, when viewed in the light of penetration theory, Indicates that the percentage of soil removed is related to the turbulent intensity of the liquid resulting from cavitation.

5. The increase in heat transfer coefficient resulting from ultrasonic vibrations depended on the 1iquid used as well as its temperature. Liquid with low gas solubility would yield higher heat transfer coefficients and higher heat transfer rates would be obtained in liquid at a higher temperature.

6. For the range of frequency of sound field studied, the effect of frequency was negligible if the cavitation activity of the 1 iquid was the same. In order to have the same cavitation activity in a liquid, higher frequency means that more acoustic energy is required. 


\section{NOMENCLATURE}

ROMAN SYMBOLS

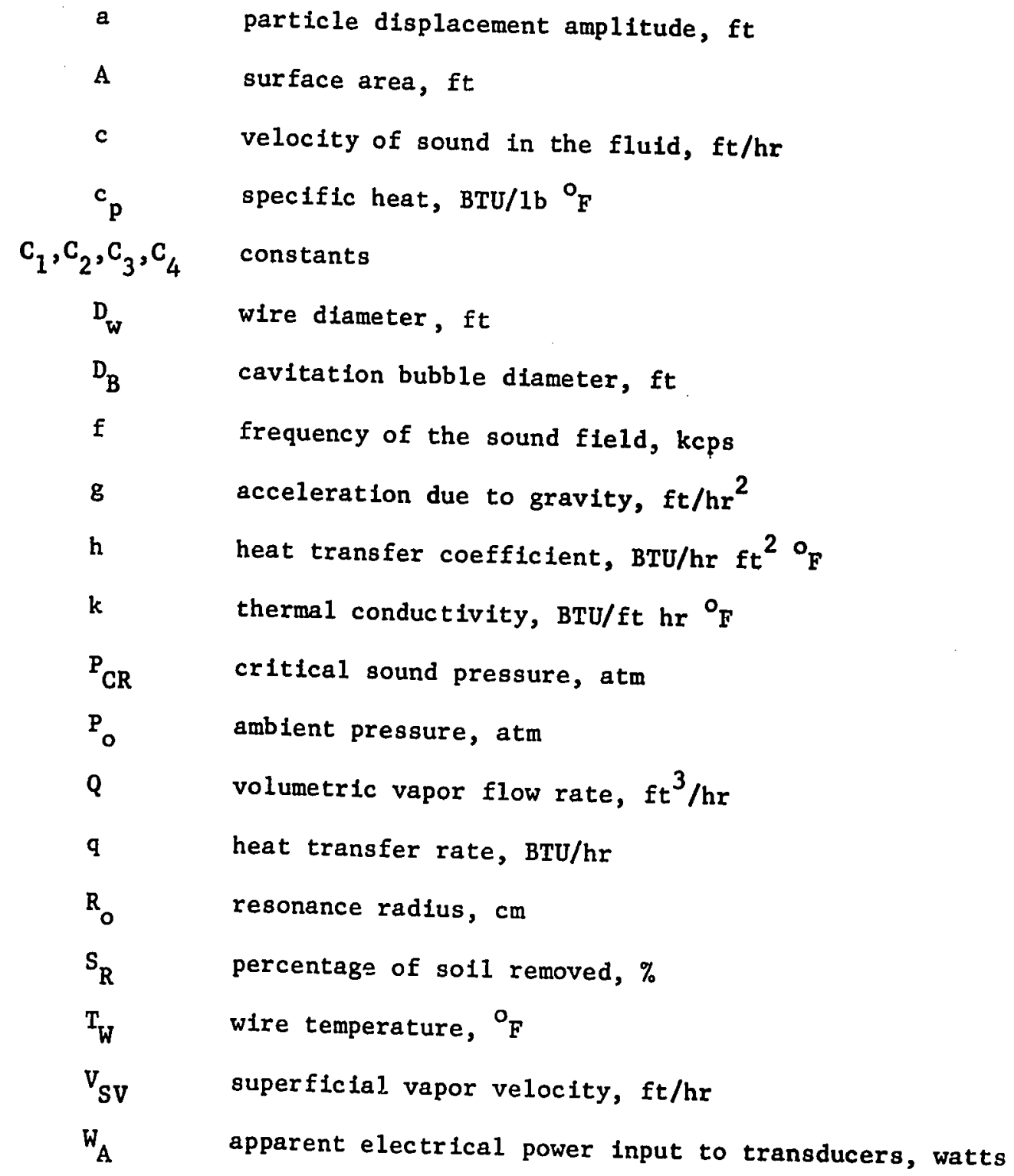

GREEK SYMBOLS

B coefficient of thermal expansion of fluid, $o_{F}^{-1}$ 


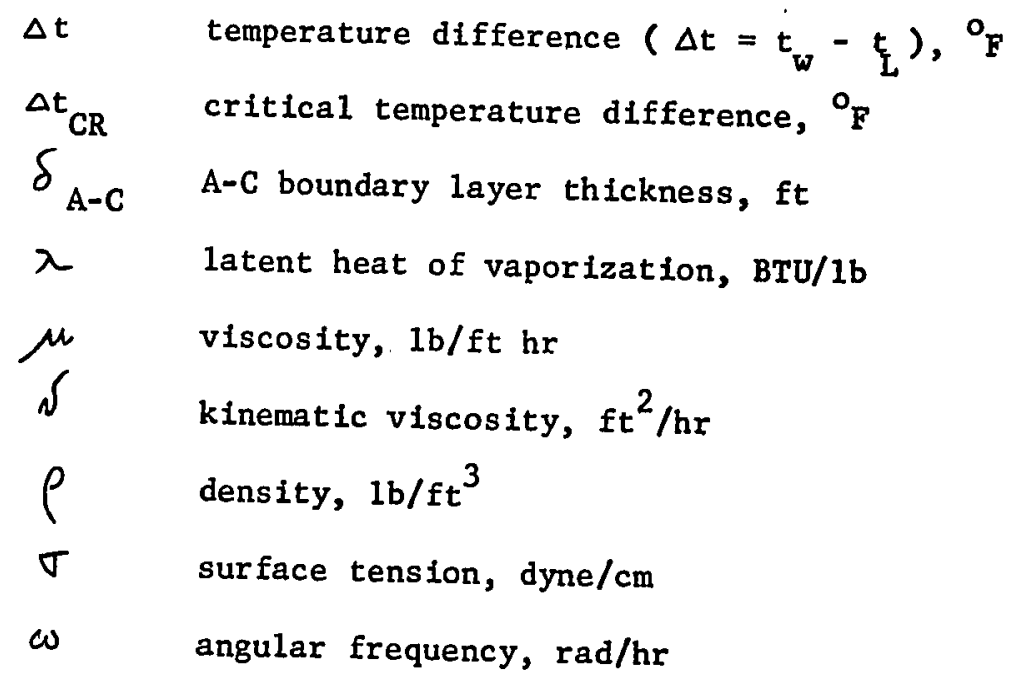

\section{DIMENS IONLESS GROUPS}

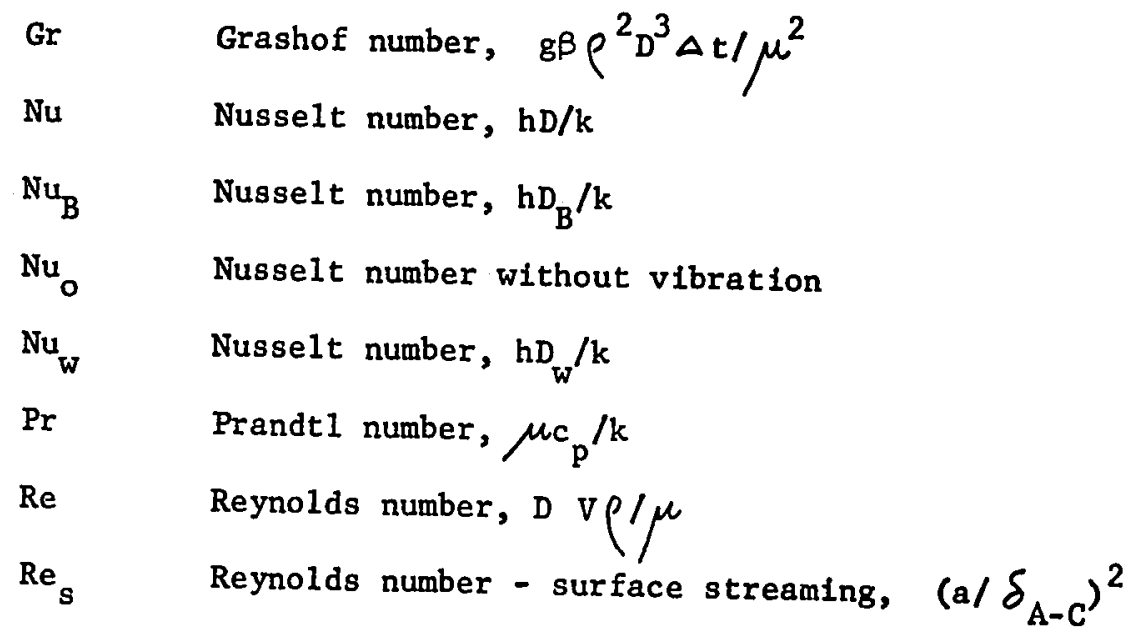

SUBSCRIPTS

B

L

$\mathrm{v}$

w cavitation bubble

1 iquid

vapor

wire 


\section{REFERENCES}

1. Westwater, J.W., paper presented at the 1960 Annual ASME Meeting, New York.

2. Courty, C. and A. Foust. Chem.Eng. Progr. Symp. Ser., 51, 1 (1955).

3. Clark, H. B., P.S. Strenge, and J.W. Westwater. Chem. Eng.Progr. Symp.Ser., 55, 103 (1959).

4. McAdams, W.H., J.N. Addoms, R.M. Rinaldo and R.S. Day. Chem.Eng. Progr. 44, 639 (1948).

5. McAdams, W.H. "Heat Transmission", McGraw-H111, p. 176, (1954).

6. Gunther, F.C. and F. Kreith, Heat Transfer and Fluid Mechanics Institute, p. 113 (1949).

7. Barger, J.E. Tech.Memo. No. 57, Acoustic Research Lab., Harvard University, Apri1 (1964).

8. Heuter, T.F. and R.H. Bolt. "Sonics". John Wiley. p. 229 (1955).

9. Hsieh, D.Y. and M.S. Plesset, J.Acoust.Soc.Am., 33, 206 (1961).

10. Lieberman, D. Phys.Fluids, 2, 466 (1959).

11. Isakoff, S.E. Proc.Heat Transfer and Fluid Mechanics Inst., Stanford University Press, Stanford, Calif., 15 (1956).

12. Romie, F.E. and C.A. Aronson, ATL-A-123, Joint U.S.-Euratom Research and Development Report, July (1961).

13. Ornatski1, A.P. and V.K. Shcherbakov. Teploenergetika, 6, 84 (1959). Translation appears in Ref. (65) In the Literature Review Section.

14. Esche, R. Akust. Bethefte, 4, 208 (1952). 
15. Kutateladze, S.S. J.Heat Mass Transfer, 4, 31 (1961).

16. Jakob, M. Mech.Eng., 58, 643, 729 (1936).

17. Danckwerts, P.V. Ind.Eng.Chem. 43, 1460 (1951).

18. Danckwerts, P.V. A.I.Ch.E. Journal, 1,456 (1955).

19. Bebchuk, A.S. In.Ia. Borisov, and L. D. Rosenberg. Soviet Physics - Acoustics, 4, 372 (1958).

20. Eckert, C. Phys.Rev., 73, 68 (1948).

21. Westerve1t, P.J. J.Acoust.Soc.Am., 32, 337 (1960).

22. Rohsenow, W: Trans.Am.Soc.Mech.Engrs., 74, 969 (1952). 


\section{PART III}

\section{EFFECTS OF ULTRASONIC VIBRATIONS ON BURNOUT HEAT}

\section{FLUX AND CRITICAL TEMPERATURE DIFFERENCE}

\section{INTRODUCTION}

The critical temperature difference is the temperature difference which produces a maximum heat flux value, or the burnout heat flux. It is desirable to operate steam-heated evaporators, vaporizers, and rebollers as closely as possible to the critical temperature difference. On the other hand, it is necessary to operate electrically heated bollers and nuclear reactors, in both of which the energy generation rates are relatively independent of material temperatures, at a temperature difference which is safely below the critical value. At temperature differences above the critical value, the mechanism of heat transfe changes from nucleate boiling to film boiling resulting In a sudden increase in the heater temperature which usually exceeds the melting point of the heating element. Information on the factors which determine the critical temperature difference or which can change the critical value is useful in the design of these systems.

The objective of this study was to determine the effects of ultrasonic vibrations at a frequency of $20.6 \mathrm{kcps}$ on the critical temperature difference and the burnout heat flux in methanol at $119^{\circ} \mathrm{F}$ with platinum wire of 0.007 in. diameter as the heating element. 
EXPER IMENTAL

The same apparatus and procedure used to study the effects of ultrasonic vibrations on heat transfer to Iiquids in Part II were used. A platinum wire of 0.007 in. diameter was used as the heating element, and the diameter of the potential leads was 0.002 in. The test section of the heating element was approximately $3 / 4 \mathrm{in.} \mathrm{1ong.} \mathrm{The}$ 1iquid was methanol maintained at a temperature of $113^{\circ} \mathrm{F} \pm 1^{\circ} \mathrm{F}$ in a11 experiments.

The burnout heat $f l u x$ and the critical temperature difference were measured both with and without vibrations. When there was no vibration, the DC current passing through the heating element was increased by small increments until the wire burned out. The burnout heat flux and the critical temperature difference were calculated from the last set of data taken on the voltage drops across the test section and the standard resistor.

The burnout heat flux and the critical temperature difference with ultrasonic vibrations were measured only at a frequency of $20.6 \mathrm{kcps}$. The voltage drop across the transducers was adjusted to 40 volts so that the apparent electrical power input to the transducers was 86 watts which was the highest acoustic energy level used in Part II. The corresponding percentage of soil removed for methanol at $113^{\circ} \mathrm{F}$ was 13.4\%. The procedure for measuring the burnout heat flux and the critical temperature difference with ultrasonic vibrations was the same as that when there was no vibration. 
RESULTS AND DISCUSSION

The burnout heat flux together with the critical temperature difference both with and without vibrations are summarized in Table $I$ and Figure 1. The experimental data are given in Table D-5 in Appendix D.

As mentioned earlier, distilled water was not used in this study because the amperage output of the existing regulated $D C$ power supply was too low to cause burnout.

The experimental error for the results shown in Table 1 was the same as that given for the heat transfer results for natural convection and surface bolling, namely $5 \%$ in the heat flux values and about $2^{\circ} \mathrm{F}$ in the temperature difference. The mean value and its standard deviation for the critical temperature difference were calculated to be $96^{\circ} \mathrm{F} \pm 3 \%$ for the case without vibration and $96^{\circ} \mathrm{F} \pm 4 \%$ for the case with vibrations. The corresponding values for burnout heat flux were $412,000 \mathrm{BTU} / \mathrm{hr} \mathrm{ft}^{2} \pm 8 \%$ and $369,000 \mathrm{BTU} / \mathrm{hr} \mathrm{ft}^{2} \pm 7 \%$. The scatter was mainly due to the instability of the burnout phenomenon. The data on burnout heat flux reported by Morozor ${ }^{(1)}$ how a maximum variation about the mean of $\pm 11 \%$, while the results of Howell and Bell ${ }^{(2)}$ scatter $\pm 19 \%$ (vs. $\pm 6 \%$ stated experimental error).

It can be seen that ultrasonic vibrations did not have any effect on the critical temperature difference at the frequency studied. The $10 \%$ decrease in the value of burnout heat flux when ultrasonic vibrations were applied was also too small to justify a conclusion on the 
TABLE 1

\section{Effects of Ultrasonic Vibrations on Burnout Heat Flux}

and Critical Temperature Difference

$$
\begin{aligned}
\text { Platinum Wire Diameter } & =0.007 \mathrm{in} . \\
\text { Test Liquid } & =\text { Methanol }\left(B_{*} P_{\bullet}=148^{\circ} \mathrm{F}\right) \\
\text { Temperature of the Liquid } & =113^{\circ} \mathrm{F} \\
\text { Frequency of Vibration } & =20.6 \mathrm{kcps}
\end{aligned}
$$

Run No.

R41

R41a

R40

R43

R46

R42

R44

R45

R48

R49

R47

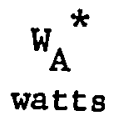

0

0

0

0

0

86

86

86

86

86

86

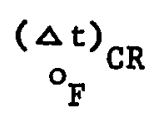

93

93

99

96

97

99

91

97

92

95

100
( $q / A)$ Burnout $\mathrm{BTU} / \mathrm{hr} \mathrm{ft}^{2}$

431,000

380,000

461,000

402,000

387,000

335,000

383,000

361,000

349,000

396,000

387,000

* $\mathrm{W}_{\mathrm{A}}=$ apparent electrical power input to the transducers. 
FIGURE 1

EFFECT OF $20.6 \mathrm{kcPs}$ ULTRASONIC VIBRATIONS ON BURNOUT HEAT FLUX AND CRITICAL TEMPERATURE DIFFERENCE IN METHANOL AT $113^{\circ} \mathrm{F}$ 


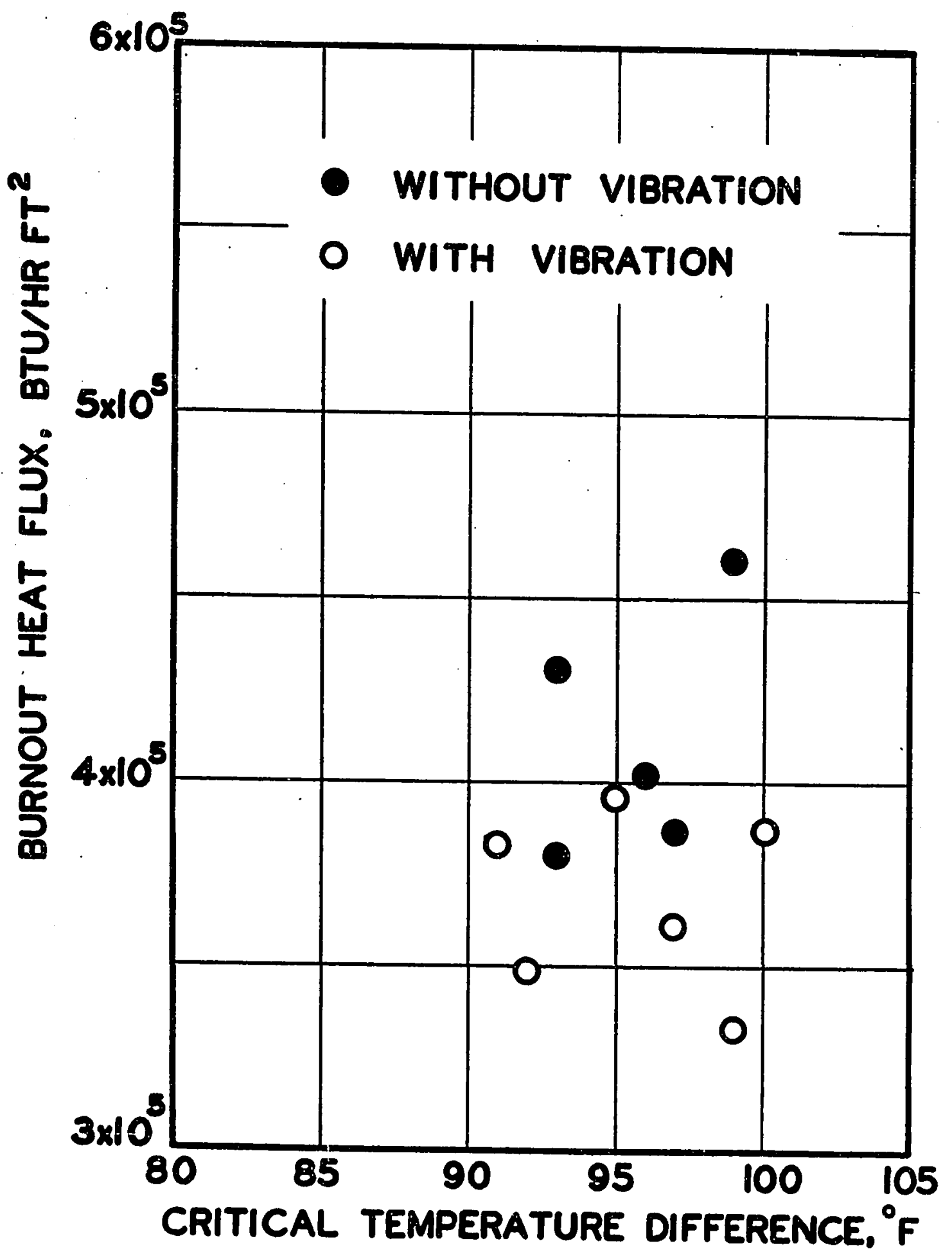


effects of ultrasonic vibrations on burnout heat flux.

In Part II of this investigation, the increase in heat transfer rates resulting from ultrasonic vibrations in the low heat flux region was due to the motion of cavitation bubbles on the wire surface. The effects diminished in the high heat flux region and finally became negligible in the well-developed nucleate boiling region, where the turbulence generated by the motion of the cavitation bubbles was overshadowed by the turbulence resulting from the growth and detachment of vapor bubbles. It is expected that ultrasonic vibration would not have any effect on both the burnout heat flux and the critical temperature difference.

As mentioned earlier, platinum wires with diameter of 0.0045 in. were used in preliminary experiments as heating elements. It was observed that they began to vibrate at heat flux values near the burnout point with the test liquid under intense ultrasonic vibrations $\left(W_{A}=86\right.$ watts $)$. While no visible vibration was observed when the diameter of the wire was changed to $0.007 \mathrm{in}$, it is doubtful whether vibration was eliminated completely.

One of the reasons that the present work was undertaken was due to the wide discrepancy in the published data on the effects of ultrasonic viliations on burnout neat fiux. Isakoff ${ }^{(3)}$ reported a $60 \%$ increase in the burnout heat flux and the data of Ornatskif and Shcherbakov $^{(4)}$ showed that up to $80 \%$ increase could be obtained depending on the degree of subcooling. Markels et a1. (5) and Romie and Aronson (6), however, reported that the effect of ultrasonic vibrations was negligible. 


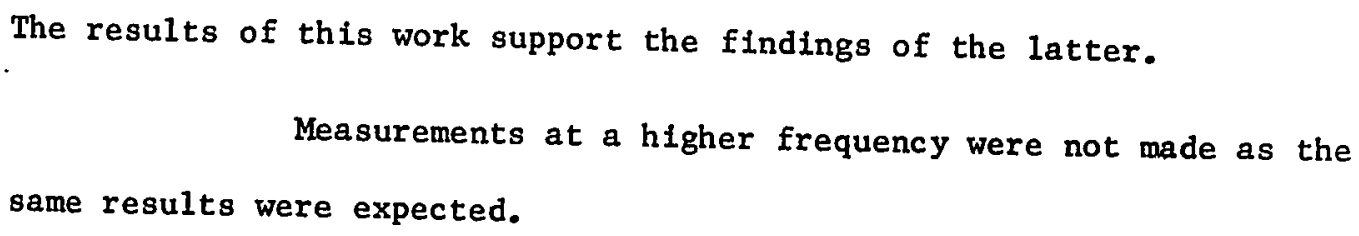

U1trasonic vibrations hà a negligible effect on the burnout heat flux and the critical temperature difference. 
REFERENCES

1. Morozov, V.G. Int.J.Heat Mass Transfer, $\underline{5}, 661$ (1962).

2. Howell, J.R. and K.J. Bell. Chem. Eng. Progr.Symp.Ser., No. 41, 59, 88 (1963).

3. Isakoff, S.E. Proc.Heat Transfer and Fluid Mechanics Inst., Stanford University Press, Stanford, Calif., 15 (1956).

4. Ornatski1, A.P. and V.K. Shcherbakov. Teploenergetika, 6, 84 (1959). Translation appears in (5).

5. Marke1s, M., R.I. Durfee, and R. Richardson. USAEC, NYO-9500, September (1960).

6. Romie, F.E. and C.A. Aronson. ATL-A-123, Joint U.S. - Euratom Research and Development Report, July (1961). 


\section{SUMMARY AND CONTRIBUTION TO KNOWLEDGE}

The effects of ultrasonic vibrations on natural convection and surface boiling heat transfer from electrically heated, horizontal, platinum wires of diameters 0.007 and 0.010 in. were measured. Two liquids, distilled water and methanol were used at three different acoustic intensity levels with frequency varying from 20.6 to $306 \mathrm{kcps}$. The temperatures of the distilled water were $113^{\circ} \mathrm{F}$ and $149^{\circ} \mathrm{F}$ and of methanol, $95^{\circ} \mathrm{F}$ and $113^{\circ} \mathrm{F}$, when the frequency was $20.6 \mathrm{kcps}$. For other frequencies, namely $44.1,108$ and $306 \mathrm{kcps}$, the temperature was $149^{\circ} \mathrm{F}$ and $113^{\circ} \mathrm{F}$ for distllied water and methanol, respectively.

1. When compared with the heat transfer rates without vibration, the effects of ultrasonic vibrations varled from an $800 \%$ increase in the natural convection region to no effect in the well-developed nucleate boiling region. In all cases, however, no increase in heat transfer rates was observed until the critical sound pressure was applied. The critical sound pressure was a function of the liquid used and its temperature, the frequency of the sound field, as well as the heat transfer surface temperature. At surface temperatures corresponding to the natural convection region, the critical sound pressure was equivalent to the cavitation threshold of the 1 iquid at the heat transfer surface.

2. The increase in heat transfer was due to the intense turbulence resulting from the radial oscillations as well as the rapid and erratic motion of the cavitation bubbles on the heat transfer 
surface, as shown by the results of high speed photographic study. The characteristics of the cavitation bubbles resembled those of a gaseous cavitation bubble with content varying from mainly gas to mainly vapor depending on the surface temperature and the gas solubility in the liquid. An increase in the surface temperature also increased the population and the activity of the cavitation bubbles. At sufficiently high surface temperatures, the turbulence generated by the motion of the cavitation bubbles could not exceed that resuiting from the growth and detachment (collapse) of vapor bubbles as in the well-developed nucleate boiling when there was no vibration and no increase in heat transfer rate was observed.

3. A technique using cavitation damage to measure the cavitation activity of the liquid at the unheated platinum wire surface was developed and the results used to correlate the heat transfer data. This quantity, the percentage of soil removed, however, did not take into account the thermal gradient in the liquid near a heated wire. Consequent1y, it was necessary to separate the heat transfer results into two regions, using the heat flux value at the incipience of boiling as the criterion. In the low heat flux region (natural convection), the wire temperature effect was reflected in the high exponent of the Grashof number while a cavitation bubble Reynolds number was defined to account for the wire temperature effect in the high heat flux region (nucleate boiling region). The final correlations for the two heat flux regions take the form of 
Low Heat Flux Region

$$
\mathrm{Nu}_{\mathrm{w}}=\mathrm{c}_{1} \frac{(\mathrm{Gr} \mathrm{Pr})^{1 / 2}\left(\mathrm{~S}_{\mathrm{R}}\right)^{1 / 2}}{\mathrm{P}_{\mathrm{CR}}}+\mathrm{c}_{2}
$$

\section{High Heat Flux Region}

$$
\mathrm{Nu}_{B}=c_{3} \frac{\mathrm{Re}^{1 / 2} \mathrm{Pr}^{2 / 3} \cdot \mathrm{S}_{\mathrm{R}}^{1 / 2}}{\mathrm{P}_{\mathrm{CR}}}+\mathrm{c}_{4}
$$

$C_{1}, C_{2}, C_{3}$ and $C_{4}$ are constants. For each frequency, there was one set of constants. These constants are given in the following table.

Frequency (kcps)

$$
c_{1}
$$

20.6

$$
0.0305
$$

44.1

0.0402

108

306

$$
0.0732
$$$$
0.174
$$

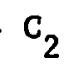

1.34

1.56

1.09

1.22
$\mathrm{C}_{3}$

$\mathrm{C}_{4}$

0.00470

0.00471

5.84

2.96

0.00881

0.745

The correlations for different frequencles could not be combined because the relation between the frequency and the critical sound pressure has not been established.

The exponent of 0.5 for the percentage of soll removed, when viewed in the light of penetration theory, Indicates that the percentage of soll removed is related to the contact time which measures the turbulent intensity of the liquid resulting from cavitation.

4. The effect of liquid as well as the liquid temperature on heat transfer in a sound field was studied. Since a cavitation bubble 
with high vapor content would collapse on the heat transfer surface and thus generate more turbulence, the liquid with lower gas solubility gave higher increase in heat transfer rates. High heat rates were also obtained at a higher temperature where both the cavitation threshold and the critical sound pressure were lowered. With the same electrical power input to the system, the result was an increase in the cavitation activity in the bulk liquid and on the heat transfer surface.

5. The effect of the frequency of the sound field was negligible if the same cavitation activity in the Iiquid was used. In order to achieve the same cavitation activity, more acoustic energy was required when the frequency was increased.

6. The effect of ultrasonic vibrations on the burnout heat flux and the critical temperature difference in methanol was studied at a . frequency of $20.6 \mathrm{kcps}$. The bulk liquid temperature was $113^{\circ} \mathrm{F}$ and the wire was platinum with 0.007 in. diameter. No effect of vibration was found. 


\section{SUGGESTIONS FOR FUTURE WORK}

1. The critical sound pressure appears to be the most important variable in the heat transfer processes being studied. In the low heat flux region, the critical sound pressure is equivalent to the cavitation threshold of the liquid at the heat transfer surface. Since little information is available on the cavitation thresholds of liquids at high temperatures, it is suggested that this information should be obtained, for example, for water at temperatures up to its boiling point. The cavitation thresholds of liquids at high temperatures can best be measured in a focussed standing wave system where the damage to the pressure probe by the cavitation process can be avolded by placing the probe at the secondary pressure maximum of the sound field. The pressure probe should be made of a piezoelectric material such as lead zirconate having a high curie point.

2. Although it has been established that the increase in heat transfer rate is the result of the motion of cavitation bubbles on the heat transfer surface, the mechanisms through which a cavitation bubble is formed and by which it grows and becomes unstable are not fully understood. Using the focussed standing wave system mentioned above and a point heat source located at the pressure maximum, the mechanism can be established much more eas1ly. In fact, this should be a better system for studying the effects of ultrasonic vibrations on heat transfer since the sound pressures above the cavitation 
threshold level can be measured with a pressure probe, and thus eliminates the cavitation damage measurement completely.

3. One subject on which almost no quantitative information exists is the mechanism by which a foreign body in a liquid can become a cavitation nucleus. Such information is useful as it may be possible to generate artificlal cavitation nuclei on or near the heat transfer surface to affect the heat transfer rates. Specifically, the problem involves a study of the dependence of wetting angle and boundary geometry on 1iquid-gas interfacial motion under ultrasonic vibration. This problem can also be studied by using the focussed standing wave system and by creating artificial nucleus of known geometry on a solid surface located at the pressure maximum of the sound field.

4. A regulated DC power supply with increased amperage output could be used so that more data can be obtained for distilled water in the high heat flux region. With a large $D C$ power supply, larger platinum wire diameters can be used as heating elements in measuring the heat transfer rate at burnout point so that vibration of the heating element may be eliminated.

5. It is suggested that heat transfer data should be obtained using a forced convective system as it may have more industrial significance. 


\section{APPENDIX A}

\section{INFORMATION ON TRANSDUCERS USED IN THIS WORK}

\section{The magnetostrictive transducers used for low}

frequency work, namely for 20.6 and 44.1 kcps were ferroxcube 7A2, double-dumb-bell transducers with ferroxcube biasing slabs, and manufactured by Philips. For higher frequencies, Glennite High Temperature ceramic transducers made of lead zirconate and manufactured by Gulton Industries were used. They were $1.5 \mathrm{in}$. diameter discs with electrodes and leads and vibrated in thickness mode. The Body No. was 41 for the frequency of $108 \mathrm{kcps}$ and 31 for $306 \mathrm{kcps}$. Three transducers were used for all frequencies except in the case of $20.6 \mathrm{kcps}$ where only two transducers were used.

\section{Cementing Procedure}

All transducers were cemented onto the bottom of the stainless steel tank ( $71 / 2$ in. $\times 41 / 2$ in. $\times 6$ in. deep). Before they were cemented, the surfaces of the transducers and metal walls were sanded with a fine emery cloth and then degreased for four minutes in a mixture of one part by volume of concentrated sulphuric acid, one part of concentrated nitric acid and eight parts of water. The ceramic transducer surfaces, however, were not prepared since the process might damage the electrodes and leads. 
To cement two pieces, the surfaces were carefully covered with a thin, homogeneous layer of Armstrong epoxy Al2T and then pressed lightly together. The joint was hardened for 24 hours at room temperature.

\section{Arrangement of Transducers}

The arrangements of transducers on the bottom of the stainless steel tank for various frequencies are shown in Figures A-1 to A-3. The length or the thickness of the transducers which depends on the frequency is also given.

\section{Impedance Matching of Transducers}

A magnetostrictive transducer is inductive because of the inductance of its coil while a piezoelectric transducer is capacitive due to the capacitance of the ceramics. In order to get the maximum acoustic energy output from a transducer, the inductance or the capacitance should be tuned out. For the magnetostrictive transducers used in this work, the required capacitance was calculated by an empirical equation given by the manufacturer. For the ceramic transducers the matching component was calculated from the equation 


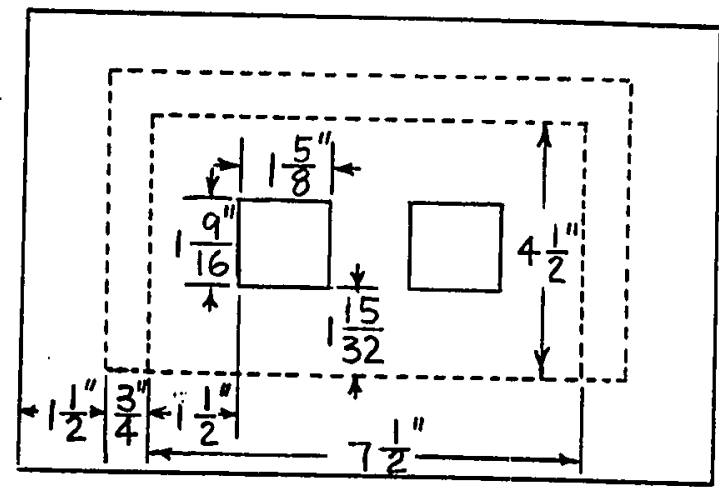

FIGURE A-1

$f=20.6 \mathrm{kcps}$

Length of transducer $=3.8 \mathrm{in}$.
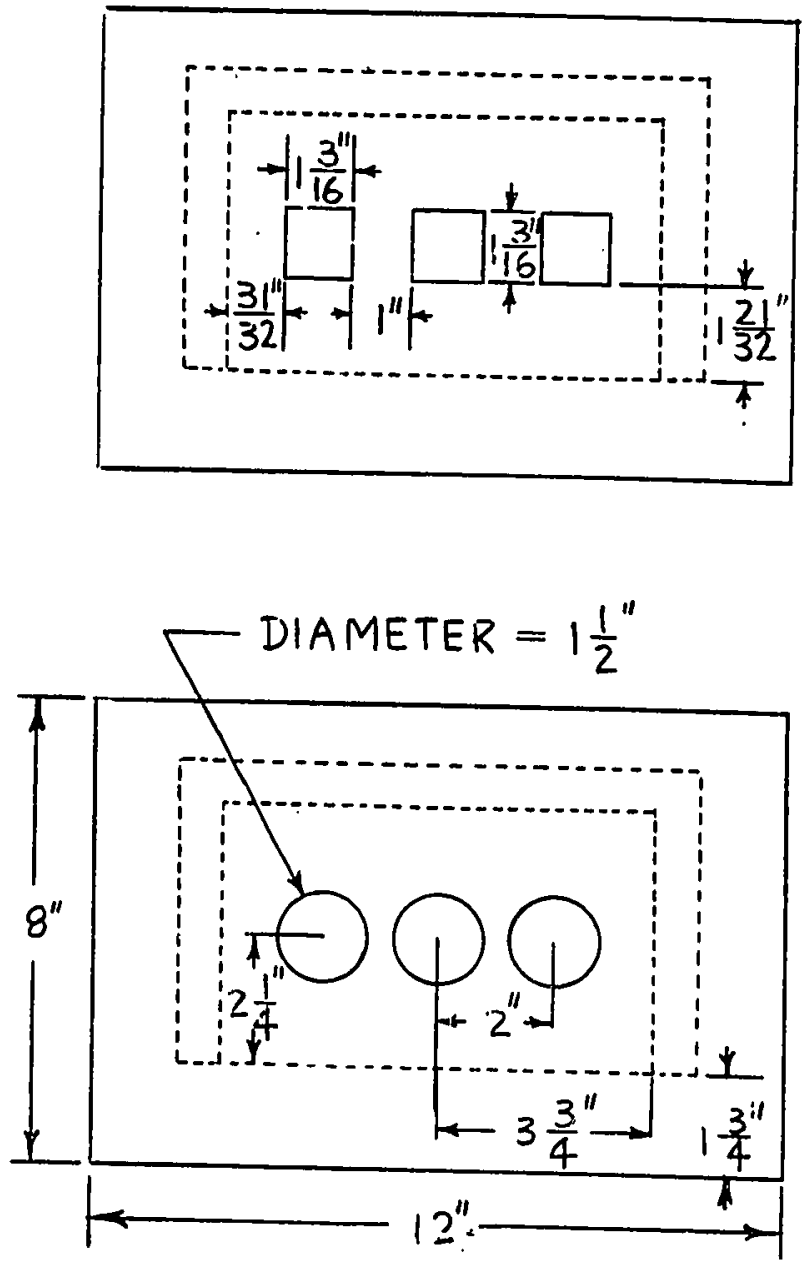

FIGURE A-2

$\tilde{z}=44.1 \mathrm{kcps}$

Length of transducer $=1.98$ in .
FIGURE A-3

Frequency Transducer

kcps

Thickness

108

306
0.75

in.

0.25 


$$
L=\frac{1}{\omega^{2} c}
$$

where L - inductance

$$
\begin{aligned}
& \omega \text { - angular frequency } \\
& c \text { - capacitance. }
\end{aligned}
$$

In both cases, minor adjustments in the matching component in the vicinity of the calculated value were required so that a satisfactory match was achieved. The acoustic energy output from a transducer was very sensitive to the driving frequency. After the determination of the matching component, the frequency of the system was varied in the vicinity of its previous value until the maximum acoustic energy output was obtained. The following table lists the matching components used for the various transducers. A satisfactory energy output was obtained in the case of 306 kcps transducers without using a matching component, so none was used.

Transducer

$20.6 \mathrm{kcps}$ (two in parallel)

44.1 kcps (three in series)

108 kcps (three in parallel)

306 kcps (three in parallel)
Matching Component

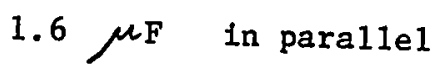

$0.35 \mu \mathrm{F}$ in parallel

$1.7 \mathrm{mh}$ in parallel

Relationship Between the Apparent Electrical Power Input to the Transducers and the Voltage Drop Across the Transducers

The relationships between the apparent electrical power input to the transducers $\left(W_{A}\right)$ and the voltage drop across the transducers for 
various frequencies are shown in Figures $\mathrm{A}-4$ and $\mathrm{A}-5$. 

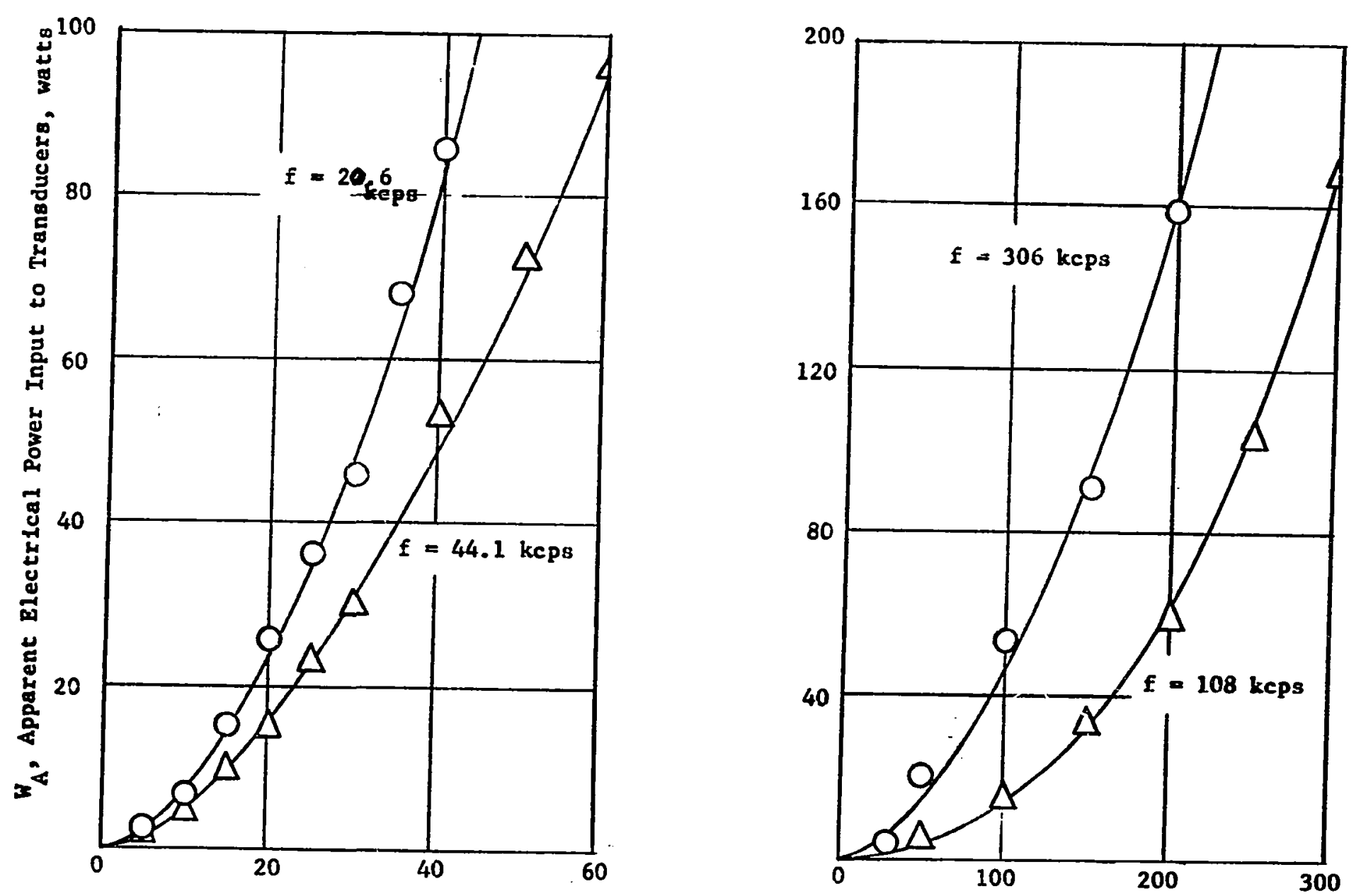

Voltage Drop Across the Transducers, Volts 


\section{APPENDIX B}

SOUND PRESSURE DATA 
TABLE B-1

LIQUID: Methanol TEMPERATURE: $113^{\circ} \mathrm{F}$ FREQUENCY: $20.6 \mathrm{kcps}$

\begin{tabular}{|c|c|c|c|c|c|c|c|c|c|}
\hline \multirow{2}{*}{$\stackrel{{ }_{A}}{W_{A}}$} & \multicolumn{6}{|c|}{$\mathrm{E}_{\mathrm{rms}}$ (volts) } & \multirow{2}{*}{$\begin{array}{l}\mathrm{E}_{\mathrm{s}} \\
\text { (rms) }\end{array}$} & \multirow[b]{2}{*}{$\begin{array}{c}P_{s} \\
\text { atm. }\end{array}$} & \multirow[b]{2}{*}{$\left(P_{p}\right)$} \\
\hline & 0.0 & $\begin{array}{l}0.2^{\prime \prime} \\
\text { (dis }\end{array}$ & $\begin{array}{l}0.4^{\prime \prime} \\
\text { ance }\end{array}$ & $\begin{array}{l}0.6^{\prime \prime} \\
\text { ong w }\end{array}$ & $0.8^{\prime \prime}$ & $1.0^{\prime \prime}$ & & & \\
\hline $\begin{array}{l}1.0 \\
2.0 \\
4.8 \\
7.0\end{array}$ & $\begin{array}{l}.0058 \\
.0082 \\
.0106 \\
.012\end{array}$ & $\begin{array}{l}.0060 \\
.0083 \\
.0110 \\
.013\end{array}$ & $\begin{array}{l}.0062 \\
.0084 \\
.0110 \\
.013\end{array}$ & $\begin{array}{l}.0060 \\
.0083 \\
.0110 \\
.012\end{array}$ & $\begin{array}{l}.0058 \\
.0080 \\
.0107 \\
.011\end{array}$ & $\begin{array}{l}.0054 \\
.0080 \\
.0105 \\
.011\end{array}$ & $\begin{array}{l}.0058 \\
.0082 \\
.0108 \\
.012\end{array}$ & $\begin{array}{l}.076 \\
.11 \\
.14 \\
.16\end{array}$ & \\
\hline
\end{tabular}

TABLE B-2

LIQUID: Methano1 TEMPERATURE: $95^{\circ} \mathrm{F}$ FREQUENCY: $20,6 \mathrm{kcps}$

\begin{tabular}{|c|c|c|c|c|c|c|c|c|c|}
\hline \multirow{2}{*}{$\underset{\text { (watts) }}{\mathrm{W}_{\mathrm{A}}}$} & \multicolumn{6}{|c|}{$\mathrm{E}_{\text {rms }}$ (volts) } & \multirow{2}{*}{$\underset{(\mathrm{rms})}{\mathrm{E}_{\mathrm{s}}}$} & \multirow{2}{*}{$\begin{array}{c}P_{s} \\
\text { atm. }\end{array}$} & \multirow{2}{*}{$\left(P_{p}\right)$} \\
\hline & 0.0 & $\begin{array}{l}0.2^{\prime \prime} \\
\text { (dis }\end{array}$ & $\begin{array}{l}0.4^{\prime \prime} \\
\text { tance a }\end{array}$ & $\begin{array}{l}0.6^{\prime \prime} \\
\text { Long w }\end{array}$ & $0.8^{\prime \prime}$ & $\overline{1.0^{\prime \prime}}$ & & & \\
\hline $\begin{array}{l}1.0 \\
2.0 \\
4.8 \\
7.0\end{array}$ & $\begin{array}{l}.0055 \\
.0078 \\
.0093 \\
.011\end{array}$ & $\begin{array}{l}.0056 \\
.0080 \\
.0094 \\
.012\end{array}$ & $\begin{array}{l}.0057 \\
.0080 \\
.0095 \\
.013\end{array}$ & $\begin{array}{l}.0056 \\
.0079 \\
.0093 \\
.011\end{array}$ & $\begin{array}{l}.0054 \\
.0075 \\
.0093 \\
.010\end{array}$ & $\begin{array}{l}.0053 \\
.0076 \\
.0090 \\
.009\end{array}$ & $\begin{array}{l}.0055 \\
.0078 \\
.0093 \\
.011\end{array}$ & $\begin{array}{l}.072 \\
.10 \\
.12 \\
.14\end{array}$ & $\begin{array}{l}\text { 1) } \\
\text { 16) } \\
\text { 23) } \\
\text { 27) }\end{array}$ \\
\hline
\end{tabular}

\section{TABLE B-3}

LIQUID: Distilled Water TEMPERATURE: $149^{\circ} \mathrm{F}$ FREQUENCY: $20.6 \mathrm{kcps}$

\begin{tabular}{|c|c|c|c|c|c|c|c|c|c|}
\hline \multirow{2}{*}{$\begin{array}{c}\mathrm{W}_{\mathrm{A}} \\
\text { (watts) }\end{array}$} & \multicolumn{6}{|c|}{$E_{r m s}$ (volts) } & \multirow{2}{*}{$\begin{array}{c}E_{s} \\
\text { (rms) }\end{array}$} & \multirow[b]{2}{*}{$\begin{array}{c}P_{s} \\
\text { acm. }\end{array}$} & \multirow{2}{*}{$\left(P_{p}\right)$} \\
\hline & 0.0 & $\begin{array}{l}0.2^{\prime \prime} \\
\quad \text { (dis }\end{array}$ & $\begin{array}{l}0.4^{\prime \prime} \\
\text { ance }\end{array}$ & $\begin{array}{l}0.6^{\prime \prime} \\
\text { long w }\end{array}$ & $0.8^{\prime \prime}$ & $1.0^{\prime \prime}$ & & & \\
\hline $\begin{array}{r}1.0 \\
2.0 \\
4.8 \\
7.0 \\
15.6\end{array}$ & $\begin{array}{l}.0065 \\
.0115 \\
.014 \\
.020 \\
.026\end{array}$ & $\begin{array}{l}.0074 \\
.0125 \\
.016 \\
.022 \\
.027\end{array}$ & $\begin{array}{l}.0076 \\
.0125 \\
.016 \\
.022 \\
.028\end{array}$ & $\begin{array}{l}.0074 \\
.0120 \\
.016 \\
.021 \\
.026\end{array}$ & $\begin{array}{l}.0067 \\
.0115 \\
.015 \\
.021 \\
.025\end{array}$ & $\begin{array}{l}.0063 \\
.0110 \\
.013 \\
.020 \\
.024\end{array}$ & $\begin{array}{l}.0070 \\
.0120 \\
.015 \\
.021 \\
.026\end{array}$ & $\begin{array}{l}.092 \\
.16 \\
.20 \\
.27 \\
.34\end{array}$ & $\begin{array}{l}.14) \\
.24) \\
.34) \\
.50) \\
.60)\end{array}$ \\
\hline
\end{tabular}


TABLE B-4

LIQUID: Dist11led Water TEMPERATURE: $113^{\circ} \mathrm{F}$ FREQUENCY: $20.6 \mathrm{kcps}$

\begin{tabular}{|c|c|c|c|c|c|c|c|c|c|}
\hline & & & ${ }_{\mathrm{rms}}$ & olts) & & & & & \\
\hline lat & 0.0 & $\begin{array}{l}0.2^{\prime \prime} \\
\text { (dis }\end{array}$ & $\begin{array}{l}0.4^{\prime \prime} \\
\text { Eance }\end{array}$ & $\begin{array}{l}0.6^{\prime \prime} \\
\text { long w }\end{array}$ & $\begin{array}{l}0.8^{\prime \prime} \\
\text { e) }\end{array}$ & $1.0^{\prime \prime}$ & $\begin{array}{c}s \\
\text { (rms) }\end{array}$ & atm. & 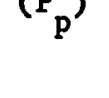 \\
\hline $\begin{array}{r}1.0 \\
2.0 \\
4.8 \\
7.0 \\
15.6\end{array}$ & $\begin{array}{l}.0065 \\
.0110 \\
.014 \\
.018 \\
.025\end{array}$ & $\begin{array}{l}.0066 \\
.0115 \\
.015 \\
.019 \\
.027\end{array}$ & $\begin{array}{l}.0067 \\
.0120 \\
.015 \\
.020 \\
.027\end{array}$ & $\begin{array}{l}.0066 \\
.0110 \\
.014 \\
.020 \\
.027\end{array}$ & $\begin{array}{l}.0064 \\
.0105 \\
.014 \\
.018 \\
.026\end{array}$ & $\begin{array}{l}.0062 \\
.0100 \\
.012 \\
.018 \\
.024\end{array}$ & $\begin{array}{l}.0065 \\
.011 \\
.0145 \\
.019 \\
.026\end{array}$ & $\begin{array}{l}.085 \\
.14 \\
.19 \\
.25 \\
.34\end{array}$ & $\begin{array}{l}(.13) \\
(.24) \\
(.34) \\
(.44) \\
(.58)\end{array}$ \\
\hline
\end{tabular}

TABLE B-5

LIQUID: Distilled Water TEMPERATURE: $149^{\circ} \mathrm{F}$ FREQUENCY: $44.1 \mathrm{kcps}$

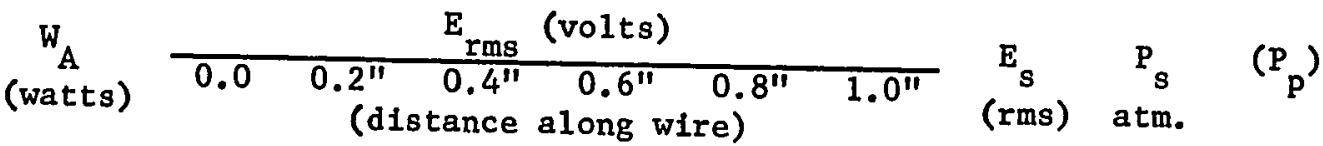

$\begin{array}{rlllllllll}0.5 & .080 & .0100 & .0110 & .0110 & .0110 & .090 & .0100 & .13 & (.20) \\ 1.3 & .0100 & .0110 & .0130 & .0130 & .0130 & .0120 & .0120 & .16 & (.24) \\ 3.2 & .0110 & .0125 & .0135 & .0135 & .0125 & .0120 & .0125 & .16 & (.25) \\ 4.6 & .0130 & .0140 & .0155 & .0155 & .0155 & .0130 & .0145 & .19 & (.33) \\ 9.5 & .018 & .020 & .022 & .022 & .019 & .019 & .020 & .26 & (.51) \\ 23.2 & .026 & .029 & .028 & .029 & .029 & .027 & .028 & .36 & (.62)\end{array}$

\section{TABLE B- 6}

LIQUID: Methano1 TEMPERATURE: $113^{\circ} \mathrm{F}$ FREQUENCY: $44.1 \mathrm{kcPs}$

\begin{tabular}{|c|c|c|c|c|c|c|c|c|c|}
\hline \multirow{2}{*}{$\begin{array}{c}{ }_{\mathrm{A}} \\
\text { (watts). }\end{array}$} & \multicolumn{6}{|c|}{$E_{\text {rms }}$ (volts) } & \multirow[b]{2}{*}{$\begin{array}{c}E_{s} \\
\text { (rms) }\end{array}$} & \multirow[b]{2}{*}{$\begin{array}{c}P_{s} \\
\text { atm. }\end{array}$} & \multirow{2}{*}{$\left(P_{P}\right)$} \\
\hline & 0.0 & $\begin{array}{l}0.2^{\prime \prime} \\
\text { (dis }\end{array}$ & $\begin{array}{l}0.4^{\prime \prime} \\
\text { zance }\end{array}$ & $\begin{array}{l}0.611 \\
\text { Long w }\end{array}$ & $\begin{array}{l}0.8^{\prime \prime} \\
\text { (e) }\end{array}$ & $\overline{1.0^{\prime \prime}}$ & & & \\
\hline $\begin{array}{l}0.5 \\
1.3 \\
3.2 \\
4.6 \\
9.5\end{array}$ & $\begin{array}{l}.0067 \\
.0096 \\
.0100 \\
.011 \\
.016\end{array}$ & $\begin{array}{l}.0068 \\
.0098 \\
.0110 \\
.013 \\
.018\end{array}$ & $\begin{array}{l}.0071 \\
.0100 \\
.0130 \\
.014 \\
.019\end{array}$ & $\begin{array}{l}.0071 \\
.0100 \\
.0130 \\
.015 \\
.019\end{array}$ & $\begin{array}{l}.0070 \\
.0098 \\
.0115 \\
.013 \\
.018\end{array}$ & $\begin{array}{l}.0067 \\
.0097 \\
.0105 \\
.012 \\
.017\end{array}$ & $\begin{array}{l}.0069 \\
.0098 \\
.0115 \\
.013 \\
.018\end{array}$ & $\begin{array}{l}.090 \\
.13 \\
.15 \\
. \frac{17}{.23}\end{array}$ & $\begin{array}{l}.13) \\
.20 \\
.24) \\
.31 \\
.47)\end{array}$ \\
\hline
\end{tabular}


TABLE B-7

LIQUID: Dist11led Water TEMPERATURE: $149^{\circ} \mathrm{F}$ FREQUENCY: $108 \mathrm{kcps}$

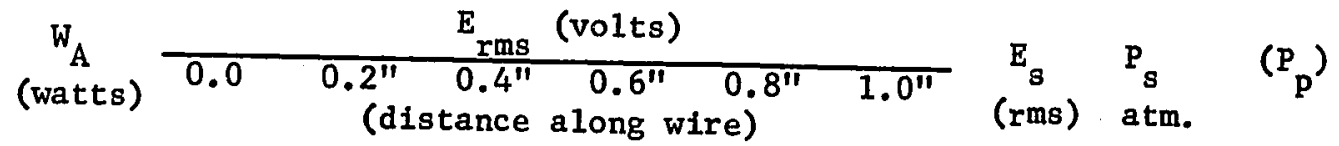

$\begin{array}{llllllllllll}16.0 & .026 & .027 & .029 & .029 & .026 & .025 & .027 & .35 & (.53)\end{array}$

$\begin{array}{llllllllll}24.0 & .032 & .035 & .037 & .036 & .032 & .032 & .034 & .45 & (.66)\end{array}$

$\begin{array}{llllllllll}34.2 & .039 & .040 & .043 & .043 & .042 & .039 & .041 & .53 & (.89)\end{array}$

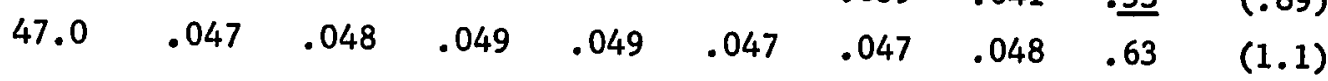

TABLE B-8

LIQUID: Methanol TEMPERATURE: $113^{\circ} \mathrm{F}$ FREQUENCY: $108 \mathrm{kcps}$

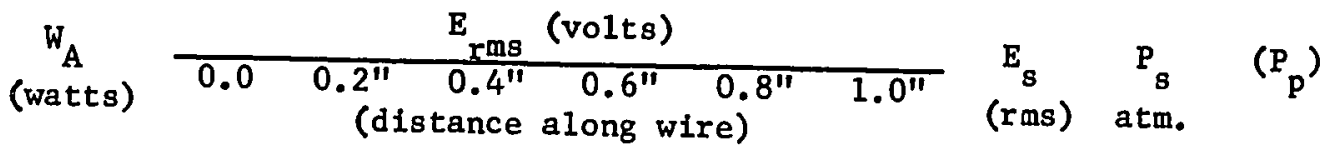

$\begin{array}{llllllllll}10.0 & .017 & .020 & .022 & .021 & .017 & .016 & .019 & .25 & (.38) \\ 16.0 & .025 & .027 & .027 & .028 & .025 & .024 & .026 & .34 & (.58) \\ 24.0 & .031 & .033 & .033 & .033 & .032 & .030 & .032 & .42 & (.76) \\ 34.2 & .037 & .038 & .038 & .038 & .036 & .035 & .031 & .48 & (.87)\end{array}$




\section{TABLE B-9}

LIQUID: Distilled Water

TEMPERATURE: $149^{\circ} \mathrm{F}$ FREQUENCY: $306 \mathrm{kcps}$

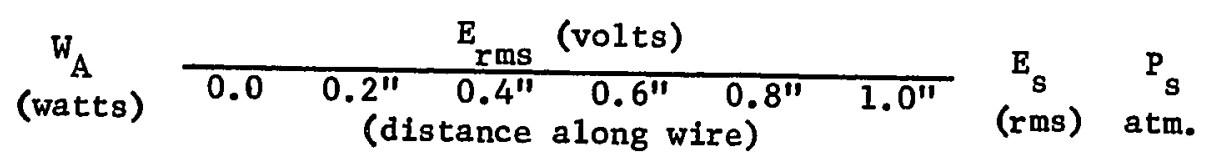

$\begin{array}{rllllllll}22 & .035 & .036 & .038 & .039 & .035 & .033 & .036 & .36 \\ 54 & .062 & .062 & .064 & .066 & .060 & .058 & .062 & .62 \\ 92 & .09 & .11 & .11 & .12 & .09 & .08 & .100 & 1.0 \\ 165 & .12 & .14 & .13 & .15 & .12 . & .12 & .13 & 1.3 \\ & & & & & & & & \text { (No cavitation) }\end{array}$

TABLE B-10

LIQUID: Methanol TEMPERATURE: $113^{\circ} \mathrm{F}$ FREQUENCY: $306 \mathrm{kcps}$

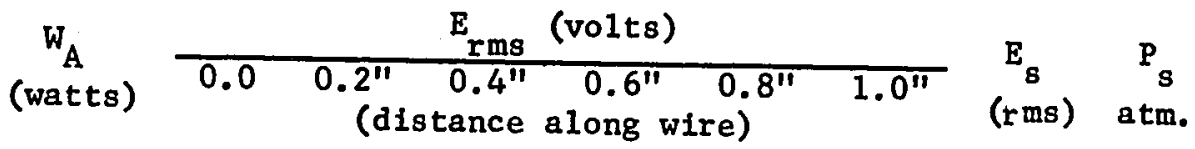

$\begin{array}{rrrrrrrrr}54 & .057 & .057 & .058 & .060 & .057 & .055 & .057 & .57 \\ 74 & .069 & .071 & .073 & .074 & .070 & .069 & .071 & .71 \\ 92 & .082 & .083 & .084 & .085 & .082 & .082 & .083 & .83 \\ 125 & .091 & .092 & .093 & .093 & .091 & .092 & .092 & .92\end{array}$


APPENDIX C

CAVITATION DAMAGE DATA 
TABLE C-1 *

Frequency : $20.6 \mathrm{kcps}$

Liquid : Distilled Water

Temperature: $149^{\circ} \mathrm{F}$

$\mathrm{W}_{\mathrm{A}}$
(watts)

RUN Al

$\begin{array}{ll}86.0 & 36200 \\ 86.0 & 37800 \\ 86.0 & 42300 \\ 86.0 & 41400 \\ 86.0 & 37200 \\ 86.0 & 35300 \\ 86.0 & 44400 \\ 86.0 & 42300 \\ 86.0 & 50100 \\ 86.0 & 49800 \\ 86.0 & 37700 \\ 86.0 & 36100\end{array}$

RUN A2

$\begin{array}{ll}68.2 & 38800 \\ 68.2 & 36200 \\ 68.2 & 46100 \\ 68.2 & 42100 \\ 68.2 & 44300 \\ 68.2 & 41900 \\ 86.0 & 47900 \\ 86.0 & 49200 \\ 86.0 & 35200 \\ 86.0 & 39900 \\ 86.0 & 39300 \\ 86.0 & 39400\end{array}$

$\mathrm{CPM}_{i}$
$\mathrm{CPM}_{\mathbf{f}}$

TIME

(min)

BACKGROUND $=486 \mathrm{CPM}$

$\begin{array}{lll}32500 & 0.5 & 15.5 \\ 30100 & 1.0 & 30.8 \\ 29200 & 1.5 & 47.0 \\ 24600 & 2.0 & 61.4 \\ 21700 & 3.0 & 63.4 \\ 17600 & 4.0 & 76.1 \\ 38200 & 0.5 & 21.0 \\ 34700 & 1.0 & 27.1 \\ 35000 & 1.5 & 45.7 \\ 32000 & 2.0 & 53.8 \\ 20100 & 3.0 & 71.0 \\ 18500 & 4.0 & 74.1\end{array}$

BACKGROUND $=772 \mathrm{CPM}$

34700
28600
28800
29100
23300
18600
41300
40400
24700
25900
21000
20300

0.5

1.0

2.0

1.5

3.0

4.0

0.5

1.0

1.5

2.0

3.0

4.0
$S_{R}(\%)$ 
TABLE C-1, continued

$\begin{array}{cc}\begin{array}{c}\mathrm{W}_{\mathrm{A}} \\ \text { (watts) }\end{array} & \mathrm{CPM}_{i} \\ \text { RUN A3 } & \\ & \\ 68.2 & 44100 \\ 68.2 & 40800 \\ 68.2 & 35700 \\ 68.2 & 36600 \\ 68.2 & 36200 \\ 68.2 & 39200 \\ 68.2 & 39500 \\ 68.2 & 50712 \\ 68.2 & 37700 \\ 68.2 & 37900 \\ 68.2 & 35600 \\ 68.2 & 36200\end{array}$

RUN A5

51.0

51.0

51.0

51.0

51.0

51.0

51.0

51.0

51.0

51.0

51.0

51.0

51.0

51.1

51.0

51.0

51.0

51.0

51.0

RUN A6

51.0

51.0

51.0

51.0

51.0

51.0

36500
44000
36000
37100
38300
42100
47100
38100
39200
39800
40300
50200
35100
37100
48900
44600
47200
43500
36800

39200

40100

49200

44100
$\mathrm{CPM}_{\mathrm{f}}$

TIME

(min)

BACKGROUND $=486 \mathrm{CPM}$

$\begin{array}{lll}39700 & 0.5 & 15.2 \\ 34600 & 1.0 & 23.1 \\ 23800 & 1.5 & 50.8 \\ 26400 & 2.0 & 42.4 \\ 21000 & 3.0 & 64.0 \\ 19900 & 4.0 & 74.6 \\ 36300 & 0.5 & 12.1 \\ 40600 & 1.0 & 30.2 \\ 24300 & 2.0 & 54.0 \\ 25800 & 1.5 & 48.3 \\ 20700 & 3.0 & 63.5 \\ 16300 & 4.0 & 83.7\end{array}$

BACKGROUND $=641 \mathrm{CPM}$

31700

37800

33400

34800

26500

30300

33100

21000

23200

18900

18600

37900

32000

32300

42600

28900

40200

33900

28600

1.0

1.0

0.5

0.5

2.0

2.0

2.0

3.0

3.0

4.0

4.0

1.5

0.5

0.5

1.0

2.0

1.0

1.5

1.5

BACKGROUND $=647 \mathrm{CPM}$
$\mathrm{S}_{\mathrm{R}}(\%)$

50.8

42.4

64.0

74.6

54.0

63.5

83.7
20.0

21.4

11.1

9.6

47.1

42.6

45.2

68.6

62.4

80.2

82.0

37.1

13.1

19.7

19.5

53.5

22.5

33.4

33.9
2.0

2.5

2.5

4.0

4.0

0.5

26000
24800
24900
19600
24400
40800

26000
24800
24900
19600
24400
40800

45.8

55.8

58.4

77.8

76.5

11.3 
TABLE C-1, continued

\begin{tabular}{|c|c|c|c|c|c|}
\hline $\begin{array}{c}{ }_{A} \\
\text { (watts) }\end{array}$ & $\mathrm{CPM}_{1}$ & $\mathrm{CPM}_{\mathrm{f}}$ & & $\begin{array}{l}\text { TIME } \\
(\min )\end{array}$ & $\mathrm{S}_{\mathrm{R}}(\%)$ \\
\hline \multicolumn{6}{|c|}{ RUN A6 - cont Inued } \\
\hline $\begin{array}{l}51.0 \\
51.0 \\
51.0 \\
51.0 \\
51.0 \\
51.0 \\
51.0 \\
51.0\end{array}$ & $\begin{array}{l}37600 \\
38900 \\
41400 \\
43700 \\
46600 \\
37800 \\
47700 \\
47200\end{array}$ & $\begin{array}{l}33200 \\
33600 \\
31900 \\
32900 \\
31900 \\
21400 \\
23600 \\
24700\end{array}$ & & $\begin{array}{l}1.0 \\
1.0 \\
1.5 \\
1.5 \\
2.0 \\
3.0 \\
4.0 \\
4.0\end{array}$ & $\begin{array}{l}18.0 \\
20.7 \\
35.0 \\
37.6 \\
48.0 \\
66.0 \\
76.8 \\
72.5\end{array}$ \\
\hline RUN A7 & & BACKGROUND & $=482$ & CPM & \\
\hline $\begin{array}{l}36.2 \\
36.2 \\
36.2 \\
26.0 \\
26.0 \\
15.6 \\
15.6 \\
15.6\end{array}$ & $\begin{array}{l}38100 \\
37900 \\
35200 \\
40700 \\
44800 \\
42100 \\
43100 \\
37100\end{array}$ & $\begin{array}{l}34900 \\
35200 \\
32500 \\
39100 \\
43200 \\
41300 \\
42100 \\
36700\end{array}$ & & $\begin{array}{l}1.0 \\
1.0 \\
1.0 \\
1.0 \\
1.0 \\
1.0 \\
1.0 \\
1.0\end{array}$ & $\begin{array}{r}12.6 \\
11.0 \\
11.7 \\
6.0 \\
5.4 \\
3.0 \\
3.5 \\
1.5\end{array}$ \\
\hline RUN A8 & & BACKGROUND & $=738$ & CPM & \\
\hline $\begin{array}{l}36.2 \\
36.2 \\
26.0 \\
26.0 \\
15.6 \\
68.2 \\
68.2 \\
86.0 \\
86.0 \\
86.0\end{array}$ & $\begin{array}{l}44500 \\
47800 \\
37900 \\
36200 \\
49200 \\
36800 \\
38900 \\
38100 \\
42100 \\
44400\end{array}$ & $\begin{array}{l}40400 \\
43600 \\
36700 \\
35300 \\
48400 \\
30200 \\
31400 \\
30600 \\
33600 \\
34800\end{array}$ & & $\begin{array}{l}1.0 \\
1.0 \\
1.0 \\
1.0 \\
1.0 \\
1.0 \\
1.0 \\
1.0 \\
1.0 \\
1.0\end{array}$ & $\begin{array}{r}13.9 \\
13.3 \\
5.0 \\
3.7 \\
2.5 \\
27.3 \\
29.5 \\
30.2 \\
30.7 \\
32.8\end{array}$ \\
\hline
\end{tabular}


FREQUENCY: 20.6 keps

LIQUID : Distilled Water

TEMPERATURE: $\quad 113^{\circ} \mathrm{F}$

$\underset{\text { (watts) }}{\mathrm{w}_{\mathrm{A}}}$

$\mathrm{CPM}_{i}$

$\mathrm{CPM}_{\mathbf{f}}$

T TME

(min)

$S_{R}(\%)$

RUN A9

BACKGROUND $=742 \mathrm{CPM}$

86.0

51.0

51.0

36.2

36.2

26.0

26.0

15.6

15.6

86.0

42300

43900

37800

37600

35300

39500

48600

48100

47800

47700

RUN AlO

$\begin{array}{rr}7.0 & 37200 \\ 15.6 & 48100 \\ 26.0 & 48900 \\ 26.0 & 50300 \\ 51.0 & 36200 \\ 51.0 & 37700 \\ 68.2 & 38100 \\ 86.0 & 38900\end{array}$

33000

36100

31500

33800

32000

36200

46000

46000

47000

36500

BACKGROUND $=768 \mathrm{cPM}$

37200
46800
46700
47200
30500
30900
30000
30100

1.0

1.0

1.0

1.0

1.0

1.0

1.0

1.0
0.0

4.1

6.7

9.5

24.0

27.6

32.4

34.7

27.1

25.2

15.3

12.8

8.1

6.2

2.0

35.6 
TABLE C-3

FREQUENCY: $20.6 \mathrm{kcps}$

LIQUID : Distilled Water

TEMPERATURE: $\quad 180^{\circ} \mathrm{F}$

$\begin{array}{cc}\begin{array}{c}\mathrm{W}_{\mathrm{A}} \\ \text { (watts) }\end{array} & \mathrm{CPM}_{1} \\ \text { RUN A12 } & \\ & \\ 26.0 & 38800 \\ 26.0 & 37200 \\ 36.2 & 37900 \\ 36.2 & 39200 \\ 51.0 & 40100 \\ 51.0 & 44800 \\ 68.2 & 37600 \\ 68.2 & 37100 \\ 86.0 & 47800 \\ 15.6 & 44200 \\ 15.6 & 45100\end{array}$

RUN A13

$\begin{array}{ll}26.0 & 39800 \\ 36.2 & 37900 \\ 36.2 & 46800 \\ 51.0 & 46100 \\ 51.0 & 44100 \\ 68.2 & 35800 \\ 86.0 & 34800 \\ 86.0 & 37900\end{array}$

$\begin{array}{rrr}\text { BACKGROUND }=629 \text { CPM } & \\ 37700 & 1.0 & 4.3 \\ 35900 & 1.0 & 5.2 \\ 35700 & 1.0 & 8.7 \\ 37600 & 1.0 & 6.0 \\ 36200 & 1.0 & 14.8 \\ 41500 & 1.0 & 11.2 \\ 32300 & 1.0 & 21.5 \\ 31300 & 1.0 & 23.6 \\ 38500 & 1.0 & 29.5 \\ 43400 & 1.0 & 2.6 \\ 44600 & 1.0 & 1.8\end{array}$

BACKGROUND $=819 \mathrm{CPM}$

39700

35900

45200

41400

40200

30500

28600

TIME

(min)

$S_{R}(\%)$

31400

1.0

1.0

0.5

1.0

1.0

1.0

1.0

1.0

1.0

8.0

5.1

15.6

13.6

22.6

27.3

26.3 


\section{TABLE C-4}

FREQUENCY : $20.6 \mathrm{kcps}$

LIQUID : Methanol

$\underset{\text { (watts) }}{\mathrm{W}_{\mathrm{A}}}$

RUN A14

7.0

15.6

15.6

36.2

36.2

51.0

51.0

68.2

68.2

86.0

86.0

RUN A15

$\begin{array}{rl}86.0 & 47200 \\ 86.0 & 41100 \\ 68.2 & 42000 \\ 68.2 & 46100 \\ 51.0 & 37800 \\ 51.0 & 35400 \\ 36.2 & 42200 \\ 36.2 & 45900 \\ 15.6 & 47300 \\ 15.6 & 36600 \\ 7.0 & 38200 \\ 7.0 & 39400\end{array}$<smiles>[Mg]</smiles>

35800

41000

42800

37900

37000

36600

45400

47700

48000

42200

35500

36700

39400

$\begin{array}{ccr} & \text { TEMPERATURE : } 113^{\circ} \mathrm{F} \\ & & \\ { }_{\mathrm{CPM}} & \mathrm{TIME} & \mathrm{S}_{\mathrm{R}}(\%) \\ & (\mathrm{mIn}) & \\ \text { BACKGROUND } & & \\ & & \\ 35800 & \mathrm{CPM} & \\ 40700 & 1.0 & 0.0 \\ 42300 & 1.0 & 1.0 \\ 37200 & 1.0 & 1.7 \\ 35800 & 1.0 & 2.7 \\ 35400 & 1.0 & 5.0 \\ 43200 & 1.0 & 5.1 \\ 45700 & 1.0 & 7.2 \\ 45000 & 1.0 & 6.4 \\ 39400 & 1.0 & 9.5 \\ 32200 & 1.0 & 10.2 \\ 33800 & 1.0 & 14.1 \\ & 1.0 & 12.0\end{array}$

BACKGROUND $=634 \mathrm{CPM}$

$\begin{array}{llr}42300 & 1.0 & 15.7 \\ 37900 & 1.0 & 11.7 \\ 38300 & 1.0 & 13.5 \\ 42900 & 1.0 & 10.4 \\ 35700 & 1.0 & 8.5 \\ 33900 & 1.0 & 6.3 \\ 40400 & 1.0 & 6.3 \\ 44400 & 1.0 & 5.1 \\ 46400 & 1.0 & 3.0 \\ 36100 & 1.0 & 1.9 \\ 38000 & 1.0 & 0.8 \\ 39400 & 1.0 & 0.0\end{array}$




\section{TABLE C-5}

FREQUENCY: $20.6 \mathrm{kcps}$ LIQUID : Methanol<smiles></smiles>

RUN A16

$\begin{array}{rr}86.0 & 39100 \\ 86.0 & 39000 \\ 68.2 & 44000 \\ 68.2 & 41100 \\ 36.2 & 37200 \\ 15.6 & 38400 \\ 15.6 & 36500 \\ 7.0 & 47200 \\ 7.0 & 49300\end{array}$

RUN A17

$\begin{array}{rr}7.0 & 37900 \\ 15.6 & 42900 \\ 36.2 & 43800 \\ 36.2 & 44400 \\ 51.0 & 45600 \\ 51.0 & 47300 \\ 51.0 & 45800 \\ 68.2 & 36800 \\ 86.0 & 36100\end{array}$

TEMPERATURE: $95^{\circ} \mathrm{F}$

$\begin{array}{lll}\mathrm{CPM}_{\mathrm{f}} & \mathrm{TIME} \\ & (\mathrm{min}) & \mathrm{S}_{\mathrm{R}}(\%)\end{array}$

BACKGROUND $=654 \mathrm{CPM}$

$\begin{array}{llr}35500 & 1.0 & 14.2 \\ 34900 & 1.0 & 16.5 \\ 40500 & 1.0 & 12.0 \\ 37400 & 1.0 & 13.7 \\ 35700 & 1.0 & 6.0 \\ 37900 & 1.0 & 2.0 \\ 35700 & 1.0 & 3.3 \\ 47200 & 1.0 & 0.0 \\ 48900 & 1.0 & 1.2\end{array}$

BACKGROUND $=650 \mathrm{CPM}$

$\begin{array}{rrr}37500 & 1.0 & 1.6 \\ 42100 & 1.0 & 2.9 \\ 42200 & 1.0 & 5.4 \\ 42500 & 1.0 & 6.6 \\ 42500 & 1.0 & 10.2 \\ 44500 & 1.0 & 9.0 \\ 42900 & 1.0 & 9.7 \\ 33600 & 1.0 & 13.3 \\ 32900 & 1.0 & 13.7\end{array}$


C-8

\section{TABLE C-6}

FREQUENCY: $44.1 \mathrm{kcps}$

LIQUID : Distilled Water

TEMPERATURE : $\quad 149^{\circ} \mathrm{F}$

$\underset{\text { (watts) }}{W_{A}} \quad{ }^{C P M_{i}}$

$\mathrm{CPM}_{f} \quad \underset{\text { (min) }}{\text { TIME }} \quad \mathrm{S}_{\mathrm{R}}(\%)$

RUN A18

BACKGROUND $=819 \mathrm{CPM}$

$\begin{array}{rr}9.5 & 37900 \\ 9.5 & 38100 \\ 15.6 & 42800 \\ 15.6 & 44100 \\ 30.2 & 46800 \\ 30.2 & 44400 \\ 42.7 & 40200 \\ 42.7 & 36800 \\ 53.3 & 39100 \\ 53.3 & 47100 \\ 42.7 & 49200 \\ 73.0 & 49800 \\ 96.0 & 39200\end{array}$

37900

38100

1.0

1.0

0.0

42600

1.0

0.0

43800

1.0

0.6

45700

1.0

1.0

42900

38100

34900

35900

43800

46000

42900

1.0

1.0

1.0

1.0

1.0

1.0

1.0

0.9

3.5

5.0

31800

7.9

7.7

12.5

10.7

10.0

RUN A19

BACKGROUND $=808 \mathrm{CPM}$

$\begin{array}{rr}96.0 & 36600 \\ 96.0 & 37400 \\ 42.7 & 38800 \\ 73.0 & 41100 \\ 73.0 & 47200 \\ 53.3 & 46600 \\ 42.7 & 43100 \\ 30.2 & 39300 \\ 9.5 & 42200 \\ 15.6 & 41800\end{array}$

29800

30600

36000

35800

39900

42800

40600

38600

42200

41300
1.0

1.0

1.0

1.0

1.0

1.0

1.0

1.0

1.0

1.0
28.4

27.6

10.7

19.7

23.4

12.4

9.0

2.9

0.0

1.8 


\section{TABLE C-7}

FREQUENCY: $44.1 \mathrm{kcps}$

LIQUID : Methanol

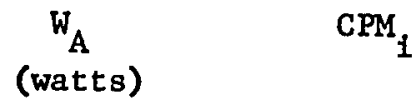

RUN A20

$\begin{array}{rr}4.6 & 34900 \\ 9.5 & 39900 \\ 9.5 & 41100 \\ 15.6 & 41700 \\ 15.6 & 36300 \\ 30.2 & 37700 \\ 30.2 & 38200 \\ 42.7 & 44300 \\ 42.7 & 41400 \\ 53.0 & 39700 \\ 73.0 & 46700 \\ 96.0 & 43400\end{array}$

RUN A21

73.0

73.0

53.3

53.3

96.0

96.0

96.0

42.7

30.2

30.2

9.5

15.6

4.6

4.6

$\mathrm{CPM}_{1}$
36600

35800

41900

42600

41500

43500

37500

37900

36600

47800

49100

50300

38800

36800
$\mathrm{CPM}_{\mathrm{f}}$

TIME

(min)

BACKGROUND $=802 \mathrm{CPM}$

$\begin{array}{llr}34900 & 1.0 & 0.0 \\ 39600 & 1.0 & 1.3 \\ 40900 & 1.0 & 0.7 \\ 41000 & 1.0 & 2.5 \\ 35500 & 1.0 & 3.2 \\ 36400 & 1.0 & 5.1 \\ 37100 & 1.0 & 4.4 \\ 42600 & 1.0 & 6.0 \\ 39400 & 1.0 & 7.5 \\ 37600 & 1.0 & 8.2 \\ 43200 & 1.0 & 11.4 \\ 39900 & 1.0 & 12.2\end{array}$

BACKGROUND = 654 CPM

$\begin{array}{rrr}33500 & 1.0 & 13.0 \\ 33700 & 1.0 & 8.9 \\ 39800 & 1.0 & 7.5 \\ 39900 & 1.0 & 9.8 \\ 37400 & 1.0 & 15.0 \\ 39900 & 1.0 & 12.6 \\ 34200 & 1.0 & 13.2 \\ 36200 & 1.0 & 6.8 \\ 35300 & 1.0 & 5.3 \\ 46200 & 1.0 & 4.9 \\ 48600 & 1.0 & 1.6 \\ 49600 & 1.0 & 2.2 \\ 38800 & 1.0 & 0.0 \\ 36800 & 1.0 & 0.0\end{array}$

8.9

15.0

6.8

5.3

1.6

2.2

0.0
$S_{R}(\%)$

3

2.5

3.2

4.4

6.0

8.2

12.2

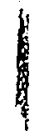




\section{TABLE C-8}

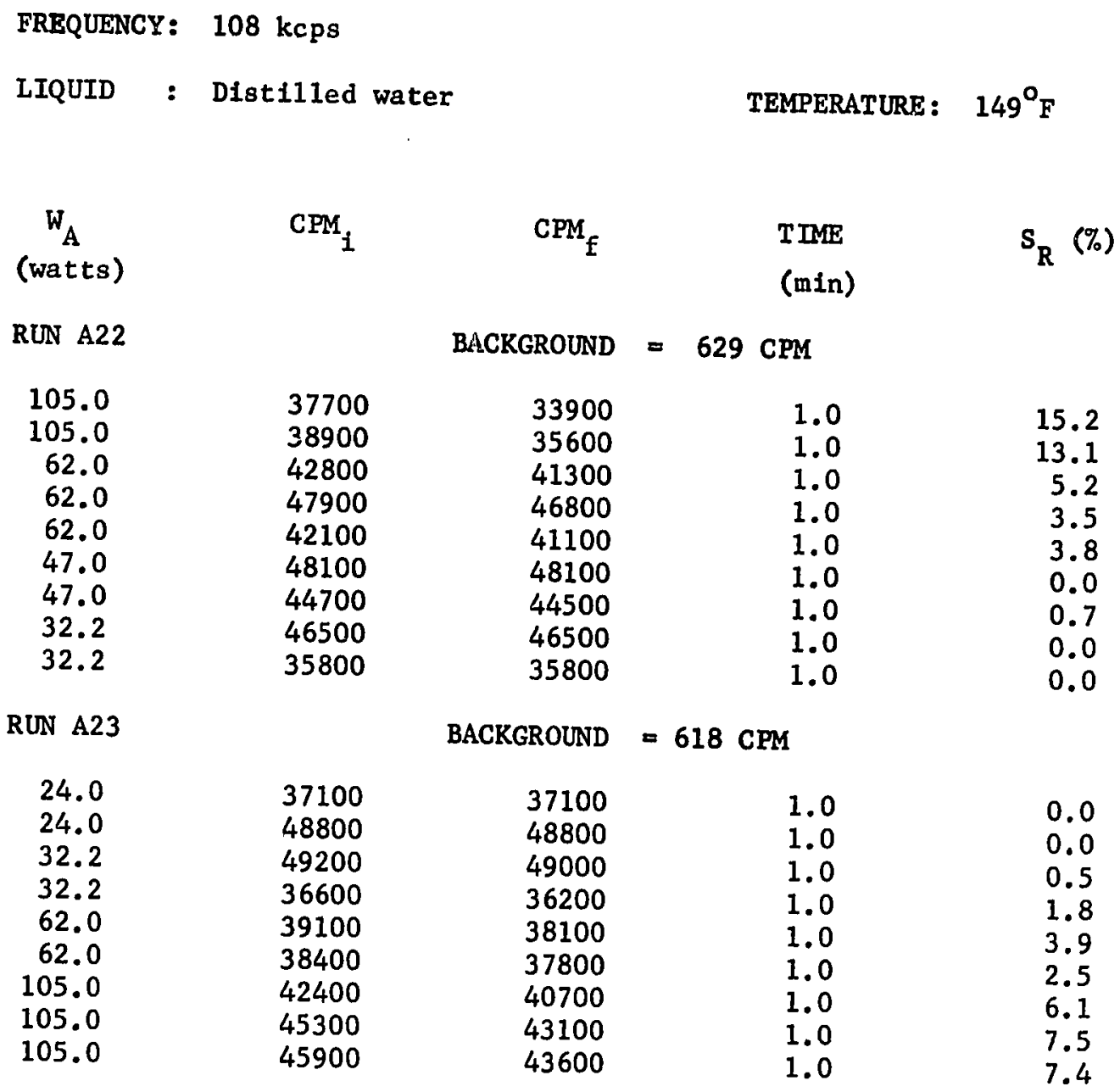


TABLE C-9

FREQUENCY : $108 \mathrm{kcps}$

LIQUID : Methanol

$\mathrm{W}_{\mathrm{A}}$

(watts)

RUN A24

$\begin{array}{rr}32.2 & 36600 \\ 47.0 & 35800 \\ 47.0 & 47200 \\ 62.0 & 49200 \\ 62.0 & 48900 \\ 105.0 & 47200 \\ 105.0 & 41400 \\ 62.0 & 42100\end{array}$

RUN A25

$\begin{array}{rr}105.0 & 35500 \\ 105.0 & 41900 \\ 62.0 & 42300 \\ 62.0 & 45400 \\ 62.0 & 45900 \\ 32.2 & 38800 \\ 32.2 & 39100 \\ 24.0 & 36200 \\ 24.0 & 37700\end{array}$

$\mathrm{CPM}_{1}$

49200

48900

41400

42100

5500

41900

42300

45400

88800

36200

37700

$\begin{array}{rcr} & \text { TEMPERATURE : } 113^{\circ} \mathrm{F} \\ & & \\ \mathrm{CPM}_{f} & \mathrm{TIME} & \mathrm{S}_{\mathrm{R}}(\%) \\ & (\mathrm{min}) & \\ \text { BACKGROUND } & 522 \mathrm{CPM} & \\ & & \\ 36600 & 1.0 & 0.0 \\ 35800 & 1.0 & 0.0 \\ 46900 & 1.0 & 1.0 \\ 47800 & 1.0 & 4.2 \\ 48000 & 1.0 & 2.8 \\ 42600 & 1.0 & 14.8 \\ 38300 & 1.0 & 11.3 \\ 41000 & 1.0 & 3.9 \\ & & \\ \text { BACKGROUND } & 654 \mathrm{CPM} & \\ 33600 & & 8.3 \\ 40000 & 1.0 & 7.0 \\ 41700 & 1.0 & 2.2 \\ 44100 & 1.0 & 4.3 \\ 45000 & 1.0 & 3.1 \\ 38600 & 1.0 & 0.8 \\ 38800 & 1.0 & 1.0 \\ 36200 & 1.0 & 0.0 \\ 37700 & 1.0 & 0.0 \\ & 1.0 & \end{array}$




\section{TADDS C-10}

FREQUENCY: $306 \mathrm{kcps}$

LIQUID : Methanol

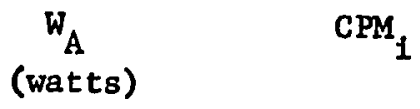

RUN A26

$\begin{array}{rl}74.0 & 37900 \\ 74.0 & 34800 \\ 92.0 & 44100 \\ 92.0 & 49100 \\ 92.0 & 48200 \\ 92.0 & 48800 \\ 125.0 & 46300 \\ 125.0 & 36600 \\ 125.0 & 35500 \\ 125.0 & 47800 \\ 160.0 & 42900 \\ 160.0 & 37400 \\ 160.0 & 48200 \\ 160.0 & 46900\end{array}$

TEMPERATURE : $113^{\circ} \mathrm{F}$

$\begin{array}{lll}\mathrm{CPM}_{\mathrm{f}} & \mathrm{TME} \\ & (\mathrm{min}) & \mathrm{S}_{\mathrm{R}}(\%)\end{array}$

BACKGROUND $=802 \mathrm{CPM}$

$\begin{array}{lll}37900 & 1.0 & 0.0 \\ 34800 & 1.0 & 0.0 \\ 44100 & 1.0 & 0.0 \\ 48900 & 1.0 & 0.5 \\ 48200 & 1.0 & 0.0 \\ 48700 & 1.0 & 0.2 \\ 45800 & 1.0 & 1.5 \\ 35800 & 1.0 & 3.2 \\ 35000 & 1.0 & 1.8 \\ 46900 & 1.0 & 2.9 \\ 40900 & 1.0 & 7.2 \\ 35000 & 1.0 & 8.8 \\ 45600 & 1.0 & 8.1 \\ 45000 & 1.0 & 6.3\end{array}$




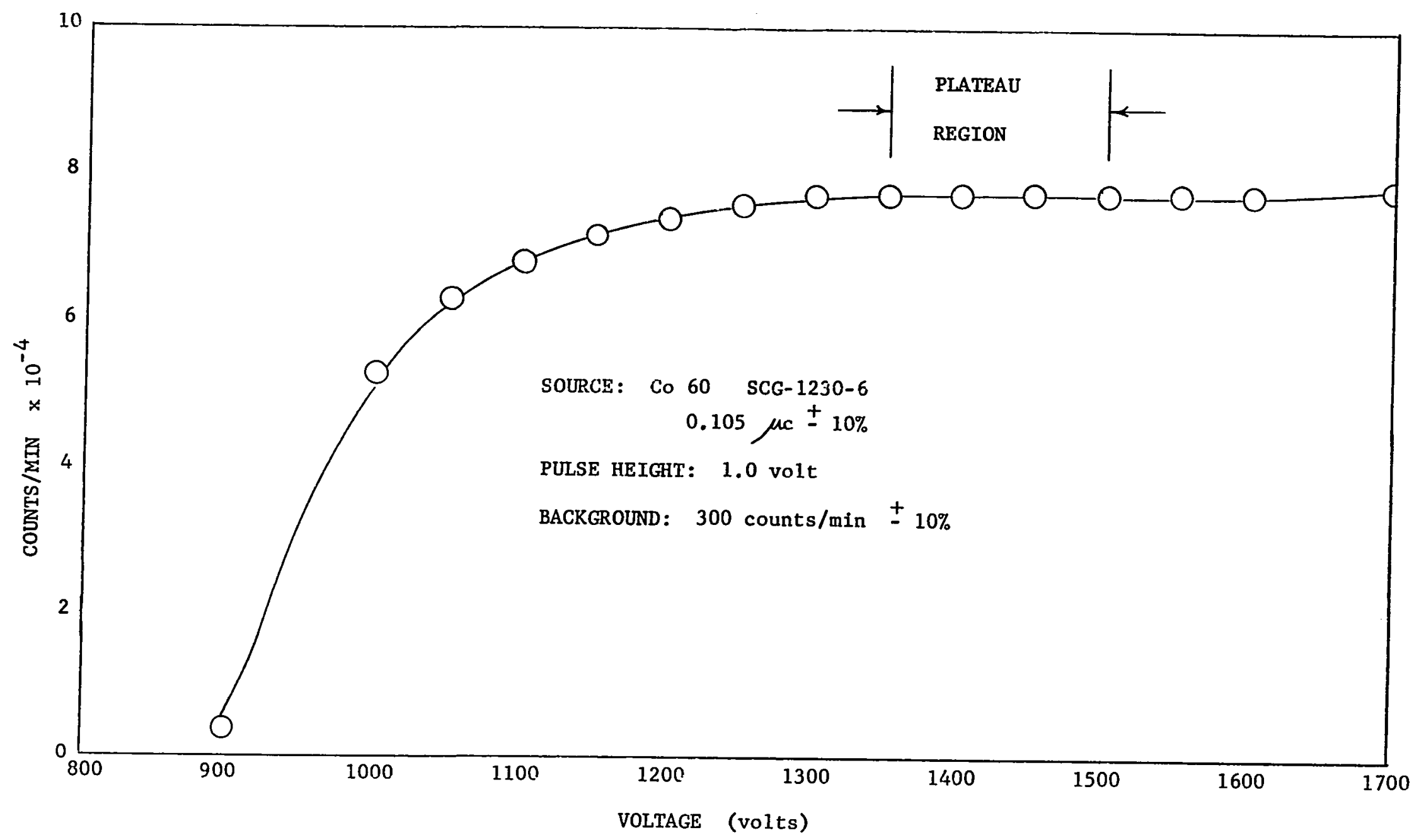

FIGURE C-1 DETERMINATION OF SCINTILIATION PLATEAU REGION 
APPENDIX D

HEAT TRANSFER DATA 
TABLE D-1

LIQUID: Methanol TEMPERATURE: $95^{\circ} \mathrm{F}$ FREQUENCY: $20.6 \mathrm{kcps}$ WIRE DIAMETER: $0.010^{\prime \prime}$

$\begin{array}{cccccccc}\mathrm{W}_{\mathrm{A}} & \mathrm{E}_{\mathrm{SR}} & \mathrm{E}_{\mathrm{PT}} & \mathrm{q} / \mathrm{A} & \mathrm{B}_{\mathrm{B}} \mathrm{t} & \mathrm{Nu} & \mathrm{Y}_{1}{ }^{*} & \mathrm{Y}_{2}{ }^{*} \\ \text { watts } & \text { Volts } & \text { Volts } & \text { BTR }{ }^{2} & { }_{\mathrm{O}} & & \end{array}$

RUN 30

$\begin{array}{rrrr}0.0 & 0.0585 & 0.1285 & 7,850 \\ 0.0 & 0.0826 & 0.1879 & 16,200 \\ 0.0 & 0.0986 & 0.2291 & 23,600 \\ 0.0 & 0.1221 & 0.2886 & 36,800 \\ 0.0 & 0.1444 & 0.3436 & 51,800 \\ 0.0 & 0.1657 & 0.3965 & 68,600 \\ 0.0 & 0.1885 & 0.4523 & 89,000 \\ 0.0 & 0.0703 & 0.1579 & 11,600 \\ 4.8 & 0.0703 & 0.1539 & 11,300 \\ 15.6 & 0.0705 & 0.1535 & 11,300 \\ 36.2 & 0.0706 & 0.1507 & 11,100 \\ 86.0 & 0.0707 & 0.1504 & 11,100 \\ 0.0 & 0.0951 & 0.2236 & 22,200 \\ 1.0 & 0.0950 & 0.2158 & 21,400 \\ 15.6 & 0.0951 & 0.2125 & 21,100 \\ 36.2 & 0.0950 & 0.2087 & 20,700 \\ 86.0 & 0.0947 & 0.2053 & 20,300 \\ 0.0 & 0.1162 & 0.2729 & 33,100 \\ 1.0 & 0.1162 & 0.2711 & 32,900 \\ 15.6 & 0.1162 & 0.2613 & 31,700 \\ 36.2 & 0.1162 & 0.2586 & 31,400 \\ 86.0 & 0.1162 & 0.2564 & 31,100 \\ 0.0 & 0.1496 & 0.3553 & 55,500 \\ 2.0 & 0.1499 & 0.3547 & 55,500 \\ 15.6 & 0.1496 & 0.3529 & 55,100 \\ 36.2 & 0.1496 & 0.3438 & 53,700 \\ 0.0 & 0.1761 & 0.4216 & 77,500 \\ 2.0 & 0.1761 & 0.4194 & 77,100 \\ 15.6 & 0.1761 & 0.4178 & 76,800\end{array}$

$$
R_{100}=.05021 \Omega
$$

$36.6 \quad 1.55$

$57.2 \quad 2.07$

$69.0 \quad 2.53$

79.5 -

82.6 -

$85.9-$

87.7

48.4

34.8

31.6

21.3

19.3

76.2

56.1

46.4

37.0

29.4

75.7

71.4

50.2

43.9

39.4

83.2

81.1

79.2

62.9

87.1

84.1

81.9

1.74

$-$

2.55

3.64

4.07

$-$

$-$

3.25

4.00

5.02

$-$

$-$

3.85

5.07

5.74

$-$

6.94

$-$

-

9.6

$\mathrm{Y}_{2}=\frac{\mathrm{Re}^{1 / 2} \operatorname{Pr}^{2 / 3} \mathrm{~S}_{\mathrm{R}}^{1 / 2}}{\mathrm{P}_{\mathrm{CR}}}$ 
TABLE D-1 continued

\begin{tabular}{|c|c|c|c|c|c|c|}
\hline$\stackrel{\mathrm{W}_{\mathrm{A}}}{\text { watts }}$ & $\begin{array}{c}\mathrm{E}_{\mathrm{SR}} \\
\text { Volts }\end{array}$ & $\begin{array}{c}\mathrm{E}_{\mathrm{PT}} \\
\text { Volts }\end{array}$ & $\begin{array}{c}\mathrm{q} / \mathrm{A} \\
\mathrm{BTU} / \mathrm{HR} \mathrm{FT}^{2}\end{array}$ & $\begin{array}{r}\Delta t \\
O_{F}\end{array}$ & $\mathrm{~N} \mathrm{u}$ & $\mathrm{Y}_{1}$ \\
\hline \multicolumn{7}{|c|}{ RUN 30 - continued } \\
\hline $\begin{array}{r}36.2 \\
86.0 \\
0.0 \\
36.2 \\
86.0\end{array}$ & $\begin{array}{l}0.1760 \\
0.1761 \\
0.2009 \\
0.2015 \\
0.2009\end{array}$ & $\begin{array}{l}0.4157 \\
0.4140 \\
0.4815 \\
0.4849 \\
0.4814\end{array}$ & $\begin{array}{r}76,400 \\
76,100 \\
101,000 \\
102,000 \\
101,000\end{array}$ & $\begin{array}{l}78.9 \\
76.3 \\
87.8 \\
90.4 \\
87.6\end{array}$ & $\begin{array}{l}- \\
- \\
-\end{array}$ & $\begin{array}{l}- \\
- \\
-\end{array}$ \\
\hline
\end{tabular}

RUN 31

$\begin{array}{rrrr}0.0 & 0.0506 & 0.1091 & 5,760 \\ 0.0 & 0.0332 & 0.0702 & 2,430 \\ 0.0 & 0.0263 & 0.5534 & 1,520 \\ 0.0 & 0.0212 & 0.0445 & 986 \\ 0.0 & 0.0384 & 0.0816 & 3,270 \\ 0.0 & 0.0445 & 0.0951 & 4,420 \\ 0.0 & 0.0584 & 0.1277 & 7,790 \\ 0.0 & 0.1212 & 0.2877 & 36,400 \\ 0.0 & 0.1649 & 0.3962 & 68,200 \\ 0.0 & 0.0309 & 0.0652 & 2,100 \\ 0.0 & 0.0409 & 0.0877 & 3,740 \\ 15.6 & 0.0408 & 0.0868 & 3,700 \\ 36.2 & 0.0408 & 0.0861 & 3,670 \\ 0.0 & 0.0486 & 0.1049 & 5,320 \\ 15.6 & 0.0486 & 0.1041 & 5,280 \\ 36.2 & 0.0485 & 0.1026 & 5,200 \\ 86.0 & 0.0485 & 0.1024 & 5,190 \\ 0.0 & 0.0613 & 0.1348 & 8,630 \\ 15.6 & 0.0613 & 0.1329 & 8,500 \\ 36.2 & 0.0613 & 0.1321 & 8,460 \\ 86.0 & 0.0613 & 0.1302 & 8,330 \\ 0.0 & 0.0830 & 0.1905 & 16,500 \\ 15.6 & 0.0829 & 0.1837 & 15,900 \\ 36.2 & 0.0829 & 0.1802 & 15,600 \\ 86.0 & 0.0830 & 0.1789 & 15,500 \\ 0.0 & 0.1292 & 0.3092 & 41,700 \\ 15.6 & 0.1290 & 0.3044 & 41,000 \\ 36.2 & 0.1290 & 0.2925 & 39,400 \\ 86.0 & 0.1288 & 0.2893 & 38,900\end{array}$

$$
I=48 / 64 \mathrm{in} . \quad R_{100}=.05040 \Omega
$$

$\begin{array}{rccc}24.9 & 1.67 & - & - \\ 14.9 & 1.15 & - & - \\ 10.8 & 1.0 & - & - \\ 8.8 & .78 & - & - \\ 17.7 & 1.77 & - & - \\ 21.2 & 1.52 & - & - \\ 32.4 & 1.72 & - & - \\ 78.4 & - & - & - \\ 86.6 & - & - & - \\ 12.9 & 1.15 & - & - \\ 21.4 & 1.28 & - & - \\ 16.6 & 1.61 & 31.5 & - \\ 11.8 & 2.27 & - & - \\ 25.1 & 1.54 & - & - \\ 21.0 & 1.75 & 40 & - \\ 13.6 & 2.72 & - & - \\ 12.3 & 2.94 & - & - \\ 35.1 & 1.77 & - & - \\ 27.1 & 2.25 & 50 & - \\ 23.9 & 2.55 & 65 & - \\ 15.8 & 3.67 & 70.5 & - \\ 59.7 & 2.02 & - & - \\ 39.5 & 2.92 & 76 & - \\ 28.4 & 3.83 & 79.5 & - \\ 24.1 & 4.55 & 103 & - \\ 84.4 & - & - & - \\ 73.7 & 5.85 & - & 600 \\ 50.6 & 7.89 & - & 567 \\ 45.2 & - & - & -\end{array}$


TABLE D-1 continued

\begin{tabular}{|c|c|c|c|c|c|c|c|}
\hline $\begin{array}{c}\mathrm{W}_{\mathrm{A}} \\
\text { watts }\end{array}$ & $\begin{array}{c}\mathrm{E}_{\mathrm{SR}} \\
\text { Volts }\end{array}$ & $\begin{array}{c}\mathrm{E}_{\mathrm{PT}} \\
\text { Volts }\end{array}$ & $\begin{array}{c}\mathrm{q} / \mathrm{A} \\
\mathrm{BTU} / \mathrm{HR} \mathrm{FT}^{2}\end{array}$ & $\begin{array}{r}\Delta t \\
o_{F}\end{array}$ & $\mathrm{Nu}$ & $Y_{1}$ & $\mathrm{Y}$ \\
\hline RUN 32 & & L & $48 / 64$ in. & $R_{100}$ & $=.05021$ & $\Omega$ & \\
\hline 0.0 & 0.0357 & 0.0756 & 2,812 & 17.2 & 1.20 & - & \\
\hline 0.0 & 0.0436 & 0.0932 & 4,236 & 22.4 & 1.38 & - & \\
\hline 15.6 & 0.0433 & 0.0917 & 4,140 & 17.3 & 1.67 & 32.3 & \\
\hline 36.2 & 0.0430 & 0.0907 & 4,072 & 13.2 & 2.21 & 38.5 & \\
\hline 86.0 & 0.0428 & 0.0899 & 4,023 & 11.4 & 2.58 & - & \\
\hline 0.0 & 0.0502 & 0.1088 & 5,708 & 27.5 & 1.51 & - & \\
\hline 15.6 & 0.0503 & 0.1076 & 5,648 & 20.5 & 1.95 & 39.5 & \\
\hline $\begin{array}{r}0.0 \\
15.6\end{array}$ & 0.0549 & 0.1193 & 6,837 & 31.4 & .77 & - & - \\
\hline $\begin{array}{l}15.6 \\
36 . ?\end{array}$ & 0.0550 & 0.1180 & 6,774 & 24.5 & 1.97 & 45.0 & - \\
\hline $\begin{array}{l}36.2 \\
86.0\end{array}$ & 0.0549 & 0.1159 & 6,629 & 17.2 & 2.73 & 48.2 & - \\
\hline $\begin{array}{r}86.0 \\
0.0\end{array}$ & $\begin{array}{l}0.0546 \\
0.0730\end{array}$ & 0.1148 & 6,538 & 14.1 & 3.28 & 64.1 & - \\
\hline 15.6 & 0.0717 & $\begin{array}{l}0.1628 \\
0.1564\end{array}$ & 12,410 & 46.2 & 1.95 & - & - \\
\hline 36.2 & 0.0684 & 0.1473 & 11,708 & 33.3 & 2.61 & 62.0 & - \\
\hline 86.0 & 0.0713 & 0.1520 & $\begin{array}{l}10,523 \\
11,313\end{array}$ & & 2.93 & 69.1 & - \\
\hline 0.0 & 0.0871 & 0.2006 & 18,245 & $\begin{array}{l}20.5 \\
64.1\end{array}$ & $\begin{array}{l}3.92 \\
2.1\end{array}$ & 81.6 & - \\
\hline 15.6 & 0.0894 & 0.1983 & 18,512 & 42.0 & $\begin{array}{l}2.1 \\
3.19\end{array}$ & $8 \overline{8}$ & - \\
\hline 36.2 & 0.0892 & 0.1943 & 18,082 & 32.5 & $\begin{array}{l}3.19 \\
3.97\end{array}$ & $\begin{array}{l}85.4 \\
90.5\end{array}$ & - \\
\hline 86.0 & 0.0889 & 0.1917 & 17,793 & 26.5 & 4.78 & 112 & - \\
\hline 0.0 & 0.1093 & 0.2557 & 29,172 & 73.4 & - & - & - \\
\hline 15.6 & 0.1093 & 0.2489 & 28,411 & 57.2 & 3.59 & 146 & - \\
\hline 36.2 & 0.1094 & 0.2427 & 27,731 & 42.4 & 4.82 & 127 & - \\
\hline 86.0 & 0.1096 & 0.2403 & 27,493 & 35.1 & 5.65 & 155 & - \\
\hline 36.2 & 0.0494 & 0.1043 & 5,382 & 14.5 & 2.62 & 41.4 & - \\
\hline 86.0 & 0.0488 & 0.1028 & 5,238 & 13.3 & 2.83 & 60.2 & \\
\hline 0.0 & 0.1395 & 0.3318 & 48,321 & 82.2 & - & - & - \\
\hline 15.6 & 0.1392 & 0.3282 & 47,700 & 76.2 & 6.40 & - & 666 \\
\hline 36.2 & 0.1401 & 0.3221 & 47,124 & 61.2 & 7.89 & - & 734 \\
\hline 86.0 & 0.1405 & 0.3179 & 46,628 & 51.8 & 9.21 & - & 990 \\
\hline 0.0 & 0.1593 & 0.3798 & 63,178 & 83.7 & - & - & \\
\hline 36.2 & 0.1587 & 0.3707 & 61,423 & 71.3 & 8.90 & - & 1040 \\
\hline 86.0 & 0.1603 & 0.3697 & 61,881 & 63.8 & 9.95 & - & 1420 \\
\hline 0.0 & 0.1702 & 0.4068 & 72,300 & 85.2 & - & - & 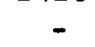 \\
\hline 0.0 & 0.2046 & 0.4916 & 105,000 & 88.6 & - & - & \\
\hline 0.0 & 0.2212 & 0.5327 & 123,000 & 90.8 & - & - & - \\
\hline 0.0 & 0.2288 & 0.5526 & 132,000 & 92.5 & - & - & - \\
\hline 0.0 & 0.2372 & 0.5735 & 142,000 & 93.3 & - & - & \\
\hline
\end{tabular}


TABLE D-2

LIQUID: Methanol TEMPERATURE: $113^{\circ} \mathrm{F}$ FREQUENCY: $20.6 \mathrm{kcps}$ WIRE DIAMETER: $\quad 0.007^{\prime \prime}$

$\begin{array}{cccccccc}\mathrm{W}_{\mathrm{A}} & \mathrm{E}_{\mathrm{SR}} & \mathrm{E}_{\mathrm{PT}} & \mathrm{q} / \mathrm{A} & \Delta \mathrm{t} & \mathrm{Nu} & \mathrm{Y}_{1} & \mathrm{Y}_{2} \\ \text { watts } & \text { Volts } & \text { Volts } & \mathrm{BTU} / \mathrm{HR}_{\mathrm{FT}} & \mathrm{O}_{\mathrm{F}} & & & \end{array}$ RUN 28

$$
L=49.5 / 64 \text { in. } \quad R_{100}=0.1049 \Omega
$$

$\begin{array}{rrrrllll}0.0 & 0.0294 & 0.1354 & 5,750 & 21.5 & 1.37 & - & - \\ 15.6 & 0.0289 & 0.1324 & 5,540 & 17.2 & 1.67 & 29.2 & - \\ 36.2 & 0.0288 & 0.1305 & 5,440 & 11.3 & 2.50 & 30.4 & - \\ 0.0 & 0.0328 & 0.1526 & 7,240 & 26.6 & 1.4 & - & - \\ 15.6 & 0.0325 & 0.1497 & 7,040 & 19.7 & 1.84 & 33.4 & - \\ 15.6 & 0.0327 & 0.1500 & 7,100 & 17.4 & 2.08 & 29.8 & - \\ 36.2 & 0.0325 & 0.1480 & 6,960 & 14.5 & 2.47 & 39.4 & - \\ 0.0 & 0.0436 & 0.2084 & 13,150 & 41.8 & 1.64 & - & - \\ 15.6 & 0.0435 & 0.2038 & 12,820 & 30.1 & 2.22 & 53.1 & - \\ 15.6 & 0.0470 & 0.2206 & 15,000 & 31.2 & 2.50 & 55.8 & - \\ 0.0 & 0.0659 & 0.3276 & 31,210 & 65.3 & 2.5 & - & - \\ 15.6 & 0.0579 & 0.2783 & 23,300 & 45.0 & 2.69 & 99.6 & - \\ 0.0 & 0.0745 & 0.3733 & 40,200 & 70.3 & - & - & - \\ 15.6 & 0.0738 & 0.3608 & 38,500 & 55.2 & 7.46 & - & 1340 \\ 36.2 & 0.0759 & 0.3599 & 39,500 & 37.4 & 11.22 & - & 1440 \\ 15.6 & 0.0835 & 0.4149 & 50,100 & 64.8 & 8.4 & - & 1790 \\ 0.0 & 0.0938 & 0.4740 & 64,300 & 75.2 & - & - & - \\ 15.6 & 0.0938 & 0.4706 & 63,800 & 71.1 & 9.74 & - & 1310\end{array}$

RUN 36

$\begin{array}{rrrrllll}0.0 & 0.0312 & 0.1444 & 6,500 & 23.5 & 1.4 & - & - \\ 15.6 & 0.0312 & 0.1425 & 6,420 & 16.0 & 2.08 & 27.7 & - \\ 36.2 & 0.0308 & 0.1402 & 6,250 & 12.6 & 2.51 & 35.4 & - \\ 0.0 & 0.0397 & 0.1880 & 10,800 & 36.0 & 1.6 & - & - \\ 15.6 & 0.0393 & 0.1814 & 10,300 & 22.3 & 2.38 & 37.4 & - \\ 36.2 & 0.0387 & 0.1772 & 9,910 & 17.5 & 2.91 & 42.8 & - \\ 0.0 & 0.0409 & 0.1943 & 11,500 & 38.0 & 1.6 & - & - \\ 15.6 & 0.0407 & 0.1889 & 11,100 & 26.0 & 2.20 & 44.8 & - \\ 36.2 & 0.0404 & 0.1850 & 10,800 & 17.2 & 3.22 & 45.4 & - \\ 0.0 & 0.0497 & 0.2438 & 17,500 & 57.0 & 1.6 & - & - \\ 0.0 & 0.0515 & 0.2519 & 18,750 & 55.0 & 1.8 & - & - \\ 15.6 & 0.0519 & 0.2465 & 18,500 & 37.5 & 2.54 & 74.1 & - \\ 36.2 & 0.0516 & 0.2400 & 17,910 & 26.1 & 3.56 & 68.8 & -\end{array}$


TABLE D-2 continued

$\begin{array}{cccccccc}\mathrm{W}_{\mathrm{A}} & \mathrm{E}_{\mathrm{SR}} & \mathrm{E}_{\mathrm{PT}} & \mathrm{q} / \mathrm{A} & \Delta \mathrm{t} & \mathrm{Nu} & \mathrm{Y}_{1} & \mathrm{Y}_{2} \\ \text { watts } & \text { Volts } & \text { Volts } & \mathrm{BTU}_{\mathrm{HR}} \mathrm{FT}^{2} & \mathrm{O}_{\mathrm{F}} & & & \end{array}$ RUN 36 continued

$\begin{array}{rrrccccc}86.0 & 0.0574 & 0.2663 & 22,100 & 25.0 & 4.56 & 103.0 & - \\ 0.0 & 0.0798 & 0.4015 & 46,300 & 73.0 & - & - & - \\ 36.2 & 0.0790 & 0.3767 & 43,000 & 42.0 & 11.24 & - & 1451 \\ 0.0 & 0.0911 & 0.4557 & 60,000 & 70.2 & - & - & - \\ 15.6 & 0.0896 & 0.4409 & 57,100 & 60.3 & 10.34 & - & 1750 \\ 0.0 & 0.1037 & 0.5283 & 79,200 & 80.4 & - & - & - \\ 15.6 & 0.1031 & 0.5197 & 77,430 & 74.1 & 11.46 & - & 999 \\ 0.0 & 0.1108 & 0.5635 & 90,200 & 79.6 & - & - & - \\ 15.6 & 0.1057 & 0.5320 & 81,300 & 72.8 & 12.28 & - & 1254 \\ 0.0 & 0.1245 & 0.6400 & 115,000 & 85.0 & - & - & - \\ 15.6 & 0.1222 & 0.6229 & 110,000 & 81.8 & - & - & - \\ 36.2 & 0.1197 & 0.6009 & 104,000 & 72.0 & 15.79 & - & 2559 \\ 0.0 & 0.1330 & 0.6817 & 131,000 & 86.2 & - & - & - \\ 0.0 & 0.1524 & 0.7809 & 172,000 & 85.9 & - & - & - \\ 15.6 & 0.1524 & 0.7810 & 172,000 & 86.1 & - & - & - \\ 0.0 & 0.1616 & 0.8350 & 195,000 & 91.2 & - & - & -\end{array}$

RUN 22

$$
\mathrm{L}=48 / 64 \text { in. }
$$

$$
R_{100}=.09915 \Omega
$$

$\begin{array}{rrrrrrrr}0.0 & 0.0533 & 0.2256 & 16,200 & 56.4 & 1.51 & - & - \\ 0.0 & 0.0810 & 0.3842 & 46,400 & 73.2 & - & - & - \\ 0.0 & 0.1087 & 0.5191 & 84,100 & 76.5 & - & - & - \\ 0.0 & 0.1286 & 0.6189 & 119,000 & 81.2 & - & - & - \\ 0.0 & 0.1547 & 0.7496 & 173,000 & 84.6 & - & - & - \\ 0.0 & 0.1785 & 0.8701 & 232,000 & 87.4 & - & - & - \\ 0.0 & 0.1930 & 0.9444 & 272,000 & 88.9 & - & - & - \\ 0.0 & 0.0397 & 0.1778 & 10,500 & 37.3 & 1.46 & - & - \\ 0.0 & 0.0643 & 0.3067 & 29,400 & 75.7 & 2.08 & - & - \\ 15.6 & 0.0643 & 0.2664 & 22,900 & 35.1 & 2.10 & 66.5 & - \\ 36.2 & 0.0643 & 0.2643 & 22,500 & 33.5 & 3.47 & 96.0 & - \\ 86.0 & 0.0643 & 0.2616 & 22,100 & 25.4 & 4.56 & 103 & - \\ 0.0 & 0.0908 & 0.4263 & 57,700 & 66.1 & 4.64 & - & - \\ 15.6 & 0.0908 & 0.4221 & 57,200 & 61.0 & 10.3 & - & 1750 \\ 36.2 & 0.0911 & 0.4191 & 56,900 & 54.8 & 11.3 & - & 1070 \\ 0.0 & 0.1205 & 0.5754 & 103,000 & 75.5 & - & - & - \\ 15.6 & 0.1205 & 0.5756 & 103,000 & 74.8 & - & - & - \\ 36.2 & 0.1205 & 0.5757 & 103,000 & 74.9 & - & - & - \\ 86.0 & 0.1205 & 0.5757 & 104,000 & 74.9 & - & - & - \\ 0.0 & 0.1504 & 0.72 .45 & 162,000 & 80.9 & - & - & - \\ 36.2 & 0.1504 & 0.7267 & 163,000 & 82.8 & - & - & - \\ 86.0 & 0.1504 & 0.7256 & 163,000 & 81.9 & - & - & -\end{array}$


TABLE D-2 continued

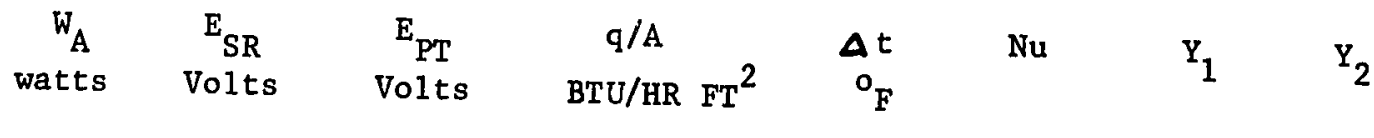

RUN 22 continued
0.0
0.1260
0.0
0.1564
0.6046
114,000
79.4
177,000
84.1

RUN 26

$\mathrm{L}=49.5 / 64 \mathrm{in}$.

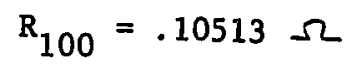

0.0

0.1794

$0.0 \quad 0.2016$

0.9210

239,000

0.0

0.497

1.0446

304,000

84.1

15.6

0.0497

0.2191

143,000

36.2

0.0497

0.2119

139,000

$\begin{array}{ll}0.0 & 0.0767\end{array}$

0.2104

138,000

$\begin{array}{ll}15.6 & 0.0767\end{array}$

0.3814

42,300

36.2

0.0767

0.3714

41,200

86.0

0.0767

0.3690

40,900

0.3634

40,300

$0.0 \quad 0.1052$

0.5261

80,000

$36.2 \quad 0.1052$

$86.0 \quad 0.1052$

0.5180

78,800

0.5174

78,700

0.0

0.1197

0.6011

104,000

15.6

0.1197

0.6000

104,000

86.0

0.1197

0.5980

103,000

15.6

0.1464

0.7458

158,000

36.2

0.1464

0.7453

158,000

86.0

0.1464

0.7450

158,000

RUN 38

$$
\mathrm{L}=48 / 64 \mathrm{in} \text {. }
$$

$\begin{array}{ll}0.0 & 0.0321\end{array}$

$0.0 \quad 0.0443$

$0.0 \quad 0.5510$

0.1463

0.2079

0.0

0.728

0.2690

0.0

0.827

0.3688

0.4076

0.0

0.1001

0.4994

0.0

0.1196

0.6004

0.6931

0.0

0.1372

0.0

0.1596

0.8112

0.1792

0.9159

0.0

0.2016

0.0

0.0191

1.0373

0.0849

0.0

0.0223

0.0

0.0226

0.0999

0.1012

0.0226

0.1011

7,000
13,700
22,100
40,000
50,300
74,500
107,000
142,000
193,000
245,000
312,000
2,420
3,320
3,420
3,410

89.9
44.9

27.3

22.6

60.9

45.1

41.3

32.4

66.2

58.6

57.

72.3

70.3

67.3

79.3

78.9

78.6

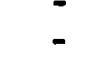

\subsection{6}

2.58

3.14

3.69

9.66

10.3

13.1

6.43

14.2

14.6

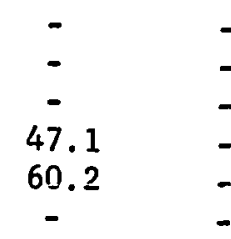

- $\quad 1040$

15.6

0.1011

$$
\mathrm{R}_{100}=0.1030 \Omega
$$

$25.1 \quad 1.44$

$42.4 \quad 1.69$

$65.6 \quad 1.76$

87.7

71.6

79.0

82.9

86.8

90.7

94.2

98.4

10.7

16.9

14.4

1.15

1.00

1.21

1.58

1913

2997

2130

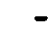


TABLE D-2 continued

$\begin{array}{cccccccc}\mathrm{W}_{\mathrm{A}} & \mathrm{E}_{\mathrm{SR}} & \mathrm{E}_{\mathrm{PT}} & \mathrm{q} / \mathrm{A} & \mathrm{At}_{\mathrm{t}} & \mathrm{Nu} & \mathrm{Y}_{1} & \mathrm{Y}_{2} \\ \text { watts } & \text { Volts } & \text { Volts } & \text { BTU/HR FT }^{2} & \mathrm{O}_{\mathrm{F}} & & & \end{array}$

RUN 38 continued

\begin{tabular}{|c|c|c|c|c|c|c|c|}
\hline 0.0 & 0.0362 & 0.1669 & 9,010 & 31.2 & 1.49 & - & - \\
\hline 2.0 & 0.0362 & 0.1666 & 9,000 & 29.4 & - & - & - \\
\hline 15.6 & 0.0361 & 0.1628 & 8,750 & 21.0 & 2.20 & 33.7 & - \\
\hline 36.2 & 0.0361 & 0.1625 & 8,750 & 18.1 & 2.49 & 47.1 & - \\
\hline 86.0 & 0.0319 & 0.1622 & 8,750 & 15.9 & 2.89 & 66.8 & - \\
\hline 0.0 & 0.0479 & 0.2284 & 16,300 & 51.5 & 1.67 & - & - \\
\hline 15.6 & 0.0479 & 0.2206 & 15,800 & 31.2 & 2.52 & 58.2 & - \\
\hline 36.2 & 0.0479 & 0.2184 & 15,600 & 25.3 & 3.18 & 67.2 & - \\
\hline 0.0 & 0.0608 & 0.2989 & 27,100 & 69.8 & 2.07 & - & - \\
\hline 36.2 & 0.05844 & 0.2686 & 23,400 & 29.3 & 4.23 & 78.3 & - \\
\hline 86.0 & 0.05844 & 0.2665 & 23,200 & 24.9 & 4.81 & 105 & - \\
\hline 0.0 & 0.0726 & 0.3704 & 40,100 & 93.9 & - & - & - \\
\hline 0.0 & 0.0863 & 0.4259 & 54,800 & 73.3 & - & - & - \\
\hline 1.0 & 0.0863 & 0.4250 & 54,700 & 72.0 & - & - & - \\
\hline 2.0 & 0.0863 & 0.4226 & 54,400 & 68.5 & - & - & - \\
\hline 7.0 & 0.0863 & 0.4214 & 54,200 & 66.8 & - & - & - \\
\hline 15.6 & 0.0863 & 0.4213 & 54,200 & 65.7 & 8.70 & - & 870 \\
\hline 36.2 & 0.0863 & 0.4140 & 53,300 & 55.3 & 14.1 & - & 1060 \\
\hline 0.0 & 0.1088 & 0.5419 & 87,900 & 77.1 & - & - & - \\
\hline 7.0 & 0.1088 & 0.5410 & 87,700 & 76.1 & - & - & - \\
\hline 15.6 & 0.1088 & 0.5402 & 87,600 & 75.2 & - & - & - \\
\hline 36.2 & 0.1088 & 0.5394 & 87,500 & 74.3 & - & - & - \\
\hline 0.0 & 0.1209 & 0.6037 & 109,000 & 78.7 & - & - & - \\
\hline 15.6 & 0.1209 & 0.6023 & 109,000 & 77.2 & - & - & - \\
\hline 36.2 & 0.1209 & 0.6017 & 108,000 & 76.6 & - & - & - \\
\hline 86.0 & 0.1209 & 0.6011 & 108,000 & 76.0 & - & - & - \\
\hline 0.0 & 0.1308 & 0.6566 & 128,000 & 82.0 & - & - & - \\
\hline 15.6 & 0.1308 & 0.6561 & 128,000 & 81.5 & - & - & - \\
\hline 36.2 & 0.1308 & 0.6554 & 128,000 & 80.8 & - & - & - \\
\hline 86.0 & 0.1308 & 0.6554 & 128,000 & 80.8 & - & - & - \\
\hline 0.0 & 0.1506 & 0.7599 & 171,000 & 85.2 & - & - & - \\
\hline 15.6 & 0.1500 & 0.7576 & 169,000 & 85.8 & - & - & - \\
\hline 36.2 & 0.1500 & 0.7575 & 169,000 & 85.7 & - & - & - \\
\hline 86.0 & 0.1500 & 0.7575 & 169,000 & 85.7 & - & - & - \\
\hline 0.0 & 0.0254 & 0.1143 & 4,330 & 17.5 & 1.26 & - & - \\
\hline 0.0 & 0.0286 & 0.1292 & 5,500 & 20.0 & 1.41 & - & - \\
\hline RUN 39 & & \multicolumn{2}{|c|}{$L=48 / 64$ in. } & $\mathrm{R}_{10}$ & $=0.1030$ & $\Omega$ & \\
\hline 0.0 & 0.0342 & 0.1568 & 8,000 & 27.2 & 1.54 & - & - \\
\hline 0.0 & 0.0536 & 0.2603 & 20,800 & 62.9 & 1.75 & - & - \\
\hline
\end{tabular}


TABLE D-2 continued

$\begin{array}{cccccccc}\mathrm{W}_{\mathrm{A}} & \mathrm{E}_{\mathrm{SR}} & \mathrm{E}_{\mathrm{PT}} & \mathrm{q} / \mathrm{A} & \Delta \mathrm{t} & \mathrm{Nu} & \mathrm{Y}_{1} & \mathrm{Y}_{2} \\ \text { watts } & \text { Volts } & \text { Volts } & \text { BTU/HR FT } & \mathrm{o}_{\mathrm{F}} & & & \end{array}$

RUN 39 continued

\begin{tabular}{|c|c|c|c|c|c|c|c|}
\hline 0.0 & 0.0740 & 0.3810 & 42,000 & 98.8 & - & - & - \\
\hline 0.0 & 0.0935 & 0.4611 & 64,300 & 71.9 & - & - & - \\
\hline 0.0 & 0.1198 & 0.5975 & 107,000 & 78.8 & - & - & - \\
\hline 0.0 & 0.1446 & 0.7282 & 157,000 & 84.9 & - & - & - \\
\hline 0.0 & 0.1694 & 0.8576 & 217,000 & 87.3 & - & - & - \\
\hline 0.0 & 0.2011 & 1.0289 & 308,000 & 93.9 & - & - & - \\
\hline 0.0 & 0.0370 & 0.1696 & 9,350 & 28.8 & 1.68 & - & - \\
\hline 4.8 & 0.0370 & 0.1682 & 9,260 & 23.9 & - & - & - \\
\hline 15.6 & 0.0369 & 0.1668 & 9,100 & 20.8 & 2.30 & 33.7 & - \\
\hline 36.2 & 0.0368 & 0.1657 & 9,080 & 16.5 & 2.91 & 42.8 & - \\
\hline 86.0 & 0.0369 & 0.1651 & 9,080 & 13.2 & 3.41 & 58.8 & - \\
\hline 0.0 & 0.0479 & 0.2261 & 16,200 & 43.4 & 1.94 & - & - \\
\hline 1.6 & 0.0479 & 0.2261 & 16,200 & 43.4 & - & - & - \\
\hline 2.0 & 0.0478 & 0.2232 & 15,900 & 37.2 & - & - & - \\
\hline 15.6 & 0.0479 & 0.2218 & 15,800 & 33.0 & 2.52 & 58.2 & - \\
\hline 36.2 & 0.0480 & 0.2178 & 15,600 & 25.5 & 3.18 & 67.2 & - \\
\hline 86.0 & 0.0480 & 0.2167 & 15,500 & 19.3 & 4.15 & .78 .6 & - \\
\hline 0.0 & 0.0577 & 0.2834 & 24,400 & 68.2 & 1.88 & - & - \\
\hline 15.6 & 0.0576 & 0.2678 & 23,000 & 35.7 & 3.49 & 66.5 & - \\
\hline 36.2 & 0.0576 & 0.2667 & 22,900 & 33.3 & 3.47 & 96.0 & - \\
\hline 0.0 & 0.0733 & 0.3583 & 39,200 & 66.5 & 3.08 & - & - \\
\hline 0.6 & 0.0733 & 0.3544 & 38,700 & 59.9 & - & - & - \\
\hline 15.6 & 0.0733 & 0.3477 & 38,000 & 46.6 & 8.87 & - & 1040 \\
\hline 36.2 & 0.0733 & 0.3438 & 37.600 & 42.0 & 9.57 & - & 1420 \\
\hline 86.0 & 0.0733 & 0.3416 & 37,300 & 38.3 & 10.2 & - & 945 \\
\hline 0.0 & 0.0905 & 0.4467 & 60,300 & 72.5 & 4.45 & - & - \\
\hline 2.0 & 0.0905 & 0.4443 & 59,900 & 69.2 & - & - & - \\
\hline 15.6 & 0.0905 & 0.4422 & 59,700 & 67.3 & 9.22 & - & 784 \\
\hline 0.0 & 0.1106 & 0.5483 & 90,400 & 75.1 & 6.45 & - & - \\
\hline 15.6 & 0.1106 & 0.5456 & 90,000 & 72.1 & - & - & - \\
\hline 36.2 & 0.1106 & 0.5444 & 89,800 & 70.8 & - & - & - \\
\hline 86.0 & 0.1106 & 0.5434 & 89,600 & 69.6 & - & - & - \\
\hline 0.0 & 0.1251 & 0.6238 & 116,000 & 78.7 & - & - & - \\
\hline 15.6 & 0.1251 & 0.6236 & 116,000 & 78.5 & - & - & - \\
\hline 36.2 & 0.1251 & 0.6228 & 116,000 & 77.7 & - & - & - \\
\hline 86.0 & 0.1251 & 0.6226 & 116,000 & 77.5 & - & - & - \\
\hline 0.0 & 0.1356 & 0.6758 & 137,000 & 79.3 & - & - & - \\
\hline 15.6 & 0.1356 & 0.6753 & 137,000 & 78.8 & - & - & - \\
\hline 36.2 & 0.1356 & 0.6749 & 136,000 & 78.5 & - & - & - \\
\hline 86.0 & 0.1356 & 0.6748 & 136,000 & 78.4 & - & - & - \\
\hline 0.0 & 0.1497 & 0.7502 & 167,000 & 82.7 & - & - & - \\
\hline
\end{tabular}


TABLE D-2 continued

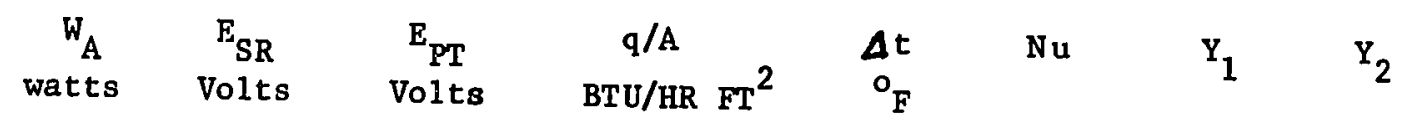

RUN 39 continued

$\begin{array}{rlllllll}15.6 & 0.1497 & 0.7498 & 167,000 & 82.4 & - & - & - \\ 36.2 & 0.1497 & 0.7491 & 167,000 & 81.8 & - & - & - \\ 86.0 & 0.1497 & 0.7490 & 167,000 & 81.7 & - & - & - \\ 0.0 & 0.1644 & 0.8261 & 202,000 & 84.4 & - & - & - \\ 15.6 & 0.1644 & 0.8260 & 202,000 & 84.3 & - & - & - \\ 36.2 & 0.1644 & 0.8258 & 202,000 & 84.2 & - & - & - \\ 86.0 & 0.1644 & 0.8260 & 202,000 & 84.3 & - & - & -\end{array}$


TABIE D-3

LIQUID: Distilled Water TEMPERATURE: $113^{\circ} \mathrm{F}$ FREQUENCY: $20.6 \mathrm{kcps}$ WIRE DIAMETER: $0.010^{\prime \prime}$

$\begin{array}{cccccccc}\mathrm{W}_{\mathrm{A}} & \mathrm{E}_{\mathrm{SR}} & \mathrm{E}_{\mathrm{PT}} & \mathrm{q} / \mathrm{a} & \Delta \mathrm{t} & \mathrm{N}_{\mathrm{U}} & \mathrm{Y}_{1} & \mathrm{Y}_{2} \\ \text { watts } & \text { Volts } & \text { Volts } & \text { BTU/HR FT } & \mathrm{O}_{\mathrm{F}} & & & \end{array}$ RUN 7

$$
\mathrm{L}=47 / 64 \text { in. } \quad \mathrm{R}_{100}=0.04928 \Omega
$$

$\begin{array}{rrrrrrrr}0.0 & 0.4394 & 1.1632 & 545,000 & 146.2 & - & - & - \\ 15.6 & 0.4495 & 1.1288 & 541,000 & 111.0 & - & - & - \\ 36.2 & 0.4456 & 1.0967 & 521,000 & 98.1 & 14.39 & - & 2073 \\ 86.0 & 0.4489 & 1.0698 & 512,000 & 76.9 & 18.11 & - & 2486 \\ 0.0 & 0.3595 & 0.9392 & 360,000 & 136.3 & - & - & - \\ 15.6 & 0.3617 & 0.8843 & 341,000 & 92.9 & 9.92 & - & 822 \\ 36.2 & 0.3547 & 0.8540 & 323,000 & 83.2 & 10.50 & - & 1440 \\ 86.0 & 0.3589 & 0.8390 & 321,000 & 64.3 & 13.7 & - & 1715 \\ 0.0 & 0.2327 & 0.6005 & 149,000 & 129.0 & - & - & - \\ 15.6 & 0.2318 & 0.5543 & 137,000 & 79.8 & 3.65 & 62.9 & - \\ 36.2 & 0.2353 & 0.5500 & 138,000 & 65.9 & 4.55 & 84.6 & - \\ 86.0 & 0.2321 & 0.5294 & 131,000 & 50.5 & 6.43 & 85.0 & - \\ 0.0 & 0.1740 & 0.4168 & 77,300 & 80.3 & 2.08 & - & - \\ 86.0 & 0.1740 & 0.3867 & 71,700 & 35.6 & 4.36 & 56.0 & - \\ 0.0 & 0.0939 & 0.2069 & 20,700 & 30.5 & 1.50 & - & - \\ 15.6 & 0.0921 & 0.2026 & 19,900 & 28.4 & 1.64 & 14.8 & - \\ 36.2 & 0.0922 & 0.2005 & 19,700 & 22.2 & 2.00 & 23.9 & - \\ 86.0 & 0.0920 & 0.1997 & 19,600 & 20.9 & 2.20 & 34.7 & -\end{array}$

RUN 53

$$
\mathrm{L}=47 / 64 \text { in. }
$$

$\begin{array}{rrrrrrrr}0.0 & 0.0811 & 0.1768 & 15,300 & 25.0 & 1.36 & - & - \\ 0.0 & 0.1171 & 0.2626 & 32,800 & 41.2 & 1.76 & - & - \\ 0.0 & 0.1671 & 0.3934 & 70,100 & 70.3 & 2.17 & - & - \\ 0.0 & 0.2109 & 0.5247 & 118,000 & 104.9 & - & - & - \\ 0.0 & 0.0972 & 0.2162 & 22,400 & 36.1 & 1.37 & - & - \\ 15.6 & 0.0971 & 0.2125 & 22,000 & 26.2 & 1.86 & 14.4 & - \\ 0.0 & 0.1284 & 0.2943 & 40,300 & 53.3 & 1.67 & - & - \\ 15.6 & 0.1281 & 0.2862 & 39,100 & 38.3 & 2.27 & 21.3 & - \\ 36.2 & 0.1276 & 0.2829 & 38,500 & 33.0 & 3.57 & 37.3 & - \\ 86.0 & 0.1273 & 0.2792 & 37,900 & 26.8 & 3.16 & 42.5 & - \\ 0.0 & 0.1406 & 0.3289 & 49,300 & 65.6 & 1.63 & - & - \\ 15.6 & 0.1418 & 0.3196 & 48,300 & 43.5 & 2.43 & 24.2 & -\end{array}$


TABLE D-3 continued

$\begin{array}{cccccccc}\mathrm{W}_{\mathrm{A}} & \mathrm{E}_{\mathrm{SR}} & \mathrm{E}_{\mathrm{PT}} & \mathrm{q} / \mathrm{a} & \Delta \mathrm{t} & \mathrm{Nu} & \mathrm{Y}_{1} & \mathrm{Y}_{2} \\ \text { watts } & \text { Volts } & \text { Volts } & \mathrm{BTU}_{\mathrm{HR}} \mathrm{FT}^{2} & \mathrm{O}_{\mathrm{F}} & & & \end{array}$

RUN 53 continued

\begin{tabular}{|c|c|c|c|c|c|c|c|}
\hline 15.6 & 0.1411 & 0.3205 & 48,200 & 48.2 & 2.19 & 27.0 & - \\
\hline 15.6 & 0.1420 & 0.3185 & 48,200 & 41.6 & 2.52 & 22.4 & - \\
\hline 0.0 & 0.1511 & 0.3539 & 57,000 & 67.3 & 1.84 & - & - \\
\hline 15.6 & 0.1493 & 0.3405 & 54,200 & 51.2 & 2.21 & 29.24 & - \\
\hline 36.2 & 0.1490 & 0.3322 & 52,800 & 37.8 & 3.10 & 42.10 & - \\
\hline 86.0 & 0.1484 & 0.3262 & 51,600 & 30.8 & 3.83 & 47.8 & - \\
\hline $\begin{array}{l}0.0 \\
7.0\end{array}$ & 0.1728 & 0.4135 & 76,200 & 81.1 & 2.03 & - & - \\
\hline $\begin{array}{r}7.0 \\
15.6\end{array}$ & 0.1719 & 0.4027 & 73,800 & 69.3 & - & - & - \\
\hline $\begin{array}{r}15.6 \\
0.0\end{array}$ & $\begin{array}{l}0.1711 \\
0.1876\end{array}$ & $\begin{array}{l}0.3959 \\
0.4614\end{array}$ & $\begin{array}{l}72,200 \\
92,300\end{array}$ & 61.8 & 2.51 & 43.0 & - \\
\hline 3.0 & 0.1903 & 0.4545 & $\begin{array}{l}92,300 \\
92,200\end{array}$ & $\begin{array}{l}97.4 \\
78.3\end{array}$ & - & - & - \\
\hline 15.6 & 0.1917 & 0.4506 & 92,100 & $\begin{array}{l}18.3 \\
67.5\end{array}$ & $\overline{3.00}$ & $\overline{5} 5$ & - \\
\hline 15.6 & 0.1922 & 0.4490 & 92,000 & 62.9 & $\begin{array}{l}3.00 \\
3.23\end{array}$ & $\begin{array}{l}45.5 \\
40.4\end{array}$ & $\overline{-}$ \\
\hline 36.2 & 0.1912 & 0.4366 & 89,000 & 49.2 & 3.98 & $\begin{array}{l}40.4 \\
53.3\end{array}$ & - \\
\hline 86.0 & 0.1919 & 0.4325 & 88,500 & 41.6 & 4.70 & 66.1 & - \\
\hline 0.0 & 0.2468 & 0.6196 & 163,000 & 110.0 & - & - & - \\
\hline 1.5 & 0.2487 & 0.6035 & 160,000 & 88.3 & - & - & - \\
\hline 15.6 & 0.2496 & 0.5976 & 159,000 & 79.9 & 5.45 & - & 482.0 \\
\hline 36.2 & 0.2474 & 0.5799 & 153,000 & 67.6 & 6.16 & - & 796.0 \\
\hline 86.0 & 0.2463 & 0.5674 & 149,000 & 57.2 & 7.23 & - & 1110.0 \\
\hline 0.0 & 0.2835 & 0.7244 & 219,000 & 122.3 & - & - & - \\
\hline 15.6 & 0.2883 & 0.7028 & 216,000 & 92.1 & - & - & - \\
\hline 36.2 & 0.2882 & 0.6867 & 211,000 & 77.8 & 7.52 & - & 1030.0 \\
\hline 86.0 & 0.2908 & 0.6772 & 210,000 & 63.7 & 9.27 & - & 1381.0 \\
\hline 0.0 & 0.3367 & 0.8690 & 312,000 & 128.1 & - & - & 1001.0 \\
\hline 15.6 & 0.3412 & 0.8413 & 306,000 & 98.4 & - & - & - \\
\hline 36.2 & 0.3392 & 0.8240 & 298,000 & 88.8 & 9.02 & - & $139 \overline{6} .0$ \\
\hline 86.0 & 0.3404 & 0.8046 & 292,000 & 71.9 & 11.20 & - & $\begin{array}{l}1390.0 \\
1750.0\end{array}$ \\
\hline 0.0 & 0.3614 & 0.9342 & 360,000 & 128.2 & - & - & 180 \\
\hline 1.5 & 0.3648 & 0.9178 & 357,000 & 110.3 & - & - & $\overline{-}$ \\
\hline 15.6 & 0.3661 & 0.9096 & 355,000 & 102.3 & - & - & $\overline{-}$ \\
\hline 0.0 & 0.3904 & 1.0138 & 422,000 & 132.3 & - & - & $=$ \\
\hline 15.6 & 0.3953 & 0.9893 & 417,000 & 107.8 & - & - & - \\
\hline 0.0 & 0.4205 & 1.1176 & 501,000 & 149.0 & - & - & - \\
\hline 3.0 & 0.4276 & 1.0945 & 499,000 & 123.5 & - & - & - \\
\hline 15.6 & 0.4308 & 1.0841 & 498,000 & 112.3 & - & - & - \\
\hline 36.2 & 0.4342 & 1.0715 & 496,000 & 99.8 & - & - & - \\
\hline 86.0 & 0.4339 & 1.0354 & 479,000 & 78.6 & 16.60 & - & 2360.0 \\
\hline 0.0 & 0.4550 & 1.2163 & 590,000 & 152.1 & - & - & - \\
\hline 4.8 & 0.4588 & 1.1940 & 584,000 & 133.8 & - & - & . \\
\hline 15.6 & 0.4590 & 1.1830 & 579,000 & 127.2 & - & - & - \\
\hline 36.2 & 0.4627 & 1.1553 & 570,000 & 106.3 & - & - & - \\
\hline
\end{tabular}


TABLE D-3 continued

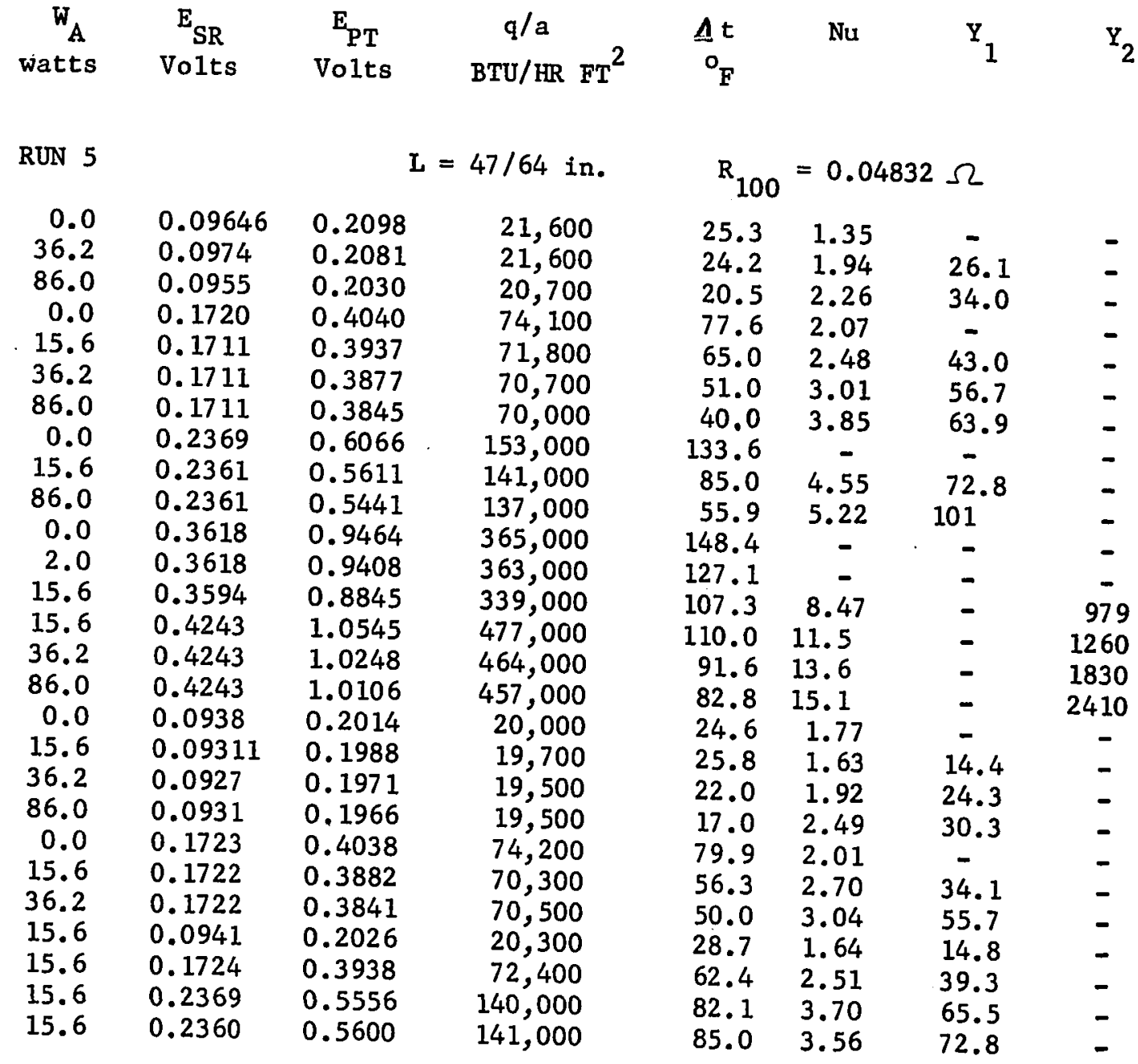


TABLE D-4

LIQUID: Distilled Water TEMPERATURE: $149^{\circ} \mathrm{F}$ FREQUENCY: $20.6 \mathrm{kcps}$ WIRE DIAMETER： $0.010^{\prime \prime}$

$\begin{array}{cccccccc}\mathrm{W}_{\mathrm{A}} & \mathrm{E}_{\mathrm{SR}} & \mathrm{E}_{\mathrm{PT}} & \mathrm{q} / \mathrm{A} & \Delta \mathrm{t} & \mathrm{Nu} & \mathrm{Y}_{1} & \mathrm{Y}_{2} \\ \text { watts } & \text { Volts } & \text { Volts } & \text { BTU/HR FT } & \mathrm{O}_{\mathrm{F}} & & & \end{array}$

RUN 20

$$
\mathrm{L}=48 / 64 \mathrm{in} . \quad \mathrm{R}_{100}=0.04989 \Omega
$$

$\begin{array}{rrrrrrrr}0.0 & 0.2023 & 0.5304 & 112,000 & 95.5 & - & - & - \\ 0.0 & 0.1072 & 0.2520 & 28,200 & 26.2 & 1.60 & - & - \\ 0.0 & 0.2352 & 0.6231 & 153,000 & 102.3 & - & - & - \\ 0.0 & 0.2791 & 0.7448 & 217,000 & 107.4 & - & - & - \\ 0.0 & 0.3478 & 0.9365 & 340,000 & 113.5 & - & - & - \\ 0.0 & 0.4034 & 1.0922 & 460,000 & 117.2 & - & - & - \\ 0.0 & 0.4591 & 1.2497 & 599,000 & 121.0 & - & - & - \\ 0.0 & 0.4845 & 1.3227 & 669,000 & 123.1 & - & - & -\end{array}$

RUN 23

$$
\mathrm{L}=48 / 64 \mathrm{in} \text {. }
$$

$\begin{array}{rlrr}0.0 & 0.1343 & 0.3288 & 46,100 \\ 4.8 & 0.1346 & 0.3245 & 45,600 \\ 15.6 & 0.1343 & 0.3217 & 45,100 \\ 0.0 & 0.1934 & 0.5052 & 102,000 \\ 1.0 & 0.1932 & 0.4830 & 97,400 \\ 15.6 & 0.1932 & 0.4760 & 96,000 \\ 36.2 & 0.1951 & 0.4675 & 95,200 \\ 0.0 & 0.2864 & 0.7794 & 233,000 \\ 7.0 & 0.2861 & 0.7265 & 217,000 \\ 15.6 & 0.2864 & 0.7125 & 213,000 \\ 36.2 & 0.2861 & 0.6997 & 209,000 \\ 0.0 & 0.3524 & 0.9540 & 351,000 \\ 15.6 & 0.3494 & 0.8827 & 322,000 \\ 36.2 & 0.3499 & 0.8732 & 319,000\end{array}$

RUN 6

$$
L=47 / 64 \mathrm{in} \text {. }
$$

$\begin{array}{rccc}\mathrm{R}_{100} & =0.04989 & \Omega & \\ 50.9 & 1.36 & - & - \\ 41.2 & - & - & - \\ 37.3 & 2.60 & 41.0 & - \\ 92.9 & 1.63 & - & - \\ 64.2 & - & - & - \\ 55.0 & 3.70 & 71.7 & - \\ 37.7 & - & - & - \\ 120.9 & - & - & - \\ 74.2 & - & - & - \\ 61.1 & 9.4 & - & 527 \\ 50.2 & 11.1 & - & 934 \\ 117.2 & - & - & - \\ 70.8 & 12.2 & - & 763 \\ 63.0 & 13.6 & - & 1310\end{array}$

$\begin{array}{rlllllll}0.0 & 0.09362 & 0.2131 & 21,300 & 26.1 & 1.76 & - & - \\ 2.0 & 0.09345 & 0.2134 & 21,300 & 27.9 & - & - & - \\ 7.0 & 0.09345 & 0.2134 & 21,300 & 27.9 & - & - & - \\ 15.6 & 0.09354 & 0.2105 & 20,500 & 19.6 & 2.24 & 21.5 & - \\ 0.0 & 0.1718 & 0.4265 & 78,100 & 78.8 & 2.10 & - & - \\ 0.8 & 0.1718 & 0.4164 & 76,300 & 63.2 & - & - & -\end{array}$


TABLE D-4 continued

\begin{tabular}{|c|c|c|c|c|c|c|c|}
\hline $\begin{array}{r}{ }_{A} \\
\text { watts }\end{array}$ & $\begin{array}{c}\mathrm{E}_{\mathrm{SR}} \\
\text { Volts }\end{array}$ & $\begin{array}{c}\mathrm{E}_{\mathrm{PT}} \\
\text { Volts }\end{array}$ & $\begin{array}{c}\mathrm{q} / \mathrm{A} \\
\mathrm{BTU} / \mathrm{HR} \mathrm{FT}^{2}\end{array}$ & $\begin{array}{c}\Delta t \\
o_{F}\end{array}$ & $\mathrm{Nu}$ & $\mathrm{Y}_{1}$ & $Y_{2}$ \\
\hline \multicolumn{8}{|c|}{ RUN 6 continued } \\
\hline 2.0 & 0.1718 & 0.4093 & 74,900 & 53.1 & - & - & - \\
\hline 7.0 & 0.1716 & 0.4053 & 74,100 & 46.4 & - & - & - \\
\hline 15.6 & 0.1716 & 0.4036 & 73,800 & 44.3 & 3.56 & 50.0 & - \\
\hline 0.0 & 0.2367 & 0.6178 & 156,000 & 1.11 .6 & - & - & - \\
\hline 2.0 & 0.2367 & 0.5943 & 150,000 & 86.5 & - & - & - \\
\hline 7.0 & 0.2366 & 0.5754 & 145,000 & 65.4 & - & - & - \\
\hline 15.6 & 0.2366 & 0.5709 & 144,000 & 60.4 & 5.00 & 86.6 & - \\
\hline 36.2 & 0.2366 & 0.5631 & 142,000 & 51.5 & 5.90 & 132 & - \\
\hline 86.0 & 0.2366 & 0.5541 & 142,000 & 41.0 & 7.41 & 152 & - \\
\hline 0.0 & 0.3695 & 0.9637 & 380,000 & 112.9 & - & - & - \\
\hline 2.0 & 0.3695 & 0.9515 & 375,000 & 104.2 & - & - & - \\
\hline 7.0 & 0.3695 & 0.9414 & 371,000 & 96.0 & - & - & - \\
\hline 15.6 & 0.3695 & 0.9294 & 393,000 & 87.0 & 12.4 & - & 1090 \\
\hline 36.2 & 0.3695 & 0.8990 & 354,000 & 65.7 & 14.4 & - & 860 \\
\hline 86.0 & 0.3695 & 0.8833 & 348,000 & 54.5 & 17.2 & - & 1981 \\
\hline 0.0 & 0.4315 & 1.1268 & 518,000 & 112.8 & - & - & - \\
\hline 4.8 & 0.4315 & 1.1140 & 513,000 & 104.9 & - & - & - \\
\hline 36.2 & 0.4315 & 1.0670 & 491,000 & 76.2 & 17.3 & - & 1908 \\
\hline 86.0 & 0.4315 & 1.0478 & 482,000 & 20.5 & - & - & 2840 \\
\hline
\end{tabular}

RUN 50

$\begin{array}{rrr}0.0 & 0.0709 & 0.1658 \\ 0.0 & 0.0956 & 0.2291 \\ 0.0 & 0.1202 & 0.2946 \\ 0.0 & 0.1516 & 0.3848 \\ 0.0 & 0.1812 & 0.4770 \\ 0.0 & 0.2053 & 0.5360 \\ 0.0 & 0.2316 & 0.5997 \\ 0.0 & 0.2704 & 0.7043 \\ 0.0 & 0.3044 & 0.8200 \\ 0.0 & 0.3314 & 0.9036 \\ 0.0 & 0.4244 & 1.1720 \\ 0.0 & 0.0626 & 0.1450 \\ 7.0 & 0.0626 & 0.1450 \\ 15.6 & 0.0626 & 0.1441 \\ 0.0 & 0.0947 & 0.2265 \\ 2.0 & 0.0947 & 0.2265 \\ 7.0 & 0.0947 & 0.2183 \\ 15.6 & 0.0947 & 0.2078 \\ 36.2 & 0.0947 & 0.2011\end{array}$

$\mathrm{L}=49.5 / 64 \mathrm{in}$.

$\begin{array}{rrccc}11,900 & 17 \% 8 & 1.44 & - & - \\ 22,200 & 32.5 & 1.47 & - & - \\ 35,800 & 46.4 & 1.65 & - & - \\ 59,100 & 67.6 & 1.86 & - & - \\ 87,500 & 91.5 & 2.03 & - & - \\ 111,000 & 86.0 & 2.74 & - & - \\ 141,000 & 80.6 & - & - & - \\ 193,000 & 84.5 & - & - & - \\ 253,000 & 107.1 & - & - & - \\ 303,000 & 115.4 & - & - & - \\ 503,000 & 123.4 & - & - & - \\ 9,200 & 14.0 & - & - & - \\ 9,200 & 14.0 & - & - & - \\ 9,100 & 10.3 & - & - & - \\ 21,700 & 31.3 & 1.49 & - & - \\ 21,700 & 31.3 & - & - & - \\ 21,000 & 25.0 & - & - & - \\ 20,700 & 21.7 & 2.06 & 23.2 & - \\ 21,200 & 17.5 & 2.61 & 40.3 & -\end{array}$


TABLE D-4 continued

$\begin{array}{cccccccc}\mathrm{W}_{\mathrm{A}} & \mathrm{E}_{\mathrm{SR}} & \mathrm{E}_{\mathrm{PT}} & \mathrm{q} / \mathrm{A} & \Delta \mathrm{t} & \mathrm{Nu} & \mathrm{Y}_{1} & \mathrm{Y}_{2} \\ \text { watts } & \text { Volts } & \text { Volts } & \mathrm{BTU}_{\mathrm{HR}} \mathrm{FT}^{2} & \mathrm{O}_{\mathrm{F}} & & & \end{array}$

RUN 50 continued

$\begin{array}{rrrrrrrr}0.0 & 0.1296 & 0.3178 & 41,700 & 48.5 & 1.84 & - & - \\ 2.0 & 0.1296 & 0.3165 & 41,500 & 45.9 & - & - & - \\ 4.8 & 0.1296 & 0.3138 & 41,200 & 40.6 & - & - \\ 15.6 & 0.1296 & 0.3110 & 41,000 & 35.2 & 2.52 & 37.5 & - \\ 36.2 & 0.1296 & 0.3011 & 40,700 & 25.0 & 3.45 & 54.6 & - \\ 0.0 & 0.1613 & 0.4124 & 67,000 & 75.0 & 1.89 & - & - \\ 2.0 & 0.1613 & 0.4030 & 65,800 & 60.2 & - & - & - \\ 15.6 & 0.1613 & 0.3910 & 63,800 & 41.3 & 3.30 & 47.1 & - \\ 0.0 & 0.2032 & 0.5407 & 111,000 & 99.7 & - & - & - \\ 1.0 & 0.2032 & 0.5407 & 111,000 & 99.7 & - & - & - \\ 2.0 & 0.2032 & 0.5104 & 105,000 & 61.8 & - & - & - \\ 15.6 & 0.2032 & 0.5037 & 104,000 & 52.4 & 4.15 & 66.6 & - \\ 0.0 & 0.2026 & 0.5420 & 111,000 & 103.3 & - & - & - \\ 2.0 & 0.2026 & 0.5074 & 107,000 & 75.3 & - & - & - \\ 0.0 & 0.2957 & 0.8068 & 241,000 & 118.6 & - & - & - \\ 2.0 & 0.2957 & 0.8068 & 241,000 & 118.6 & - & - & - \\ 4.8 & 0.2957 & 0.8080 & 242,000 & 119.6 & - & - & - \\ 7.0 & 0.2957 & 0.7616 & 228,000 & 79.8 & - & - & - \\ 15.6 & 0.2957 & 0.7505 & 225,000 & 70.3 & 8.49 & - & 635 \\ 0.0 & 0.3417 & 0.9385 & 325,000 & 121.4 & - & - & - \\ 15.6 & 0.3417 & 0.8770 & 303,000 & 74.7 & 10.8 & - & 773 \\ 36.2 & 0.3417 & 0.8548 & 296,000 & 59.2 & 13.1 & - & 1210 \\ 0.0 & 0.3925 & 1.0843 & 431,000 & 123.6 & - & - & - \\ 2.0 & 0.3925 & 1.0830 & 430,000 & 122.8 & - & - & - \\ 7.0 & 0.3925 & 1.0564 & 420,000 & 105.6 & - & - & - \\ 15.6 & 0.3925 & 1.0206 & 405,000 & 82.5 & 13.1 & - & 1071 \\ 36.2 & 0.3925 & 0.9940 & 395,000 & 65.3 & 15.9 & - & 1581 \\ 0.0 & 0.4215 & 1.1583 & 494,000 & 121.8 & - & - & - \\ 15.6 & 0.4215 & 1.1017 & 470,000 & 87.7 & - & - & - \\ 36.2 & 0.4215 & 1.0179 & 456,000 & 67.3 & 18.6 & - & 1817 \\ 86.0 & 0.4215 & 1.0464 & 446,000 & 54.4 & 22.2 & - & 2250 \\ 0.0 & 0.2847 & 0.7550 & 218,000 & 99.2 & - & - & - \\ 15.6 & 0.2847 & 0.7152 & 206,000 & 63.7 & 8.61 & - & 547 \\ 36.2 & 0.2847 & 0.6968 & 201,000 & 47.3 & 11.5 & - & 868 \\ 86.0 & 0.2847 & 0.6897 & 199,000 & 41.0 & 13.2 & - & 1290 \\ 0.0 & 0.3421 & 0.9238 & 320,000 & 111.5 & - & - & - \\ 15.6 & 0.3421 & 0.8748 & 303,000 & 75.1 & 10.8 & - & 773 \\ 86.0 & 0.3421 & 0.8326 & 288,000 & 43.8 & 18.0 & - & 1596 \\ & & & & & - \\ 150 & \end{array}$


TABLEE $D-4$ continued

\begin{tabular}{|c|c|c|c|c|c|c|c|}
\hline $\begin{array}{c}\mathrm{W}_{\mathrm{A}} \\
\text { watts }\end{array}$ & $\begin{array}{c}\mathrm{E}_{\mathrm{SR}} \\
\text { Volts }\end{array}$ & $\begin{array}{c}\mathrm{E}_{\mathrm{PT}} \\
\text { Volts }\end{array}$ & $\begin{array}{l}\text { q/A } \\
\text { BTU/HR FT }\end{array}$ & $\begin{array}{c}\Delta t \\
O_{F}\end{array}$ & $\mathrm{Nu}$ & $\mathrm{Y}_{1}$ & $Y_{2}$ \\
\hline RUN 51 & & & $4 \overline{9} .5 ; 6 \dot{4}$ in. & $\mathrm{R}_{10}$ & $=0.05$ & $\Omega$ & \\
\hline 0.0 & 0.0520 & 0.1201 & 6,300 & 11.4 & 1.20 & - & - \\
\hline 0.0 & 0.0838 & 0.1981 & 16,800 & 26.1 & 1.40 & - & - \\
\hline 0.0 & 0.1206 & 0.2952 & 36,000 & 47.4 & 1.63 & - & - \\
\hline 0.0 & 0.1747 & 0.4518 & 79,900 & 81.6 & 2.08 & - & - \\
\hline 0.0 & 0.3942 & 1.0634 & 424,000 & 108.1 & - & - & - \\
\hline 15.6 & 0.3942 & 1.0324 & 412,000 & 88.1 & 12.6 & - & 1126 \\
\hline 36.2 & 0.3942 & 0.9968 & 398,000 & 65.2 & 16.0 & - & 1685 \\
\hline 86.0 & 0.3942 & 0.9767 & 390,000 & 52.2 & 20.2 & - & 2100 \\
\hline 0.0 & 0.3590 & 0.9610 & 349,000 & 102.9 & - & - & - \\
\hline 15.6 & 0.3590 & 0.9270 & 337,000 & 78.2 & 11.4 & - & 898 \\
\hline 36.2 & 0.3590 & 0.8990 & 327,000 & 59.0 & 14.6 & - & 1248 \\
\hline 86.0 & 0.3590 & 0.8881 & 320,000 & 46.5 & 18.6 & - & 1754 \\
\hline 0.0 & 0.3256 & 0.8627 & 284,000 & 96.8 & - & - & - \\
\hline 15.6 & 0.3256 & 0.8333 & 275,000 & 73.9 & 9.80 & - & 690 \\
\hline 36.2 & 0.3256 & 0.8080 & 266,000 & 54.1 & 13.2 & - & 1070 \\
\hline 86.0 & 0.3256 & 0.7920 & 261,000 & 41.7 & 16.6 & - & 1500 \\
\hline 15.6 & 0.2771 & 0.7002 & 196,000 & 65.6 & 7.95 & - & 558 \\
\hline 36.2 & 0.2771 & 0.6806 & 191,000 & 47.7 & 11.0 & - & 850 \\
\hline 86.0 & 0.2771 & 0.6692 & 188,000 & 37.2 & 13.7 & - & 1200 \\
\hline 15.6 & .2276 & 0.5684 & 131,000 & 58.1 & 4.81 & 77.4 & - \\
\hline 36.2 & 0.2276 & 0.5512 & 127,000 & 39.0 & 6.62 & 91.5 & - \\
\hline 86.0 & 0.2276 & 0.5424 & 125,000 & 29.2 & 9.14 & 104 & - \\
\hline 15.6 & 0.1809 & 0.4435 & 81,000 & 46.5 & 3.64 & $37: 4$ & - \\
\hline 36.2 & 0.1809 & 0.4333 & 79,300 & 32.2 & 5.39 & 70.0 & - \\
\hline 86.0 & 0.1809 & 0.4275 & 77,300 & 24.7 & 6.66 & 86.2 & - \\
\hline 0.0 & 0.1462 & 0.3670 & 54,300 & 61.4 & 1.89 & - & - \\
\hline 15.6 & 0.1462 & 0.3554 & 52,000 & 41.3 & 2.70 & 47.1 & - \\
\hline 86.0 & 0.1462 & 0.3432 & 50,800 & 20.7 & 5.51 & 71.8 & - \\
\hline 0.0 & 0.1018 & 0.2454 & 25,300 & 37.0 & 1.47 & - & - \\
\hline 15.6 & 0.1018 & 0.2420 & 24,900 & 28.6 & 1.87 & 30.2 & - \\
\hline 86.0 & 0.1018 & 0.2372 & 24,400 & 16.6 & 3.18 & 61.2 & \\
\hline
\end{tabular}

RUN 52

$$
I=48 / 64 \mathrm{in} \text {. }
$$

$\begin{array}{rrrrrl}0.0 & 0.0589 & 0.1314 & 8,500 & 11.1 & 1.66 \\ 0.0 & 0.0908 & 0.2173 & 20,600 & 26.3 & 1.69 \\ 0.0 & 0.1329 & 0.3324 & 46,100 & 54.4 & 1.81 \\ 0.0 & 0.1821 & 0.4813 & 91,500 & 90.2 & 2.15 \\ 0.0 & 0.2262 & 0.5860 & 138,000 & 77.0 & - \\ 0.0 & 0.2694 & 0.7600 & 214,000 & 105.2 & - \\ 0.0 & 0.3033 & 0.8317 & 263,00 & 115.2 & - \\ 0.0 & 0.3426 & 0.9514 & 340,000 & 124.0 & - \\ 0.0 & 0.3815 & 1.0634 & 424,000 & 126.7 & -\end{array}$


TABLE D-4 continued

$\begin{array}{cccccccc}\mathrm{W}_{\mathrm{A}} & \mathrm{E}_{\mathrm{SR}} & \mathrm{E}_{\mathrm{PT}} & \mathrm{q} / \mathrm{A} & \Delta \mathrm{t} & \mathrm{Nu} & \mathrm{Y}_{1} & \mathrm{Y}_{2} \\ \text { watts } & \text { Volts } & \text { Volts } & \text { BTU/HR } \mathrm{FT}^{2} & \begin{array}{c}\Delta \mathrm{O}_{\mathrm{F}} \\ \mathrm{O}^{2}\end{array} & & & \end{array}$

RUN 52 continued

$\begin{array}{rrrrrrrr}0.0 & 0.4134 & 1.1560 & 499,000 & 128.9 & - & - & - \\ 0.0 & 0.4572 & 1.2828 & 612,000 & 131.3 & - & - & - \\ 0.0 & 0.4256 & 1.1972 & 532,000 & 133.1 & - & - & - \\ 2.0 & 0.4256 & 1.1972 & 532,000 & 133.1 & - & - & - \\ 4.8 & 0.4256 & 1.1972 & 532,000 & 133.1 & - & - & - \\ 7.0 & 0.4256 & 1.1902 & 529,000 & 129.0 & - & - & - \\ 15.6 & 0.4256 & 1.1388 & 506,000 & 98.5 & - & - & - \\ 36.2 & 0.4256 & 1.1088 & 493,000 & 80.7 & - & - & - \\ 86.0 & 0.4256 & 1.0798 & 480,000 & 63.5 & 20.5 & - & 2717 \\ 0.0 & 0.3877 & 1.0832 & 438,000 & 128.3 & - & - & - \\ 2.0 & 0.3877 & 1.0832 & 438,000 & 128.3 & - & - & - \\ 7.0 & 0.3877 & 1.0608 & 429,000 & 113.7 & - & - & - \\ 0.0 & 0.3359 & 0.9207 & 323,000 & 113.1 & - & - & - \\ 2.0 & 0.3359 & 0.9227 & 324,000 & 114.6 & - & - & - \\ 4.8 & 0.3359 & 0.8862 & 311,000 & 87.2 & - & - & - \\ 15.6 & 0.3359 & 0.8662 & 304,000 & 72.2 & 11.4 & - & 737 \\ 86.0 & 0.3359 & 0.8317 & 292,000 & 47.2 & 17.0 & - & 1660 \\ 0.0 & 0.2994 & 0.8219 & 254,000 & 110.2 & - & - & - \\ 2.0 & 0.2994 & 0.8200 & 255,000 & 117.1 & - & - & - \\ 3.0 & 0.2994 & 0.8001 & 250,000 & 99.4 & - & - & - \\ 7.0 & 0.2994 & 0.7787 & 243,000 & 81.4 & - & - & - \\ 15.6 & 0.2994 & 0.7648 & 239,000 & 69.7 & 9.05 & - & 662 \\ 36.2 & 0.2994 & 0.7440 & 233,000 & 52.1 & 11.7 & - & 916 \\ 86.0 & 0.2994 & 0.7376 & 231,000 & 46.2 & 13.5 & - & 1480 \\ 0.0 & 0.2527 & 0.6680 & 176,000 & 92.1 & - & - & - \\ 0.8 & 0.2527 & 0.6725 & 180,000 & 94.6 & - & - & - \\ 1.0 & 0.2527 & 0.6539 & 173,000 & 78.1 & - & - & - \\ 2.0 & 0.2527 & 0.6469 & 171,000 & 71.1 & - & - & - \\ 15.6 & 0.2527 & 0.6355 & 168,000 & 59.7 & 7.36 & - & 452 \\ 36.2 & 0.2527 & 0.6225 & 164,000 & 46.7 & 9.26 & - & 780 \\ 86.0 & 0.2527 & 0.6140 & 162,000 & 38.2 & 11.8 & - & 1120 \\ 0.0 & 0.2082 & 0.5480 & 119,000 & 88.4 & - & - & - \\ 0.8 & 0.2082 & 0.5296 & 115,000 & 66.1 & - & - & - \\ 2.0 & 0.2082 & 0.5248 & 113,000 & 61.3 & - & - & - \\ 7.0 & 0.2082 & 0.5199 & 112,000 & 55.0 & - & - & - \\ 15.6 & 0.2082 & 0.5158 & 112,000 & 49.4 & 4.71 & 40.5 & - \\ 36.2 & 0.2082 & 0.5054 & 110,000 & 36.0 & 6.52 & 78.4 & - \\ 86.0 & 0.2082 & 0.4991 & 108,000 & 29.1 & 8.00 & 102 & - \\ 0.0 & 0.1586 & 0.4008 & 66,400 & 62.8 & 2.25 & - & - \\ 0.8 & 0.1586 & 0.4008 & 66,400 & 62.8 & - & - & - \\ 2.0 & 0.1586 & 0.3995 & 66,100 & 60.7 & - & - & - \\ & & & & & & & - \\ 0.0 & \end{array}$


TABLE D-4 continued

$\begin{array}{cccccccc}{ }_{\mathrm{A}}^{\mathrm{W}_{\mathrm{A}}} & { }_{\mathrm{SR}} & \mathrm{E}_{\mathrm{PT}} & \mathrm{q} / \mathrm{A} & \Delta \mathrm{t} & \mathrm{Nu} & \mathrm{Y}_{1} & \mathrm{Y}_{2} \\ \text { watts } & \text { Volts } & \text { Volts } & \text { BTU/HR FT } & { }_{\mathrm{O}}{ }_{\mathrm{F}} & & \end{array}$

RUN 52 continued

$\begin{array}{rrrrrrrr}4.8 & 0.1586 & 0.3964 & 65,600 & 55.8 & - & - & - \\ 15.6 & 0.1586 & 0.3847 & 63,000 & 37.2 & 3.63 & 40.8 & - \\ 36.2 & 0.1586 & 0.3805 & 62,500 & 30.5 & 4.44 & 65.8 & - \\ 86.0 & 0.1586 & 0.3770 & 62,400 & 24.9 & 5.54 & 85.0 & - \\ 0.0 & 0.1288 & 0.3078 & 38,000 & 47.0 & 1.73 & - & - \\ 4.8 & 0.1288 & 0.3013 & 37,100 & 38.0 & - & - & - \\ 7.0 & 0.1288 & 0.2926 & 36,500 & 33.0 & - & - & - \\ 0.0 & 0.1052 & 0.2556 & 28,100 & 33.3 & 1.81 & - & - \\ 2.0 & 0.1052 & 0.2558 & 28,100 & 33.3 & - & - & - \\ 7.0 & 0.1052 & 0.2527 & 27,800 & 30.4 & - & - & - \\ 15.6 & 0.1052 & 0.2500 & 27,200 & 23.9 & 2.41 & 25.3 & - \\ 86.0 & 0.1052 & 0.2484 & 27,300 & 20.0 & 3.07 & 70.0 & - \\ 0.0 & 0.0651 & 0.1526 & 10,400 & 14.8 & 1.52 & - & - \\ 7.0 & 0.0651 & 0.1526 & 10,400 & 14.8 & - & - & - \\ 15.6 & 0.0651 & 0.1517 & 10,300 & 11.3 & - & - & - \\ 36.2 & 0.0651 & 0.1513 & 10,300 & 9.8 & - & - & - \\ 86.0 & 0.0651 & 0.1503 & 10,200 & 5.9 & - & - & -\end{array}$




\section{TABLE D-5}

\begin{tabular}{|c|c|c|c|c|c|}
\hline LIQUID: & \multicolumn{2}{|c|}{ Methano1 } & \multirow[t]{2}{*}{ TEMPERATURE : } & $13^{\circ} \mathrm{F}$ & \multirow[t]{2}{*}{ FREQUENCY: } \\
\hline WIRE DI & VETER: & $0.007^{11}$ & & & \\
\hline $\begin{array}{c}\mathrm{W}_{\mathrm{A}} \\
\text { watts }\end{array}$ & $\begin{array}{c}E_{S R} \\
\text { Volts }\end{array}$ & $\begin{array}{c}\mathrm{E}_{\mathrm{PT}} \\
\text { Vo1ts }\end{array}$ & $\begin{array}{c}\mathrm{q} / \mathrm{A} \\
\mathrm{BTU} / \mathrm{HR} \mathrm{FT}^{2}\end{array}$ & $\underset{{ }_{F}}{\Delta t}$ & \\
\hline RUN 40 & & & $L=47.5 / 64 \mathrm{in}$ & $R_{100}$ & $=0.09874 \Omega$ \\
\hline $\begin{array}{l}0.0 \\
0.0 \\
0.0 \\
0.0 \\
0.0 \\
0.0 \\
0.0 \\
0.0 \\
0.0 \\
0.0\end{array}$ & $\begin{array}{l}0.0989 \\
0.1444 \\
0.1889 \\
0.2095 \\
0.2145 \\
0.2187 \\
0.2263 \\
0.2340 \\
0.2414 \\
0.2489\end{array}$ & $\begin{array}{l}0.4703 \\
0.6944 \\
0.9206 \\
1.023 \\
1.049 \\
1.0714 \\
1.1116 \\
1.1517 \\
1.1908 \\
1.2297\end{array}$ & $\begin{array}{r}70,100 \\
151,000 \\
262,000 \\
323,000 \\
339,000 \\
353,000 \\
379,000 \\
406,000 \\
433,000 \\
461,000\end{array}$ & $\begin{array}{l}74.9 \\
82.4 \\
90.5 \\
91.8 \\
93.0 \\
93.8 \\
95.5 \\
96.8 \\
98.3 \\
99.3\end{array}$ & (BURNOUT) \\
\hline
\end{tabular}

RUN 41

$$
L=48 / 64 \text { in. }
$$

$\begin{array}{ll}0.0 & 0.1216 \\ 0.0 & 0.1610 \\ 0.0 & 0.2005 \\ 0.0 & 0.2105 \\ 0.0 & 0.2203 \\ 0.0 & 0.2275 \\ 0.0 & 0.2347 \\ 0.0 & 0.2423\end{array}$

$0.5848 \quad 1.06,000$

0.7792

187,000

0.9801

1.0293

293,000

323,000

$1.0808 \quad 355,000$

379,000

1.1174

404,000

$\begin{array}{ll}1.1931 & 431,000\end{array}$

$$
\mathrm{R}_{100}=0.09935 \Omega
$$

RUN 41a

$$
I=47 / 64 \mathrm{In} .
$$

79.5

83.3

88.5

88.8

90.8

91.5

92.4

93.1 (BURNOUT)
0.0
0.1118
0.0
0.1857
0.5375
0.8985
91,500
0.0
0.1991
0.9665
293,000
84.1
88.3
90.2
0.0
0.2262
1.0439
341,000
91.8
93.2 (BURNOUT)

$\mathrm{R}_{100}=0.09811 \Omega$ 
TABLE D-5 continued

\begin{tabular}{|c|c|c|c|c|c|}
\hline $\begin{array}{c}\mathrm{W}_{\mathrm{A}} \\
\text { watts }\end{array}$ & $\begin{array}{c}\mathrm{E}_{\mathrm{SR}} \\
\text { Volts }\end{array}$ & $\begin{array}{c}\mathrm{E}_{\mathrm{PT}} \\
\text { Volts }\end{array}$ & $\begin{array}{c}\mathrm{q} / \mathrm{A} \\
\mathrm{BTU} / \mathrm{HR} \mathrm{FT}^{2}\end{array}$ & $\begin{array}{l}\Delta t \\
o_{F}\end{array}$ & \\
\hline RUN 42 & & \multicolumn{2}{|c|}{$\mathrm{L}=48.5 / 64 \mathrm{in}$} & $R_{100}$ & $=0.1052 \Omega$ \\
\hline $\begin{array}{r}0.0 \\
0.0 \\
0.0 \\
0.0 \\
86.0 \\
86.0 \\
86.0 \\
86.0\end{array}$ & $\begin{array}{l}0.0530 \\
0.1097 \\
0.1649 \\
0.2134 \\
0.1086 \\
0.1526 \\
0.1952 \\
0.2078\end{array}$ & $\begin{array}{l}0.2615 \\
0.5652 \\
0.8617 \\
1.1258 \\
0.5512 \\
0.7890 \\
1.0236 \\
1.0924\end{array}$ & $\begin{array}{r}20,400 \\
91,500 \\
210,000 \\
354,000 \\
88,000 \\
178,000 \\
295,000 \\
335,000\end{array}$ & $\begin{array}{l}57.6 \\
84.1 \\
92.1 \\
99.1 \\
75.7 \\
87.2 \\
96.1 \\
98.6\end{array}$ & (BURNOUT) \\
\hline \multicolumn{2}{|c|}{ RUN $4 \not 75$} & \multicolumn{2}{|c|}{$\mathrm{L}=46.5 / 64 \mathrm{in}}$. & $\mathrm{R}_{100}$ & $=0.09548 \Omega$ \\
\hline $\begin{array}{l}86.0 \\
86.0 \\
86.0 \\
86.0 \\
86.0\end{array}$ & $\begin{array}{l}0.1133 \\
0.1612 \\
0.1935 \\
0.2090 \\
0.2187\end{array}$ & $\begin{array}{l}0.5602 \\
0.8113 \\
0.9844 \\
1.0671 \\
1.1186\end{array}$ & $\begin{array}{r}93,600 \\
193,000 \\
281,000 \\
329,000 \\
361,000\end{array}$ & $\begin{array}{l}76.2 \\
86.8 \\
93.9 \\
96.2 \\
97.1\end{array}$ & (BURNOUT) \\
\hline RUN 44 & & \multicolumn{2}{|c|}{$\mathrm{L}=49 / 64 \mathrm{in}}$. & $R_{100}$ & $=0.1000 \Omega$ \\
\hline $\begin{array}{r}0.0 \\
0.0 \\
0.0 \\
0.0 \\
86.0 \\
86.0 \\
86.0 \\
86.0 \\
86.0 \\
86.0 \\
86.0\end{array}$ & $\begin{array}{l}0.1070 \\
0.1567 \\
0.1909 \\
0.2109 \\
0.1265 \\
0.1663 \\
0.1932 \\
0.2077 \\
0.2150 \\
0.2248 \\
0.2302\end{array}$ & $\begin{array}{l}0.5194 \\
0.7690 \\
0.9433 \\
1.0462 \\
0.6088 \\
0.8111 \\
0.9515 \\
1.0280 \\
1.0662 \\
1.1164 \\
1.1396\end{array}$ & $\begin{array}{r}81,200 \\
176,000 \\
263,000 \\
322,000 \\
112,000 \\
197,000 \\
268,000 \\
312,000 \\
335,000 \\
367,000 \\
383,000\end{array}$ & $\begin{array}{l}82.2 \\
87.2 \\
91.5 \\
94.0 \\
74.2 \\
82.4 \\
88.5 \\
91.6 \\
92.0 \\
92.9 \\
90.0\end{array}$ & (BURNOUT) \\
\hline \multicolumn{2}{|c|}{ RUN 463} & \multicolumn{2}{|c|}{$\mathrm{L}=48.5 / 64 \mathrm{in}}$. & $\mathrm{R}_{100}$ & $=0.1024 \Omega$ \\
\hline $\begin{array}{l}0.0 \\
0.0 \\
0.0 \\
0.0 \\
0.0\end{array}$ & $\begin{array}{l}0.1594 \\
0.1829 \\
0.1959 \\
0.2226 \\
0.2333\end{array}$ & $\begin{array}{l}0.7470 \\
0.8619 \\
0.9230 \\
1.0552 \\
1.1090\end{array}$ & $\begin{array}{l}185,000 \\
245,000 \\
281,000 \\
365,000 \\
402,000\end{array}$ & $\begin{array}{l}87.2 \\
90.4 \\
90.3 \\
94.2 \\
96.1\end{array}$ & (BURNOUT) \\
\hline
\end{tabular}


TABLE D-5 continued

\begin{tabular}{|c|c|c|c|c|c|}
\hline $\begin{array}{c}{ }_{A} \\
\text { watts }\end{array}$ & $\begin{array}{c}\mathrm{E}_{\mathrm{SR}} \\
\text { Volts }\end{array}$ & ${ }_{\text {PT }}^{E_{\text {ts }}}$ & $\begin{array}{c}\mathrm{q} / \mathrm{A} \\
\mathrm{BTU} / \mathrm{HR} \mathrm{FT}^{2}\end{array}$ & $\underset{o_{F}}{\Delta t}$ & \\
\hline RUN 46 & & \multicolumn{2}{|c|}{$\mathrm{L}=47 / 64 \mathrm{in.}$} & $\mathrm{R}_{100}$ & $=0.09789 \Omega$ \\
\hline $\begin{array}{l}0.0 \\
0.0 \\
0.0 \\
0.0\end{array}$ & $\begin{array}{l}0.1808 \\
0.1991 \\
0.2091 \\
0.2281\end{array}$ & $\begin{array}{l}0.8717 \\
0.9631 \\
1.0176 \\
1.1144\end{array}$ & $\begin{array}{l}240,000 \\
292,000 \\
324,000 \\
387,000\end{array}$ & $\begin{array}{l}88.2 \\
90.3 \\
94.1 \\
96.7\end{array}$ & (BURNOUT) \\
\hline RUN 47 & & \multicolumn{2}{|c|}{$I=48 / 64 \mathrm{in}}$. & $\mathrm{R}_{100}$ & $=0.09993 \Omega$ \\
\hline $\begin{array}{l}86.0 \\
86.0 \\
86.0 \\
86.0\end{array}$ & $\begin{array}{l}0.1854 \\
0.2122 \\
0.2256 \\
0.2279\end{array}$ & $\begin{array}{l}0.9119 \\
1.0526 \\
1.1239 \\
1.1389\end{array}$ & $\begin{array}{l}252,000 \\
333,000 \\
378,000 \\
387,000\end{array}$ & $\begin{array}{l}89.8 \\
95.1 \\
97.8 \\
99.7\end{array}$ & (BURNOUT) \\
\hline RUN 48 & & \multicolumn{2}{|c|}{$\mathrm{L}=49.5 / 64 \mathrm{in}}$. & $\mathrm{R}_{100}$ & $=0.1033 \Omega$ \\
\hline $\begin{array}{r}0.0 \\
0.0 \\
0.0 \\
86.0 \\
86.0 \\
86.0 \\
86.0\end{array}$ & $\begin{array}{l}0.0914 \\
0.1794 \\
0.2063 \\
0.1069 \\
0.1445 \\
0.2034 \\
0.2178\end{array}$ & $\begin{array}{l}0.4512 \\
0.9082 \\
1.0490 \\
0.5290 \\
0.7228 \\
1.0328 \\
1.1080\end{array}$ & $\begin{array}{r}59,600 \\
236,000 \\
313,000 \\
81,700 \\
151,000 \\
304,000 \\
349,000\end{array}$ & $\begin{array}{l}69.8 \\
86.3 \\
89.1 \\
73.1 \\
80.7 \\
90.0 \\
92.1\end{array}$ & (BURNOUT) \\
\hline RUN 49 & & \multicolumn{2}{|c|}{$L=48 / 64 \mathrm{in}}$. & $\mathrm{R}_{100}$ & $=0.1009 \Omega$ \\
\hline $\begin{array}{r}0.0 \\
0.0 \\
86.0 \\
86.0 \\
86.0 \\
86.0 \\
86.0\end{array}$ & $\begin{array}{l}0.0867 \\
0.1847 \\
0.1086 \\
0.1416 \\
0.2031 \\
0.2158 \\
0.2301\end{array}$ & $\begin{array}{l}0.4231 \\
0.9189 \\
0.5261 \\
0.6963 \\
1.0170 \\
1.0817 \\
1.1542\end{array}$ & $\begin{array}{r}54,700 \\
253,000 \\
85,200 \\
147,000 \\
308,000 \\
348,000 \\
396,000\end{array}$ & $\begin{array}{l}77.8 \\
90.0 \\
93.3 \\
82.5 \\
93.9 \\
94.6 \\
95.0\end{array}$ & (BURNOUI) \\
\hline
\end{tabular}


$\underline{\text { TABLE } \mathrm{D}-6}$

LIQUID: Distilled Water

TEMPERATURE : $149^{\circ} \mathrm{F}$

FREQUENCY : $44.1 \mathrm{kcps}$

WIRE DIAMETER: $0.010^{\prime \prime}$

\begin{tabular}{|c|c|c|c|c|c|c|c|}
\hline $\begin{array}{c}{ }_{\mathrm{A}} \\
\text { watts }\end{array}$ & $\begin{array}{c}\mathrm{E}_{\mathrm{SR}} \\
\text { Volts }\end{array}$ & $\begin{array}{l}\mathrm{E}_{\mathrm{PT}} \\
\text { Volts }\end{array}$ & $\begin{array}{c}\mathrm{q} / \mathrm{A} \\
\mathrm{BTU} / \mathrm{HR} \quad \mathrm{FT}^{2}\end{array}$ & $\begin{array}{r}\Delta \mathrm{t} \\
\mathrm{o}_{\mathrm{F}}\end{array}$ & $\mathrm{Nu}$ & $Y_{1}$ & $\mathrm{Y}_{2}$ \\
\hline RUN 59 & & \multicolumn{2}{|c|}{$L=48 / 64 \mathrm{in}}$. & \multicolumn{3}{|c|}{$\mathrm{R}_{100}=0.05021 \Omega$} & \\
\hline $\begin{array}{r}0.0 \\
15.6\end{array}$ & $\begin{array}{l}0.0704 \\
0.0704\end{array}$ & $\begin{array}{l}0.1646 \\
0.1646\end{array}$ & $\begin{array}{l}12,100 \\
12,100\end{array}$ & $\begin{array}{l}16.0 \\
16.2\end{array}$ & 1.63 & - & - \\
\hline 23.2 & 0.0701 & 0.1639 & $\begin{array}{l}12,100 \\
12,000\end{array}$ & $\begin{array}{l}10.2 \\
16.2\end{array}$ & $\overline{-}$ & - & - \\
\hline 30.2 & 0.0699 & 0.1632 & 11,900 & 15.5 & 2.89 & 15.8 & 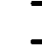 \\
\hline 53.3 & 0.0697 & 0.1622 & 11,800 & 13.6 & 1.86 & 24.3 & 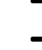 \\
\hline 96.0 & 0.0692 & 0.1606 & 11,600 & 11.8 & 2.11 & 33.5 & - \\
\hline 0.0 & 0.0980 & 0.2347 & 24,000 & 30.0 & 1.72 & - & - \\
\hline 23.2 & 0.0962 & 0.2291 & 23,000 & 26.3 & - & - & - \\
\hline 30.2 & 0.0955 & 0.2257 & 22,500 & 22.0 & 2.20 & 20.2 & - \\
\hline 53.3 & 0.0952 & 0.2244 & 22,300 & 19.1 & 2.52 & 30.9 & - \\
\hline 96.0 & 0.0938 & 0.2195 & 21,500 & 15.0 & 3.08 & 40.0 & - \\
\hline 0.0 & 0.1092 & 0.2649 & 30,200 & 38.5 & 1.68 & - & - \\
\hline 4.5 & 0.1095 & 0.2659 & 30,400 & 38.8 & - & - & - \\
\hline 9.5 & 0.1088 & 0.2640 & 30,000 & 38.3 & - & - & - \\
\hline 15.6 & 0.1085 & 0.2621 & 29,700 & 35.6 & - & - & - \\
\hline 53.3 & 0.1074 & 0.2542 & 28,500 & 22.5 & 2.72 & 36.4 & - \\
\hline 96.0 & 0.1069 & 0.2509 & 28,000 & 17.5 & 3.00 & 49.5 & - \\
\hline 0.0 & 0.1322 & 0.3267 & 45,100 & 49.0 & 1.97 & - & - \\
\hline 9.5 & 0.1317 & 0.3220 & 44,300 & 42.3 & - & - & \\
\hline 23.2 & 0.1317 & 0.3201 & 44,000 & 38.7 & - & - & - \\
\hline 30.2 & 0.1316 & 0.3173 & 43,600 & 33.5 & 2.79 & 30.8 & - \\
\hline 53.2 & 0.1316 & 0.3137 & 43,100 & 27.6 & 3.35 & 43.5 & - \\
\hline 96.0 & 0.1304 & 0.3086 & 42,000 & 23.5 & 5.00 & 57.0 & - \\
\hline 0.0 & 0.1521 & 0.3855 & 61,200 & 67.0 & 1.95 & - & . \\
\hline 4.6 & 0.1529 & 0.3823 & 61,000 & 58.3 & - & - & - \\
\hline 30.2 & 0.1550 & 0.3769 & 61,000 & 41.5 & 3.16 & 39.2 & - \\
\hline 53.3 & 0.1527 & 0.3637 & 58,000 & 29.0 & 4.29 & 46.0 & - \\
\hline 96.0 & 0.1519 & 0.3589 & 56,900 & 24.5 & 5.00 & 60.1 & . \\
\hline 0.0 & 0.1861 & 0.4894 & 95,100 & 90.0 & 2.24 & - & . \\
\hline 1.0 & 0.1861 & 0.4829 & 93,800 & 81.3 & - & - & - \\
\hline 30.2 & 0.1878 & 0.4693 & 92,000 & 57.1 & 3.47 & 63.6 & - \\
\hline 53.3 & 0.1882 & 0.4595 & 90,300 & 42.2 & 4.62 & 69.6 & - \\
\hline 96.0 & 0.1870 & 0.4512 & 88,100 & 35.0 & 5.40 & 85.6 & - \\
\hline 0.0 & 0.2297 & 0.6506 & 156,000 & 141.4 & - & - & - \\
\hline 0.0 & 0.2376 & 0.6369 & 158,000 & 101.9 & - & - & \\
\hline
\end{tabular}


TABLE D-6 continued

\begin{tabular}{|c|c|c|c|c|c|c|}
\hline$\stackrel{\mathrm{W}_{\mathrm{A}}}{\text { watts }}$ & $\begin{array}{c}\mathrm{E}_{\mathrm{SR}} \\
\text { Volts }\end{array}$ & $\begin{array}{c}\mathrm{E}_{\mathrm{PT}} \\
\text { Volts }\end{array}$ & $\begin{array}{c}\mathrm{q} / \mathrm{A} \\
\mathrm{BTU} / \mathrm{HR} \quad \mathrm{FT}^{2}\end{array}$ & $\begin{array}{c}\Delta t \\
o_{F}\end{array}$ & $\mathrm{Nu}$ & $\mathrm{Y}_{1}$ \\
\hline
\end{tabular}

RUN 59 continued

$\begin{array}{rrrrrrrr}3.2 & 0.2367 & 0.6192 & 153,000 & 85.7 & - & - & - \\ 30.2 & 0.2324 & 0.5853 & 142,000 & 61.0 & 5.00 & 71.2 & - \\ 53.3 & 0.2319 & 0.5782 & 140,000 & 54.5 & 5.15 & 104.2 & - \\ 96.0 & 0.2301 & 0.5621 & 135,000 & 41.0 & 6.95 & 102.7 & - \\ 0.0 & 0.2783 & 0.7847 & 228,000 & 136.2 & - & - & - \\ 0.0 & 0.2764 & 0.7521 & 217,000 & 112.4 & - & - & - \\ 4.6 & 0.2782 & 0.7368 & 214,000 & 93.8 & - & - & - \\ 30.2 & 0.2802 & 0.7180 & 210,000 & 72.2 & 3.65 & - & 350 \\ 53.3 & 0.2748 & 0.6867 & 197,000 & 56.0 & 4.42 & - & 486 \\ 96.0 & 0.2755 & 0.6779 & 195,000 & 46.3 & 5.34 & - & 644 \\ 0.0 & 0.2932 & 0.8069 & 247,000 & 120.9 & - & - & - \\ 0.0 & 0.3226 & 0.9028 & 304,000 & 132.8 & - & - & - \\ 30.2 & 0.3272 & 0.8579 & 293,000 & 88.1 & 4.11 & - & 477 \\ 96.0 & 0.3323 & 0.8214 & 285,000 & 50.0 & 7.16 & - & 830 \\ 0.0 & 0.3480 & 0.9689 & 352,000 & 128.3 & - & - & - \\ 9.5 & 0.3483 & 0.9709 & 353,000 & 129.1 . & - & - & - \\ 15.6 & 0.3551 & 0.9494 & 352,000 & 99.3 & - & - & - \\ 30.2 & 0.3571 & 0.9388 & 350,000 & 88.0 & 4.96 & - & 524 \\ 53.3 & 0.3596 & 0.9189 & 345,000 & 68.5 & 6.26 & - & 754 \\ 96.0 & 0.3627 & 0.9111 & 345,000 & 57.5 & 7.54 & - & 1020 \\ 0.0 & 0.3635 & 1.0119 & 384,000 & 128.2 & - & - & - \\ 0.0 & 0.3764 & 1.0613 & 417,000 & 137.3 & - & - & - \\ 0.0 & 0.3885 & 1.0823 & 439,000 & 129.5 & - & - & - \\ 30.2 & 0.3922 & 1.0379 & 425,000 & 94.2 & 5.62 & - & 555 \\ 53.3 & 0.3904 & 1.0058 & 410,000 & 75.5 & 6.79 & - & 910 \\ 96.0 & 0.3929 & 0.9897 & 406,000 & 61.0 & 8.36 & - & 1150 \\ 0.0 & 0.4156 & 1.1639 & 505,000 & 133.2 & - & - & - \\ 23.2 & 0.4191 & 1.1359 & 497,000 & 110.4 & - & - & - \\ 30.2 & 0.4153 & 1.1070 & 480,000 & 98.1 & 6.09 & - & 542 \\ 53.3 & 0.4145 & 1.0701 & 463,000 & 77.0 & 7.52 & - & 985 \\ 96.0 & 0.4194 & 1.0667 & 467,000 & 67.3 & 8.71 & - & 1230 \\ 0.0 & 0.4471 & 1.2555 & 586,000 & 134.3 & - & - & - \\ 30.2 & 0.4420 & 1.1966 & 552,000 & 108.0 & - & - & - \\ 53.3 & 0.4414 & 1.1502 & 530,000 & 82.2 & 8.06 & - & 1090 \\ 96.0 & 0.4441 & 1.1345 & 526,000 & 69.2 & 9.53 & - & 1420\end{array}$


TABLE D-6 continued

$\begin{array}{cccccccc}\mathrm{W}_{\mathrm{A}} & \mathrm{E}_{\mathrm{SR}} & \mathrm{E}_{\mathrm{PT}} & \mathrm{q} / \mathrm{A} & \Delta \mathrm{t} & \mathrm{N}_{\mathrm{U}} & \mathrm{Y}_{1} & \mathrm{Y}_{2} \\ \text { watts } & \text { Volts } & \text { Volts } & \text { BTU/HR FT } & { }_{\mathrm{O}}{ }_{F} & & \end{array}$

RUN 64

$\mathrm{L}=49 / 64 \mathrm{in}$.

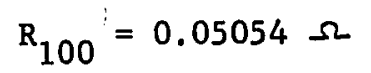

0.0

0.0767

0.1812

14,200

21.6

1.41

30.2

0.0750

0.1762

13,500

0.1738

13,200

96.0

0.0743

0.1724

13,000

$0.0 \quad 0.0889$

0.2124

19,300

$30.2 \quad 0.0878$

0.2082

18,700

$53.3 \quad 0.0868$

0.2040

18,100

96.0

0.0865

0.2024

17,900

24,100

$30.2 \quad 0.0987$

0.2388

23,600

$53.3 \quad 0.0992$

0.232

23,600

96.0

0.0989

0.2314

23,400

37,100

0.3000

30.2

0.1210

0.2879

35,500

$53.3 \quad 0.1200$

0.2840

34,800

96.0

0.1190

0.2804

0.3471

30.2

0.1378

0.3412

34,100

48,900

48,800

46,100

$96.0 \quad 0.1362$

0.3292

45,200

77,900

0.4471

76,100

30.2

0.1704

0.4321

73,900

0.4074

96.0

0.1719

70,100

0.0

0.2100

0.5729

123,000

117,000

0.5255

113,000

53.3

0.2126

0.5183

112,000

0.0

0.2114

0.6010

138,000

30.2

0.2246

0.5739

133,000

53.3

0.2267

0.5634

131,000

96.0

0.2270

0.5558

129,000

0.0

0.2636

0.7124

192,000

30.2

0.2703

0.6841

189,000

0.6665

183,000

0.0

0.2686

0.8586

274,000

30.2

0.3153

0.8160

263,000

53.3

0.3166

0.7441

257,000

0.7827

254,000

18.2

1.60

$15.2 \quad 1.88$

$13.7 \quad 2.03$

$27.4 \quad 1.52$

$22.3 \quad 1.81$

18.32 .13

$15.4 \quad 2.51$

$35.5 \quad 1.46$

$24.4 \quad 2.08$

$18.2 \quad 2.80$

$16.3 \quad 3.10$

$52.6 \quad 1.51$

$29.0 \quad 2.63$

$24.8 \quad 3.02$

21.5

3.40

$60.8 \quad 1.72$

$\begin{array}{ll}40.5 & 2.58\end{array}$

$31.6 \quad 3.14$

$26.4 \quad 3.69$

87.2

57.2

41.5

1.89

2.84

3.82

34.9

112.5

62.4

53.6

42.1

98.5

63.0

49.2

41.9

106.2

63.8

51.3

119.2

78.2

58.9

48.1

4.31

4.00

4.50

5.70

5.00

5.70

6.60

$-$

2.65

4.50

5.47

5.50

6.64

$\begin{array}{cc}- & - \\ 17.2 & - \\ 26.3 & - \\ 37.5 & - \\ - & - \\ 20.3 & - \\ 28.2 & - \\ 40.2 & - \\ - & - \\ 22.1 & - \\ 37.8 & - \\ 41.8 & - \\ - & - \\ 26.2 & - \\ 39.4 & - \\ 55.9 & - \\ - & - \\ 37.1 & - \\ 50.5 & - \\ 63.8 & - \\ - & - \\ 63.2 & - \\ 70.3 & - \\ 85.9 & - \\ - & - \\ 74.1 & - \\ 101 & - \\ 107 & - \\ - & - \\ 76.3 & - \\ 88.3 & - \\ 107.2 & - \\ - & - \\ - & 252 \\ - & 445 \\ - & - \\ - & 449 \\ - & 569 \\ - & 756 \\ - & -\end{array}$

$0.0 \quad 0.3324$

0.9123

310,000

119.6 
TABLE D-6 continued

\begin{tabular}{|c|c|c|c|c|c|c|}
\hline$\underset{\text { watts }}{\mathrm{W}_{\mathrm{A}}}$ & $\begin{array}{c}\text { ESR }_{\text {SR }} \\
\text { Volts }\end{array}$ & $\begin{array}{c}\mathrm{E}_{\mathrm{PT}} \\
\text { Volts }\end{array}$ & $\begin{array}{c}\mathrm{q} / \mathrm{A} \\
\mathrm{BTU} / \mathrm{HR} \quad \mathrm{FT}^{2}\end{array}$ & $\underset{\mathrm{O}_{\mathrm{F}}}{\Delta \mathrm{t}}$ & $\mathrm{Nu}_{\mathrm{u}}$ & $Y_{1}$ \\
\hline
\end{tabular}

RUN 64 continued

$\begin{array}{rrrrrrrr}30.2 & 0.3407 & 0.8843 & 308,000 & 81.9 & 4.70 & - & 490 \\ 53.3 & 0.3397 & 0.8580 & 298,000 & 64.2 & 5.82 & - & 668 \\ 96.0 & 0.3414 & 0.8482 & 296,000 & 53.0 & 7.02 & - & 895 \\ 0.0 & 0.3695 & 1,0192 & 385,000 & 122.0 & - & - & - \\ 30.2 & 0.3742 & 0.9802 & 375,000 & 85.2 & 5.50 & - & 574 \\ 53.3 & 0.3772 & 0.9595 & 370,000 & 66.0 & 7.03 & - & 768 \\ 96.0 & 0.3778 & 0.9451 & 365,000 & 55.5 & 8.26 & - & 1030 \\ 0.0 & 0.4024 & 1.1132 & 458,000 & 123.2 & - & - & - \\ 30.2 & 0.4065 & 1.0709 & 445,000 & 90.0 & 6.16 & - & 601 \\ 53.3 & 0.4081 & 1.0498 & 438,000 & 74.2 & 7.40 & - & 944 \\ 96.0 & 0.4088 & 1.0362 & 433,000 & 63.8 & 8.51 & - & 1220 \\ 0.0 & 0.4422 & 1.2321 & 557,000 & 127.3 & - & - & -\end{array}$


TABLE D-7

LIQUID: Methanol TEMPERATURE: $113^{\circ} \mathrm{F}$ FREQUENCY: $44.1 \mathrm{kcps}$ WIRE DIAMETER: $0.007 "$

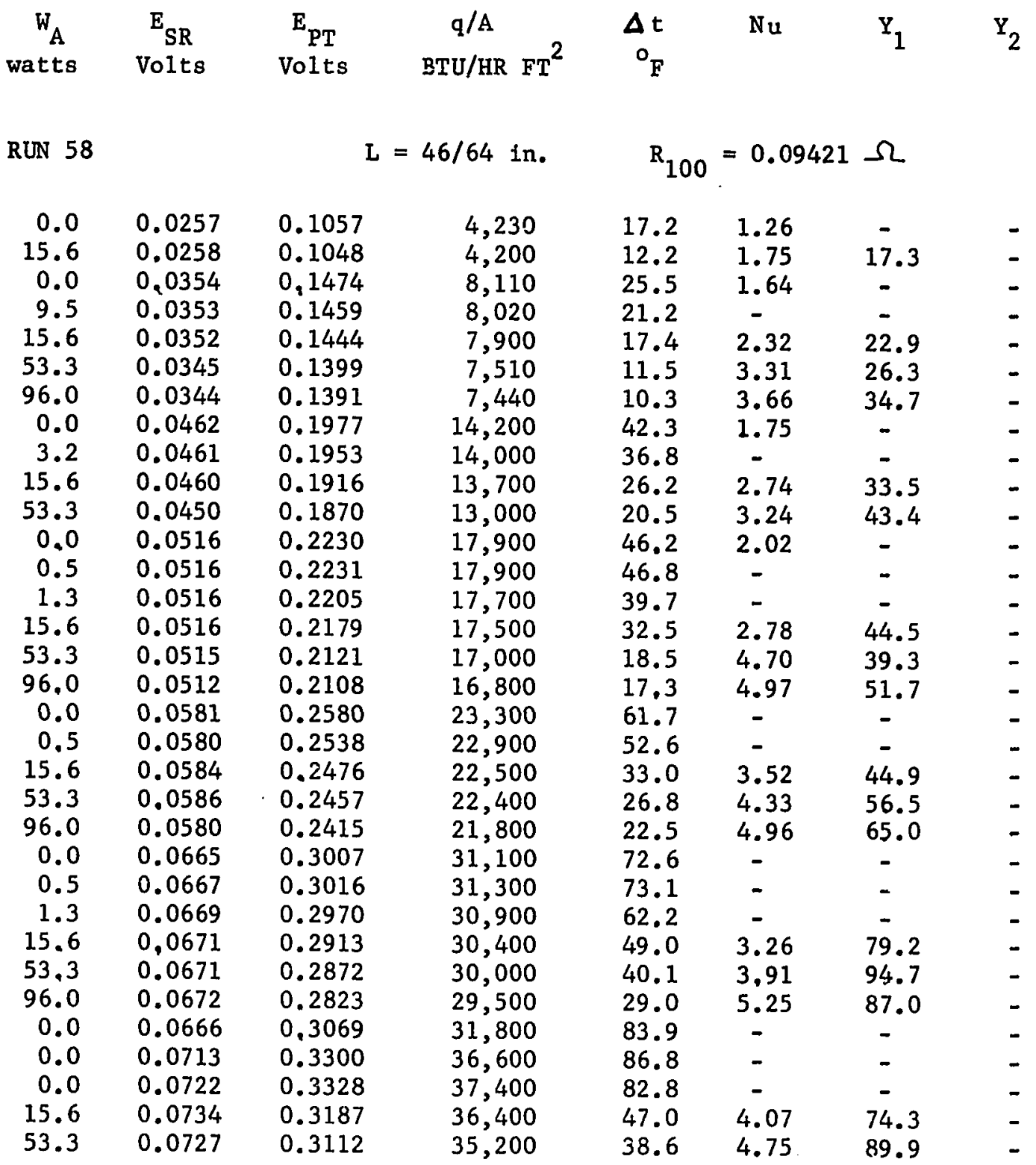


TABLE D-7 continued

$\begin{array}{cccccccc}\mathrm{W}_{\mathrm{A}} & \mathrm{E}_{\mathrm{SR}} & \mathrm{E}_{\mathrm{PT}} & \mathrm{q} / \mathrm{A} & \underset{\mathrm{C}}{\Delta} & \mathrm{Nu} & \mathrm{Y}_{1} & \mathrm{Y}_{2} \\ \text { watts } & \text { Volts } & \text { Volts } & \text { BTU/HR FT } & \mathrm{O}_{\mathrm{F}} & & \end{array}$

RUN 58 continued

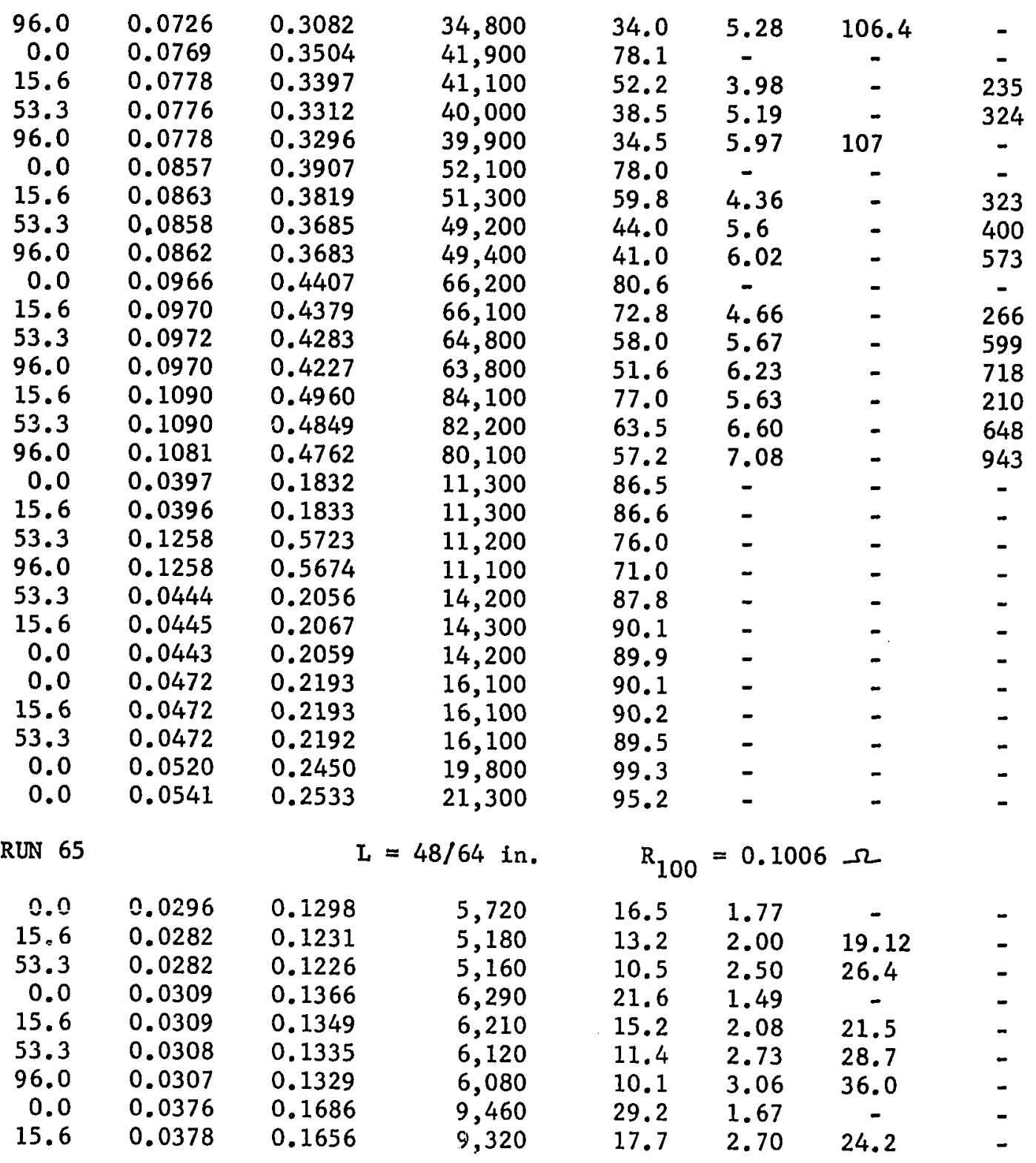


TABLE D-7 continued

$\begin{array}{cccccccc}\mathrm{W}_{\mathrm{A}} & \mathrm{E}_{\mathrm{SR}} & \mathrm{E}_{\mathrm{PT}} & \mathrm{q} / \mathrm{A} & \Delta \mathrm{t} & \mathrm{Nu} & \mathrm{Y}_{1} & \mathrm{Y}_{2} \\ \text { watts } & \text { Volts } & \text { Volts } & \mathrm{BTU} / \mathrm{HR}_{\mathrm{FT}} & \mathrm{O}_{\mathrm{F}} & & & \end{array}$

RUN 65 continued

$\begin{array}{rrrrrrrr}53.3 & 0.0368 & 0.1607 & 8,830 & 14.9 & 3.02 & 34.4 & - \\ 96.0 & 0.0368 & 0.1599 & 8,780 & 12.4 & 3.60 & 40.2 & - \\ 0.0 & 0.0416 & 0.1884 & 11,700 & 35.5 & 1.71 & - & - \\ 15.6 & 0.0415 & 0.1827 & 11,300 & 20.8 & 2.78 & 27.7 & - \\ 53.3 & 0.0415 & 0.1812 & 11,200 & 16.8 & 3.40 & 38.0 & - \\ 96.0 & 0.0414 & 0.1799 & 11,100 & 13.9 & 4.07 & 44.6 & - \\ 0.0 & 0.0465 & 0.2105 & 14,600 & 36.2 & 2.09 & - & - \\ 15.6 & 0.0466 & 0.2071 & 14,400 & 24.7 & 3.00 & 33.5 & - \\ 53.3 & 0.0460 & 0.2014 & 13,800 & 17.6 & 4.00 & 39.0 & - \\ 96.0 & 0.0456 & 0.1988 & 13,500 & 15.0 & 4.58 & 48.1 & - \\ 0.0 & 0.0548 & 0.2559 & 20,900 & 53.2 & 2.07 & - & - \\ 15.6 & 0.0554 & 0.2483 & 20,500 & 29.4 & 3.60 & 38.8 & - \\ 53.3 & 0.0543 & 0.2408 & 19,500 & 22.8 & 4.40 & 49.2 & - \\ 96.0 & 0.0540 & 0.2383 & 19,200 & 20.2 & 4.86 & 61.4 & - \\ 0.0 & 0.0621 & 0.2938 & 27,200 & 60.1 & 2.40 & - & - \\ 15.6 & 0.0630 & 0.2863 & 26,900 & 36.1 & 3.87 & 51.8 & - \\ 53.3 & 0.0628 & 0.2818 & 26,400 & 28.5 & 4.77 & 61.4 & - \\ 96.0 & 0.0629 & 0.2794 & 26,200 & 24.1 & 5.60 & 74.3 & - \\ 0.0 & 0.0703 & 0.3366 & 35,300 & 67.7 & - & - & - \\ 15.6 & 0.0702 & 0.3247 & 34,000 & 47.2 & 3.78 & 74.7 & - \\ 53.3 & 0.0700 & 0.3180 & 33,200 & 36.6 & 4.70 & 84.2 & - \\ 96.0 & 0.0698 & 0.3133 & 32,600 & 31.0 & 5.43 & 90.0 & - \\ 0.0 & 0.0726 & 0.3547 & 38,400 & 81.1 & - & - & - \\ 15.6 & 0.0739 & 0.3439 & 37,900 & 51.8 & 3.85 & 85.3 & - \\ 53.3 & 0.0742 & 0.3361 & 37,200 & 35.8 & 5.40 & 83.4 & - \\ 96.0 & 0.0743 & 0.3339 & 37,000 & 31.5 & 6.07 & 91.0 & - \\ 0.0 & 0.0809 & 0.3895 & 47,000 & 71.2 & - & - & - \\ 15.6 & 0.0820 & 0.3839 & 46,900 & 54.8 & 4.32 & - & 301 \\ 53.3 & 0.0814 & 0.3719 & 45,100 & 40.5 & 5.57 & - & 370 \\ 96.0 & 0.0814 & 0.3682 & 44,700 & 34.2 & 6.50 & - & 461 \\ 0.0 & 0.0911 & 0.4396 & 59,700 & 72.8 & - & - & - \\ 15.6 & 0.0909 & 0.4345 & 58,900 & 66.0 & 4.56 & - & 337 \\ 53.3 & 0.0917 & 0.4258 & 58,200 & 49.0 & 5.98 & - & 494 \\ 96.0 & 0.0914 & 0.4199 & 57,200 & 42.8 & 6.70 & - & 602 \\ 0.0 & 0.1023 & 0.4969 & 75,800 & 75.8 & - & - & - \\ 15.6 & 0.1014 & 0.4906 & 74,200 & 73.3 & - & - & - \\ 53.3 & 0.1005 & 0.4754 & 71,200 & 60.0 & 6.03 & - & 620 \\ 96.0 & 0.1006 & 0.4729 & 70,900 & 56.2 & 6.39 & - & 685 \\ 0.0 & 0.1149 & 0.5591 & 95,800 & 77.8 & - & - & - \\ 15.6 & 0.1151 & 0.5604 & 96,200 & 78.1 & - & - & - \\ 53.3 & 0.1145 & 0.5511 & 94,100 & 70.2 & - & - & - \\ & & & & & & & \\ 0.0 & \end{array}$


TABLE D-7 continued

$\begin{array}{cccccccc}\mathrm{W}_{\mathrm{A}} & \mathrm{E}_{\mathrm{SR}} & \mathrm{E}_{\mathrm{PT}} & \mathrm{q} / \mathrm{A} & \Delta \mathrm{t} & \mathrm{Nu} & \mathrm{Y}_{1} & \mathrm{Y}_{2} \\ \text { watts } & \text { Volts } & \text { Volts } & \text { BTU/HR FT } & \mathrm{O}_{\mathrm{F}} & & & \end{array}$

RUN 65 continued

$\begin{array}{rrrrrrrr}96.0 & 0.1142 & 0.5422 & 92,300 & 62.2 & - & - & - \\ 0.0 & 0.0414 & 0.2026 & 12,500 & 80.7 & - & - & - \\ 15.6 & 0.0415 & 0.2034 & 12,600 & 80.9 & - & - & - \\ 53.3 & 0.0414 & 0.2024 & 12,500 & 79.3 & - & - & - \\ 96.0 & 0.0412 & 0.2003 & 12,300 & 75.6 & - & - & - \\ 0.0 & 0.0457 & 0.2246 & 15,300 & 82.6 & - & - & - \\ 53.3 & 0.0466 & 0.2262 & 15,500 & 83.1 & - & - & - \\ 96.0 & 0.0457 & 0.2245 & 15,300 & 81.8 & - & - & - \\ 0.0 & 0.0498 & 0.2477 & 18,400 & 88.5 & - & - & - \\ 0.0 & 0.0530 & 0.2630 & 20,800 & 87.1 & - & - & - \\ 0.0 & 0.0569 & 0.2841 & 24,100 & 91.2 & - & - & -\end{array}$




\section{TABLE D-8}

LIQUID: Distilled Water

TEMPERATURE: $149^{\circ} \mathrm{F}$ FREQUENCY: $108 \mathrm{kcps}$ WIRE DIAMETER: $0.010^{\prime \prime}$

$\begin{array}{cccccccc}\mathrm{W}_{\mathrm{A}} & { }_{\mathrm{SR}}^{\mathrm{E}_{\mathrm{SR}}} & \mathrm{E}_{\mathrm{PT}} & \mathrm{q} / \mathrm{A} & \underset{\mathrm{t}}{\Delta} & \mathrm{Nu} & \mathrm{Y}_{1} & \mathrm{Y}_{2} \\ \text { watts } & \text { Volts } & \text { Volts } & \text { BTU/HR } \text { FT }^{2} & { }_{\mathrm{O}} \mathrm{F} & & \end{array}$

RUN 68

$$
I=49 / 64 \text { in. } \quad R_{100}=0.05054 \Omega
$$

$\begin{array}{rrrrrrrr}0.0 & 0.0820 & 0.1958 & 16,400 & 27.8 & 1.27 & - & - \\ 34.2 & 0.0824 & 0.1970 & 16,600 & 28.3 & - & - & - \\ 47.0 & 0.0821 & 0.1954 & 16,400 & 25.7 & - & - & - \\ 62.0 & 0.0820 & 0.1935 & 16,200 & 21.1 & 1.65 & 12.1 & - \\ 105.0 & 0.0816 & 0.1918 & 16,000 & 18.4 & 1.87 & 31.9 & - \\ 0.0 & 0.0998 & 0.2430 & 14,800 & 39.5 & 1.35 & - & - \\ 62.0 & 0.0998 & 0.2392 & 24,400 & 29.8 & 1.76 & 15.7 & - \\ 105.0 & 0.1001 & 0.2364 & 24,200 & 21.9 & 2.38 & 23.3 & - \\ 0.0 & 0.1163 & 0.2851 & 33,900 & 44.5 & 1.64 & - & - \\ 62.0 & 0.1166 & 0.2795 & 33,300 & 31.0 & 2.30 & 16.3 & - \\ 105.0 & 0.1145 & 0.2708 & 31,700 & 23.4 & 2.91 & 24.7 & - \\ 0.0 & 0.1314 & 0.3267 & 43,900 & 54.2 & 1.73 & - & - \\ 34.2 & 0.1317 & 0.3230 & 43,500 & 45.7 & - & - & - \\ 62.0 & 0.1323 & 0.3180 & 43,000 & 33.4 & 2.76 & 17 & - \\ 105.0 & 0.1309 & 0.3108 & 41,600 & 26.8 & 3.34 & 26.9 & - \\ 0.0 & 0.1668 & 0.4340 & 74,000 & 83.5 & 1.88 & - & - \\ 62.0 & 0.1703 & 0.4200 & 73,100 & 48.4 & 3.23 & 24.1 & - \\ 105.0 & 0.1700 & 0.4097 & 71,200 & 34.2 & 4.46 & 32.2 & - \\ 0.0 & 0.2122 & 0.5624 & 122,000 & 94.7 & - & - & - \\ 16.0 & 0.2120 & 0.5629 & 122,000 & 95.1 & - & - & - \\ 24.0 & 0.0654 & 0.1676 & 11,200 & 72.2 & - & - & - \\ 62.0 & 0.2157 & 0.5396 & 119,000 & 56.3 & 4.27 & 30.1 & - \\ 105.0 & 0.2153 & 0.5316 & 117,000 & 48.2 & 5.19 & 44.9 & - \\ 0.0 & 0.1932 & 0.5165 & 102,000 & 99.8 & - & - & - \\ 62.0 & 0.1950 & 0.4877 & 97,200 & 56.3 & 3.68 & 27.6 & - \\ 105.0 & 0.1949 & 0.4744 & 94,500 & 39.3 & 5.15 & 36.6 & - \\ 0.0 & 0.2195 & 0.6062 & 136,000 & 122.2 & - & - & - \\ 62.0 & 0.2255 & 0.5726 & 132,000 & 66.8 & 4.20 & 33.2 & - \\ 0.0 & 0.2362 & 0.6337 & 153,000 & 103.2 & - & - & - \\ 62.0 & 0.2408 & 0.6136 & 151,000 & 69.1 & 1.11 & - & 68.7 \\ 105.0 & 0.2427 & 0.6006 & 149,000 & 50.5 & 1.50 & - & 130 \\ 0.0 & 0.2583 & 0.6936 & 183,000 & 102.1 & - & - & - \\ 62.0 & 0.2631 & 0.6691 & 180,000 & 66.8 & 1.37 & - & 75.4 \\ 105.0 & 0.2633 & 0.6577 & 177,000 & 55.5 & 1.62 & - & 139\end{array}$


TABLE D-8 continued

$\begin{array}{cccccccc}\mathrm{W}_{\mathrm{A}} & \mathrm{E}_{\mathrm{SR}} & \mathrm{E}_{\mathrm{PT}} & \mathrm{q} / \mathrm{A} & \Delta \mathrm{t} & \mathrm{Nu} & \mathrm{Y}_{1} & \mathrm{Y}_{2} \\ \text { watts } & \text { Volts } & \text { Volts } & \text { BTU/HR } \mathrm{FT}^{2} & \mathrm{o}_{\mathrm{F}} & & & \end{array}$

RUN 68 continued

$\begin{array}{rrrrrrrr}0.0 & 0.2807 & 0.7666 & 220,000 & 113.3 & - & - & - \\ 24.0 & 0.2812 & 0.7687 & 221,000 & 114.0 & - & - & - \\ 34.2 & 0.2820 & 0.7596 & 219,000 & 103.8 & - & - & - \\ 62.0 & 0.2839 & 0.7408 & 215,000 & 81.7 & 1.34 & - & 80.6 \\ 105.0 & 0.2838 & 0.7171 & 208,000 & 61.0 & 1.71 & - & 152 \\ 0.0 & 0.3070 & 0.8413 & 264,000 & 115.0 & - & - & - \\ 62.0 & 0.3098 & 0.8147 & 258,000 & 87.0 & 1.51 & - & 88.0 \\ 105.0 & 0.3118 & 0.7905 & 252,000 & 63.0 & 2.04 & - & 165 \\ 0.0 & 0.3379 & 0.9321 & 322,000 & 121.2 & - & - & - \\ 34.2 & 0.3393 & 0.9371 & 325,000 & 122.1 & - & - & - \\ 47.0 & 0.3390 & 0.9291 & 322,000 & 116.7 & - & - & - \\ 62.0 & 0.3415 & 0.9165 & 320,000 & 102.3 & 1.60 & - & 84.9 \\ 105.0 & 0.3462 & 0.8901 & 315,000 & 73.9 & 2.17 & - & 184 \\ 0.0 & 0.3833 & 1.0694 & 419,000 & 129.2 & - & - & - \\ 62.0 & 0.3876 & 1.0372 & 411,000 & 100.3 & - & - & - \\ 105.0 & 0.3925 & 1.0169 & 408,000 & 78.0 & 2.66 & - & 207 \\ 0.0 & 0.4049 & 1.1356 & 470,000 & 132.0 & - & - & - \\ 62.0 & 0.4085 & 1.0991 & 459,000 & 103.1 & - & - & - \\ 105.0 & 0.4137 & 1.0688 & 452,000 & 76.1 & 3.03 & - & 227 \\ 0.0 & 0.4430 & 1.2697 & 575,000 & 148.4 & - & - & - \\ 62.0 & 0.4512 & 1.2249 & 565,000 & 110.2 & - & - & - \\ 105.0 & 0.4532 & 1.87 \gamma & 550,000 & 86.2 & 3.25 & - & 242\end{array}$

RUN 69

$$
\mathrm{L}=47 / 64 \text { in. }
$$

$\begin{array}{rlll}0.0 & 0.0712 & 0.1635 & 12,400 \\ 62.0 & 0.0709 & 0.1626 & 12,300 \\ 105.0 & 0.0708 & 0.1616 & 12,200 \\ 0.0 & 0.0869 & 0.2030 & 18,800 \\ 62.0 & 0.0865 & 0.1994 & 18,400 \\ 105.0 & 0.0862 & 0.1980 & 18,200 \\ 0.0 & 0.0968 & 0.2268 & 23,400 \\ 62.0 & 0.0963 & 0.2231 & 22,900 \\ 105.0 & 0.0957 & 0.2196 & 22,400 \\ 0.0 & 0.1162 & 0.2792 & 34,600 \\ 62.0 & 0.1176 & 0.2752 & 34,500 \\ 105.0 & 0.1170 & 0.2709 & 33,800 \\ 0.0 & 0.1445 & 0.3584 & 55,200 \\ 62.0 & 0.1454 & 0.3477 & 53,900 \\ 105.0 & 0.1455 & 0.3423 & 53,100 \\ 0.0 & 0.1564 & 0.3911 & 65,200\end{array}$

$$
R_{100}=0.04928 \Omega
$$

$\begin{array}{llcl}18.70 & 1.43 & - & - \\ 17.3 & 1.53 & 10.5 & - \\ 15.7 & 1.67 & 18.7 & - \\ 29.7 & 1.36 & - & - \\ 21.3 & 1.85 & 12.2 & - \\ 19.2 & 2.04 & 21 & - \\ 31.8 & 1.58 & - & - \\ 25.5 & 1.93 & 13.7 & - \\ 19.9 & 2.42 & 21.7 & - \\ 47.7 & 1.55 & - & - \\ 32.4 & 2.28 & 16.7 & - \\ 25.8 & 2.81 & 26.1 & - \\ 69.0 & 1.70 & - & - \\ 44.8 & 2.57 & 22 & - \\ 34.8 & 3.27 & 33.6 & - \\ 73.2 & 1.89 & - & -\end{array}$


TABLE $D-8$ continued

\begin{tabular}{|c|c|c|c|c|c|c|c|}
\hline $\begin{array}{c}{ }_{A} \\
\text { watts }\end{array}$ & $\begin{array}{c}\mathrm{E}_{\mathrm{SR}} \\
\text { Vo1ts }\end{array}$ & $\begin{array}{c}\mathrm{E}_{\mathrm{PT}} \\
\text { Volts }\end{array}$ & $\begin{array}{c}\text { q/A } \\
\mathrm{BTU} / \mathrm{HR} F \mathrm{~T}^{2}\end{array}$ & $\begin{array}{r}\Delta t \\
o_{F}\end{array}$ & $\mathrm{Nu}$ & $Y_{1}$ & $Y_{2}$ \\
\hline \multicolumn{8}{|c|}{ RUN 69 continued } \\
\hline 62.0 & 0.1591 & 0.3821 & 64,800 & 46.6 & 2.97 & 23.3 & - \\
\hline $\begin{array}{r}105.0 \\
0.0\end{array}$ & 0.1582 & 0.3724 & 62,800 & 34.5 & 3.90 & 32.4 & - \\
\hline $\begin{array}{r}0.0 \\
62.0\end{array}$ & 0.1774 & 0.4558 & 86,200 & 90.2 & - & - & - \\
\hline 62.0 & 0.1815 & 0.4434 & 85,800 & 57.4 & 3.19 & 28.3 & - \\
\hline 105.0 & 0.1828 & 0.4346 & 84,700 & 39.4 & 4.60 & 36.6 & - \\
\hline 0.0 & 0.2041 & 0.5377 & 117,000 & 106.2 & - & - & - \\
\hline 62.0 & 0.2090 & 0.5205 & 116,000 & 68.7 & 3.60 & 34.1 & - \\
\hline 105.0 & 0.2 .092 & 0.5067 & 113,000 & 51.2 & 4.71 & 47.3 & - \\
\hline 0.0 & 0.2190 & 0.5697 & 133,000 & 98.5 & - & - & - \\
\hline 62.0 & 0.2232 & 0.5462 & 130,000 & 58.4 & 4.75 & 28.7 & - \\
\hline 105.0 & 0.2231 & 0.5382 & 128,000 & 49.5 & 5.53 & 45.9 & - \\
\hline 0.0 & 0.2414 & 0.6372 & 164,000 & 108.2 & - & - & - \\
\hline 62.0 & 0.2480 & 0.6165 & 163,000 & 68.5 & 1.21 & - & 71.4 \\
\hline 105.0 & 0.2478 & 0.6056 & 160,000 & 57.6 & 1.42 & - & 131 \\
\hline 0.0 & 0.2659 & 0.6914 & 196,000 & 97.2 & - & - & - \\
\hline 62.0 & 0.2682 & 0.6715 & 192,000 & 72.1 & 1.36 & - & 77.8 \\
\hline 105.0 & 0.2687 & 0.6527 & 187,000 & 52.8 & 1.81 & - & 144 \\
\hline 0.0 & 0.2872 & 0.7642 & 234,000 & 112.8 & - & - & - \\
\hline 62.0 & 0.2914 & 0.7338 & 228,000 & 75.8 & 1.53 & - & 86.3 \\
\hline 105.0 & 0.2924 & 0.7154 & 223,000 & 57.4 & 1.99 & - & 154 \\
\hline 0.0 & 0.3112 & 0.8288 & 275,000 & 114.4 & - & - & - \\
\hline 62.0 & 0.3154 & 0.8030 & 270,000 & 84.0 & 1.65 & - & 88.2 \\
\hline 105.0 & 0.3163 & 0.7918 & 267,000 & 73.0 & 1.86 & - & 170 \\
\hline 0.0 & 0.3347 & 0.9079 & 324,000 & 127.1 & - & - & - \\
\hline 62.0 & 0.3371 & 0.8571 & 308,000 & 83.2 & 1.88 & - & 94.1 \\
\hline 105.0 & 0.3357 & 0.8326 & 298,000 & 66.9 & 2.27 & - & 181 \\
\hline 0.0 & 0.3730 & 1.0084 & 401,000 & 125.8 & - & - & - \\
\hline 62.0 & 0.3794 & 0.9840 & 398,000 & 97.3 & - & - & - \\
\hline 105.0 & 0.3847 & 0.9533 & 391,000 & 67.3 & 2.97 & - & 207 \\
\hline 0.0 & 0.4051 & 1.0974 & 474,000 & 127.1 & - & - & - \\
\hline 62.0 & 0.4107 & 1.0712 & 469,000 & 100.2 & - & - & - \\
\hline 105.0 & 0.4159 & 1.0555 & 468,000 & 82.0 & 2.88 & - & 220 \\
\hline 0.0 & 0.4271 & 1.1683 & 532,000 & 133.1 & - & - & 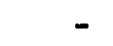 \\
\hline 62.0 & 0.4351 & 1.1382 & 528,000 & 102.1 & - & - & - \\
\hline 105.0 & 0.4349 & 1.1108 & 515,000 & 86.2 & 3.04 & - & 234 \\
\hline
\end{tabular}


TABLE D-9

IIQUID: Methanol

WIRE DIAMETER: $\quad 0.007 "$
TEMPERATURE: $113^{\circ} \mathrm{F}$ FREQUENCY: $108 \mathrm{kcps}$

\begin{tabular}{|c|c|c|c|c|c|c|c|}
\hline $\begin{array}{c}\mathrm{W}_{\mathrm{A}} \\
\text { watts }\end{array}$ & $\begin{array}{c}\mathrm{E}_{\mathrm{SR}} \\
\text { Volts }\end{array}$ & $\begin{array}{c}\mathrm{E}_{\mathrm{PT}} \\
\text { Volts }\end{array}$ & $\begin{array}{c}\mathrm{q} / \mathrm{A} \\
\mathrm{BTU} / \mathrm{HR} \mathrm{FT}^{2}\end{array}$ & $\Delta_{O_{F}}$ & $\mathrm{Nu}$ & $Y_{1}$ & $Y_{2}$ \\
\hline RUN 66 & & \multicolumn{2}{|c|}{$I=48 / 64 \mathrm{in}}$. & \multicolumn{3}{|c|}{$\mathrm{R}_{100}=0.1006 \Omega$} & \\
\hline 0.0 & 0.0197 & 0.0855 & 2,510 & 11.2 & 1.14 & - & \\
\hline 0.0 & 0.0223 & 0.0998 & 3,420 & $11.8^{\circ}$ & 1.48 & - & \\
\hline 0.0 & 0.0262 & 0.1150 & 4,490 & 17.2 & 1.33 & - & \\
\hline 16.0 & 0.0262 & 0.1150 & 4,490 & 17.4 & - & - & \\
\hline 24.0 & 0.0262 & 0.1144 & 4,460 & 15.1 & - & - & \\
\hline 62.0 & 0.0261 & 0.1135 & 4,420 & 12.2 & 1.84 & 11.9 & \\
\hline 105.0 & 0.0260 & 0.1129 & 4,380 & 10.2 & 2.18 & 16.0 & \\
\hline 0.0 & 0.0306 & 0.1358 & 6,200 & 22.1 & 1.44 & - & \\
\hline $\begin{array}{r}62.0 \\
05\end{array}$ & 0.0303 & 0.1328 & 5,990 & 15.7 & 1.95 & 14.2 & \\
\hline $\begin{array}{r}105.0 \\
0.0\end{array}$ & 0.0301 & 0.1310 & 5,880 & 11.2 & 2.67 & 16.9 & \\
\hline $\begin{array}{l}0.0 \\
4.3\end{array}$ & 0.0361 & 0.1621 & 8,720 & 28.7 & 1.57 & - & \\
\hline $\begin{array}{r}4.3 \\
16.0\end{array}$ & 0.0362 & 0.1629 & 8,800 & 29.3 & - & - & \\
\hline $\begin{array}{l}16.0 \\
62.0\end{array}$ & 0.0 .362 & 0.1611 & 8,700 & 23.2 & - & - & \\
\hline $\begin{array}{r}62.0 \\
105.0\end{array}$ & 0.0361 & 0.1597 & 8,600 & 19.8 & 2.22 & 16.8 & \\
\hline $\begin{array}{r}105.0 \\
0.0\end{array}$ & $\begin{array}{l}0.0359 \\
0.0417\end{array}$ & 0.1568 & 8,400 & 12.3 & 3.48 & 18.3 & \\
\hline 62.0 & 0.0422 & 0.1912 & 11,900 & 42.0 & 1.47 & - & \\
\hline 105.0 & 0.0416 & 0.1878 & 11,800 & 25.8 & 2.35 & 21.0 & - \\
\hline 0.0 & 0.0524 & 0.1823 & 11,300 & 16.6 & 3.48 & 22.2 & - \\
\hline 62.0 & 0.0518 & $\begin{array}{l}0.2445 \\
0.2368\end{array}$ & 19,100 & 52.8 & 1.90 & - & - \\
\hline 105.0 & 0.0519 & 0.2312 & $\begin{array}{l}18,300 \\
17,900\end{array}$ & 40.10 & 2.38 & 31.0 & - \\
\hline 0.0 & 0.0602 & 0.2874 & 25,800 & $\begin{array}{l}25.5 \\
66.1\end{array}$ & 3.60 & 31.8 & \\
\hline 10.0 & 0.0603 & 0.2825 & 25,400 & 53.8 & - & - & - \\
\hline 62.0 & 0.0606 & 0.2790 & 25,200 & 44.0 & 3.00 & 35.5 & - \\
\hline 105.0 & 0.0604 & 0.2732 & 24,600 & 33.4 & 3.81 & 40.3 & - \\
\hline 0.0 & 0.0699 & 0.3385 & 35,300 & 73.8 & - & - & \\
\hline 16.0 & 0.0701 & 0.3341 & 34,900 & 64.7 & - & - & - \\
\hline 62.0 & 0.0700 & 0.3307 & 34,500 & 59.1 & 3.07 & 48.7 & - \\
\hline 105.0 & 0.0703 & 0.3223 & 33,800 & 40.1 & 4.39 & 49.9 & - \\
\hline 0.0 & 0.0775 & 0.3904 & 45,100 & 97.9 & - & - & - \\
\hline 62.0 & 0.0781 & 0.3744 & 43,600 & 67.0 & - & - & . \\
\hline 105.0 & 0.0776 & 0.3596 & 41,600 & 46.8 & 1.84 & - & 121 \\
\hline 0.0 & 0.0794 & 0.3901 & 46,200 & 83.7 & - & - & \\
\hline 62.0 & 0.0789 & 0.3834 & 45,100 & 77.0 & - & - & \\
\hline
\end{tabular}


TABLE D-9 continued

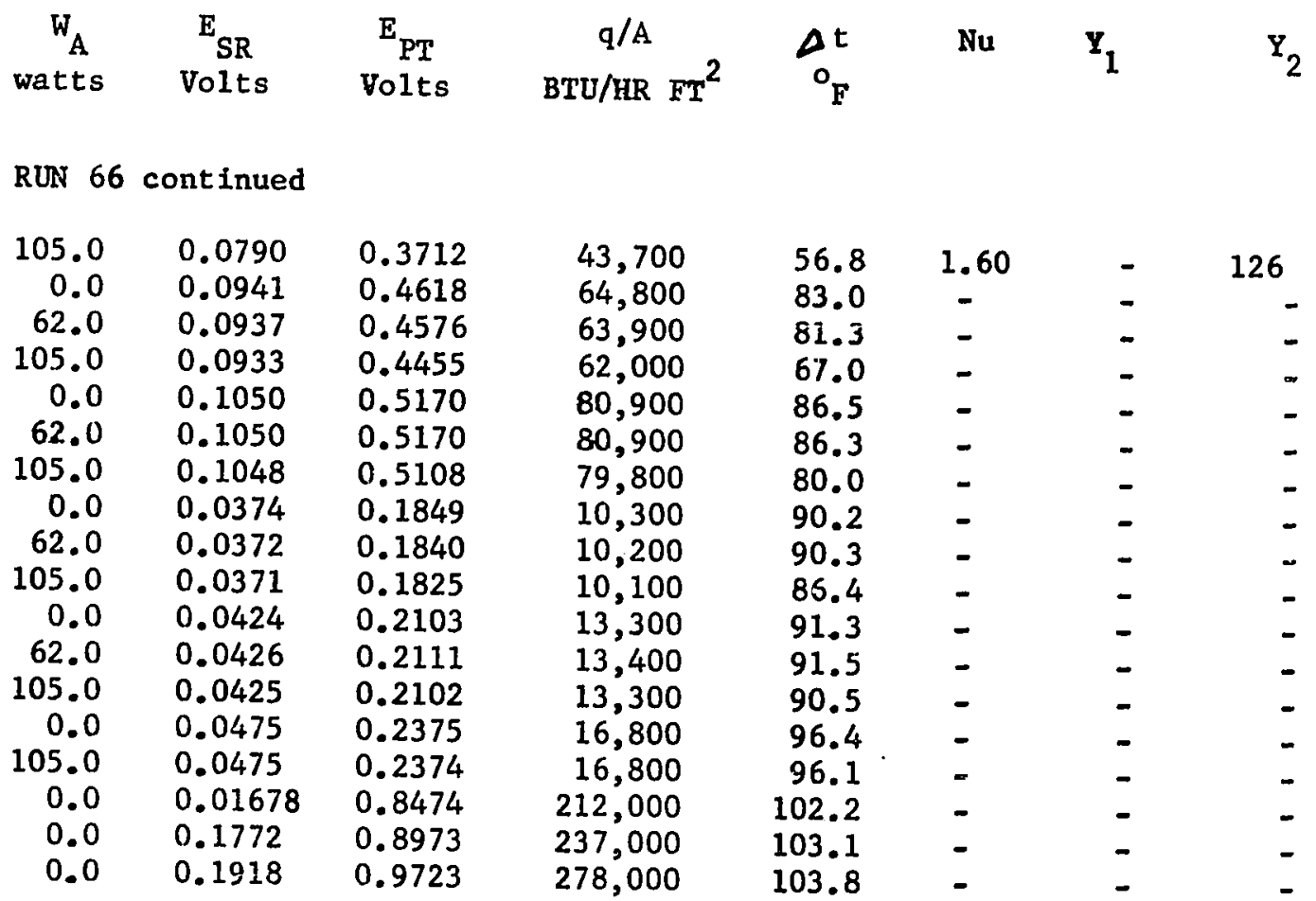

RINN 67

$\begin{array}{rl}0.0 & 0.0211 \\ 0.0 & 0.0252 \\ 62.0 & 0.0252 \\ 0.0 & 0.0341 \\ 62.0 & 0.0341 \\ 105.0 & 0.0338 \\ 0.0 & 0.0395 \\ 62.0 & 0.0396 \\ 105.0 & 0.0394 \\ 0.0 & 0.0468 \\ 62.0 & 0.0469 \\ 105.0 & 0.0465 \\ 0.0 & 0.0573 \\ 62.0 & 0.0573 \\ 105.0 & 0.0571 \\ 0.0 & 0.0667 \\ 62.0 & 0.0660 \\ 105.0 & 0.0663 \\ 0.0 & 0.0756\end{array}$

0.0856

0.1034

0.1025

0.1421

0.1396

0.1374

0.1661

0.1639

0.1604

0.2021

0.1960

0.1923

0.2522

0.2444

0.2388

0.3008

0.2885

0.2811

0.3495
$\mathrm{L}=46 / 64 \mathrm{in}$.

2,810
4,060
4,020
7,530
7,400
7,220
10,200
10,100
9,820
14,700
14,300
13,900
22,500
21,800
21,200
31,200
29,600
29,000
41,100

$R_{100}=0.09421 \Omega$

$10.2 \quad 1.40$

$15.8 \quad 1.31$

$11.1 \quad 1.84$

$25.4 \quad 1.52$

$16.8 \quad 2.25$

$12.7 \quad 2.90$

$32.5 \quad 1.65$

$22.9 \quad 2.26$

14.23 .53

$47.7 \quad 1.61$

$27.5 \quad 2.68$

22.23 .21

$56.4 \quad 2.10$

$38.2 \quad 2.97$

$27.6 \quad 3.96$

71.8

53.2

34.7

$-$

2.92

4.33
$Y_{2}$

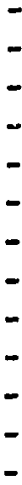


3

TABLE D-9 continued

$\begin{array}{cccccccc}\mathrm{W}_{\mathrm{A}} & \mathrm{E}_{\mathrm{SR}} & \mathrm{E}_{\mathrm{PT}} & \mathrm{q} / \mathrm{A} & \Delta t & \mathrm{Nu} & \mathrm{Y}_{1} & \mathrm{Y}_{2} \\ \text { watts } & \text { Volts } & \text { Volts } & \text { BTU/HR FT } & \mathrm{O}_{\mathrm{F}} & & \end{array}$

RUN 67 continued

$\begin{array}{rllllllr}62.0 & 0.0762 & 0.3367 & 39,900 & 57.7 & 1.44 & - & 82 \\ 105.0 & 0.0759 & 0.3328 & 39,300 & 51.8 & 1.57 & - & 121 \\ 0.0 & 0.0825 & 0.3773 & 48,400 & 77.7 & - & - & - \\ 62.0 & 0.0829 & 0.3706 & 47,800 & 64.2 & - & - & - \\ 105.0 & 0.0826 & 0.3603 & 46,300 & 49.7 & 1.93 & - & 131 \\ 0.0 & 0.0998 & 0.4578 & 71,100 & 81.8 & - & - & - \\ 0.0 & 0.0989 & 0.4491 & 69,100 & 75.8 & - & - & - \\ 105.0 & 0.0985 & 0.4423 & 67,800 & 68.8 & - & - & - \\ 105.0 & 0.0866 & 0.3873 & 52,500 & 65.2 & - & - & - \\ 0.0 & 0.1108 & 0.5135 & 88,500 & 87.5 & - & - & - \\ 62.0 & 0.1109 & 0.5137 & 88,600 & 88.2 & - & - & - \\ 105.0 & 0.1109 & 0.5099 & 88,000 & 83.2 & - & - & - \\ 0.0 & 0.1263 & 0.5852 & 115,000 & 88.2 & - & - & - \\ 105.0 & 0.1258 & 0.5826 & 114,000 & 88.0 & - & - & - \\ 0.0 & 0.1431 & 0.6650 & 148,000 & 90.3 & - & - & - \\ 105.0 & 0.1431 & 0.6649 & 148,000 & 90.1 & - & - & - \\ 0.0 & 0.1577 & 0.7417 & 182,000 & 97.6 & - & - & - \\ 105.0 & 0.1578 & 0.7415 & 182,000 & 97.2 & - & - & - \\ 0.0 & 0.1745 & 0.8215 & 223,000 & 98.3 & - & - & - \\ 105.0 & 0.1745 & 0.8215 & 223,000 & 98.4 & - & - & - \\ 0.0 & 0.1851 & 0.8716 & 251,000 & 98.5 & - & - & -\end{array}$


TABLE D-10

LIQUID: Methanol TEMPERATURE: $113^{\circ} \mathrm{F}$ FREQUENCY: $306 \mathrm{kcps}$ WIRE DIAMETER: $\quad 0.007^{\prime \prime}$

$\begin{array}{cccccccc}\mathrm{W}_{\mathrm{A}} & \mathrm{E}_{\mathrm{SR}} & \mathrm{E}_{\mathrm{PT}} & \mathrm{q} / \mathrm{A} & \Delta t & \text { Nu } & \mathrm{Y}_{1} & \mathrm{Y}_{2} \\ \text { watts } & \text { Volts } & \text { Volts } & \text { BTU/HR FT } & { }^{\circ} \mathrm{F} & & & \end{array}$

RUN 70

$\begin{array}{rllr}0.0 & 0.0233 & 0.0977 & 3,460 \\ 92.0 & 0.0232 & 0.0975 & 3,450 \\ 125.0 & 0.0231 & 0.0968 & 3,410 \\ 0.0 & 0.0278 & 0.1176 & 4,980 \\ 125.0 & 0.0278 & 0.1171 & 4,960 \\ 160.0 & 0.0278 & 0.1164 & 4,920 \\ 0.0 & 0.0339 & 0.1449 & 7,470 \\ 125.0 & 0.0335 & 0.1422 & 7,260 \\ 160.0 & 0.0334 & 0.1410 & 7,170 \\ 0.0 & 0.0394 & 0.1718 & 10,300 \\ 74.0 & 0.0394 & 0.1718 & 10,300 \\ 92.0 & 0.0394 & 0.1702 & 10,200 \\ 125.0 & 0.0396 & 0.1691 & 10,200 \\ 160.0 & 0.0393 & 0.1668 & 9,980 \\ 0.0 & 0.0468 & 0.2051 & 14,600 \\ 92.0 & 0.0466 & 0.2017 & 14,300 \\ 125.0 & 0.0464 & 0.1997 & 14,100 \\ 160.0 & 0.0457 & 0.1955 & 13,600 \\ 0.0 & 0.0617 & 0.2818 & 26,400 \\ 125.0 & 0.0624 & 0.2748 & 26,100 \\ 160.0 & 0.0620 & 0.2700 & 25,500 \\ 0.0 & 0.0525 & 0.2350 & 18,800 \\ 125.0 & 0.0528 & 0.2290 & 18,400 \\ 160.0 & 0.0518 & 0.2231 & 17,600 \\ 0.0 & 0.0678 & 0.3157 & 32,600 \\ 74.0 & 0.0681 & 0.3098 & 32,100 \\ 125.0 & 0.0680 & 0.3061 & 31,700 \\ 160.0 & 0.0674 & 0.2971 & 30,500 \\ 0.0 & 0.0755 & 0.3637 & 41,800 \\ 125.0 & 0.0767 & 0.3493 & 40,800 \\ 160.0 & 0.0770 & 0.3422 & 40,100 \\ 0.0 & 0.0794 & 0.3712 & 44,900 \\ 92.0 & 0.0795 & 0.3659 & 44,300\end{array}$

$\mathrm{L}=47 / 64 \mathrm{in}$.

$\mathrm{R}_{100}=0.09723 \Omega$

$\begin{array}{lccl}11.7 & 1.51 & - & - \\ 11.8 & - & - & - \\ 10.2 & 1.70 & 4.67 & - \\ 15.4 & 1.65 & - & - \\ 12.7 & 1.96 & 5.28 & - \\ 11.2 & 2.24 & 7.96 & - \\ 21.3 & 1.80 & - & - \\ 16.0 & 2.31 & 6.11 & - \\ 13.3 & 2.75 & 8.78 & - \\ 31.3 & 1.70 & - & - \\ 31.5 & - & - & - \\ 27.3 & - & - & - \\ 19.7 & 2.65 & 7.0 & - \\ 16.8 & 3.04 & 10.3 & - \\ 36.5 & 2.07 & - & - \\ 29.2 & - & - & - \\ 25.8 & 2.81 & 8.4 & - \\ 22.1 & 3.15 & 12.2 & - \\ 59.1 & 2.36 & - & - \\ 37.8 & 3.59 & 11.2 & - \\ 31.1 & 4.24 & 15.7 & - \\ 47.0 & 2.09 & - & - \\ 29.4 & 3.24 & 9.29 & - \\ 24.2 & 3.73 & 13.0 & - \\ 70.0 & - & - & - \\ 56.4 & - & - & - \\ 48.7 & 3.41 & 13.7 & - \\ 36.2 & 4.37 & 17.5 & - \\ 93.1 & - & - & - \\ 58.4 & 3.57 & 15.9 & - \\ 44.3 & 4.72 & 20.4 & - \\ 74.0 & - & - & - \\ 66.3 & - & - & -\end{array}$


TABLE D-10 continued

$\begin{array}{cccccccc}{ }_{A} & E_{S R} & E_{P T} & q / A & \Delta t & N u & Y_{1} & Y_{2} \\ \text { watts } & \text { Volts } & \text { Volts } & \text { BTU/HR FT } & \text { o }_{F} & & & \end{array}$

RUN 70 continued

$\begin{array}{rrrrrrrr}125.0 & 0.0794 & 0.3622 & 43,800 & 61.1 & 3.80 & 16.4 & - \\ 160.0 & 0.2508 & 1.1261 & 430,000 & 51.8 & 4.36 & 23.4 & - \\ 0.0 & 0.0924 & 0.4351 & 61,200 & 80.5 & - & - & - \\ 125.0 & 0.0921 & 0.4273 & 59,900 & 71.7 & - & - & - \\ 160.0 & 0.0865 & 0.3939 & 51,900 & 59.8 & - & - & - \\ 0.0 & 0.1112 & 0.5273 & 89,300 & 83.8 & - & - & - \\ 125.0 & 0.1107 & 0.5221 & 88,000 & 80.5 & - & - & - \\ 160.0 & 0.1103 & 0.5125 & 86,100 & 71.2 & - & - & - \\ 0.0 & 0.1251 & 0.5988 & 114,000 & 90.0 & - & - & - \\ 125.0 & 0.1251 & 0.5987 & 114,000 & 89.8 & - & - & - \\ 160.0 & 0.1250 & 0.5936 & 113,000 & 84.8 & - & - & - \\ 0.0 & 0.1466 & 0.7033 & 157,000 & 90.2 & - & - & - \\ 160.0 & 0.1471 & 0.7055 & 158,000 & 90.1 & - & - & - \\ 0.0 & 0.1652 & 0.7989 & 201,000 & 95.2 & - & - & - \\ 0.0 & 0.1760 & 0.8507 & 228,000 & 95.0 & - & - & - \\ 0.0 & 0.1879 & 0.9121 & 261,000 & 96.8 & - & - & -\end{array}$

RUN 71

$\begin{array}{rll}0.0 & 0.0219 & 0.0919 \\ 0.0 & 0.0258 & 0.1090 \\ 125.0 & 0.0256 & 0.1073 \\ 160.0 & 0.0255 & 0.1068 \\ 0.0 & 0.0311 & 0.1328 \\ 125.0 & 0.0310 & 0.1308 \\ 160.0 & 0.0309 & 0.1298 \\ 0.0 & 0.0355 & 0.1523 \\ 125.0 & 0.0352 & 0.1496 \\ 160.0 & 0.0351 & 0.1478 \\ 0.0 & 0.0410 & 0.1777 \\ 125.0 & 0.0408 & 0.1739 \\ 160.0 & 0.0407 & 0.1727 \\ 0.0 & 0.0497 & 0.2220 \\ 125.0 & 0.0496 & 0.2144 \\ 160.0 & 0.0499 & 0.2134 \\ 0.0 & 0.0585 & 0.2640 \\ 125.0 & 0.0582 & 0.2541 \\ 160.0 & 0.0578 & 0.2514 \\ 0.0 & 0.0714 & 0.3311 \\ 125.0 & 0.0713 & 0.3231\end{array}$

$I=47 / 64$ in.

$$
\begin{aligned}
& 3,060 \\
& 4,290 \\
& 4,180 \\
& 4,150 \\
& 6,280 \\
& 6,170
\end{aligned}
$$

6,110

8,230

8,010

7,900

11,100

10,800

10,700

16,800

16,200

16,200

23,500

22,500

22,200

36,000

35,100

$$
R_{100}=0.09723 \Omega
$$

$\begin{array}{cccc}12.3 & 1.27 & - & - \\ 14.2 & 1.54 & - & - \\ 11.2 & 1.90 & 4.94 & - \\ 10.1 & 2.09 & 7.55 & - \\ 21.5 & 1.49 & - & - \\ 14.9 & 2.11 & 5.80 & - \\ 11.3 & 2.75 & 8.05 & - \\ 24.2 & 1.75 & - & - \\ 19.3 & 2.12 & 6.73 & - \\ 13.3 & 3.02 & 8.78 & - \\ 29.1 & 1.96 & - & - \\ 20.4 & 2.71 & 7.14 & - \\ 17.5 & 3.13 & 10.52 & - \\ 47.0 & 1.87 & - & - \\ 27.8 & 3.00 & 8.94 & - \\ 22.3 & 3.72 & 12.3 & - \\ 53.4 & 2.30 & - & - \\ 34.0 & 3.43 & 10.2 & - \\ 29.6 & 3.87 & 15.2 & - \\ 69.2 & - & - & - \\ 55.2 & 3.36 & 15.0 & -\end{array}$


TABLE D-10 continued

$\begin{array}{cccccccc}\mathrm{W}_{\mathrm{A}} & \mathrm{E}_{\mathrm{SR}} & \mathrm{E}_{\mathrm{PT}} & \mathrm{q} / \mathrm{A} & \Delta \mathrm{t} & \mathrm{Nu} & \mathrm{Y}_{1} & \mathrm{Y}_{2} \\ \text { watts } & \text { Volts } & \text { Volts } & \text { BTU/HR FT } & \underset{\mathrm{O}}{\mathrm{O}_{\mathrm{F}}} & & & \end{array}$

RUN 71 continued

$\begin{array}{rrrrrrrr}160.0 & 0.0716 & 0.3173 & 34,600 & 42.1 & 4.28 & 19.6 & - \\ 0.0 & 0.0720 & 0.3401 & 37,300 & 80.3 & - & - & - \\ 125.0 & 0.0733 & 0.3307 & 36,900 & 53.1 & 3.66 & 14.6 & - \\ 160.0 & 0.0736 & 0.3246 & 36,400 & 39.2 & 4.83 & 18.6 & - \\ 0.0 & 0.0861 & 0.4035 & 52,900 & 75.8 & - & - & - \\ 125.0 & 0.0860 & 0.3948 & 51,700 & 63.0 & - & - & - \\ 160.0 & 0.0863 & 0.3882 & 51,000 & 51.0 & 5.25 & 23.2 & - \\ 0.0 & 0.0988 & 0.4635 & 69,700 & 76.6 & - & - & - \\ 125.0 & 0.0986 & 0.4595 & 69,000 & 72.2 & - & - & - \\ 160.0 & 0.0974 & 0.4463 & 66,200 & 61.8 & - & - & - \\ 0.0 & 0.1143 & 0.5391 & 93,800 & 79.9 & - & - & - \\ 125.0 & 0.1143 & 0.5388 & 93,700 & 79.8 & - & - & - \\ 160.0 & 0.1147 & 0.5355 & 93,500 & 73.6 & - & - & - \\ 0.0 & 0.1244 & 0.5912 & 112,000 & 84.2 & - & - & - \\ 125.0 & 0.1250 & 0.5939 & 113,000 & 84.4 & - & - & - \\ 160.0 & 0.0389 & 0.1842 & 10,900 & 82.7 & - & - & - \\ 0.0 & 0.0430 & 0.2045 & 13,400 & 84.3 & - & - & - \\ 160.0 & 0.0430 & 0.2045 & 13,400 & 84.2 & - & - & - \\ 0.0 & 0.0489 & 0.2339 & 17,400 & 89.0 & - & - & - \\ 0.0 & 0.1693 & 0.8185 & 211,000 & 95.2 & - & - & - \\ 0.0 & 0.1849 & 0.8953 & 252,000 & 96.3 & - & - & - \\ 0.0 & 0.1975 & 0.9642 & 290,000 & 101.3 & - & - & -\end{array}$




\section{APPENDIX E}

CRITICAL SOUND PRESSURE DATA 
TABLE E-1

LIQUID: Distilled Water

$\mathrm{V*}$

volts

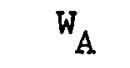
watts

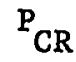

atm.

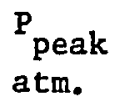

Liquid Temperature $=149^{\circ} \mathrm{F}$

10.0

10.0

7.5

6.0

3.0

2.5

5.0

7.5

10.0

15.0

$\begin{array}{rl}7.0 & .27 \\ 7.0 & .27 \\ 4.8 & .20 \\ 3.0 & .17 \\ 1.0 & .092 \\ 0.8 & .080 \\ 2.0 & .16 \\ 4.8 & .20 \\ 7.0 & .27 \\ 15.6 & .34\end{array}$

Liquid Temperature $=113^{\circ} \mathrm{F}$

\section{5}

6.0

3.0

5.0

6.0

10.0

15.0

4.8

3.0

.19

.17

.12

1.5

1.5

3.0

7.0

15.6

.12

.17

.25

.34

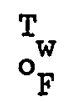

$\Delta t$

${ }^{\circ}$

$q / A$

\section{.50}

.50

.34

.28

.14

.13

.24

.34

.50

.60

FREQUENCY: $20.6 \mathrm{kcps}$

$\begin{array}{rrr}282 & 133.1 & 500,000 \\ 277 & 128.1 & 430,000 \\ 262 & 113.1 & 310,000 \\ 259 & 110.2 & 250,000 \\ 241 & 92.1 & 170,000 \\ 237 & 88.3 & 120,000 \\ 211 & 62.8 & 66,000 \\ 196 & 47.0 & 38,000 \\ 182 & 33.3 & 28,000 \\ 164 & 14.8 & 10,000\end{array}$

$.34 \quad 265$

262

152.1

149.0

128.2

110.0

97.4

81.1

$180 \quad 67.3$
$.21 \quad 223$

$.28 \quad 210$

$.44 \quad 194$

$.58 \quad 180$
$\mathrm{BTU} / \mathrm{hr} \mathrm{ft}^{2}$ 2 
TABIE E-2

LIQUID: Methano1

$\begin{array}{cc}\mathrm{V} * & \mathrm{~W}_{\mathrm{A}} \\ \text { volts } & \text { watts }\end{array}$
$o_{F}^{T}$

Liquid Temperature $=113^{\circ} \mathrm{F}$

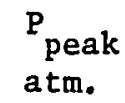

$$
7.0
$$

7.0

$\begin{array}{rl}7.5 & 4.8\end{array}$

$5 \quad 2.0$

$3 \quad 1.0$

$2 \quad 0.8$

$3 \quad 1.0$

$5 \quad 2.0$

10

7.0

\subsection{6}

0.16

0.14

0.11

0.076

0.055

0.076

0.11

0.16

$\Delta t$

${ }^{\circ} \mathrm{F}$

$\stackrel{\mathrm{q} / \mathrm{A}}{\mathrm{BTU} / \mathrm{hr}} \mathrm{ft}^{2}$

Liquid Temperature $=95^{\circ} \mathrm{F}$

$\begin{array}{rr}12.5 & 12.0 \\ 7.5 & 7.0 \\ 5 & 4.8 \\ 3 & 1.0 \\ 3 & 1.0 \\ 5 & 2.0 \\ 10 & 7.0\end{array}$

0.20

0.14

0.12

0.072

0.072

0.30

0.30

0.25

0.17

0.12

0.087

0.123

0.17

0.30

129
136
142
156
167
178
185
187
189

16.3

23.8

28.8

43.4

54.4

65.5

72.2

74.2

76.7

$$
4,100
$$

7,800

11,200

19,400

25, 000

39,000

60,000

90,000

105,000

0.10

0.14

$\begin{array}{ll}0.36 & 130 \\ 0.27 & 142 \\ 0.23 & 152 \\ 0.11 & 170 \\ 0.11 & 179 \\ 0.16 & 186 \\ 0.27 & 192\end{array}$

35.1

47.4

57.3

75.4

84.4

91.0

97.0

8,600

11,500

16,000

33,000

41,500

55,000

77,000 
TABLE E-3

IIQUID: Distilled Water

LIQUID TEMPERATURE: $\quad 149^{\circ} \mathrm{F}$

\begin{tabular}{|c|c|c|c|c|c|c|}
\hline $\begin{array}{c}V * \\
\text { volts }\end{array}$ & $\underset{\text { watts }}{\mathrm{w}_{\mathrm{A}}}$ & $\begin{array}{l}\mathrm{P}_{\mathrm{CR}} \\
\text { atm. }\end{array}$ & $\begin{array}{l}P_{\text {peak }} \\
\text { atm. }\end{array}$ & $\begin{array}{l}T_{w} \\
o_{F}\end{array}$ & $\begin{array}{l}\Delta t \\
o_{F}\end{array}$ & $\begin{array}{c}\mathrm{q} / \mathrm{A} \\
\mathrm{BTU} / \mathrm{hr} \mathrm{ft}^{2}\end{array}$ \\
\hline
\end{tabular}

Frequency $=44.1 \mathrm{kcps}$

$\begin{array}{rrrrrrr}25 & 23.2 & .36 & .62 & 179 & 30.0 & 24,000 \\ 20 & 15.6 & .31 & .55 & 188 & 38.5 & 30,800 \\ 15 & 9.5 & .26 & .51 & 198 & 49.0 & 45,100 \\ 10 & 4.6 & .19 & .33 & 216 & 67.0 & 61,200 \\ 3 & 0.5 & .13 & .20 & 239 & 90.0 & 95,100 \\ 7.5 & 3.2 & .16 & .25 & 251 & 102.0 & 158,000 \\ 10 & 4.6 & .19 & .33 & 261 & 112.0 & 217,000 \\ 20 & 15.6 & .31 & .55 & 277 & 128.3 & 352,000 \\ 25 & 23.2 & .36 & .62 & 282 & 133.0 & 505,000\end{array}$

Frequency $=108 \mathrm{kcps}$

$\begin{array}{rrrrrrr}175 & 47.0 & .63 & 1.1 & 177 & 27.8 & 16,400 \\ 175 & 47.0 & .63 & 1.1 & 189 & 39.5 & .24,800 \\ 150 & 34.2 & .53 & .89 & 203 & 54.2 & 43,900 \\ 125 & 34.2 & .45 & .66 & 249 & 99.8 & 102,000 \\ 125 & 24.0 & .45 & .66 & 244 & 94.7 & 122,000 \\ 125 & 24.0 & .45 & .66 & 251 & 102.0 & 183,000 \\ 150 & 34.2 & .53 & .89 & 262 & 113.3 & 220,000 \\ 150 & 34.2 & .53 & .89 & 264 & 115.0 & 264,000 \\ 175 & 47.0 & .63 & 1.1 & 270 & 121.2 & 322,000\end{array}$


TABLE E-4

LIQUID: Methanol

$\begin{array}{cc}V & W_{A} \\ \text { volts } & \text { watts }\end{array}$

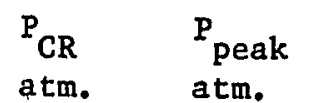

$T$
$O_{F}$

$\Delta \mathrm{t}$

${ }_{F}$
$\stackrel{\mathrm{qT} / \mathrm{A}}{\mathrm{BTU} / \mathrm{hr}} \mathrm{ft}^{2}$

Frequency $=44.1 \mathrm{kcps}$
$5 \quad 1.3$

$3 \quad 0.5$

$5 \quad 1.3$

$10 \quad 4.6$

15

9.5 $\begin{array}{lll}7.5 & 3.2 & .23\end{array}$
.15

.13

.09

.13

.17

.23

$$
\begin{aligned}
& .47 \\
& .24 \\
& .20 \\
& .13 \\
& .20 \\
& .31 \\
& .47
\end{aligned}
$$

Frequency $=108 \mathrm{kcps}$

$\begin{array}{rl}125 & 24 \\ 125 & 24 \\ 100 & 16 \\ 75 & 10 \\ 75 & 10 \\ 100 & 16 \\ 175 & 47\end{array}$

.42

.42

.34

.25

.25

.34

.42

.76
.76
.58
.38
.38
.58
.76

130

135

142

166

179

186

196 $\begin{array}{ll}138.5 & 25.5 \\ 155.0 & 42.3 \\ 159.0 & 46.2 \\ 173.0 & 61.7 \\ 185.0 & 72.0 \\ 191.0 & 78.1 \\ 193.0 & 80.6\end{array}$
8,110

14,200

17,900

23,300

31,000

41,900

66,000

Frequency $=306 \mathrm{kcps}$

$\begin{array}{rrr}175 & 125 & .92 \\ 175 & 125 & .92 \\ 150 & 92 & .83 \\ 150 & 92 & .83 \\ 125 & 74 & .71 \\ 150 & 92 & .83 \\ 175 & 125 & .92\end{array}$

$\begin{array}{lll}- & 124.7 \quad 11.7\end{array}$

- $\quad 128.4 \quad 15.4$

- $\quad 144.3 \quad 31.3$

- $\quad 149.5 \quad 36.5$

- $\quad 183.070 .0$

- $\quad 187.074 .0$

17.2
22.1

28.7

52.8

66.2

73.3

83.0

4,510

6,200

8,720

19,100

25,800

35,200

64,800

$\begin{array}{lll}- & 196.8 & 83.8\end{array}$

3,460

4,980

10,300

14,600

32,600

44,900

89,300 
APPENDIX F

SAMPLE CALCULATIONS 
I. SAMPLE CALCULATION FOR THE PERCENTAGE OF SOIL REMOVED

Using data from Run $A 1$ in Table $C-1$ where $W_{A}=86.0$ watts, $\mathrm{CPM}_{1}=36200, \mathrm{CPM}_{\tilde{I}}=32500$, Background $=486 \mathrm{CPM}$

$$
\begin{aligned}
\mathrm{S}_{\mathrm{R}}(\text { Percentage So11 Removed }) & =\frac{\mathrm{CPM}_{1}-\mathrm{CPM}_{f}}{\frac{2}{3}\left(\mathrm{CPM}_{1}\right)} \times 100 \% \\
& =\frac{(36200-486)-(32500-486)}{\frac{2}{3}(36200-486)} \times 100 \% \\
& =15.5 \%
\end{aligned}
$$

II. SAMPLE CALCULATION FOR THE HEAT TRANSHEF FẼILTS

The formulae used are as follows:

$$
\begin{aligned}
I & =E_{S R} / 0.02 \\
q & =3.415 E_{P T} I \\
q / A & =3.415 E_{P T} I / \pi D_{w} l \\
R_{P T} & =E_{P T} / I ; \quad T_{P T}=\left(\frac{R_{P T}-R_{0}}{R_{100}-R_{0}} 100 .\right.
\end{aligned}
$$

Taking $R_{100} / R_{0}=1.3925$

$$
\begin{gathered}
\mathrm{T}_{\mathrm{PT}}=\frac{354.777 \mathrm{E}_{\mathrm{PT}}}{\mathrm{R}_{100} \mathrm{I}}-254.777 \\
\Delta \mathrm{T}=\mathrm{T}_{\mathrm{PT}}-\mathrm{T}_{\mathrm{L}} \\
\text { where } \mathrm{D}_{\mathrm{w}}-\text { wire diameter, ft } \\
\mathrm{E}_{\mathrm{SR}}-\text { voltage drop across the standard resistor, volts }
\end{gathered}
$$




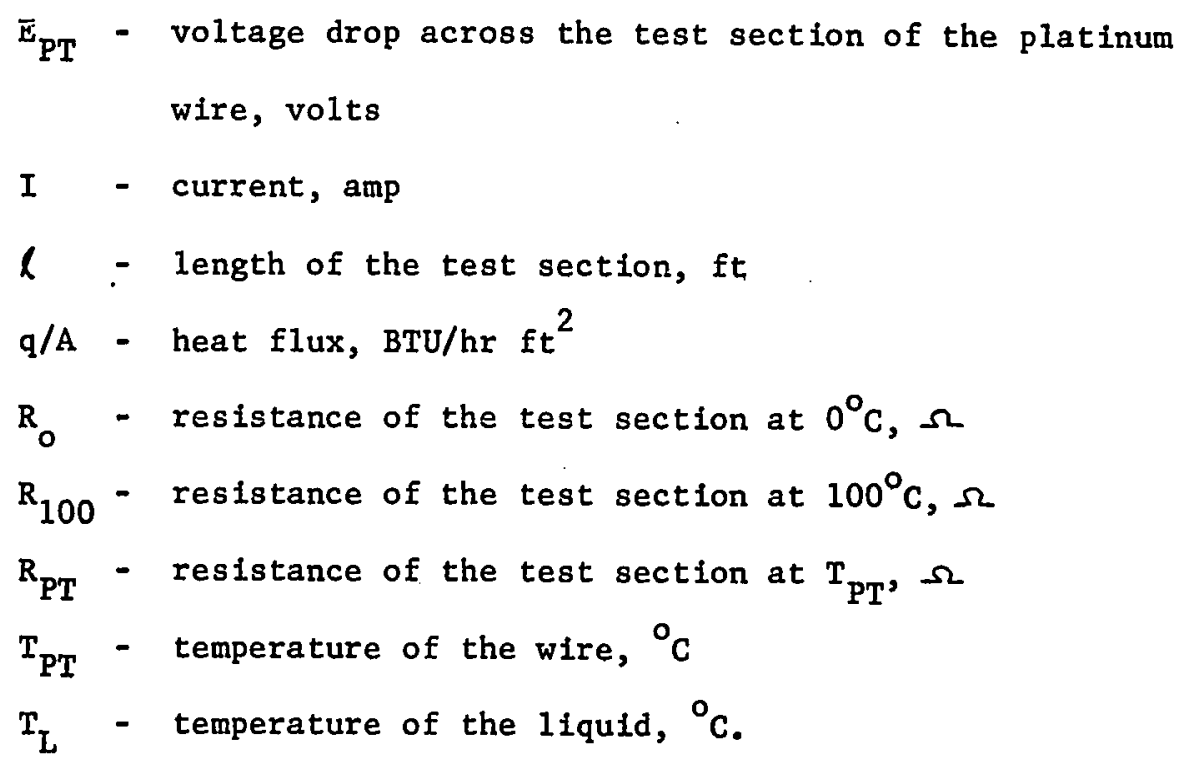

Using data from Run 30 in Table $D-1$, where

$$
\begin{aligned}
& \mathrm{T}_{\mathrm{L}}=95^{\circ} \mathrm{F}\left(35^{\circ} \mathrm{C}\right), \quad \mathrm{W}_{\mathrm{A}}=15.6 \text { watts, } \\
& \mathrm{E}_{\mathrm{SR}}=0.0705 \text { volts, } \quad \mathrm{E}_{\mathrm{PT}}=0.1535 \text { volts } \\
& \mathrm{D}_{\mathrm{w}}=0.010 \mathrm{in} .=0.000833 \mathrm{ft}, l=48 / 64 \mathrm{in} .=0.0625 \mathrm{ft} \\
& R_{100}=0.05021 \Omega
\end{aligned}
$$

1. Calculation of $\Delta t$ and $q / A$

$$
\begin{aligned}
\mathrm{I} & =0.0705 / 0.02=3.525 \mathrm{amp} \\
\mathrm{q} / \mathrm{A} & =\frac{3.415 \times 0.1535 \times 3.525}{3.1415 \times 0.000833 \times 0.0625} \\
& =11,300 \mathrm{BTU} / \mathrm{hr} \mathrm{\textrm {ft } ^ { 2 }} \\
\mathrm{T}_{\mathrm{PT}} & =\frac{354.777 \times 0.1535}{0.05021 \times 3.525}-254.777 \\
& =52.6^{\circ} \mathrm{C}=127^{\circ} \mathrm{F} \\
\Delta \mathrm{T} & =52.6-35=17.6^{\circ} \mathrm{C}=31.6^{\circ} \mathrm{F}
\end{aligned}
$$


2. Calculation of $N u_{w}$ and $(G r P r)^{1 / 2} S_{R}^{1 / 2} / P_{C R}$

$$
\begin{aligned}
& \text { When } \mathrm{W}_{\mathrm{A}}=15.6 \text { watts, } \mathrm{S}_{\mathrm{R}}=2.7 \% \\
& \text { when } \mathrm{T}_{\mathrm{PT}}=127^{\circ} \mathrm{F}, \quad \mathrm{P}_{\mathrm{CR}}=0.21 \mathrm{~atm} \\
& T_{f}=\frac{T_{L}+T_{P T}}{2}=\frac{95+127}{2}=111^{\circ} \mathrm{F} \\
& k_{L}=0.117 \mathrm{BTU} / \mathrm{ft} \mathrm{hr}{ }_{\mathrm{F},}^{\mathrm{o}} \quad \beta=6.72 \times 10^{-4} \mathrm{o}_{\mathrm{F}}^{-1} \\
& \rho_{L}=48 \mathrm{1b} / \mathrm{ft}^{3} \quad \mu=1.051 \mathrm{~b} / \mathrm{ft}-\mathrm{hr} \\
& \mathrm{C}_{\mathrm{P}}=0.625 \mathrm{BTU} / 1 \mathrm{~b}^{\circ} \mathrm{F} \\
& \mathrm{h}=\frac{\mathrm{g} / \mathrm{A}}{\Delta \mathrm{t}}=\frac{11300}{31.6}=358 \mathrm{BTU} / \mathrm{hr} \mathrm{ft}^{2} \mathrm{o}_{\mathrm{F}} \\
& \mathrm{Nu}=\frac{\mathrm{hD}}{\mathrm{k}_{\mathrm{L}}}=\frac{358 \times 0.000833}{0.117}=2.55 \\
& G r=\frac{g B P_{L}^{2} \Delta t D_{w}^{3}}{2}=\frac{32.2 \times 3600^{2} \times 6.72 \times 10^{-4} \times 48^{2} \times 31.6 \times .000833^{3}}{1.05^{2}} \\
& =10.5 \\
& \operatorname{Pr}=\frac{c_{p} \mu}{k_{L}}=\frac{0.625 \times 1.05}{0.117}=5.6 \\
& (\text { Gr } \mathrm{Pr})^{1 / 2}\left(\mathrm{~S}_{\mathrm{R}}\right)^{1 / 2} / \mathrm{P}_{\mathrm{CR}}=(10.5 \times 5.6)^{1 / 2}(2.7)^{1 / 2} / 0.21 \\
& =59.5
\end{aligned}
$$

3. Calculation of $\mathrm{Nu}_{\mathrm{B}}$ and $\mathrm{Re}^{1 / 2} \mathrm{Pr}^{2 / 3} \mathrm{~S}_{\mathrm{R}}{ }^{1 / 2} / \mathrm{PC}_{\mathrm{R}}$ Using data from Run 30 in Table D-1 where

$$
\mathrm{w}_{\mathrm{A}}=15.6 \text { watts, } \quad \mathrm{s}_{\mathrm{R}}=2.7 \%
$$




$$
\begin{aligned}
& E_{S R}=0.1496 \text { volts, } \quad E_{P T}=0.3529 \text { volts } \\
& I=0.1496 / 0.02=7.48 \mathrm{amp} \\
& \mathrm{q} / \mathrm{A}=\frac{3.415 \times 0.3529 \times 7.48}{3.14 \times 0.000833 \times 0.0625}=55,100 \mathrm{BTU} / \mathrm{hr} \mathrm{ft}^{2} \\
& \mathrm{~T}_{\mathrm{PT}}=\frac{354.777 \times 0.3529}{0.05021 \times 7.48}-254.777 \\
& =78.2^{\circ} \mathrm{C}=173^{\circ} \mathrm{F} ; \quad \Delta \mathrm{T}=173-93.8=79.2^{\circ} \mathrm{F} \\
& T_{f}=\frac{93.8+173}{2}=136^{\circ} F \\
& k_{L}=0.116 \mathrm{BTU} / \mathrm{ft} \mathrm{hr}{ }^{\circ} \mathrm{F}, \quad \lambda=480 \mathrm{BTU} / \mathrm{lb} \\
& \rho_{L}=47.1 \mathrm{lb} / \mathrm{ft}^{3}, \quad \quad \mu_{L}=0.90 \mathrm{lb} / \mathrm{ft}-\mathrm{hr} \\
& \rho_{v}=1 / v_{v}=1 / 18.61 \mathrm{~b} / \mathrm{ft}^{3} \\
& D_{B}=12 \times 10^{4} \mathrm{ft} \text { (see calculation for } D_{B} \text { below) } \\
& \operatorname{Re}=\frac{q \rho_{L} D_{B}}{A \lambda \mu_{L} \rho_{V}}=\frac{55100 \times 47.1 \times 12 \times 10^{-4} \times 18.6}{480 \times 0.90}=134 \\
& \operatorname{Pr}=4.80 \quad \mathrm{P}_{\mathrm{CR}}=0.073 \mathrm{~atm} \\
& \mathrm{Nu}_{\mathrm{B}}=\frac{\mathrm{hD}_{\mathrm{B}}}{\mathrm{k}_{\mathrm{L}}}=\frac{55100 \times 12 \times 10^{-4}}{79.2 \times 0.116}=6.94 \\
& \operatorname{Re}^{1 / 2} \operatorname{Pr}^{2 / 3} S_{R}^{1 / 2} / P_{C R}=(134)^{1 / 2}(4.8)^{2 / 3}(2.7)^{1 / 2} / .073=746
\end{aligned}
$$

\section{Calculation of Radial Gradient in Temperature Within the Wire}

Assuming that the thermal conductivity is constant and the electric heat is uniformly generated, McAdams et al. derived the following equation:

* McAdams, W.H.,J.N. Addoms, R.M. Rinaldo and R.S. Day, ChemEng.Prog. 44, 639(1948) 


$$
T_{s}=T_{W}-\frac{(q / A) D_{W}}{8 K}
$$

where $\mathrm{T}_{\mathrm{S}}=$ surface temperature of the wire, ${ }_{\mathrm{F}}$

$$
\begin{aligned}
T_{w} & =\text { measured mean temperature of the wire, }{ }_{F} \\
q / A & =\text { heat flux, BTU/hr } \mathrm{ft}^{2}
\end{aligned}
$$$$
D_{w}=\text { wire diameter, } f t
$$

$k=$ thermal conductivity of the wire, BTU/hr ft ${ }^{\circ} \mathrm{F}$.

Using data from Run 53 in Table $D-3$ where $D_{W}=0.000833 \mathrm{ft}$,

$$
\mathrm{q} / \mathrm{A}=590,000 \mathrm{BTU} / \mathrm{hr} \mathrm{ft}^{2}
$$

$$
\begin{aligned}
\Delta T & =152^{\circ} \mathrm{F} \\
T_{L} & =113^{\circ} \mathrm{F} \\
T_{W} & =152+113=265^{\circ} \mathrm{F} \\
\frac{(\mathrm{q} / \mathrm{A}) \mathrm{D}_{\mathrm{W}}}{8 \mathrm{k}} & =\frac{590,000 \times 0.000833}{8 \times 42}=1.5^{\circ} \mathrm{F} \\
T_{s} & =T_{W}-1.5=263.5^{\circ} \mathrm{F} .
\end{aligned}
$$

It can be seen that the error involved in neglecting the radial temperature gradient of the wire is less than $0.6 \%$. At lower hea $t$ flux values, the error is even smaller.

III. CALCULATION OF RESONANCE SIZE

From Equation (1) in Part II

$$
R_{0}=\frac{0.326 \mathrm{P}_{0}^{1 / 2}}{f \rho_{L}^{1 / 2}}
$$

where $R_{0}$ - resonance radius, $\mathrm{cm}$ 


$$
\begin{aligned}
& \rho_{L} \text { - density of the liquid, } \mathrm{g} / \mathrm{cm}^{3} \\
& f \text { - frequency, kcps } \\
& P_{0} \text { - ambient pressure, atm. }
\end{aligned}
$$

\begin{tabular}{|c|c|c|c|c|}
\hline Liquid & $\begin{array}{l}\text { Densiţy } \\
\mathrm{g} / \mathrm{cm}^{3}\end{array}$ & $\underset{k c p s}{f}$ & $\begin{array}{l}\mathrm{R}_{\mathrm{O}} \\
\mathrm{cm}\end{array}$ & $D_{B_{f t} \times 10^{4}}={ }^{2 R}$ \\
\hline Water & 0.980 & 20.6 & 0.0160 & 10.5 \\
\hline Methanol & 0.755 & 20.6 & 0.0182 & 12.0 \\
\hline Water & 0.980 & 44.1 & 010748 & 4.9 \\
\hline Methanol & 0.755 & 44.1 & $0 \$ 0850$ & 5.6 \\
\hline Water & 0.980 & 108 & 0.00305 & 2.0 \\
\hline Methanol & 0.755 & 108 & 0.00347 & 2.3 \\
\hline lfe thano1 & 0.755 & 306 & 0.00122 & 0.72 \\
\hline
\end{tabular}

Since $P_{0}=1 \mathrm{~atm}$, values of $R_{0}$ at different frequencles are calculated and given in the following table: 


\section{APPENDIX G \\ PHOTOGRAPHIC STUDY OF THE SURFACE CONDITIONS}

\section{OF PLATINUM WIRE}

The photographs shown in the following pages were taken through a mlcroscope with a $160 \times$ magnification.

FIGURE 1

Photograph of a new platinum wire $D_{w}=0.010$ in. Magnification $=160 \times(G-2)$.

FIGURE 2 Photograph of a platinum wire after 3 tests. $D_{w}=0.007 \mathrm{in.} \mathrm{Magnification} 160 \mathrm{x} . \quad(G-3)$

FIGURE 3 Photograph of a platinum wire after 5 tests. $D_{W}=0.007$ in. Magnification $=160 \times$. $\quad(G-4)$. 


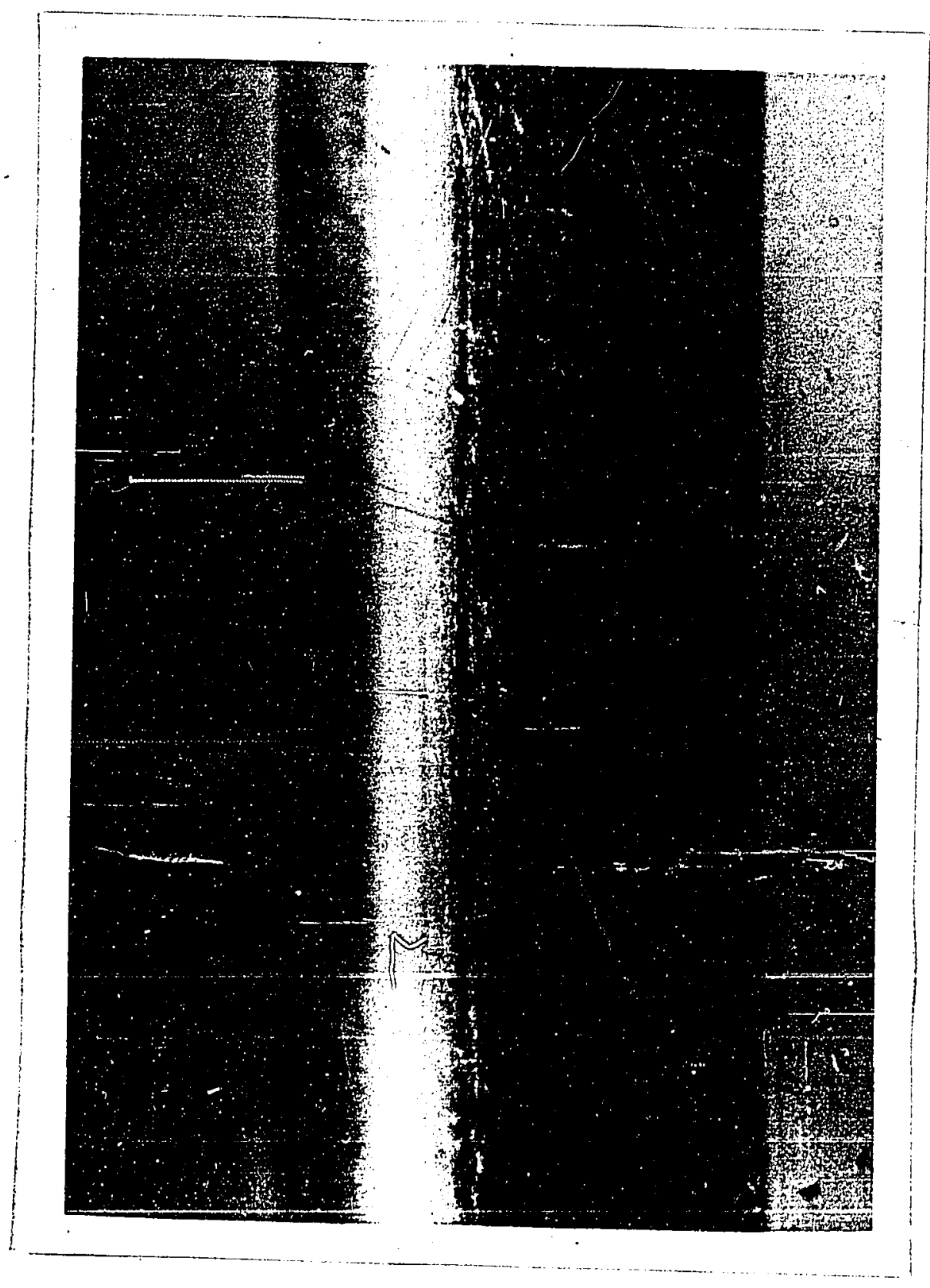


$G-2$

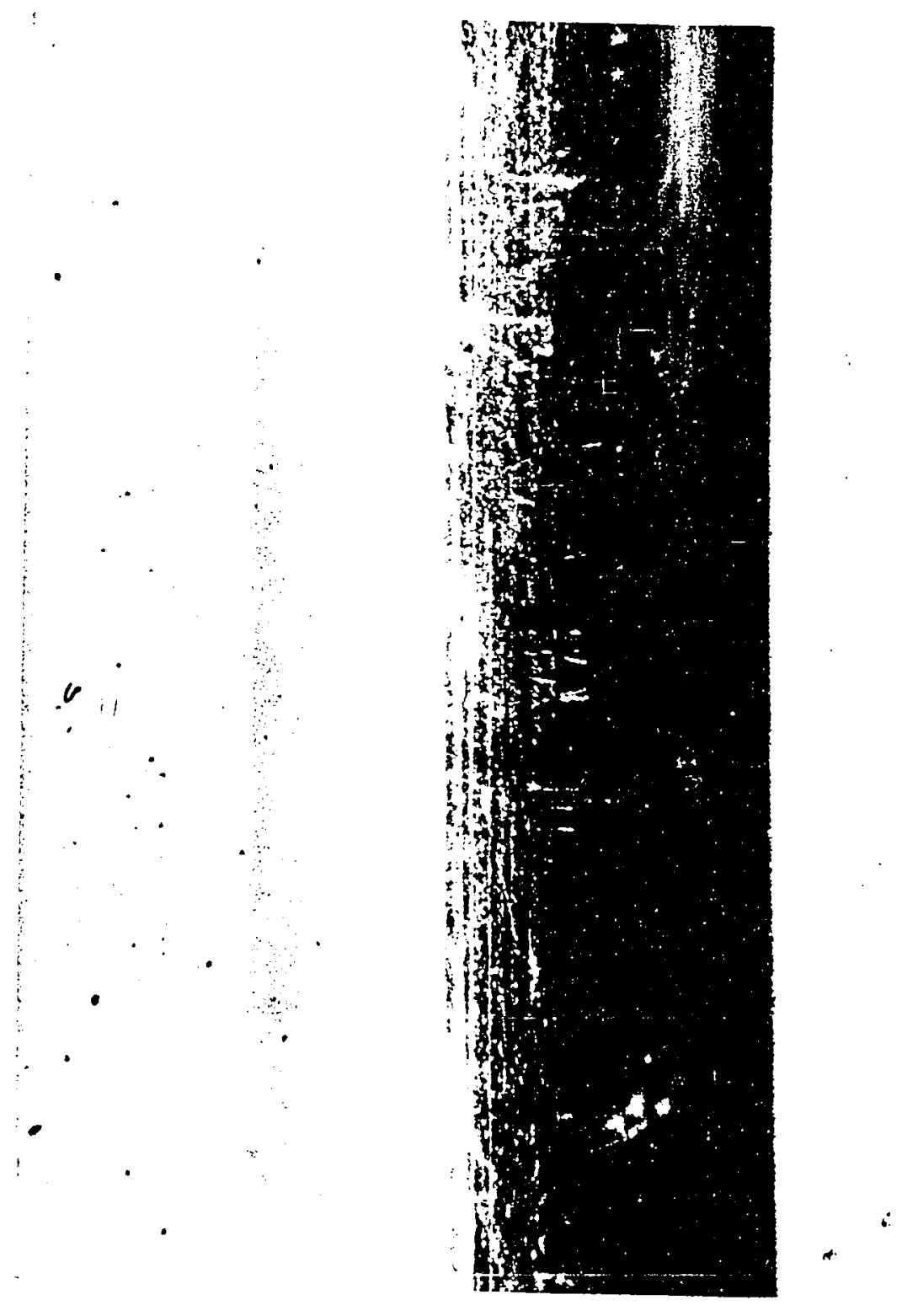


G-3

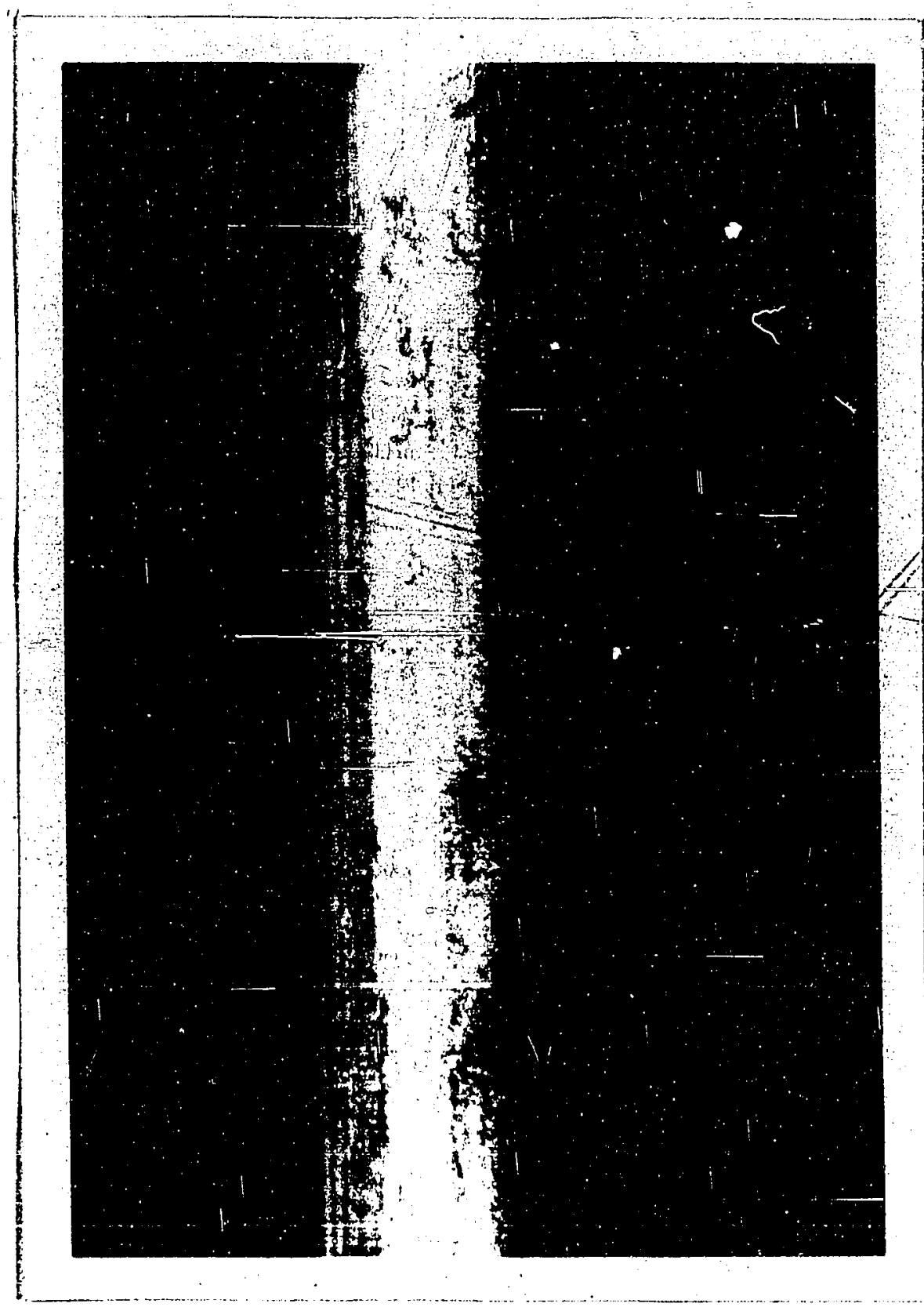


$6-3$
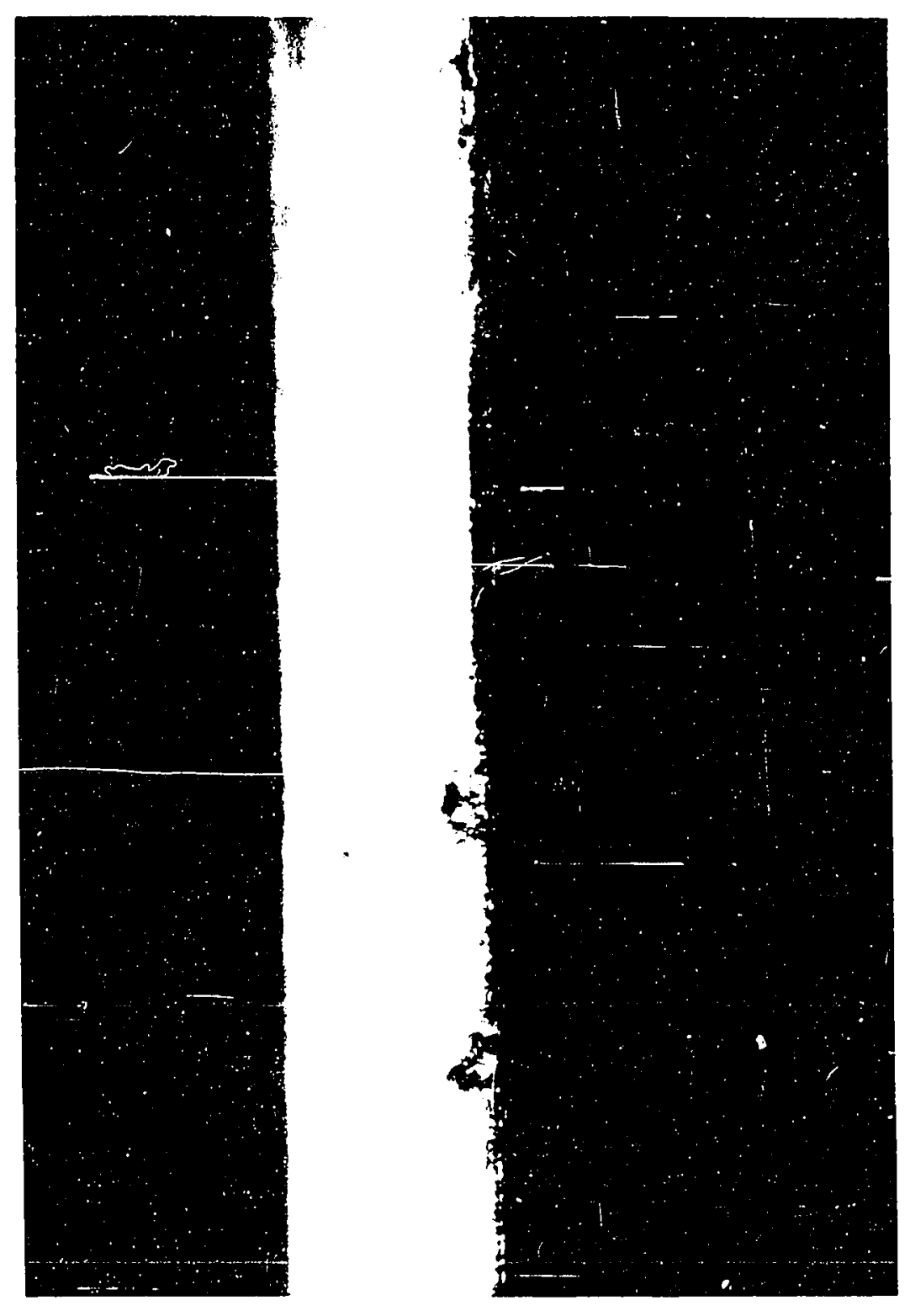
G-4

$(j$

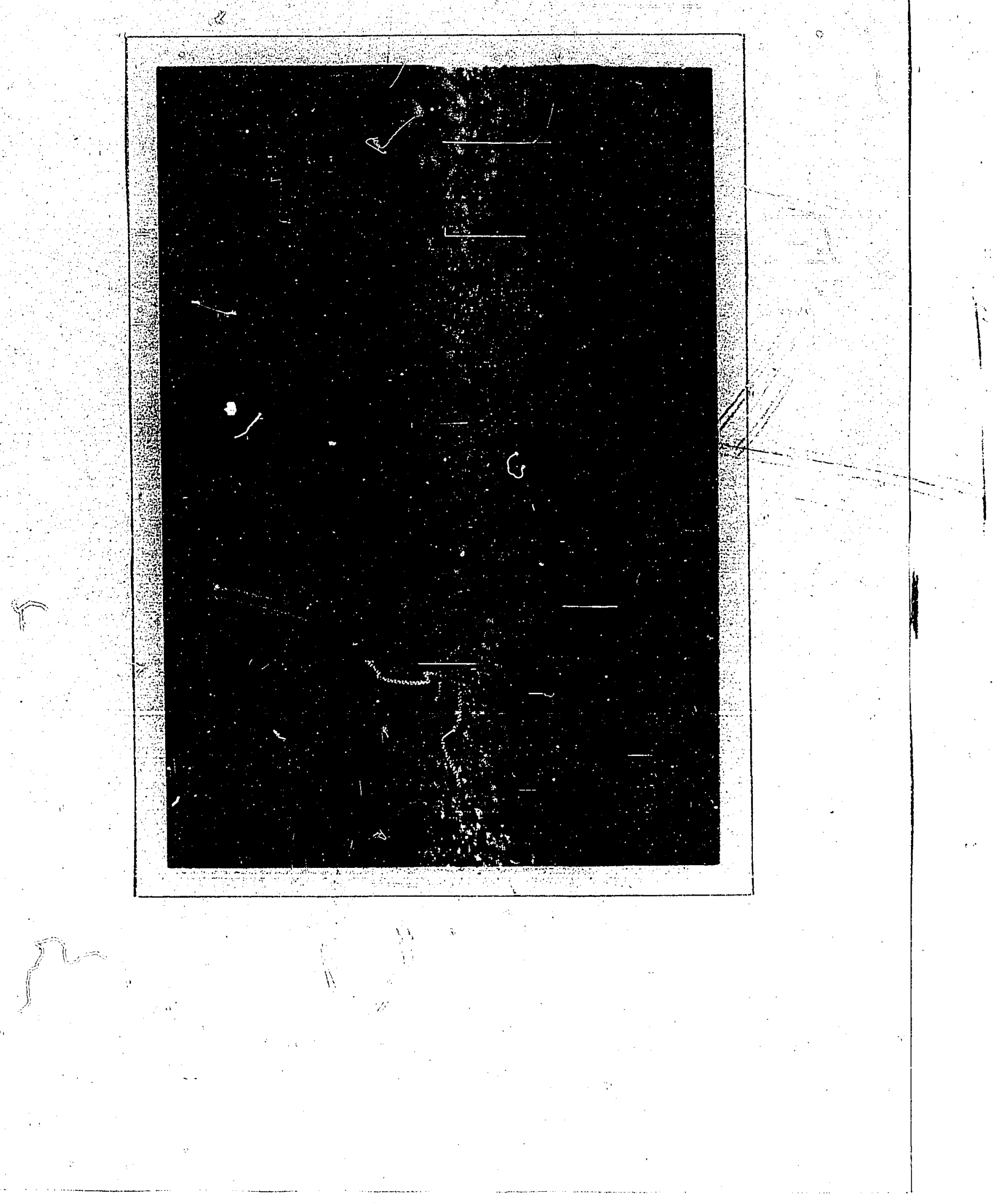




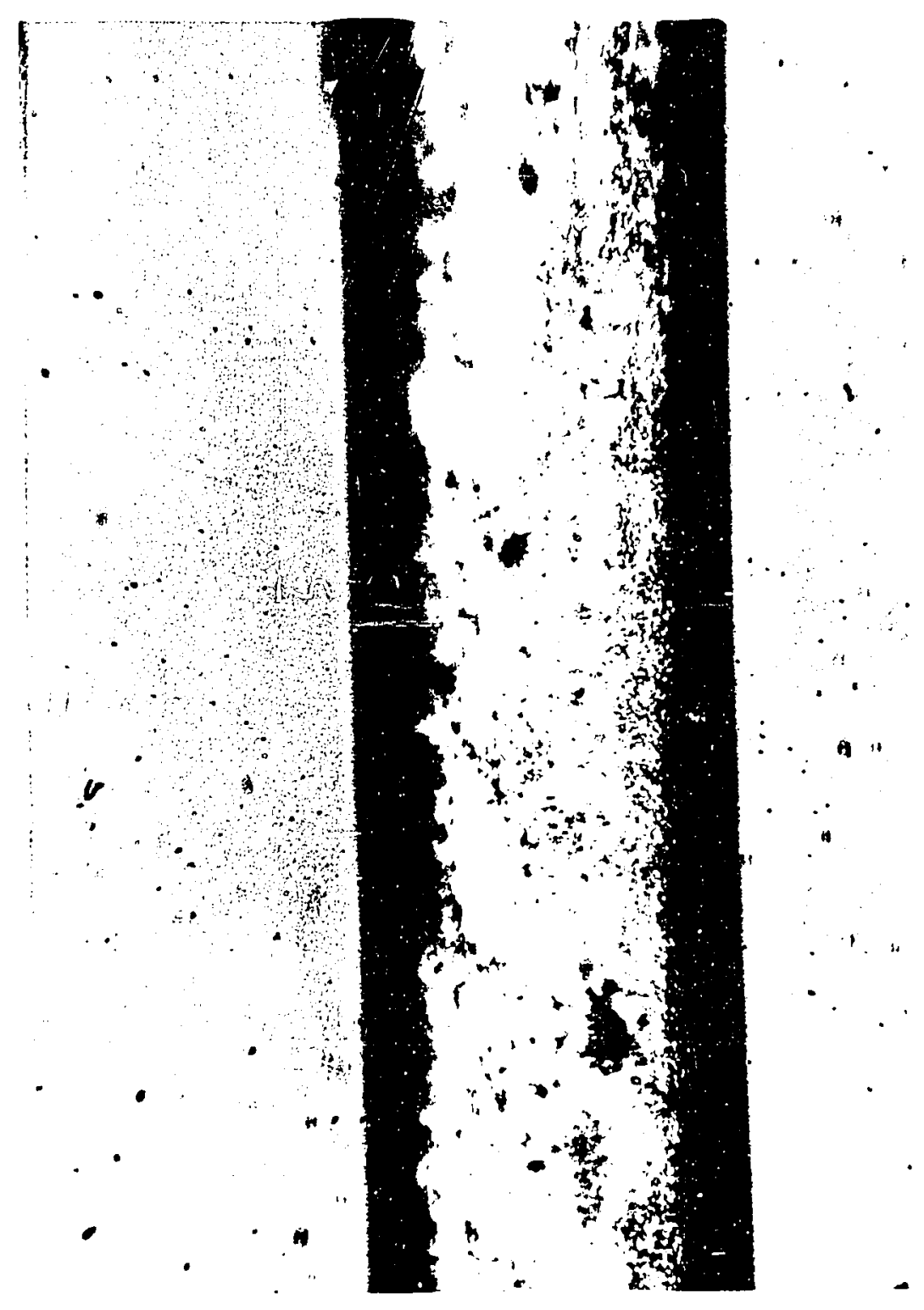

